\title{
Aperture Coupled Microstrip Antenna Design and Analysis
}

\author{
A Thesis \\ presented to \\ the Faculty of California Polytechnic State University, \\ San Luis Obispo
}

\author{
In Partial Fulfillment \\ of the Requirements for the Degree \\ Master of Science in Electrical Engineering
}

by

Michael Paul Civerolo

June 2010 
(C) 2010

Michael Paul Civerolo

ALL RIGHTS RESERVED 


\section{COMMITTEE MEMBERSHIP}

TITLE:

AUTHOR:

DATE SUBMITTED:

June 2010

COMMITTEE CHAIR: Dr. Dean Arakaki,

Associate Professor of Electrical Engineering

COMMITTEE MEMBER: Dr. Dennis Derickson,

Assistant Professor of Electrical Engineering

COMMITTEE MEMBER: Dr. Cheng Sun,

Professor of Electrical Engineering 


\section{Abstract}

Aperture Coupled Microstrip Antenna Design and Analysis

Michael Paul Civerolo

A linearly-polarized aperture coupled patch antenna design is characterized and optimized using HFSS antenna simulation software [1]. This thesis focuses on the aperture coupled patch antenna due to the lack of fabrication and tuning documentation for the design of this antenna and its usefulness in arrays and orthogonally polarized communications. The goal of this thesis is to explore dimension effects on aperture coupled antenna performance, to develop a design and tuning procedure, and to describe performance effects through electromagnetic principles.

Antenna parameters examined in this study include the dimensions and locations of the substrates, feed line, ground plane coupling slot, and patch. The operating frequency, input VSWR, percent bandwidth, polarization ratio, and broadside gain are determined for each antenna configuration.

The substrate material is changed from RT Duroid (material in nominal HFSS design [1]) to FR4 due to lower cost and availability. The operating frequency is changed from $2.3 \mathrm{GHz}$ (specified in nominal HFSS design) to $2.4 \mathrm{GHz}$ for wireless communication applications. Required dimensional adjustments when changing substrate materials and operating frequencies for this antenna are non-trivial and the new design procedure is used to tune the antenna.

The antenna is fabricated using 59mil thick double and single sided FR4 boards joined together with double sided 45 mil thick acrylic tape. The antenna is characterized in an anechoic chamber and experimental results are compared to theoretical predictions. 
The results show that the new design procedure can be successfully applied to aperture coupled antenna design. 


\section{Acknowledgements}

I thank God for faithfully keeping me healthy and focused and for blessing me with the resources to complete this project. I thank my fiancée Jacqueline for her encouragement throughout this project.

I thank my advisor, Dr. Dean Arakaki, for his patience and advice. His enthusiastic support made this an enjoyable experience and without him the facilities and equipment that made this project possible would not be at Cal Poly. I would like to thank Dr. Cheng Sun and Dr. Dennis Derickson for their input on my thesis and for being on my graduate committee.

I would like to thank my parents Paul and Jeni Civerolo and my grandfather Richard Civerolo for blessing me with the financial support to attend college. 


\section{Table of Contents}

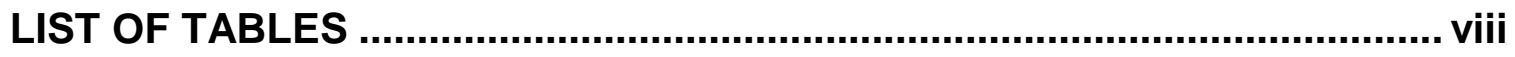

LIST OF FIGURES....................................................................................... ix

CHAPTER I. THE APERTURE COUPLED ANTENNA …............................... 1

CHAPTER II. ANTENNA OPERATION ........................................................ 4

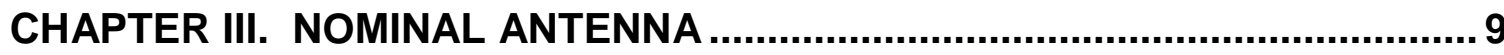

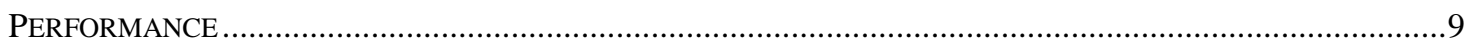

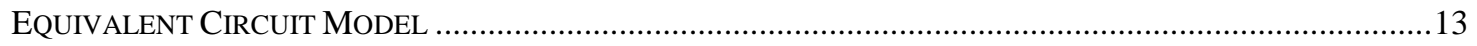

CHAPTER IV. PARAMETRIC STUDY ....................................................... 17

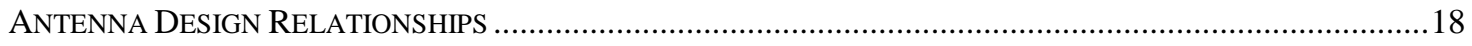

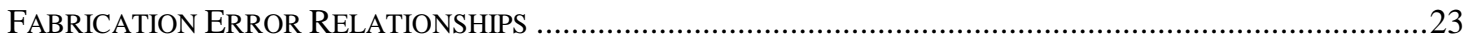

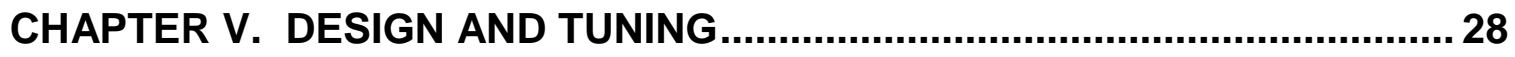

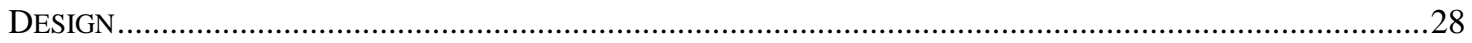

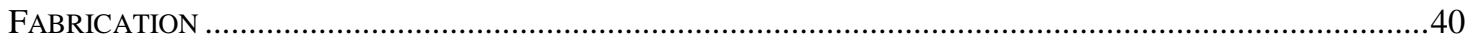

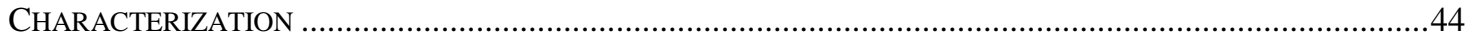

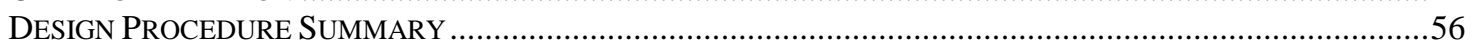

FUTURE PROJECT RECOMMENDATIONS............................................. 58

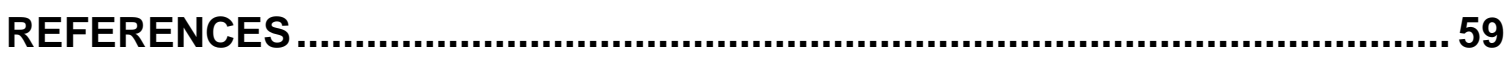

APPENDIX A: COMPLETE PARAMETRIC STUDY.....................................60

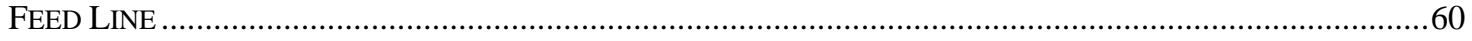

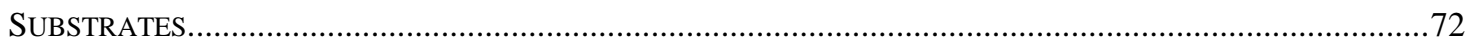

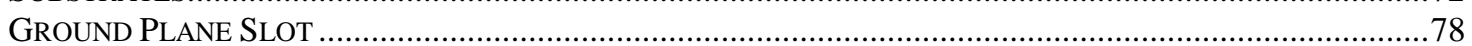

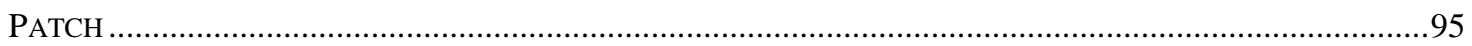

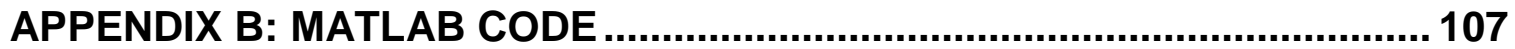




\section{List of Tables}

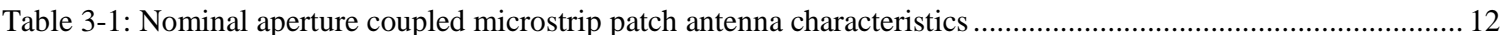

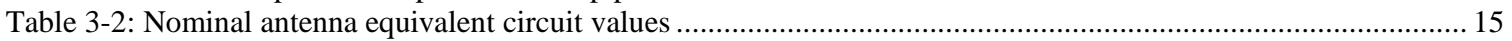

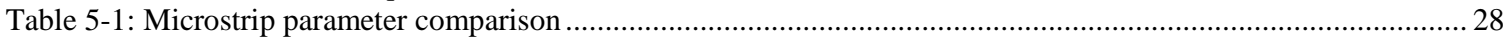

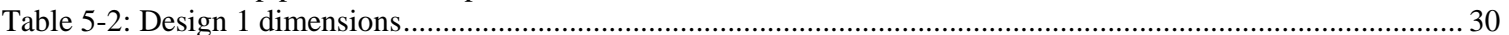

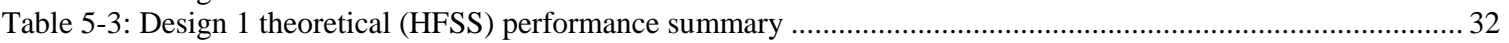

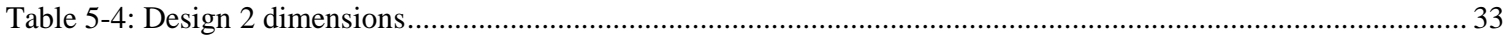

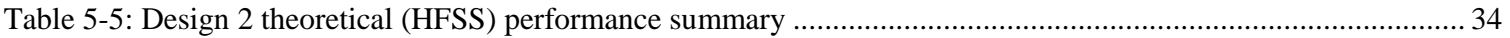

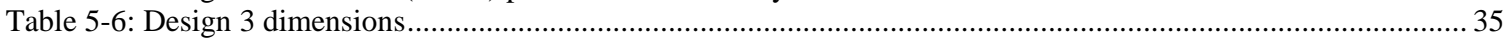

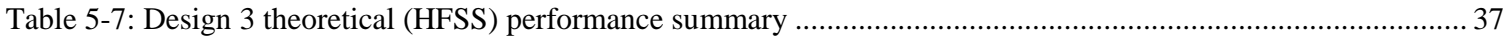

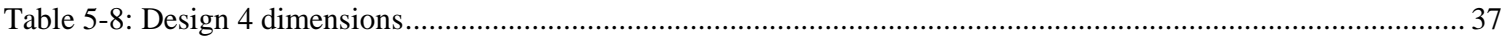

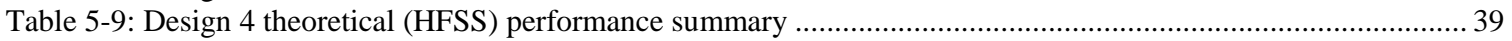

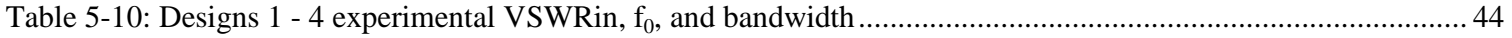

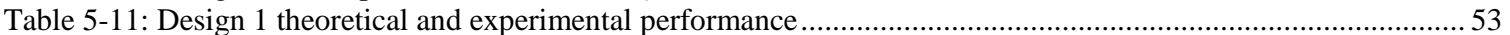

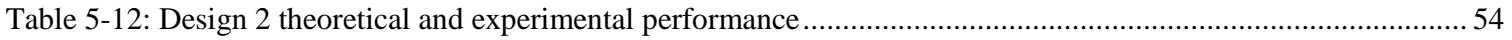

Table 5-13: Design 3 theoretical and experimental performance ….....................................................................5

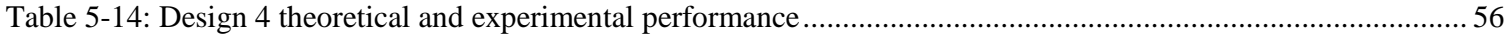




\section{List of Figures}

Figure 1-1: Aperture coupled microstrip patch antenna transparent structure ......................................................... 1

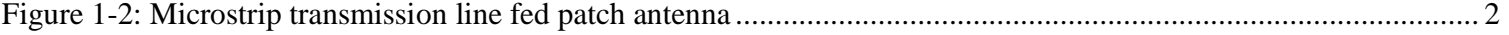

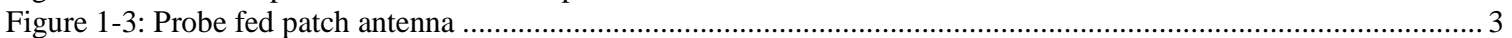

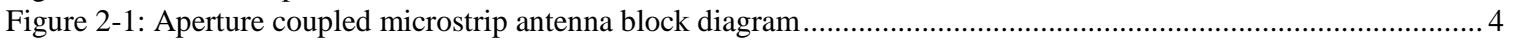

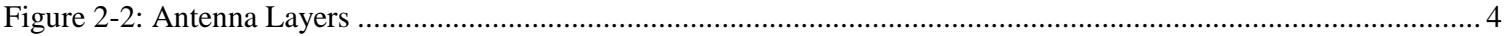

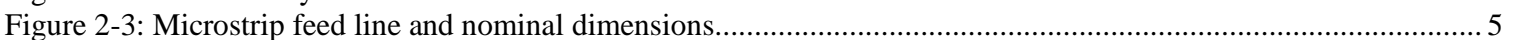

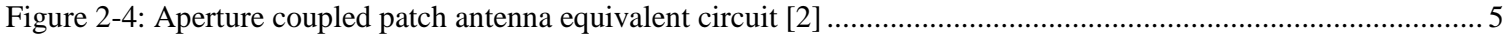

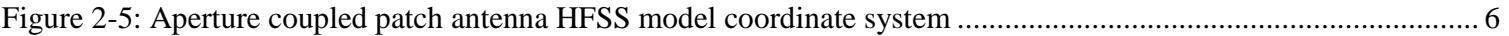

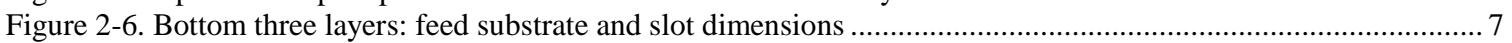

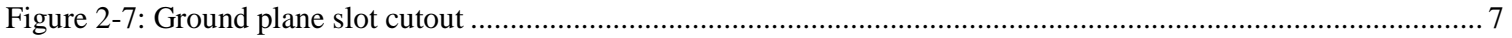

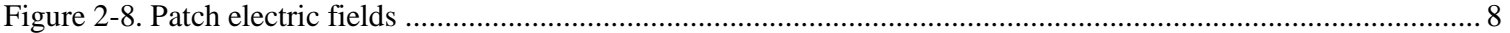

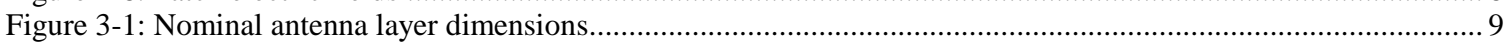

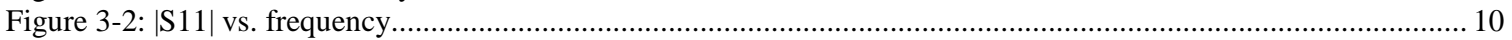

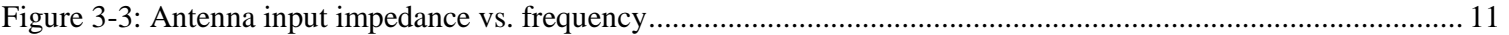

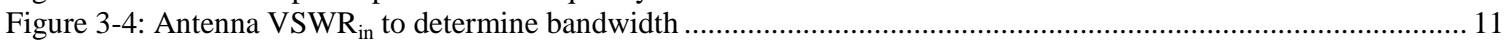

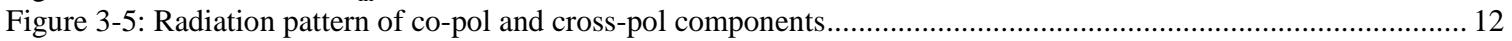

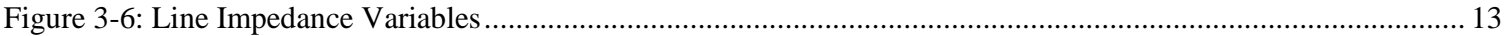

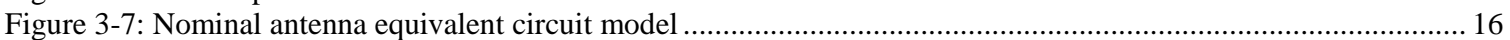

Figure 3-8: HFSS antenna model (red) and equivalent circuit model (green): VSWRin vs. frequency ......................... 16

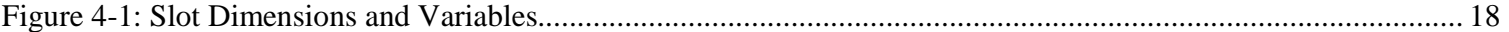

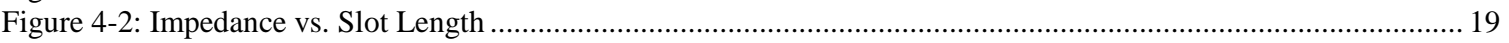

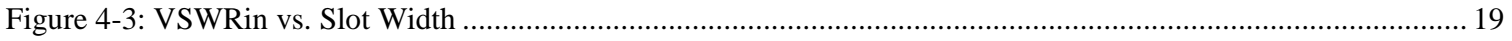

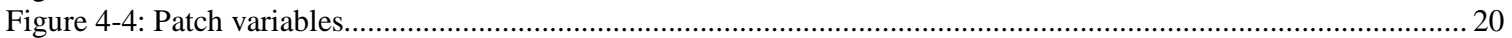

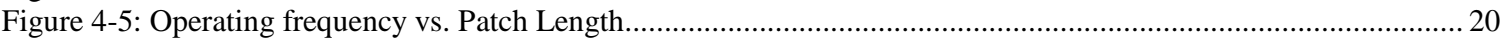

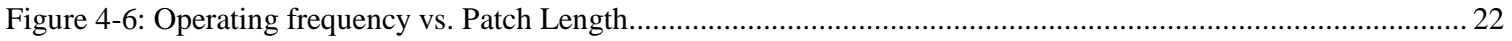

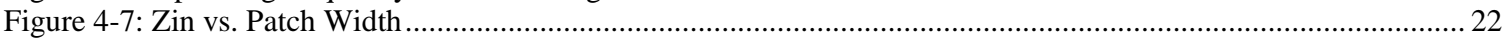

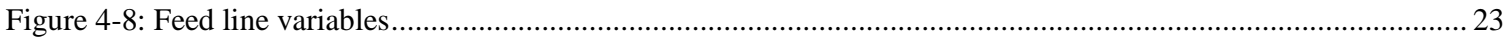

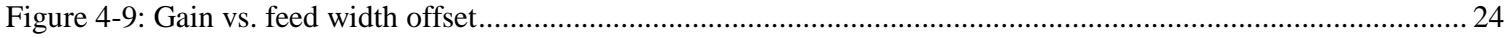

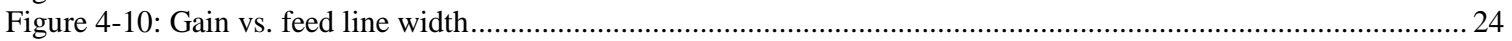

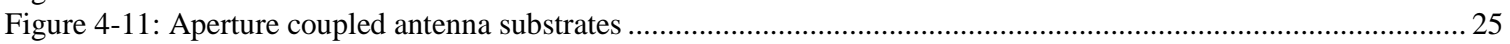

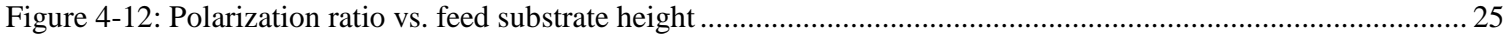

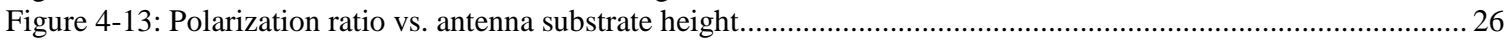

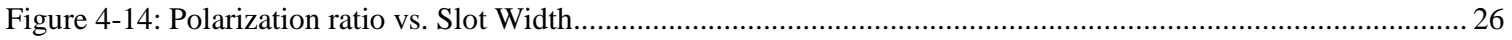

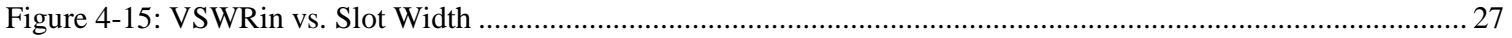

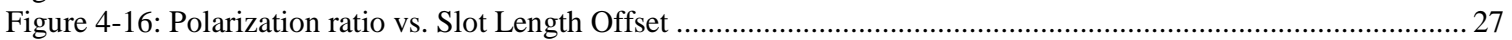

Figure 5-1: Double sided FR4 board with ground slot and adhesive (drawn to scale) .............................................2 29

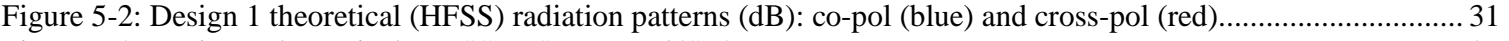

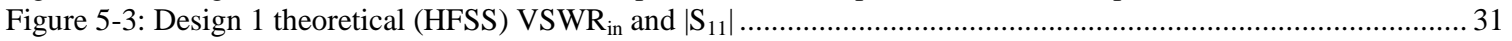

Figure 5-4: Design 2 theoretical (HFSS) radiation patterns (dB): co-pol (blue) and cross-pol (red)..............................3

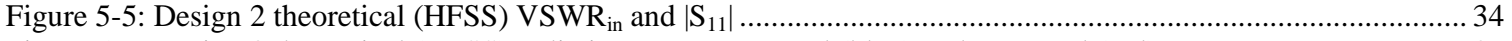

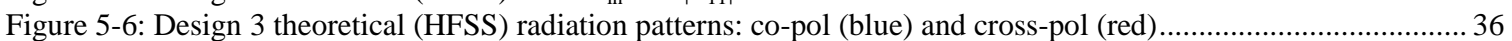

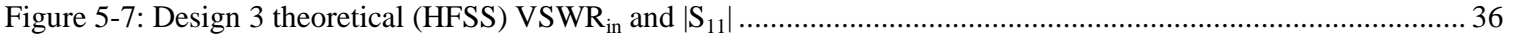

Figure 5-8: Design 4 theoretical (HFSS) radiation patterns: co-pol (blue) and cross-pol (red) ................................... 38

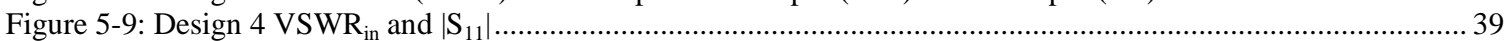

Figure 5-10: LPKF Milling Machine: Design 1 and 2 Ground Planes ................................................................ 41

Figure 5-11: SMA Connector Soldered on Double Sided FR4 Board .................................................................. 41

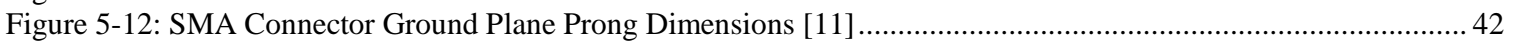

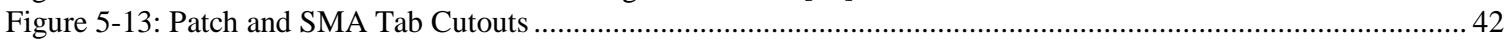

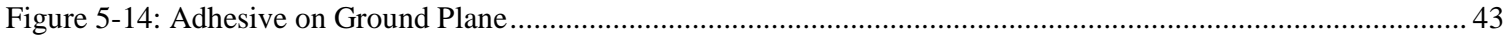

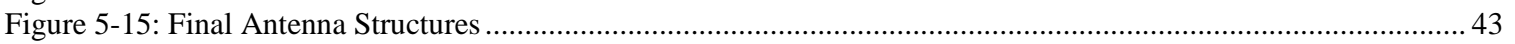

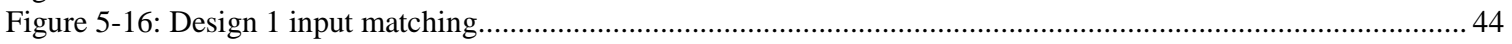

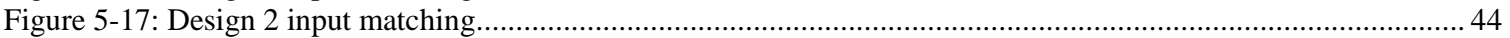

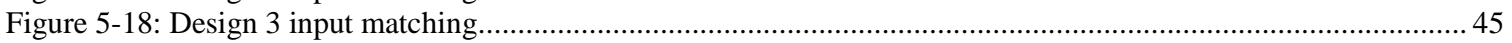

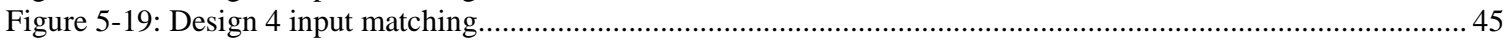

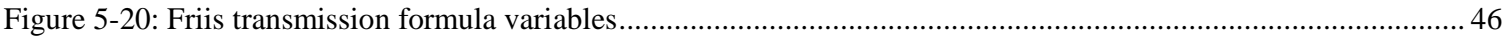

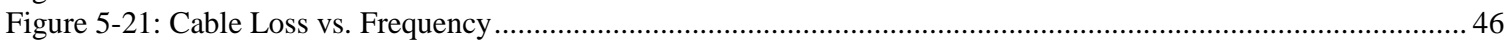

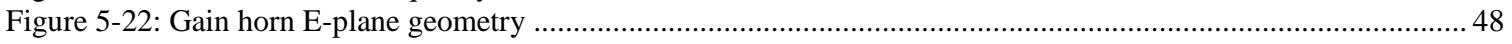

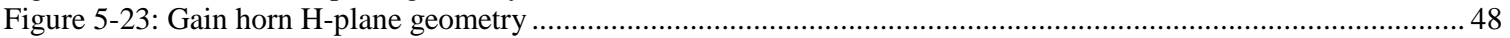




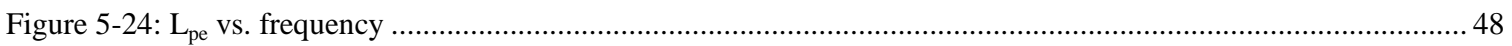

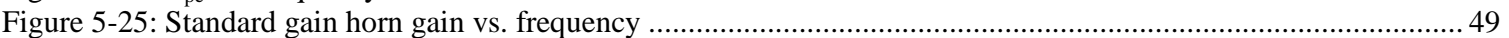

Figure 5-26: Standard gain horn gain vs. frequency [12] $(1.7-2.6 \mathrm{GHz}$ horn data circled in red) .............................50

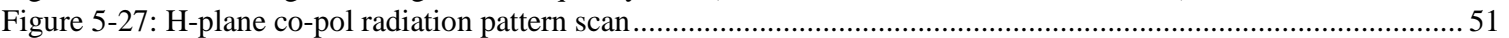

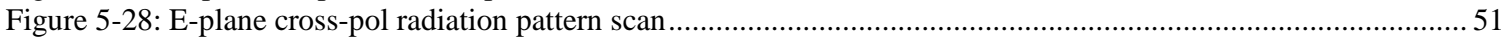

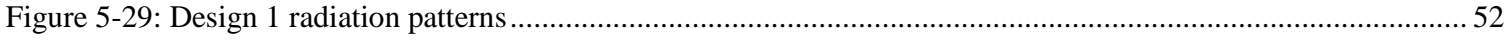

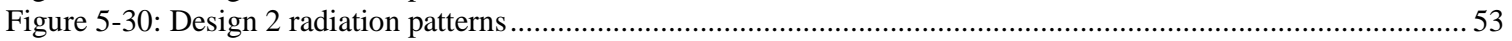

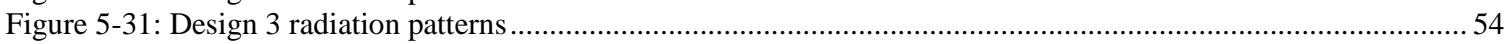

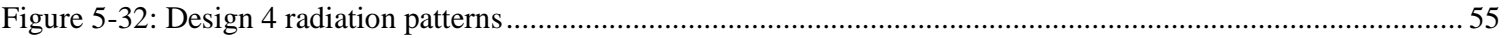

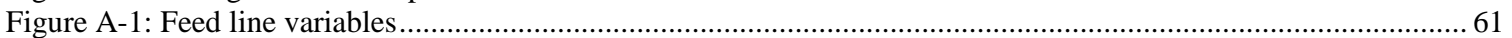

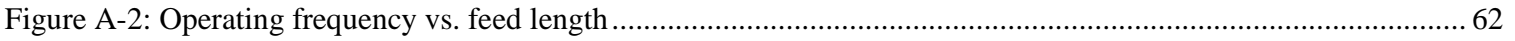

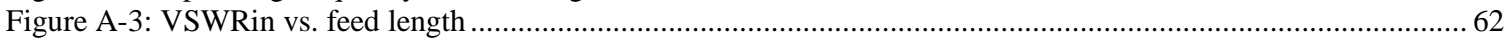

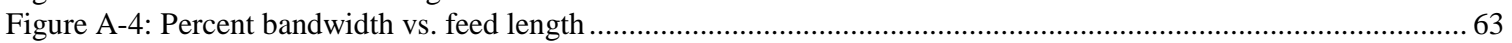

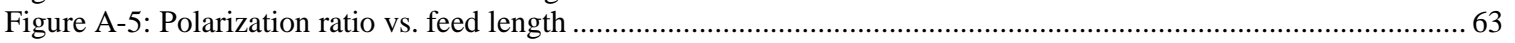

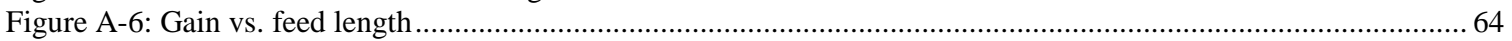

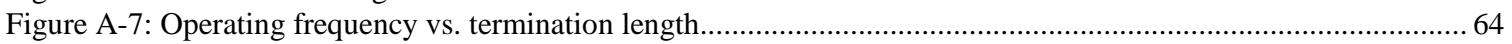

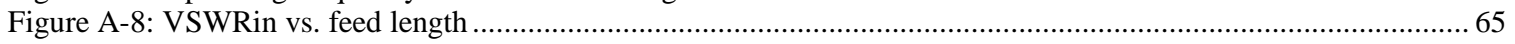

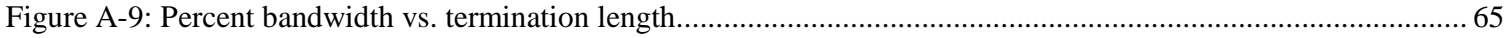

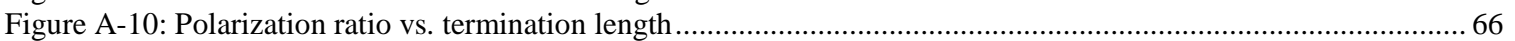

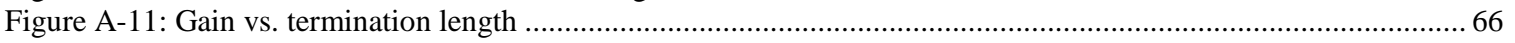

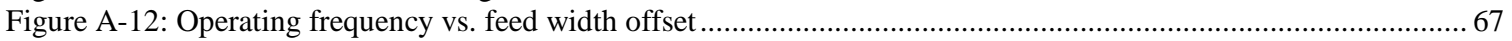

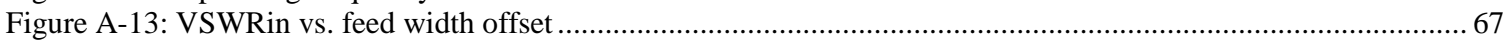

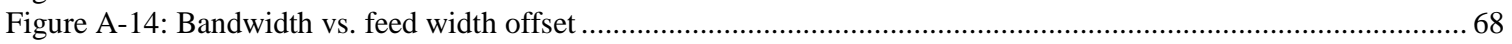

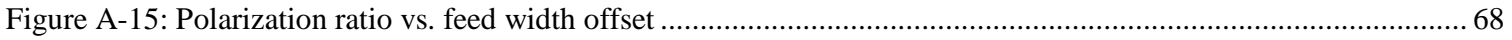

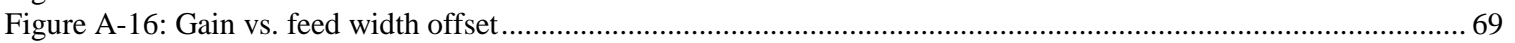

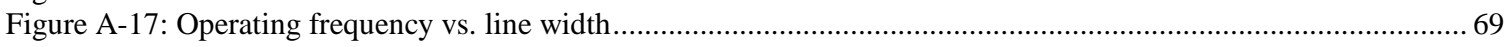

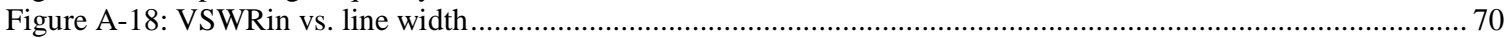

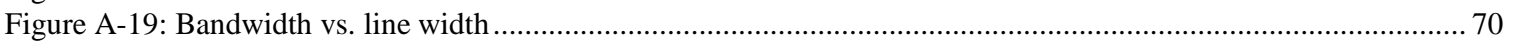

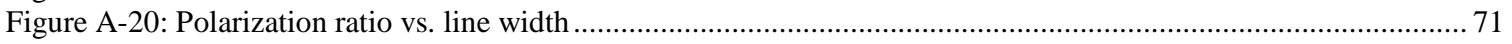

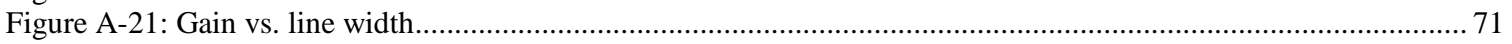

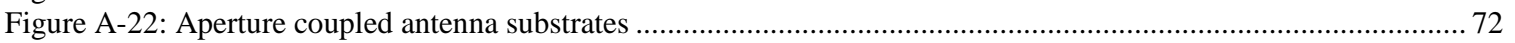

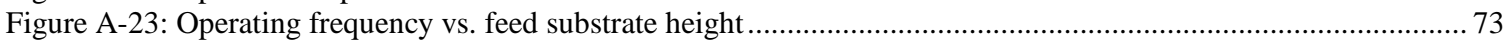

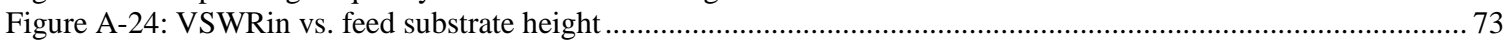

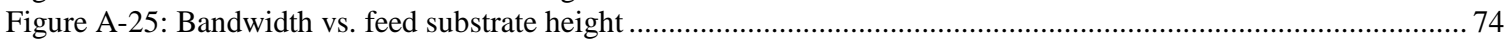

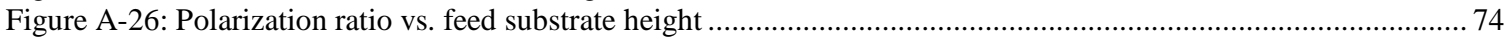

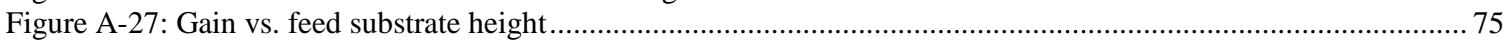

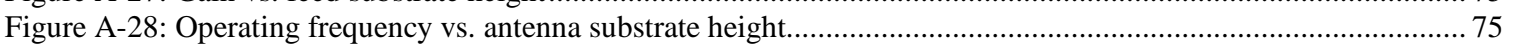

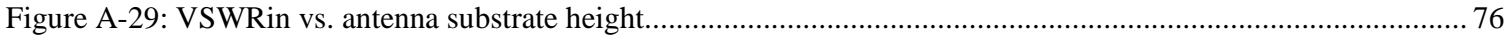

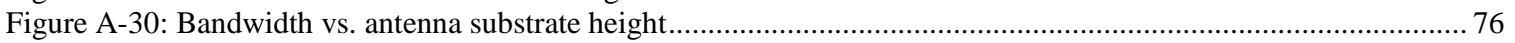

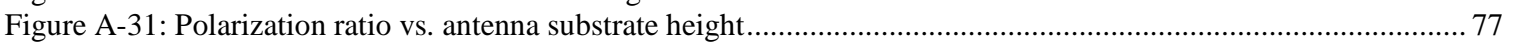

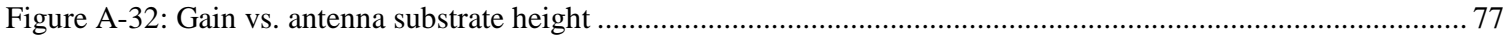

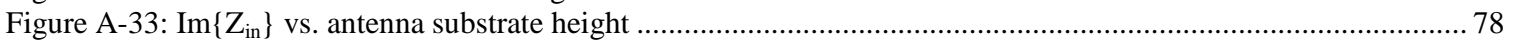

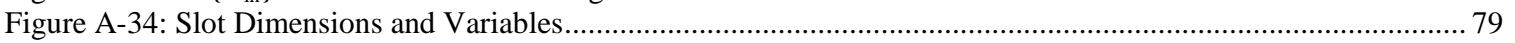

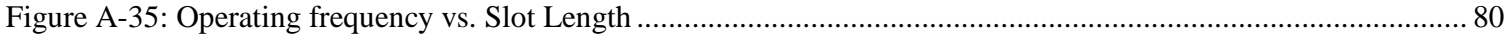

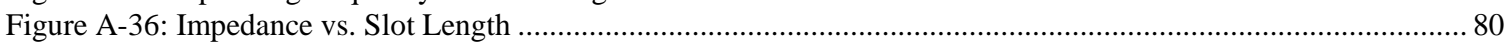

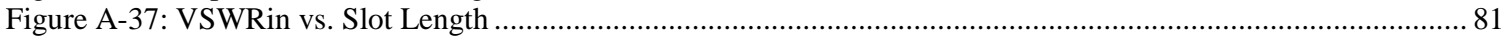

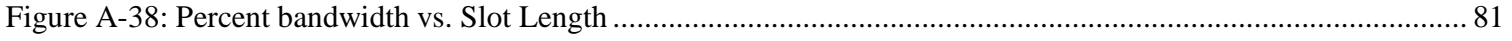

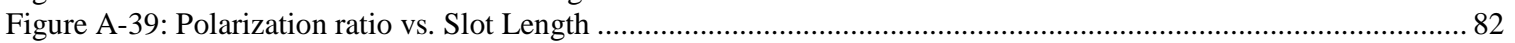

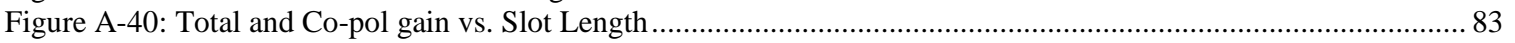

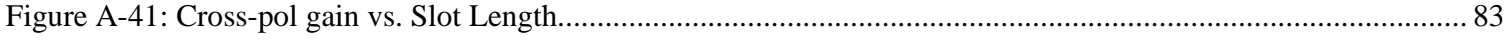

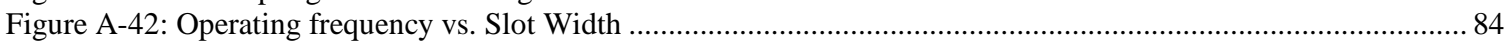

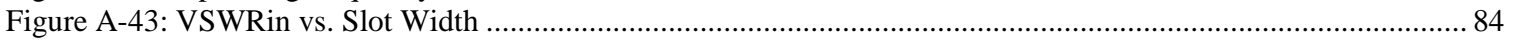

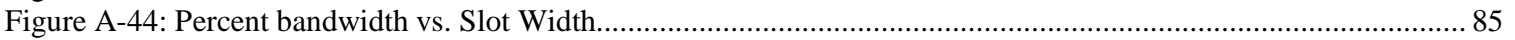

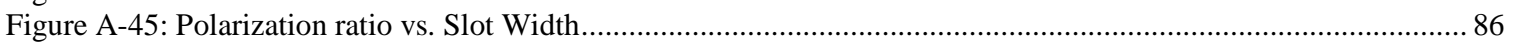

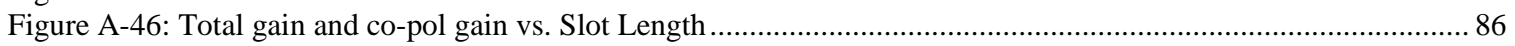

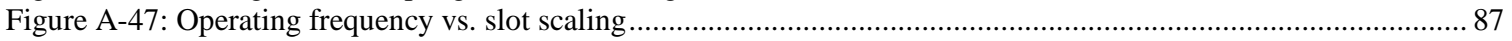

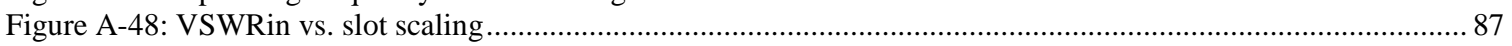

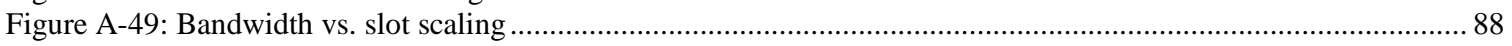

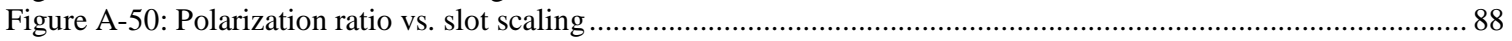

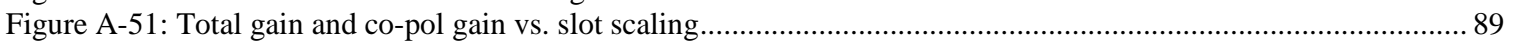

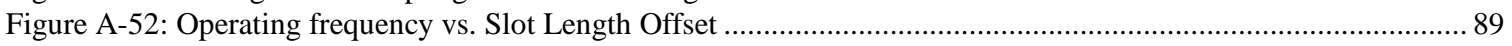

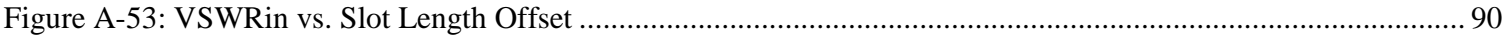




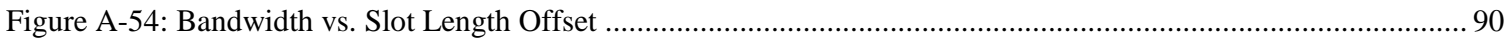

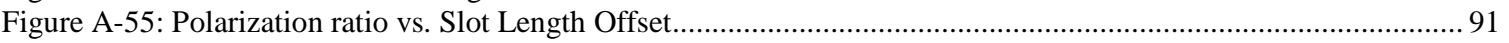

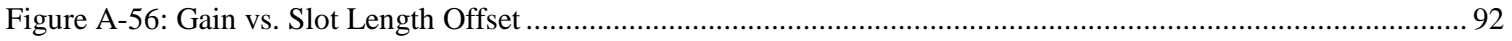

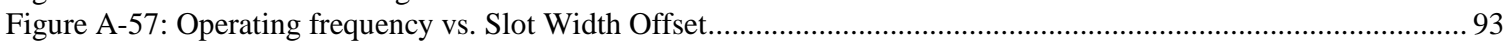

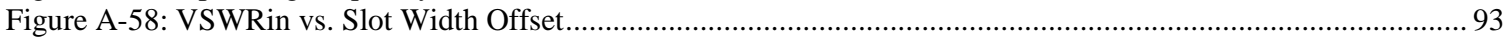

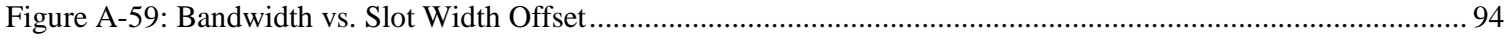

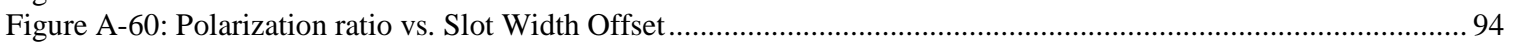

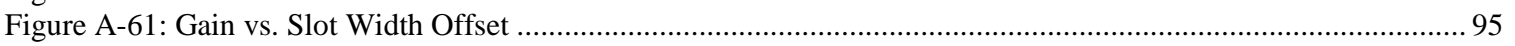

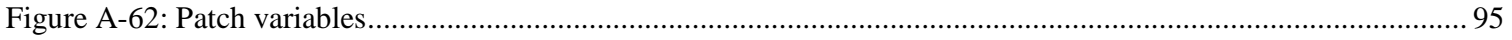

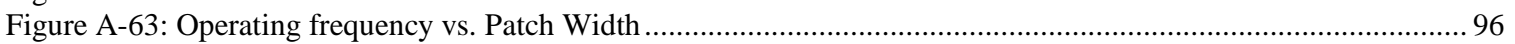

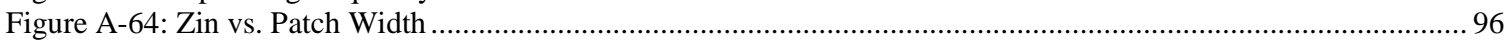

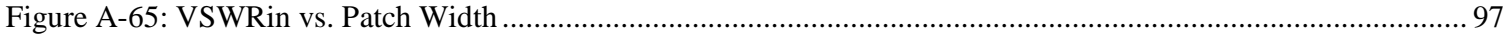

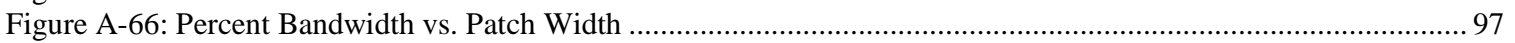

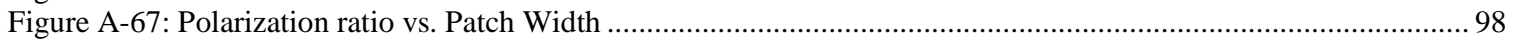

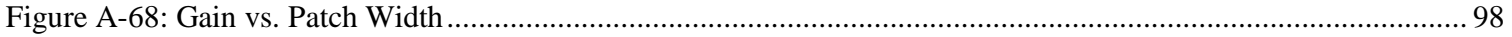

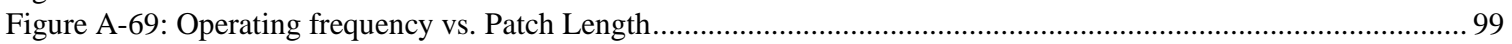

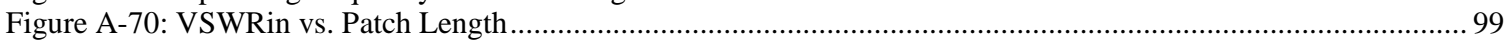

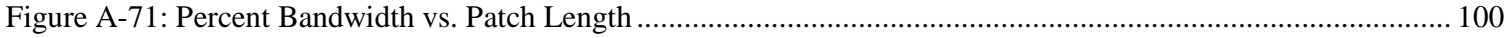

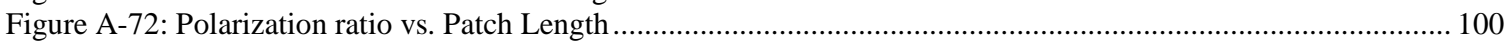

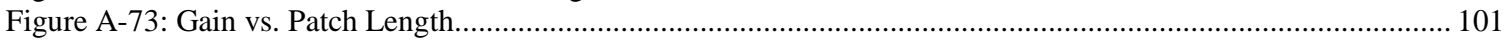

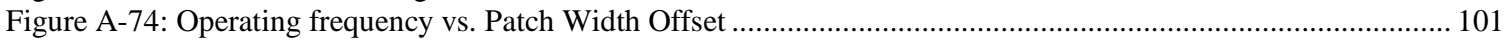

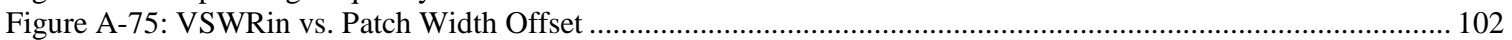

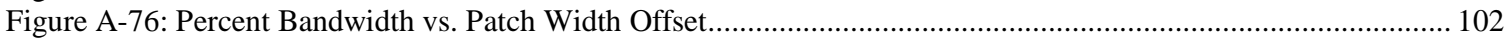

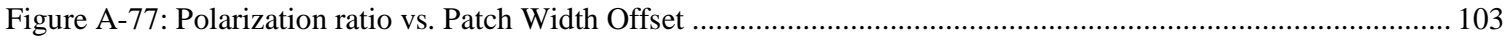

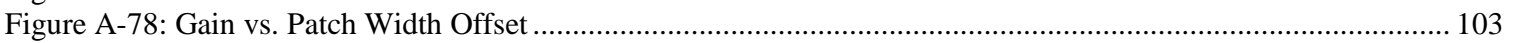

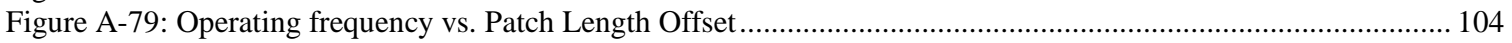

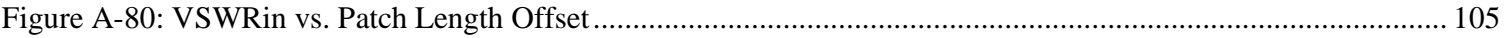

Figure A-81: Percent Bandwidth vs. Patch Length Offset .......................................................................... 105

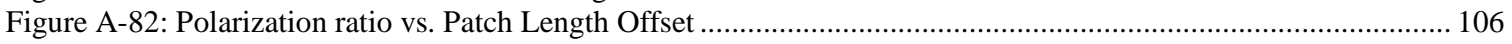

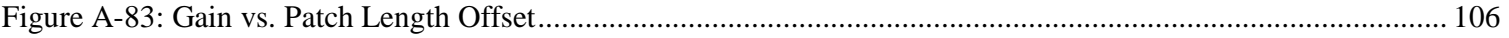




\section{Chapter I. The Aperture Coupled Antenna}

In 1985, a new feed technique involving a microstrip line electromagnetically coupled to a patch conductor through an electrically small ground plane aperture was proposed (see Figure 1-1) [1]. At that time, patch antenna feed techniques included microstrip transmission lines and coaxial probes.

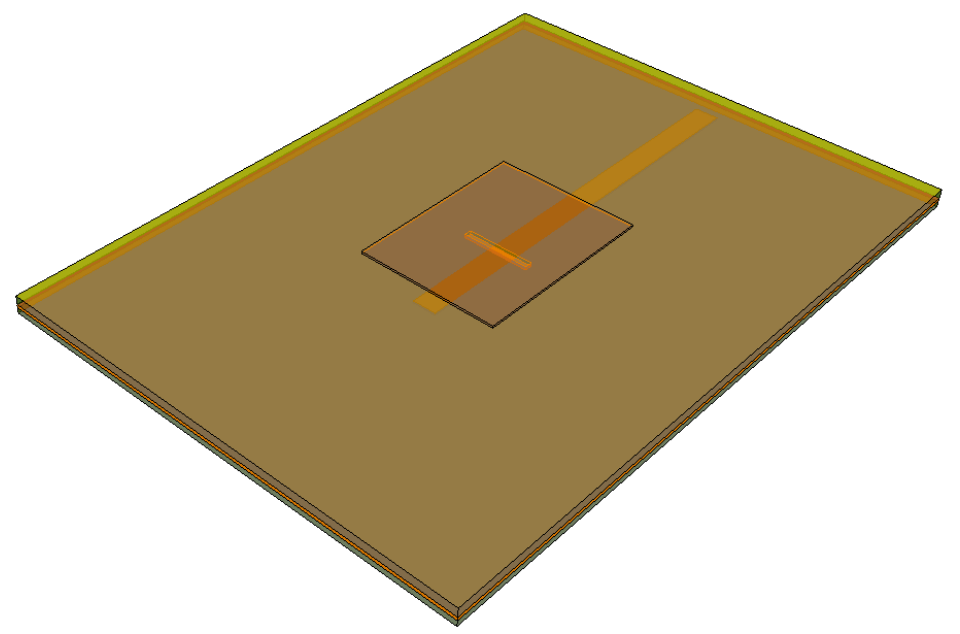

Figure 1-1: Aperture coupled microstrip patch antenna transparent structure

A microstrip feed uses a transmission line to connect the radiating patch to receive or transmit circuitry (see Figure 1-2). Electromagnetic field lines are focused between the microstrip line and ground plane to excite only guided waves as opposed to radiated or surface waves. Guided waves dominate in electrically thin dielectrics with relatively large permittivities [2]. For the patch antenna, radiated waves at the patch edges are maximized using electrically thick dielectric substrates with relatively low permittivities. Hence, it is difficult to meet substrate height and permittivity requirements for both the microstrip transmission line and patch antenna. Dielectric substrates selected to satisfy the two conflicting criteria increase surface waves, reduce radiation efficiency 
due to increased guided waves below the patch, and increase sidelobes and crosspolarization levels from spurious feed line radiation [2].

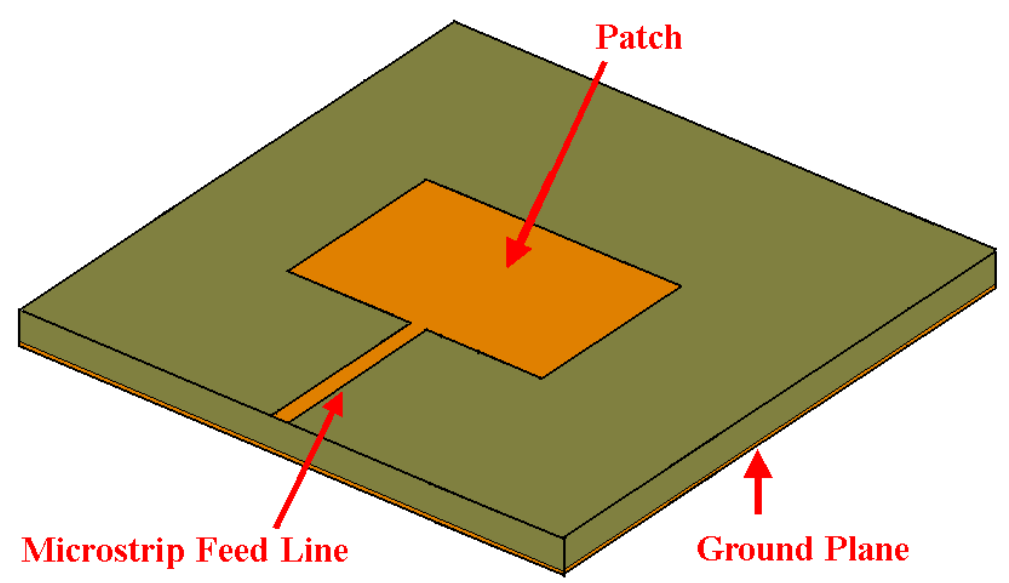

Figure 1-2: Microstrip transmission line fed patch antenna

A probe fed antenna consists of a microstrip patch fed by the center conductor of a coaxial line (see Figure 1-3). The outer coax conductor is electrically connected to the ground plane. Due to the absence of a microstrip feed line, the substrate thickness and permittivity can be designed to maximize antenna radiation. However, the probe center conductor underneath the patch causes undesired distortion in the electric field between the patch and ground plane and produces undesired reactive loading effects at the antenna input port [2], [3]. The undesired reactance can be compensated by adjusting the probe location on the patch. 


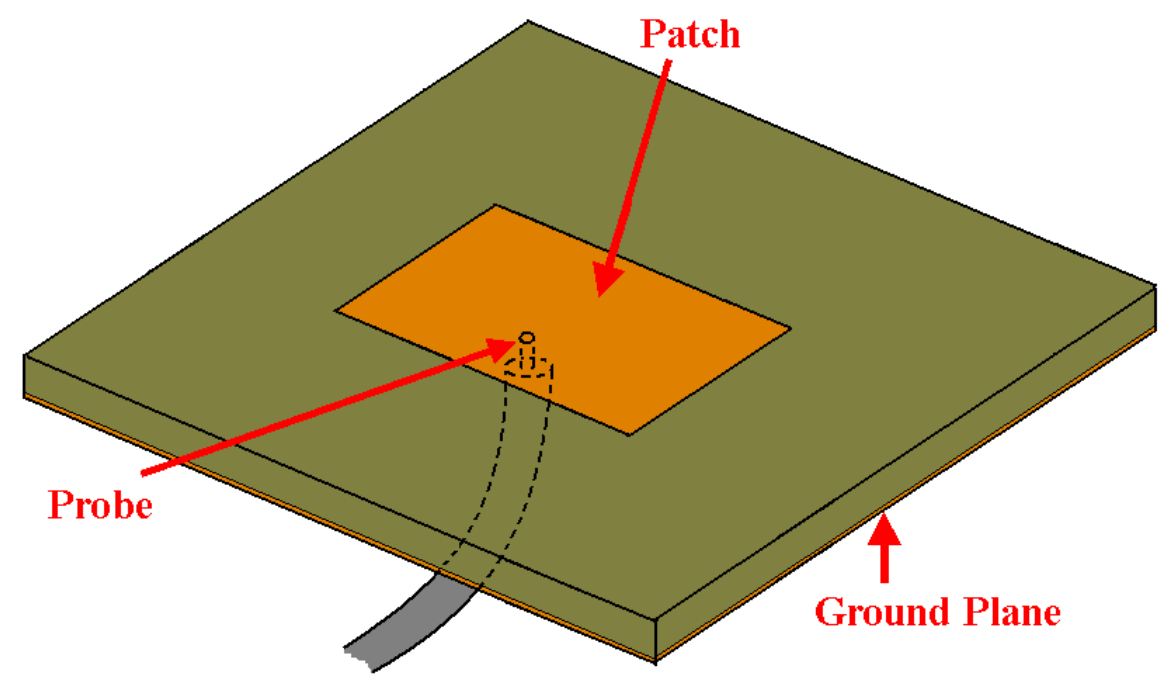

Figure 1-3: Probe fed patch antenna

An aperture coupled antenna eliminates direct electrical connections between the feed conductor and radiating patch, and the ground plane electrically isolates the two structures. The two dielectric substrates can be selected independently to optimize both microstrip guided waves and patch radiating waves. Aperture coupled antennas are advantageous in arrays because they electrically isolate the feed and phase shifting circuitry from the patch antennas. The disadvantage is the required multilayer structure which increases fabrication complexity and cost [2]. 


\section{Chapter II. Antenna Operation}

Figure 2-1 shows the aperture coupled microstrip antenna in block diagram form. The feed line creates an electric field in the aperture (ground plane slot), which induces surface currents on the patch. The patch edges perpendicular to the feed line create fringing fields that radiate into free space.

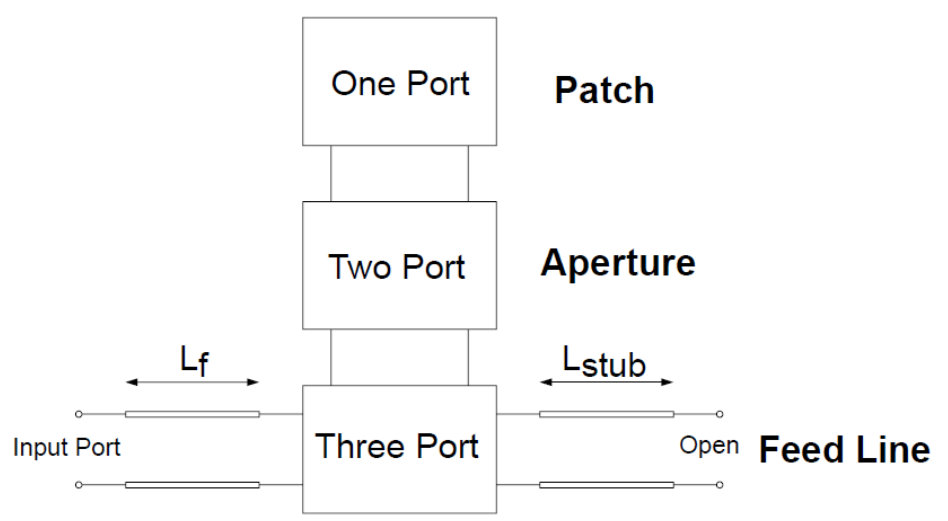

Figure 2-1: Aperture coupled microstrip antenna block diagram [2]

Figure 2-2 shows the aperture coupled antenna layers, which include (from bottom to top) the feed microstrip, feed substrate, slotted ground plane, antenna substrate, and radiating patch (Figure 2-2A - 2-2C). The antenna substrate in Figure 2-2A is made transparent to show the feed line.

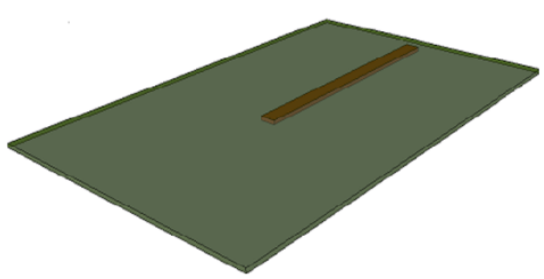

A)

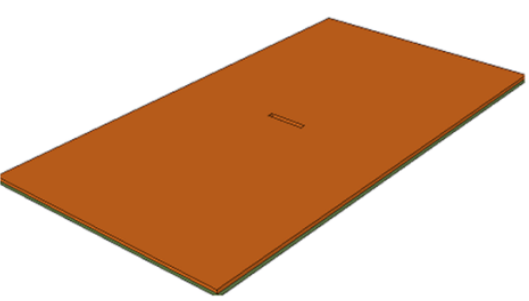

B)

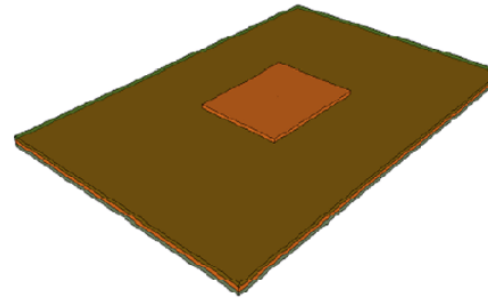

C)

Figure 2-2: Antenna Layers

A) Conductive microstrip feed $\left(1^{\text {st }}\right.$ layer $)$ underneath feed substrate $\left(2^{\text {nd }}\right.$ layer $)$

B) Slotted ground plane $\left(3^{\text {rd }}\right.$ layer $)$ C) Radiating patch $\left(5^{\text {th }}\right.$ layer $)$ on antenna substrate $\left(4^{\text {th }}\right.$ layer $)$ 
The nominal HFSS antenna design defined in [1] is fed by an open-circuit terminated microstrip line $0.739 \lambda$ in length (see Figure 2-3). The wavelength in dielectric is calculated with ADS2006A linecalc at $2.3 \mathrm{GHz}$. A slot in the ground plane is located above the feed line $0.211 \lambda$ (microstrip wavelength in dielectric) from the open termination.

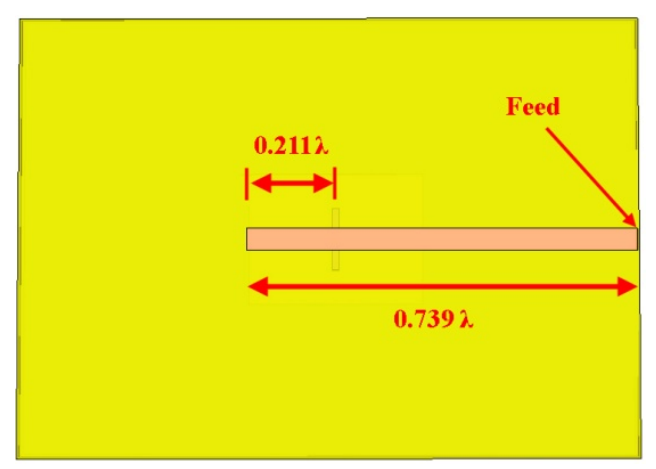

Figure 2-3: Microstrip feed line and nominal dimensions

The ground plane slot acts as an impedance transformer and parallel LC circuit ( $\mathrm{L}_{\mathrm{ap}}$ and $\mathrm{C}_{\mathrm{ap}}$ in Figure 2-4) in series with the microstrip feed line [2]. The LC circuit represents the ground plane slot resonant behavior. The N:1 impedance transformer represents the patch antenna's impedance effects being coupled through the ground plane slot. The patch is modeled as two transmission lines terminated by parallel RC components $\left(\mathrm{R}_{\mathrm{rad}}\right.$ and $\left.\mathrm{C}_{\text {fring }}\right)$ due to patch edge fringing fields [2].

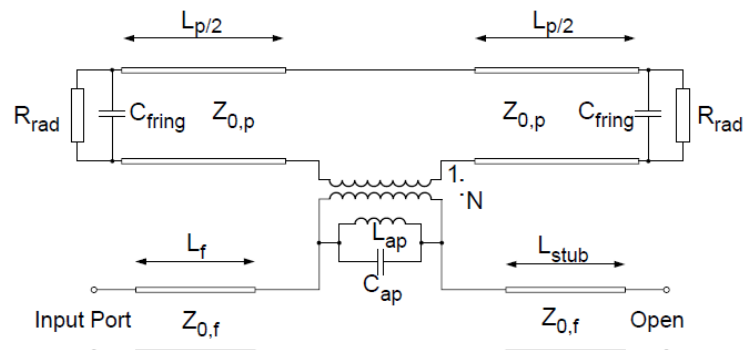

Figure 2-4: Aperture coupled patch antenna equivalent circuit [2] 
The ground plane slot and patch center are positioned above the microstrip line $0.211 \lambda$ from the open termination (see Figures 2-3 and 2-5). On microstrip lines above a solid ground plane, a voltage null and current maximum occur $\lambda / 4$ from an open termination. Due to ground slot and patch loading effects, the maximum current occurs $0.211 \lambda$ away from the open termination.

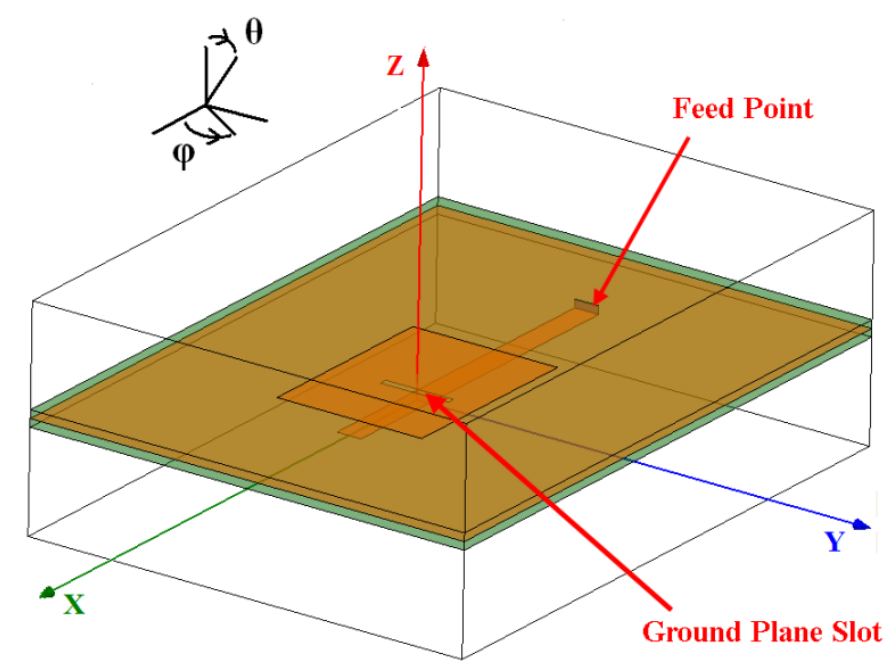

Figure 2-5: Aperture coupled patch antenna HFSS model coordinate system

The X-polarized (assuming first order TEM mode) feed line current induces an Xpolarized electric field in the ground slot. The nominal HFSS model feed substrate height and ground slot length are $0.0169 \lambda$ and $0.0164 \lambda$ (see Figure 2-6) [1]. The x-polarized feed line current radiates an electric field into the region where no ground plane exists (Ground Plane Slot in Figure 2-5). The ground plane slot electric field is x-polarized because the slot is electrically narrow in the $\mathrm{x}$-direction and the line surface current is $\mathrm{x}$ directed [4], [5]. 


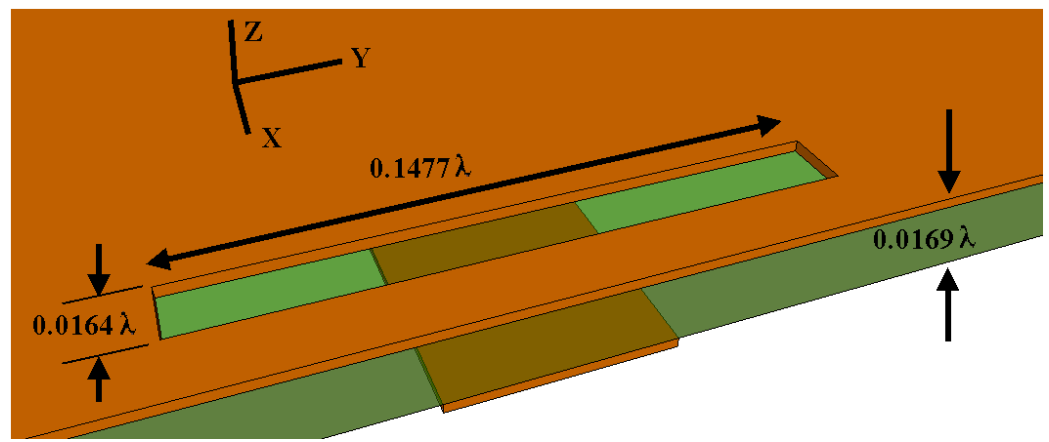

Figure 2-6. Bottom three layers: feed substrate and slot dimensions (drawn to scale)

The slot length and width $(\mathrm{y}, \mathrm{x})$ dimensions are nominally $0.148 \lambda$ and $0.016 \lambda[1]$. The equivalence principle is used to represent the x-polarized electric field and ground plane slot as a PEC boundary with y-polarized magnetic currents on either side (see Figure 2-7) [4]. To satisfy the continuous tangential electric field boundary condition (1.1), the y-directed magnetic currents are in opposing directions due to the surface normal on either side of the ground plane.

$$
\bar{M}_{s}=-\hat{n} \times \bar{E}
$$
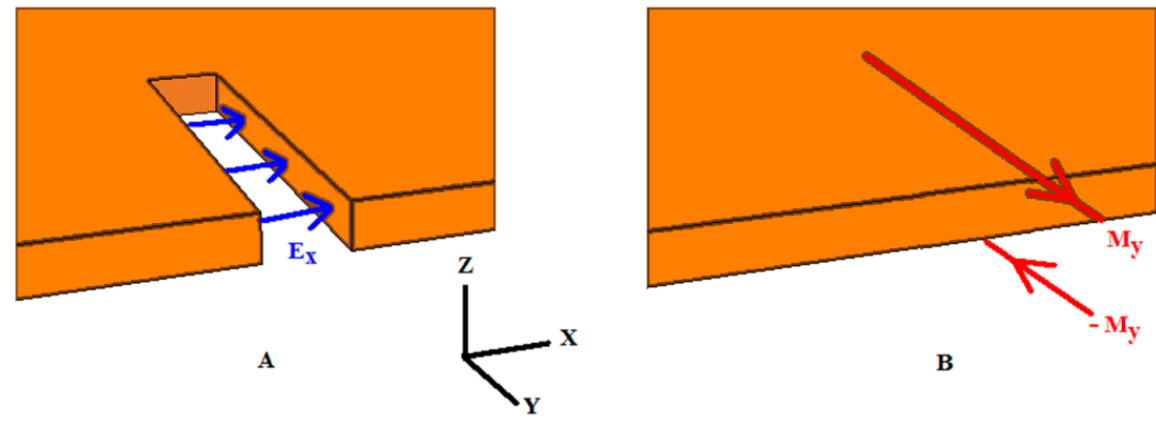

Figure 2-7: Ground plane slot cutout

A) x-polarized electric field B) Equivalent PEC boundary with y-polarized magnetic currents 
The ground plane slot electric field induces x-polarized patch antenna surface currents due to patch centering over the ground plane slot width and the x-polarized slot electric field. The patch length (x-dimension) is nominally $0.422 \lambda(0.211 \lambda$ on either side of the ground plane slot, microstrip wavelength in dielectric). As previously mentioned, aperture loading effects cause a $0.211 \lambda$ microstrip line to behave as a $\lambda / 4$ line. The patch emulates a $\lambda / 2$ length microstrip line centered over the ground plane slot.

The open circuited patch edges exhibit electric field maximums and current nulls. This induces electric field extension from patch edges into the surrounding air and substrate and termination at the ground plane. Figure 2-8A shows that these fringing fields contain $\mathrm{x}$ and $\mathrm{z}$ components. The z-components at opposite patch edges are out of phase. The $\mathrm{x}$-components at opposite patch edges are in phase and interfere constructively in the far field normal to the patch (see Figure 2-8B).

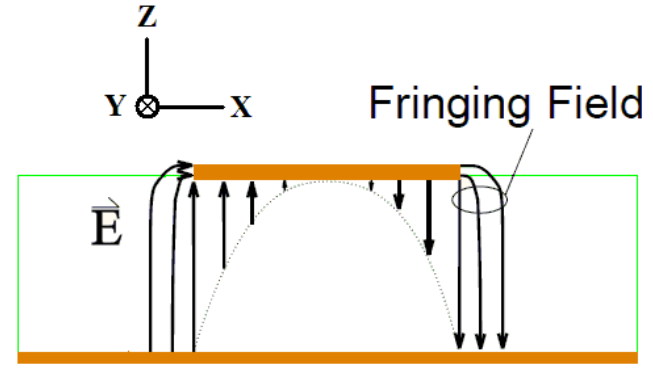

A

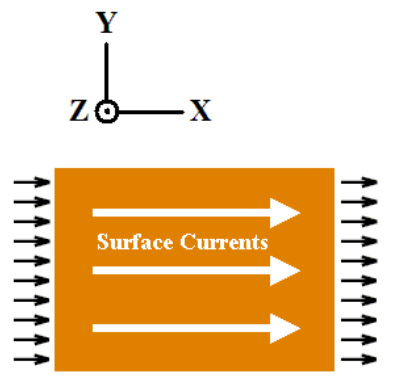

B

Figure 2-8. Patch electric fields

A) Side view (at y=0) B) Top view [2]

Due to the x-polarized ground plane slot electric field and antenna symmetry about the $\mathrm{x}$-axis, the radiating electric fields are $\mathrm{x}$-polarized and exhibit minimum co-pol to cross-pol ratios of $25 \mathrm{~dB}$. The E-plane (xz) co-pol direction is $\theta$ for $\theta \square\left[0^{\circ}, 90^{\circ}\right.$ ) and $\varphi=0^{\circ}, 180^{\circ}$, see Figure 2-8B. 


\section{Chapter III. Nominal Antenna}

\section{Performance}

The linearly-polarized aperture coupled patch antenna design defined in [1] is modeled in HFSS. Simulation results are used as the baseline antenna performance for comparison against all parametric adjustments. The center frequency, input impedance, VSWR, bandwidth, polarization ratio, and radiation patterns are determined and summarized below.

The nominal $2.3 \mathrm{GHz}$ antenna design is modeled on 63 mil thick RT Duroid 5880 substrate [1]. Figure 3-1 shows the five antenna layers and nominal dimensions in mils. The conductive elements (Figure 3-1 A, C, and E) are defined as zero thickness PEC surfaces. The antenna is composed of layers A through E from bottom to top.

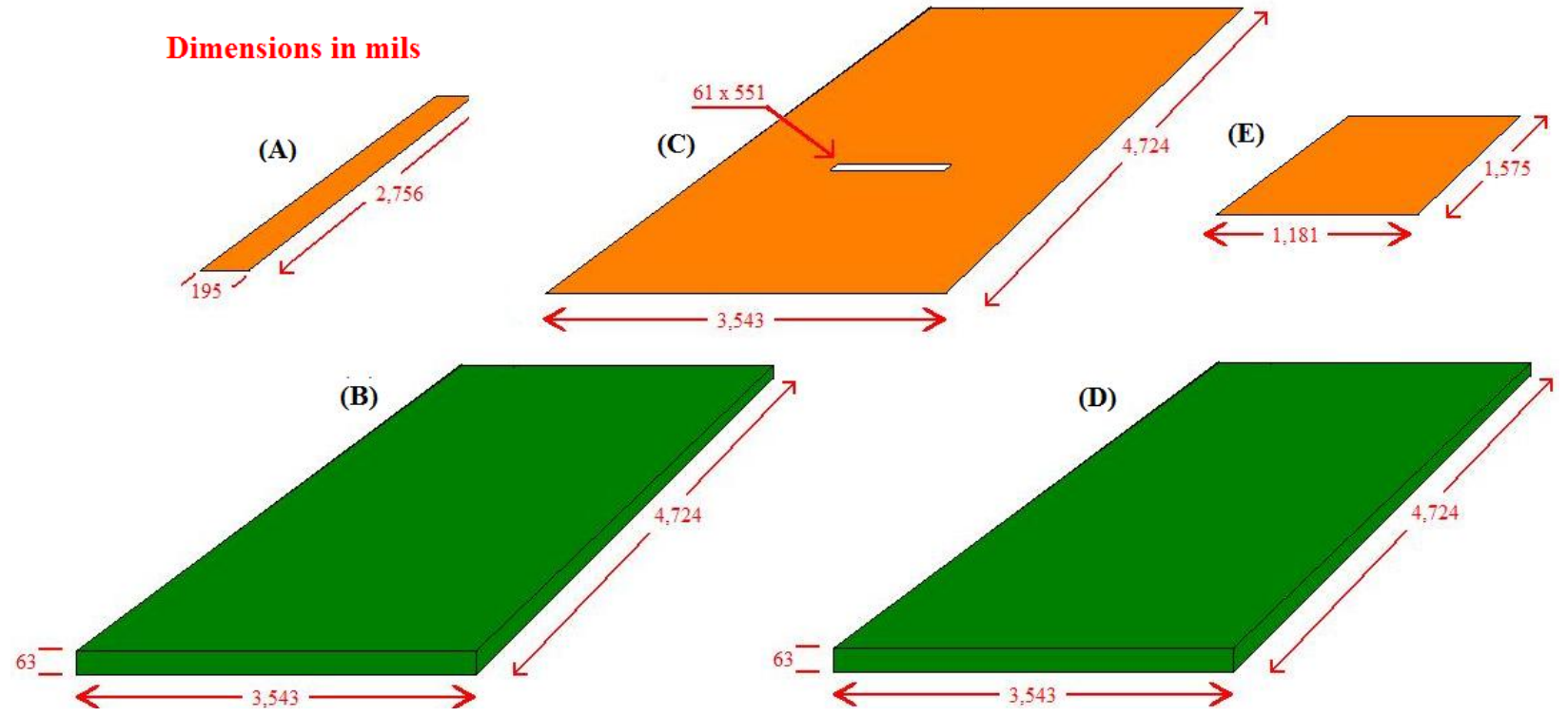

Figure 3-1: Nominal antenna layer dimensions

A) Feed strip ( $\left(1^{\text {st }}\right.$ layer $)$ B) RT duroid substrate $\left(2^{\text {nd }}\right.$ layer $)$ C) Slotted ground plane ( $3^{\text {rd }}$ layer $)$ D) RT duroid substrate $\left(4^{\text {th }}\right.$ layer $)$ E) Radiating patch $\left(5^{\text {th }}\right.$ layer $)$ 
The nominal HFSS antenna model is shown in Figure 2-5. The $\mathrm{z}$ axis is normal to the antenna surface, the feed strip axis is aligned with the $\mathrm{x}$ direction, and the larger ground slot dimension is oriented in the $\mathrm{y}$ direction. The angle relative to the $\mathrm{z}$ axis is defined as $\theta$. The angle relative to the positive $\mathrm{x}$ axis in the $\mathrm{xy}$ plane is defined as $\varphi$.

The frequency where the minimum $\left|S_{11}\right|$ value occurs defines the operating frequency. Figure 3-2 shows that the center frequency occurs at $2.279 \mathrm{GHz}$. The antenna is designed for $2.3 \mathrm{GHz}[1]$.

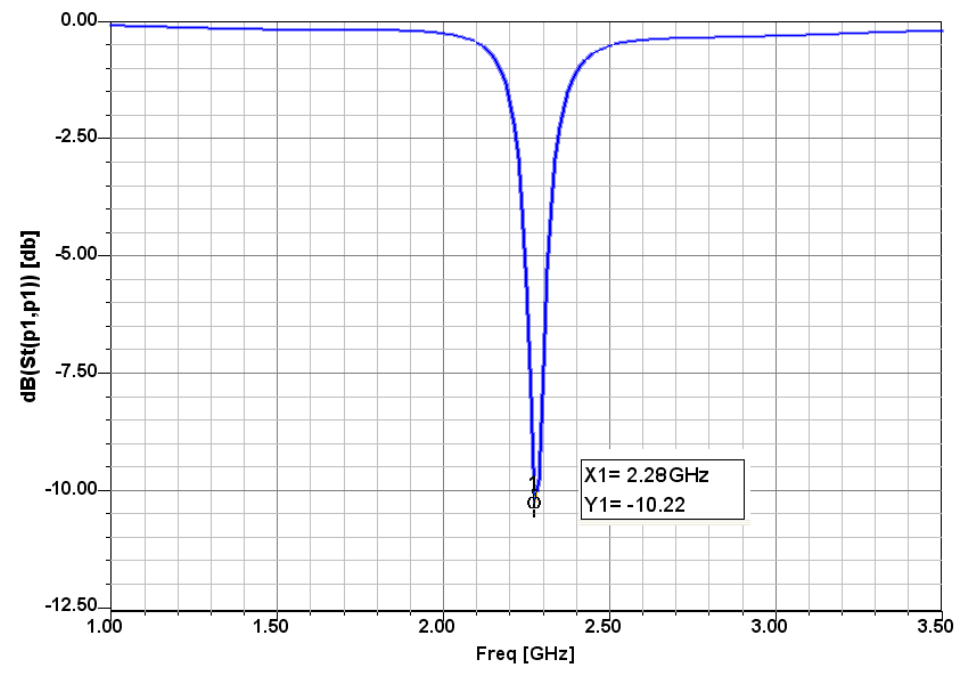

Figure 3-2: $|\mathrm{S} 11|$ vs. frequency, $\mathrm{f}_{\mathrm{o}}=\mathbf{2 . 2 7 9 \mathrm { GHz }}$

Figure 3-3 shows the input impedance real and imaginary components vs. frequency. Maximum power transfer to the antenna occurs when $\mathrm{VSWR}_{\text {in }}$ approaches unity, equivalent to $\left|S_{11}\right|$ approaching zero, when $Z_{\text {in }}$ equals $50+j 0 \Omega\left(Z_{0}\right)$. Minimum $\mathrm{VSWR}_{\text {in }}$ occurs at $2.279 \mathrm{GHz}$ where $\mathrm{Z}_{\text {in }}$ is $72.5-\mathrm{j} 30.5 \Omega$, yielding $\left|\mathrm{S}_{11}\right|$ equal to $-10.45 \mathrm{~dB}$ and $\mathrm{VSWR}_{\text {in }}$ equal to 1.858 . 
Antenna Input Impedance vs. Frequency

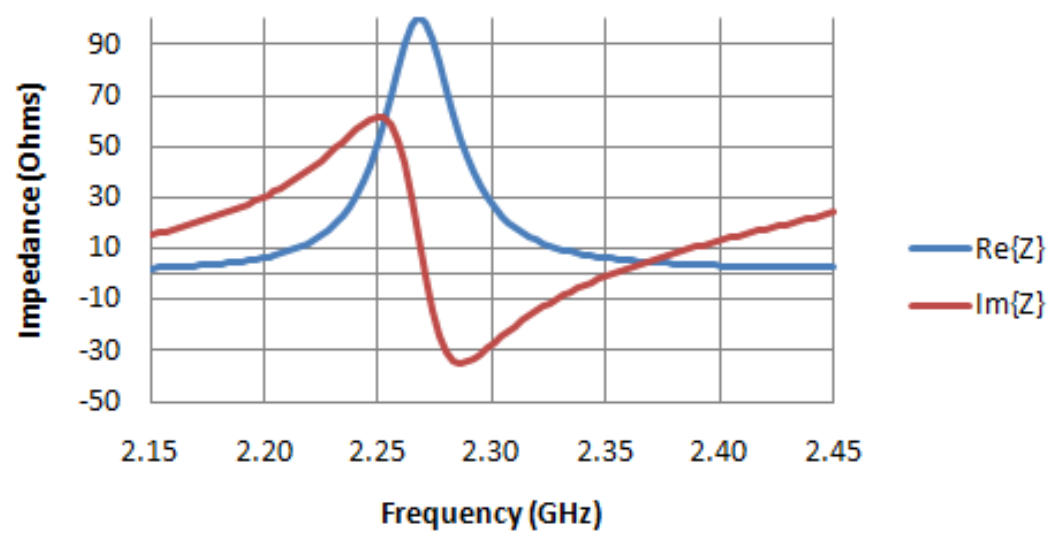

Figure 3-3: Antenna input impedance vs. frequency, $Z_{i n}=\operatorname{Re}(b l u e)+j * \operatorname{Im}($ red) at each frequency

The aperture coupled antenna bandwidth is defined as the frequency range over which $\mathrm{VSWR}_{\text {in }}$ is less than 2. Figure 3-4 shows $\mathrm{VSWR}_{\text {in }}$ vs. frequency. The antenna bandwidth is $20 \mathrm{MHz}\left(0.88 \%\right.$ relative to $\left.\mathrm{f}_{\mathrm{o}}\right)$. This narrow bandwidth is characteristic of microstrip patch antennas [6].

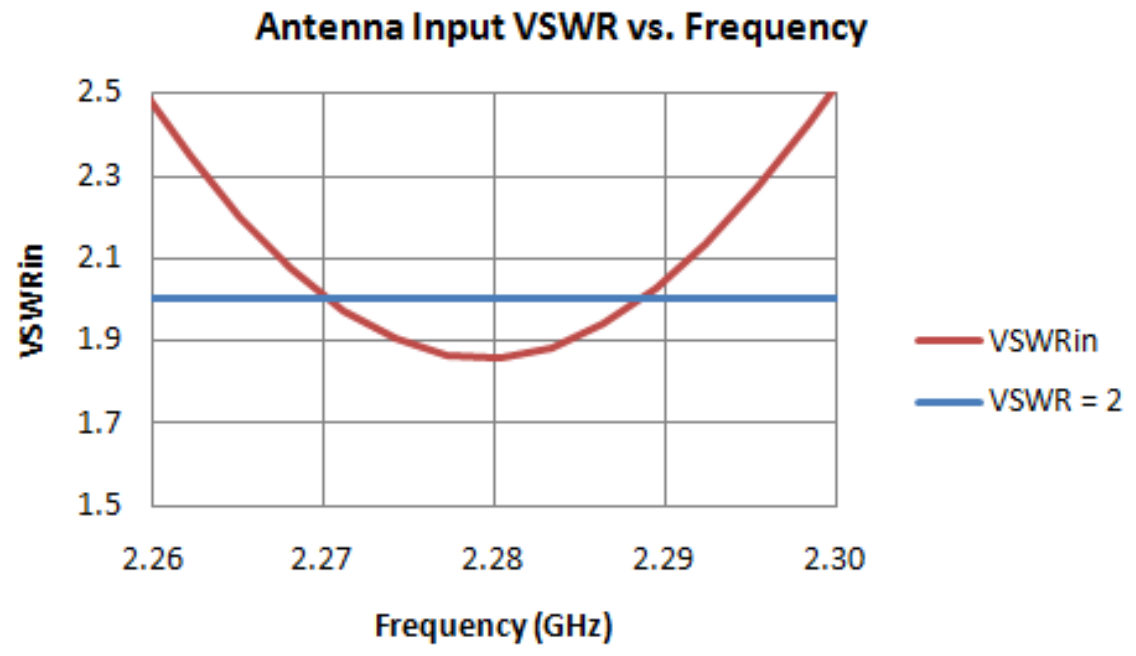

Figure 3-4: Antenna $\mathrm{VSWR}_{\text {in }}$ to determine bandwidth (blue line shows $\mathrm{VSWR}_{\mathrm{in}}=2$ threshold)

Aperture coupled microstrip patch antennas can have polarization ratios $10 \mathrm{~dB}$ greater than other microstrip patch antenna configurations [7]. Figure 3-5 shows that 
normal to the patch antenna surface, the co-pol $\left(\theta\right.$ polarized radiation at $\left.\theta=0^{\circ}, \varphi=0^{\circ}\right)$ gain is $6.01 \mathrm{~dB}$ and the cross-pol $\left(\varphi\right.$ polarized radiation at $\left.\theta=0^{\circ}, \varphi=0^{\circ}\right)$ gain is $-37.28 \mathrm{~dB}$ (see Figure 2-5 for coordinate system and $\varphi$ and $\theta$ directions). This yields a polarization ratio of $43.29 \mathrm{~dB}$ normal to the antenna's surface. The back radiation lobe is due to $-\mathrm{z}$ direction microstrip feed line and ground plane slot radiation [7].

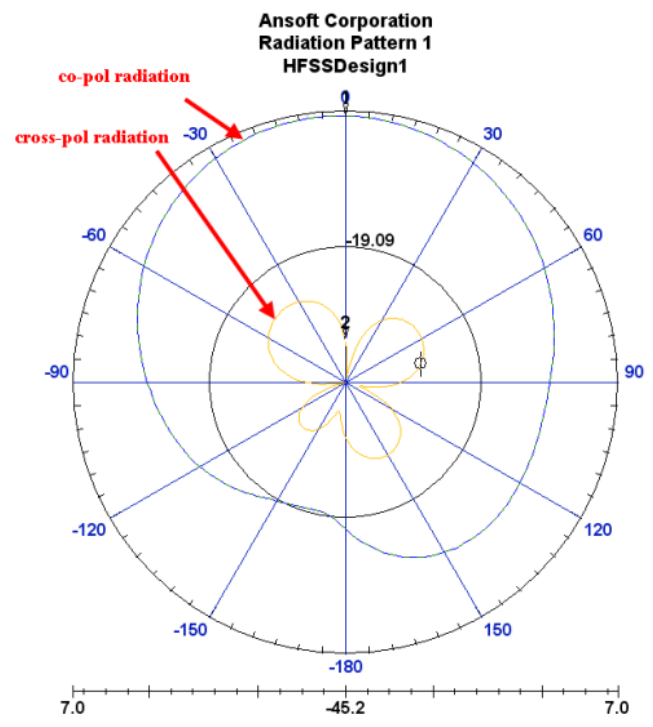

Figure 3-5: Radiation pattern of co-pol and cross-pol components

Table 3-1 summarizes simulation results for the nominal antenna design. These results are used as a baseline for parametric adjustments.

\begin{tabular}{|l|l|}
\hline $\mathrm{f}_{\mathrm{o}}$ & $2.279 \mathrm{GHz}$ \\
\hline $\mathrm{Z}_{\mathrm{o}}$ at $\mathrm{f}_{\mathrm{o}}$ & $72.5-\mathrm{j} 30.5 \Omega$ \\
\hline Minimum VSWR & 1.857 \\
\hline Percent Bandwidth & $0.88 \%$ \\
\hline Broadside polarization ratio at $\mathrm{f}_{\mathrm{o}}$ & $43.29 \mathrm{~dB}$ \\
\hline Broadside gain at $\mathrm{f}_{\mathrm{o}}$ & $6.006 \mathrm{~dB}$ \\
\hline
\end{tabular}

Table 3-1: Nominal aperture coupled microstrip patch antenna characteristics 


\section{Equivalent Circuit Model}

Nominal antenna circuit model parameters (Figure 2-4) are determined from equations (3.1) through (3.8) [8], [9]. Figure 3-6 shows dimensions required to calculate radiation capacitance and resistance, and microstrip line impedance.

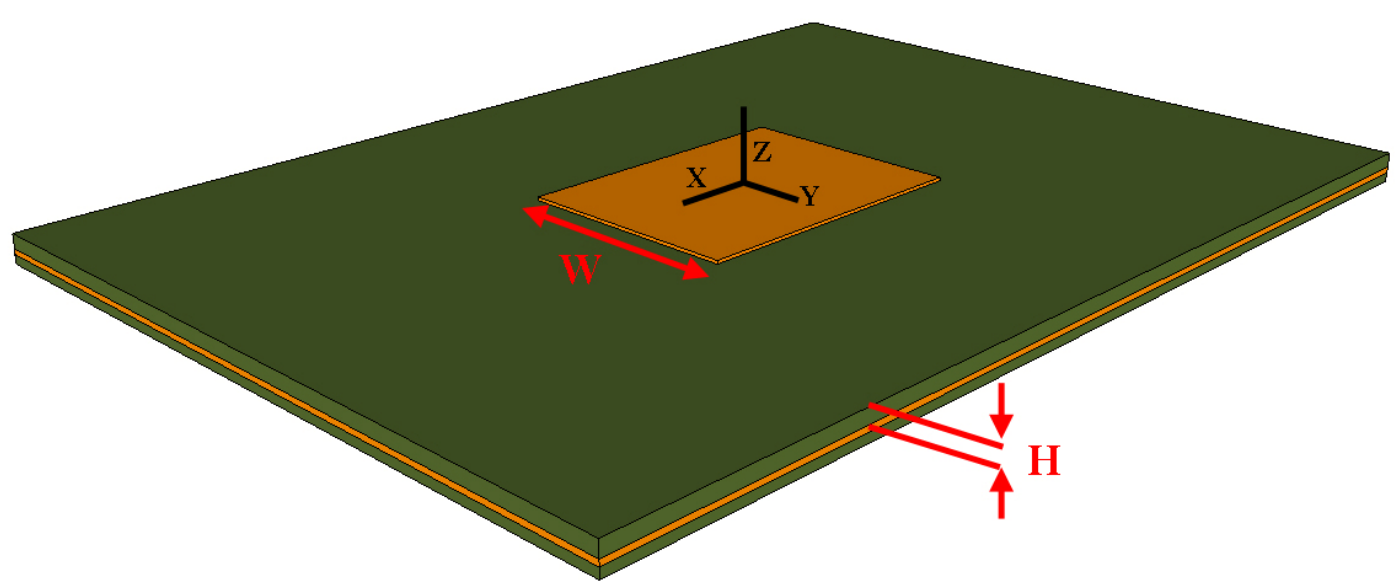

Figure 3-6: Line Impedance Variables

$$
\begin{gathered}
\varepsilon_{e f f}=\frac{\varepsilon_{r}+1}{2}+\frac{\varepsilon_{r}-1}{2}\left(1+\frac{10 H}{W}\right)^{-0.5} \\
\Delta=0.412 H\left(\frac{\varepsilon_{e f f}+0.300}{\varepsilon_{e f f}-0.258}\right)\left(\frac{\frac{W}{H}+0.262}{\frac{W}{H}+0.813}\right) \\
G=\frac{\pi W}{\eta \lambda_{o}}\left(1-\frac{\left(\frac{2 \pi H}{\lambda_{o}}\right)^{2}}{24}\right) \\
B=0.01668 \frac{\Delta}{H}\left(\frac{W}{\lambda_{o}}\right) \varepsilon_{e f f}
\end{gathered}
$$




$$
\begin{gathered}
R_{\text {rad }}=\frac{1}{G} \\
C_{\text {fringe }}=\frac{B}{2 \pi f} \\
Z_{0}=\frac{\frac{120 \pi}{\sqrt{\varepsilon_{e f f}}}}{\frac{W}{H}+1.393+0.667 \ln \left(\frac{W}{H}+1.444\right)} \\
L_{a p} C_{a p} \sim\left(\frac{1}{2 \pi f_{o}}\right)^{2}
\end{gathered}
$$

Table 3-2 contains the nominal antenna variable values and descriptions for equations (3.1) through (3.7). $\mathrm{L}_{\mathrm{ap}}$ and $\mathrm{C}_{\mathrm{ap}}$ are initially selected to satisfy equality in (3.8). The impedance transformer turns ratio $\mathrm{N}$ is initially selected as the nominal patch width to slot length ratio $(3 \mathrm{~cm} / 1.4 \mathrm{~cm}) . \mathrm{L}_{\mathrm{ap}}, \mathrm{C}_{\mathrm{ap}}$, and $\mathrm{N}$ are adjusted in the $\mathrm{ADS}$ equivalent circuit model to match $\mathrm{VSWR}_{\text {in }}$ vs. frequency results. Through ADS2009 parametric adjustments, the impedance transformer turns ratio $(\mathrm{N})$ is inversely proportional to bandwidth and operating frequency and directly proportional to minimum $\mathrm{VSWR}_{\text {in }}$. 


\begin{tabular}{|l|c|c|}
\hline Variable & Value & Description \\
\hline $\mathrm{f}_{\mathrm{o}}$ & $2.3 \mathrm{GHz}$ & Operating frequency \\
\hline$\lambda_{\mathrm{o}}$ & $0.1304 \mathrm{~m}$ & Free space wavelength \\
\hline$\eta_{\mathrm{o}}$ & $376.7 \Omega$ & Free space impedance \\
\hline$\varepsilon_{\mathrm{r}}$ & 2.20 & Substrate dielectric constant \\
\hline$\varepsilon_{\text {eff }}$ & 2.08 & Patch effective relative dielectric constant \\
\hline$\varepsilon_{\text {eff }}$ & 1.89 & Feed effective relative dielectric constant \\
\hline $\mathrm{W}_{\mathrm{p}}$ & $0.0300 \mathrm{~m}$ & Patch width \\
\hline $\mathrm{H}_{\mathrm{p}}$ & $0.0016 \mathrm{~m}$ & Patch substrate height \\
\hline $\mathrm{W}_{\mathrm{f}}$ & $0.0050 \mathrm{~m}$ & Feed width \\
\hline $\mathrm{H}_{\mathrm{f}}$ & $0.0016 \mathrm{~m}$ & Feed substrate height \\
\hline$\Delta$ & $0.0008 \mathrm{~m}$ & Effective patch edge field extension \\
\hline $\mathrm{G}$ & $0.0019 \mathrm{~S}$ & Parallel plate radiator conductance \\
\hline $\mathrm{B}$ & $0.0042 \mathrm{~S}$ & Fringing field capacitive susceptance \\
\hline $\mathrm{Z}_{\mathrm{o}, \mathrm{p}}$ & $11.8 \Omega$ & Patch microstrip line impedance \\
\hline $\mathrm{Z}_{\mathrm{o}, \mathrm{f}}$ & $49.9 \Omega$ & Feed microstrip line impedance \\
\hline $\mathrm{L}_{\mathrm{p} / 2}$ & $0.211 \lambda$ & Half of patch length \\
\hline $\mathrm{L}_{\mathrm{f}}$ & $0.528 \lambda$ & Feed slot length to ground slot \\
\hline $\mathrm{L}_{\mathrm{stub}}$ & $0.211 \lambda$ & Stub length beyond ground slot \\
\hline $\mathrm{C}_{\mathrm{ap}}$ & $19.6 \mathrm{pF}$ & Effective aperture capacitance \\
\hline $\mathrm{L}_{\mathrm{ap}}$ & $186 \mathrm{pH}$ & Effective aperture inductance \\
\hline $\mathrm{R}_{\mathrm{rad}}$ & $522 \Omega$ & Fringing field resistance \\
\hline $\mathrm{C}_{\text {fring }}$ & $0.29 \mathrm{pF}$ & Fringing field capacitance \\
\hline $\mathrm{N}$ & 1.48 & Impedance transformer turns ratio \\
\hline
\end{tabular}

Table 3-2: Nominal antenna equivalent circuit values

The nominal antenna equivalent circuit model is created in ADS (Figure 3-7). The line lengths $(\mathrm{E})$ are in degrees $\left(\lambda \rightarrow 360^{\circ}\right)$. 


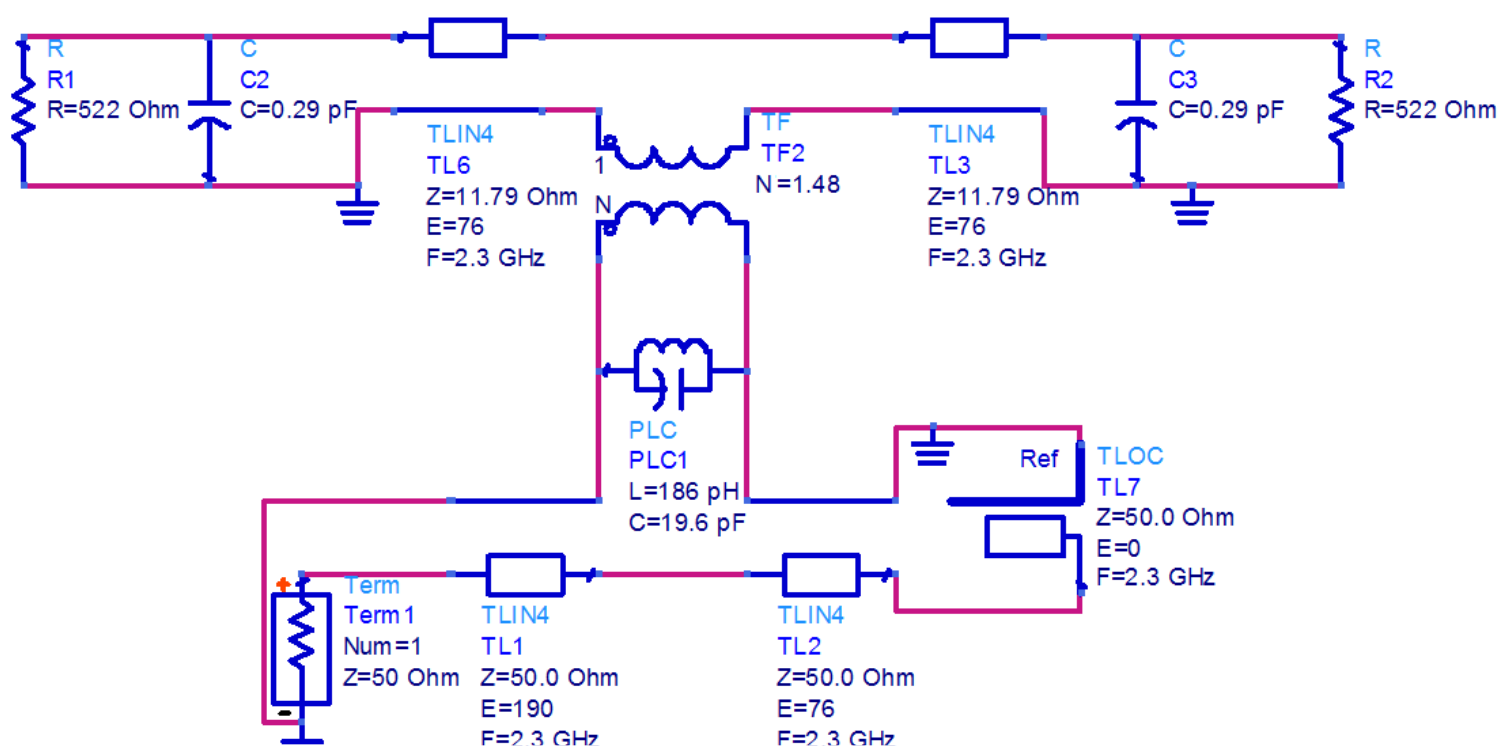

Figure 3-7: Nominal antenna equivalent circuit model

Figure 3-8 shows VSWR in vs. frequency for the nominal antenna in HFSS (see Figure 3-4) and equivalent circuit model in ADS20009. VSWR in is 1.858 at $2.279 \mathrm{GHz}$ and 1.879 at $2.280 \mathrm{GHz}$ for the nominal HFSS antenna model and equivalent circuit model. The bandwidth is $20 \mathrm{MHz}(0.88 \%$ of operating frequency) and $19 \mathrm{MHz}(0.83 \%)$ for the nominal HFSS antenna model and equivalent circuit model.

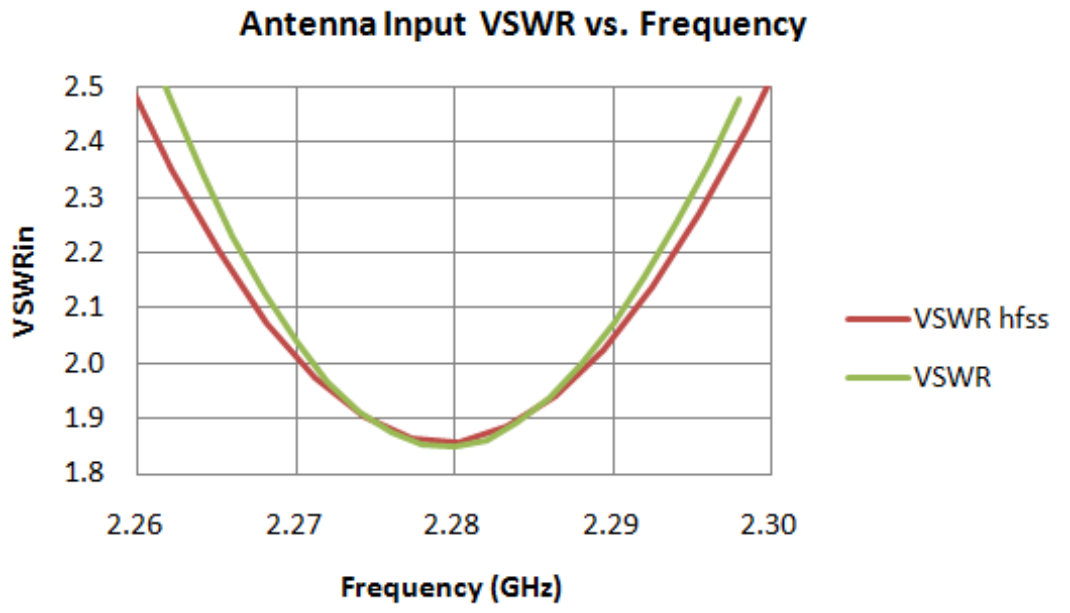

Figure 3-8: HFSS antenna model (red) and equivalent circuit model (green): VSWRin vs. frequency 


\section{Chapter IV. Parametric Study}

The aperture coupled patch antenna microstrip feed line, substrates, ground plane slot, and patch dimensions are varied in HFSS to determine effects on antenna performance. The operating frequency, VSWR, percent bandwidth, polarization ratio, and broadside gain are observed for each configuration. The operating frequency is the location of minimum VSWR in over the test bandwidth. The percent bandwidth is the ratio of frequency range over which $\mathrm{VSWR}_{\text {in }}$ is less than 2 to the operating frequency. The polarization ratio is the co-pol $\left(\theta\right.$ polarized radiation at $\left.\theta=0^{\circ}, \varphi=0^{\circ}\right)$ to cross-pol $(\varphi$ polarized radiation at $\theta=0^{\circ}, \varphi=0^{\circ}$ ) ratio in the far field. The total broadside gain from all polarizations is determined at the antenna operating frequency. All dimensions given in wavelengths are determined with ADS2009 Linecalc at $2.3 \mathrm{GHz}$ in 63 mil thick RT Duroid $\left(\varepsilon_{\underline{r}}=2.2\right.$, loss tangent $\left.=0.0009\right)$.

The nominal antenna design from [1] is used as a baseline for comparison. For each adjustment, only one variable is varied while all other dimensions remain at nominal values. The parametric study results are used to develop a design procedure which is demonstrated in the design, optimization, fabrication, and characterization of four aperture coupled antennas.

This chapter summarizes the parametric study and defines relationships between physical antenna dimensions and performance parameters which either indicate how fabrication errors can degrade aperture coupled microstrip antenna performance or are used to design the four antennas described in the next section. Appendix A contains the entire parametric study. 


\section{Antenna Design Relationships}

Figure 4-1 shows an expanded view of the ground plane (orange) and ground plane slot (yellow). Slot Width Offset and Slot Length Offset are the distances from the center of the slot to a point directly below the center of the radiating patch (z-axis). Slot Width Offset and Slot Length Offset are nominally 0. The nominal slot dimensions are $0.148 \lambda$ by $0.016 \lambda$ (Slot Length by Slot Width) equivalent to $551.2 \mathrm{mils}$ by $61.0 \mathrm{mils}$ (wavelength in dielectric found with ADS2006A linecalc at 2.3GHz).

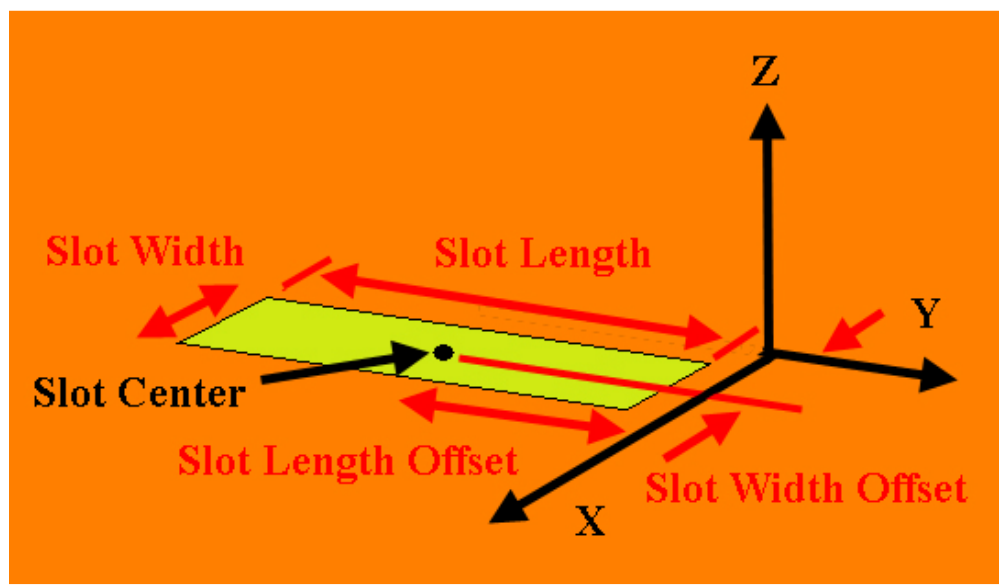

Figure 4-1: Slot Dimensions and Variables

Figure 4-2 contains input reactance and resistance data at $f_{o}$ for Slot Length values between 393.7 and 669.3 mils. This figure indicates that increasing Slot Length increases input resistance and decreases input reactance. These graphs indicate that there exists a Slot Length value approximately 25mils less than nominal (551.2mils) that yields an input impedance near $50+\mathrm{j} 0 \Omega$. 

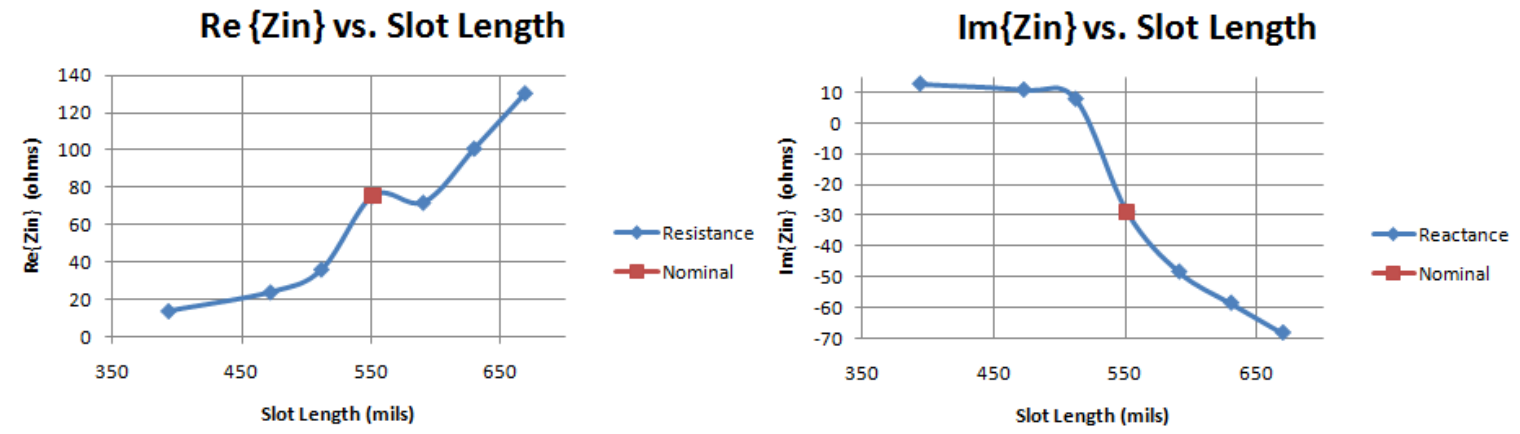

Figure 4-2: Impedance vs. Slot Length

Slot Width is nominally 61.0mils and is varied between 11.8 and 196.9 mils. Figure 4-3 shows minimum $\mathrm{VSWR}_{\text {in }}$ vs. Slot Width. $Z_{\text {in }}$ is nominally $75.5-\mathrm{j} 29.0 \Omega$ at the operating frequency. Slot Width values between 11.8 and 49.2mils result in reactances less than $-\mathrm{j} 29.0 \Omega$ at operating frequency (except for Slot Width equal to $78.7 \mathrm{mils}$ ) and, therefore, larger $\mathrm{VSWR}_{\text {in }}$ values. This indicates that impedance tuning may require slot dimension adjustments.

VSWRmin vs. Slot Width

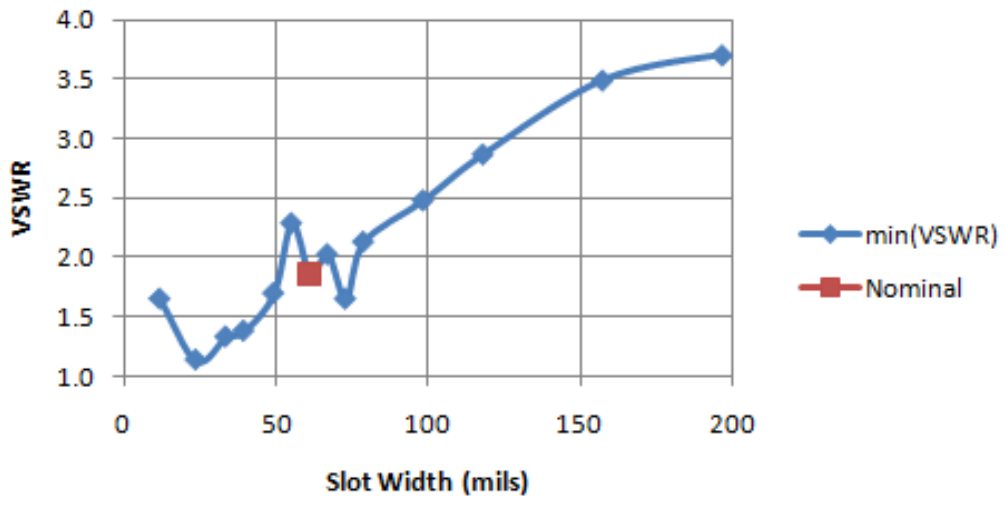

Figure 4-3: VSWRin vs. Slot Width

Patch dimensions and location are varied in HFSS. Figure 4-4 shows the four patch variables: Patch Width, Patch Length, Patch Width Offset, and Patch Length 
Offset. The offsets are measured from the coordinate origin (see Figure 2-5) to the center of the patch.

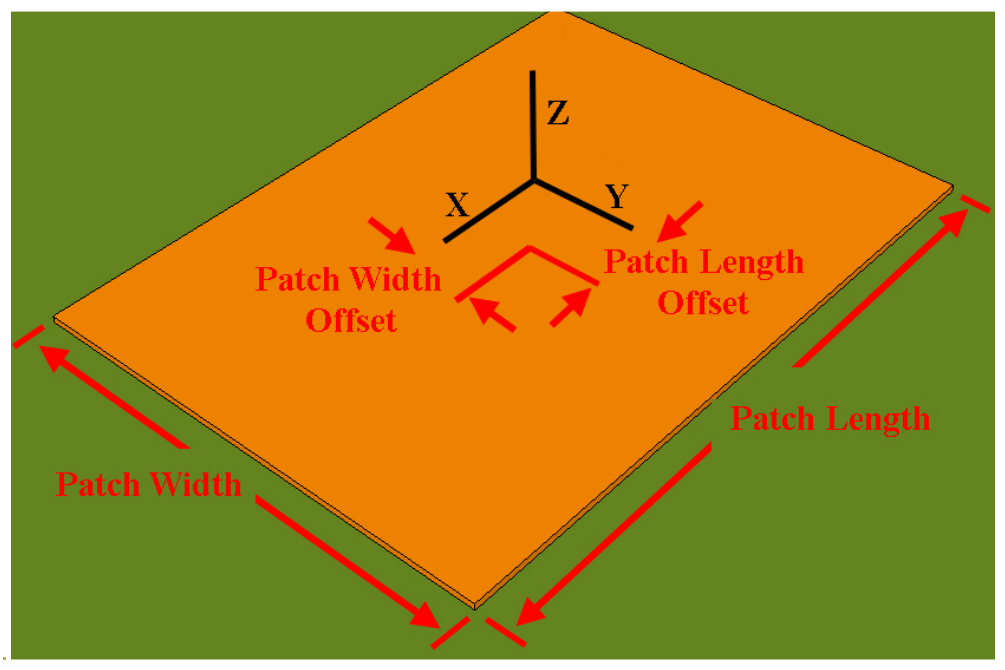

Figure 4-4: Patch variables

Patch Length is nominally 1.575 inches equal to $0.422 \lambda$ (wavelength in $50 \Omega$ microstrip line found using ADS2006A's Linecalc at 2.3GHz). Figure 4-5 shows that increasing Patch Length decreases operating frequency. Resonant frequency approximates a constant slope function of Patch Length between 0.78 and 2.50 inches. The average slope in this range is $-1.295 \mathrm{kHz} / \mathrm{inch}$. Adjusting Patch Length tunes the operating frequency.
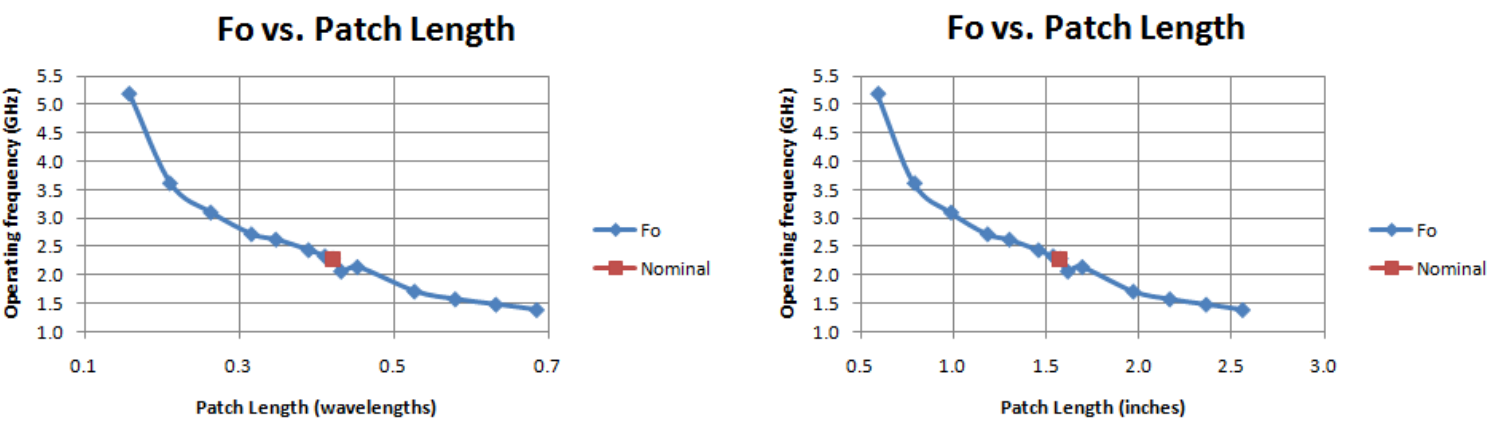

Figure 4-5: Operating frequency vs. Patch Length 
A Matlab program is created to show that the antenna operating frequency is inversely proportional to patch length. The nominal patch design has a Patch Length of $0.422 \lambda$ (wavelength in dielectric at $2.3 \mathrm{GHz}$ ). The feed line termination length is $0.211 \lambda$. This indicates that a $0.211 \lambda$ microstrip line with aperture loading effects approximates a $\lambda / 4$ line over a dielectric with a solid ground plane. To test this theory, a Matlab program wass created (code in Appendix B). The speed of light in the medium is $2.16 \times 10^{8} \mathrm{~m} / \mathrm{s}$ from nominal wavelength and operating frequency values. The program computes theoretical operating frequency at each Patch Length value by determining the ratio of the speed of light in the medium to the theoretical wavelength (Patch Length (mils) divided by 0.422 ) as shown in equation (4.1). The results are shown in Figure 4-6 calculated via Matlab code in Appendix B. The theoretical operating frequency vs. Patch Length curve (blue curve in Figure 4-6) has the same shape as the experimental HFSS results (red curve). The two curves are nearly identical for operating frequencies between $1.5 \mathrm{GHz}$ and $2.5 \mathrm{GHz}$.

$$
f_{o}=\frac{v}{\lambda}=\frac{2.16 \times 10^{8}}{\text { Patch Length } / 0.422}
$$




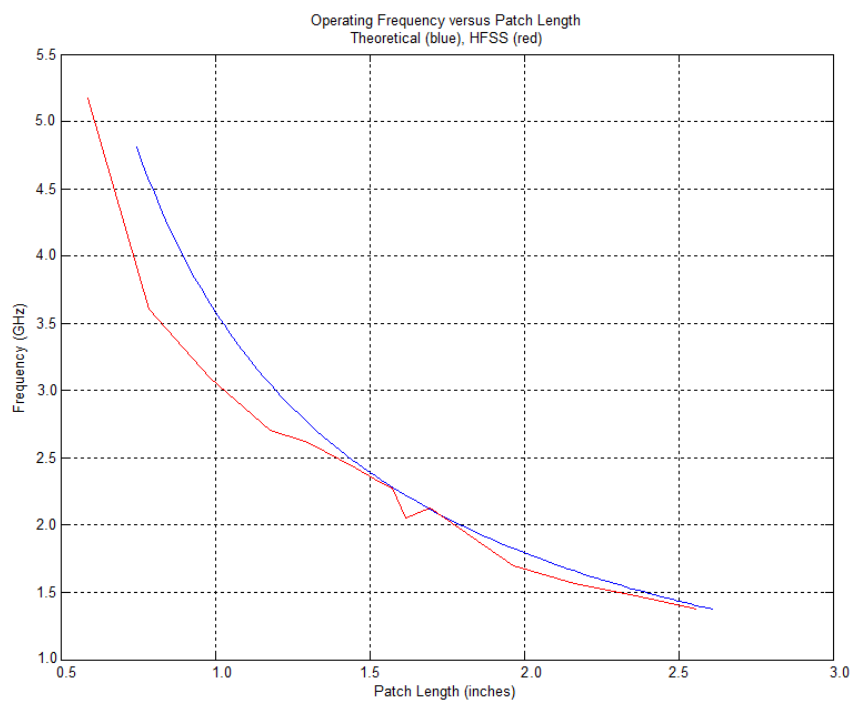

Figure 4-6: Operating frequency vs. Patch Length Theoretical (red), HFSS (blue)

Patch Width is nominally $1,181.1$ mils equal to $0.317 \lambda$ (wavelength in microstrip line from ADS2006A's Linecalc at 2.3GHz). Figure 4-7 shows the input impedance at resonance vs. Patch Width. Increasing Patch Width increases reactance and decreases resistance. The nominal antenna design has an input impedance of 75.5 -j29.0 2 . Patch Width equal to $0.475 \lambda$ results in an input impedance of $51.8+\mathrm{j} 0.93 \Omega$. This indicates that Patch Width can be used to improve input matching if input impedance has both a real component greater than $50 \Omega$ and negative reactance component or both a real component less than $50 \Omega$ and positive reactance component.
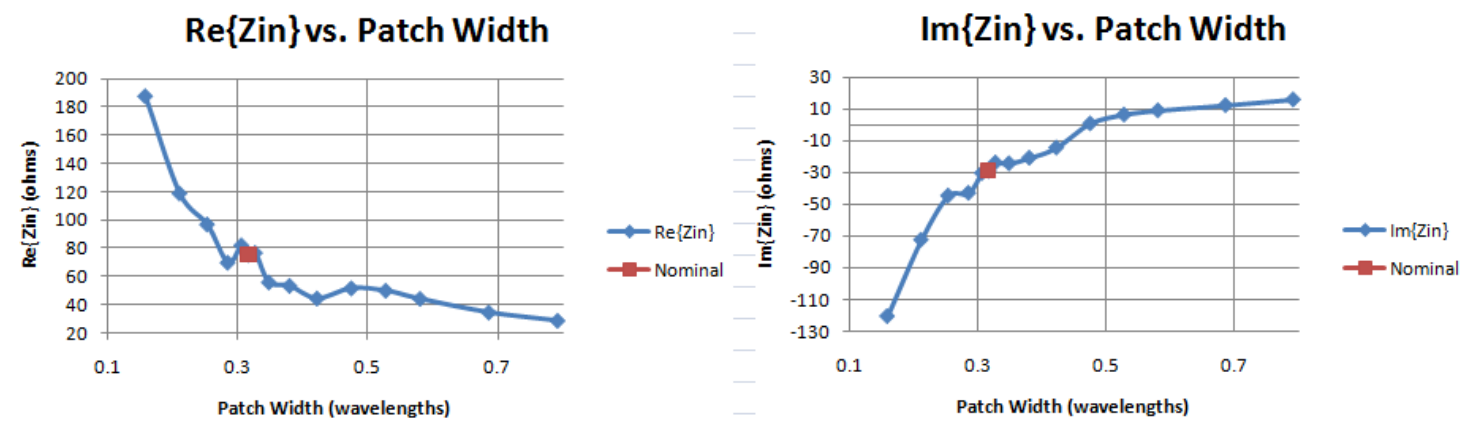

Figure 4-7: Zin vs. Patch Width 


\section{Fabrication Error Relationships}

The aperture coupled patch antenna microstrip feed is varied in HFSS. The antenna model is shown below in Figure 4-8. The feed strip is the bottom most layer (thin, long rectangle in Figure 4-8). It is excited via an edge-connected SMA at the end labeled "FEED POINT," includes an open termination at the end labeled "OPEN TERMINATION," and is electrically isolated from all other conductive layers.

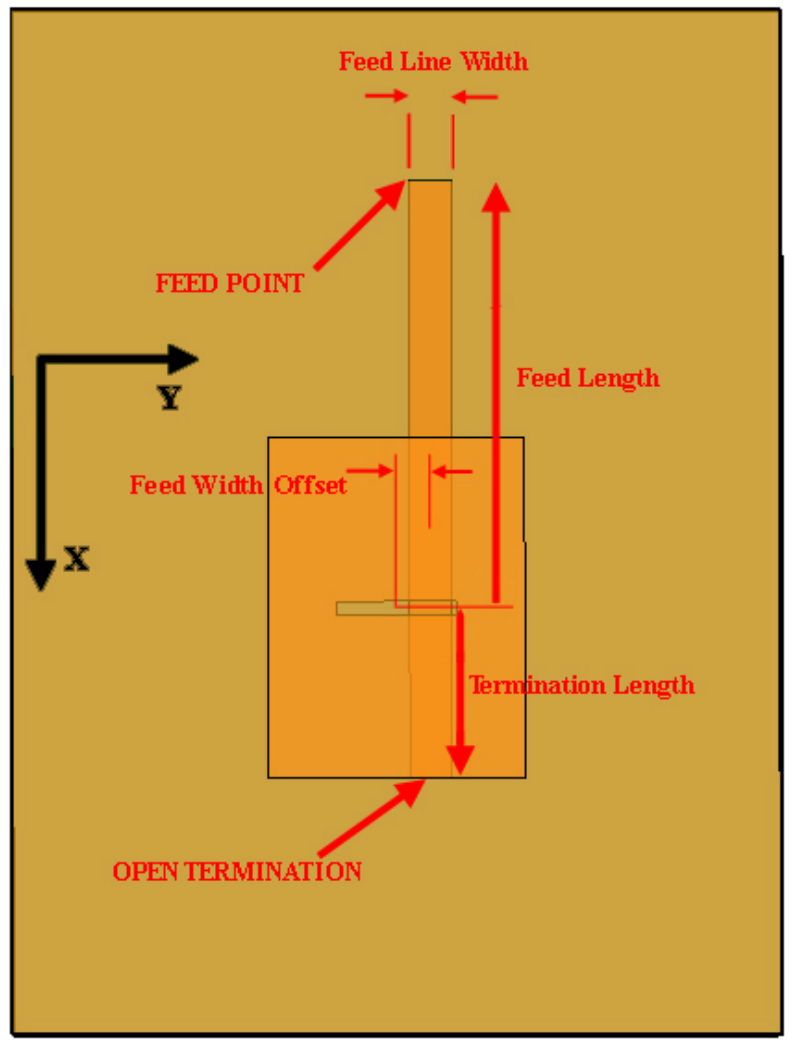

Figure 4-8: Feed line variables

Figure 4-9 shows that feed width offset errors of approximately 20mils $(0.005 \lambda)$ can decrease broadside gain by $4 \mathrm{~dB}$. 


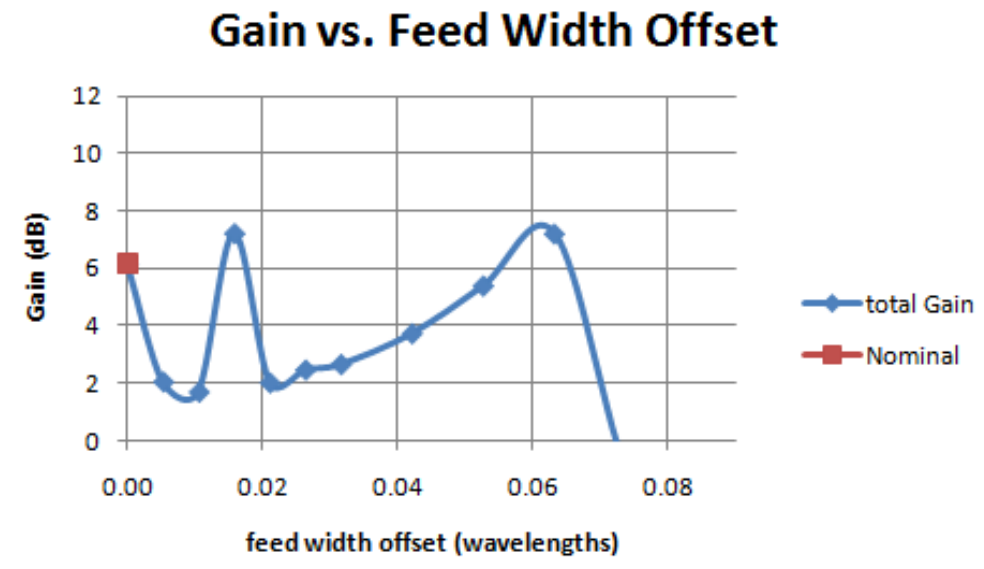

Figure 4-9: Gain vs. feed width offset

Feed line width is nominally 194.9mils. The feed strip is modeled in ADS2006A as a 194.9mil wide microstrip line over a ground plane and 63 mil height substrate with a dielectric constant of 2.2. The line impedance is $49.8 \Omega$ for a feed line width of 194.9 mils. Figure 4-10 shows that adjusting feed line width by \pm 20 mils $( \pm 0.005 \lambda)$ can decrease gain by $4 \mathrm{~dB}$.

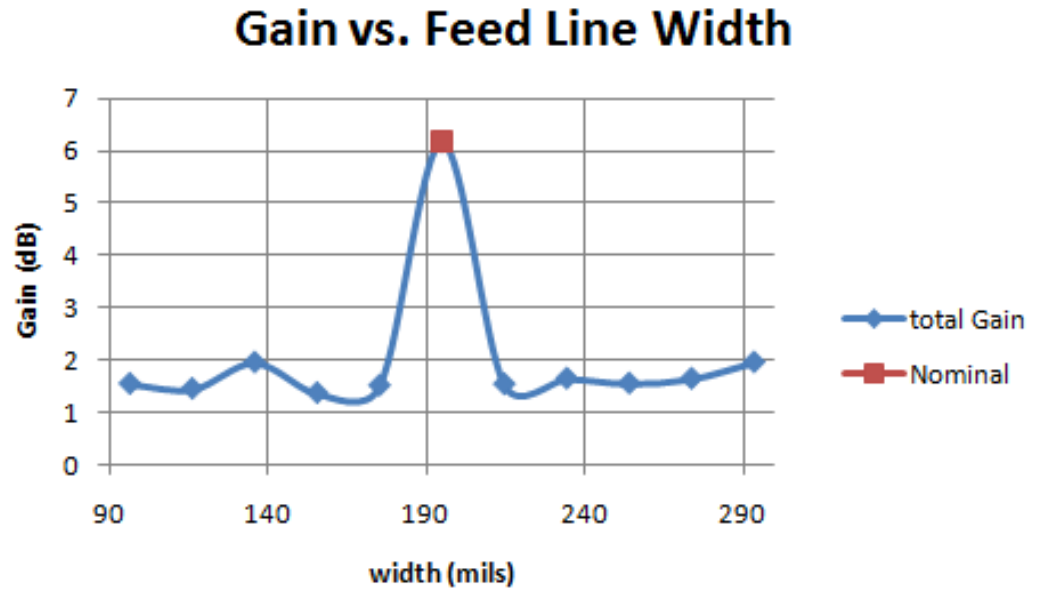

Figure 4-10: Gain vs. feed line width

Substrate heights and material are varied in HFSS. Figure 4-11 shows the antenna side view. The layers from bottom to top are feed line, feed substrate, ground plane, 
antenna substrate, and patch. The terms "feed substrate" and "antenna substrate" are adopted from [7]. The nominal substrates are 63mil height RT Duroid 5880 [1].

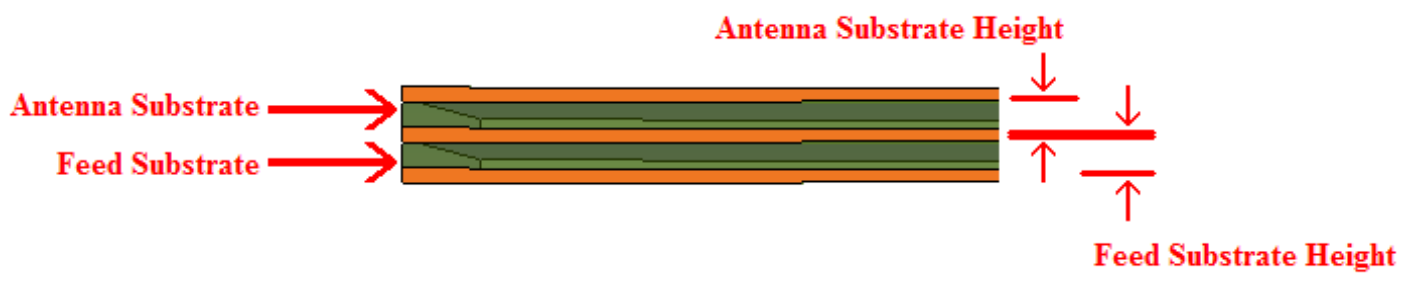

Figure 4-11: Aperture coupled antenna substrates

Nominal substrate height is $63 \mathrm{mil}$, equivalent to $0.017 \lambda$ (wavelength in $50 \Omega$ microstrip line, ADS2006A Linecalc, at 2.3GHz). Figures 4-12 and 4-13 show that substrate height changes of approximately $\pm 0.001 \lambda$ ( \pm 3 mils) from nominal can decrease polarization ratio by 3 to $10 \mathrm{~dB}$.

\section{Polarization Ratio vs. Feed Substrate Height}

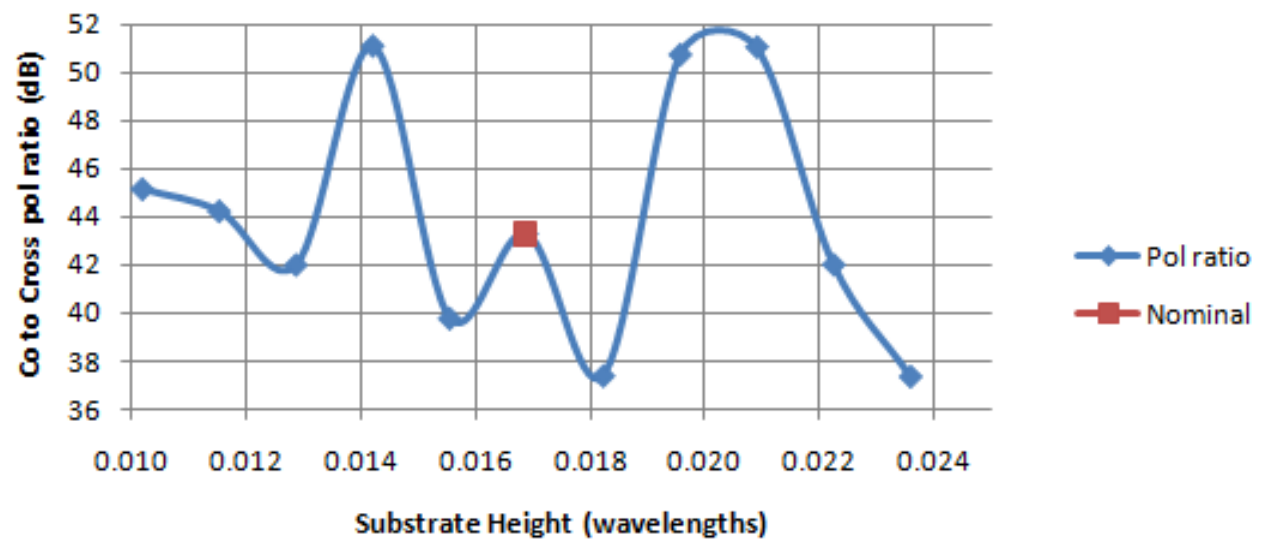

Figure 4-12: Polarization ratio vs. feed substrate height 


\section{Polarization Ratio vs. Antenna Substrate Height}

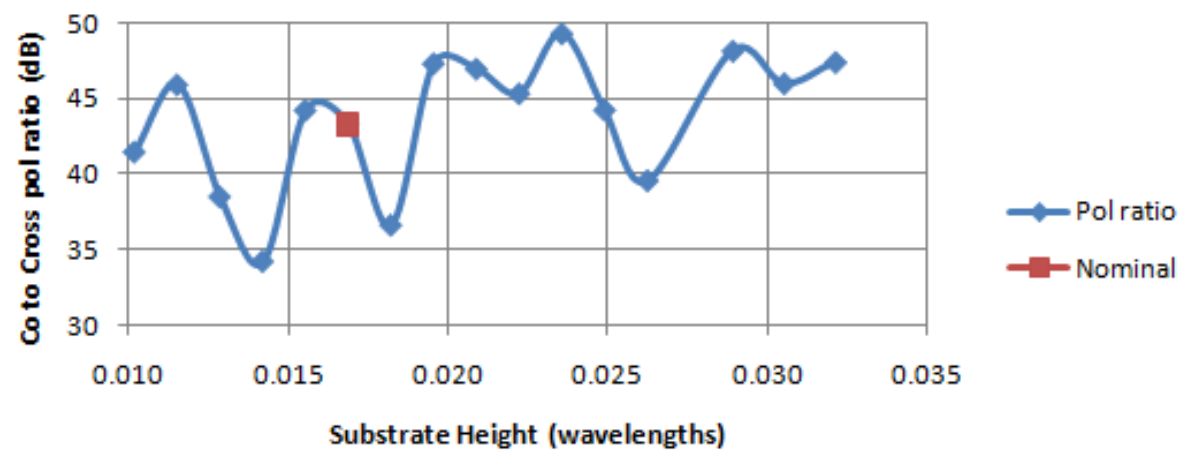

Figure 4-13: Polarization ratio vs. antenna substrate height

Figure 4-14 shows that Slot Width errors (see Figure 4-1) of approximately $0.002 \lambda$ (5mils) can decrease polarization ratio by $10 \mathrm{~dB}$ or more.

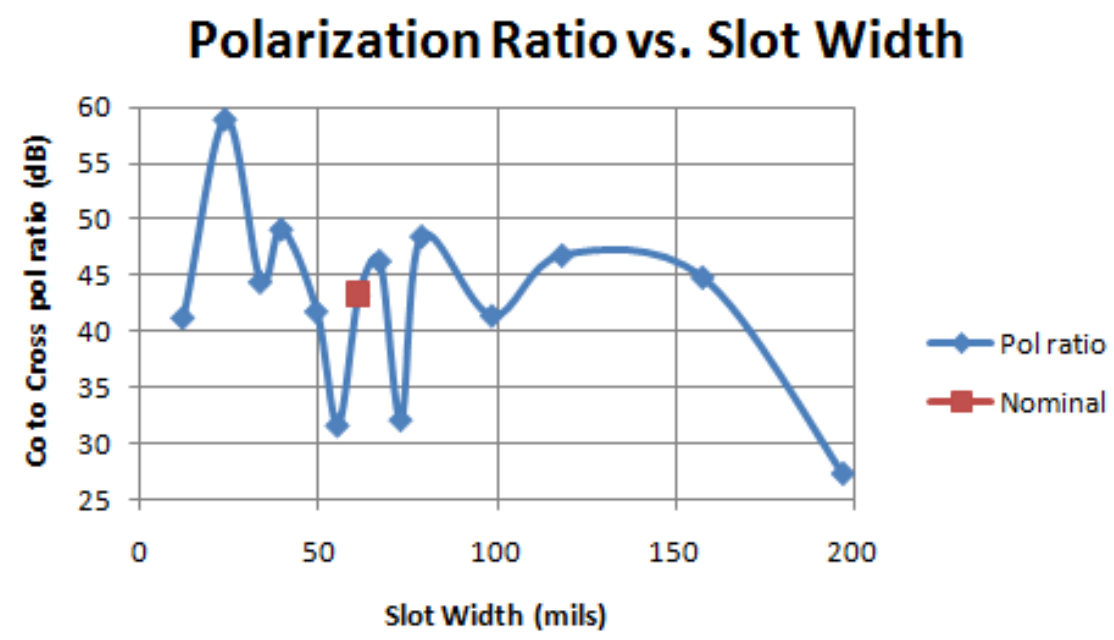

Figure 4-14: Polarization ratio vs. Slot Width

Figure 4-15 shows that Slot Width errors (see Figure 4-1) of approximately 5mils $(0.001 \lambda)$ can cause $\mathrm{VSWR}_{\text {in }}$ to be greater than 2 . 


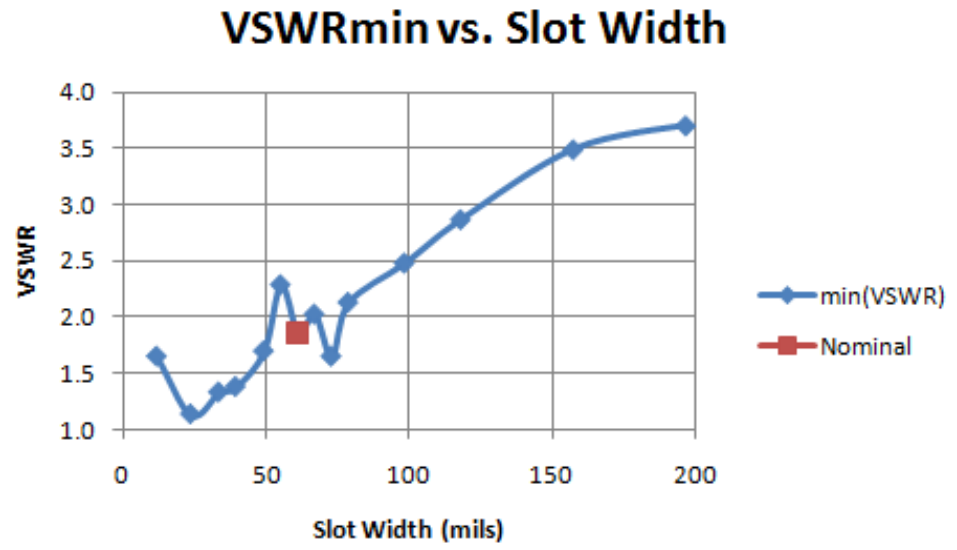

Figure 4-15: VSWRin vs. Slot Width

Figure 4-16 shows that Slot Length Offset errors of approximately 25mils $(0.007 \lambda)$ can decrease polarization ratio by $10 \mathrm{~dB}$ or more.

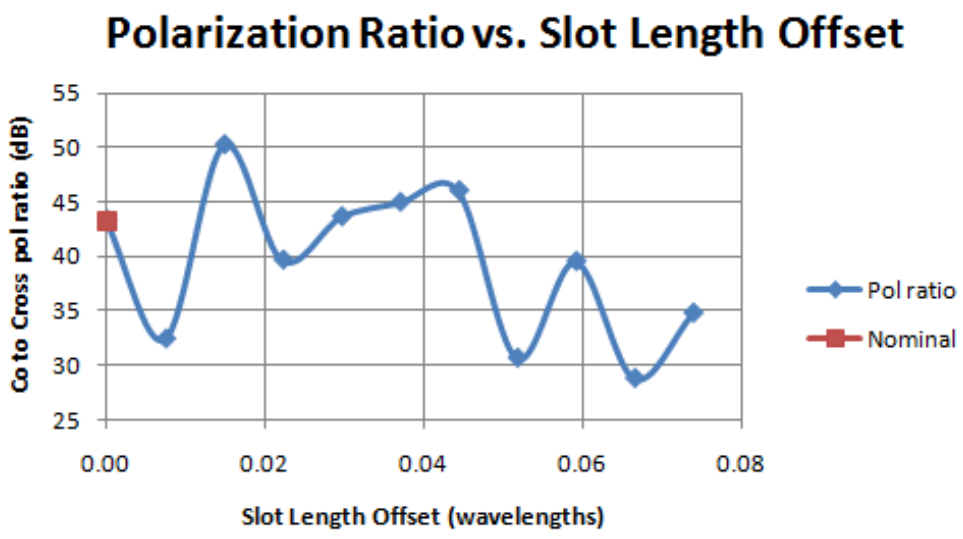

Figure 4-16: Polarization ratio vs. Slot Length Offset 


\section{Chapter V. Design and Tuning}

Design

Four 2.4GHz aperture coupled antenna designs were created in HFSS. A 915MHz design was attempted, but gains greater than $2.0 \mathrm{~dB}$ are not realized. Gerber files are created in ADS for each conductive layer of the $2.4 \mathrm{GHz}$ designs. Figures $2-5,4-1,4-4$, and 4-8 show the coordinate system and the variables adjusted to tune the antenna design.

The nominal HFSS antenna design found in [1] $(2.3 \mathrm{GHz}, 63 \mathrm{mil}$ Duroid 5880 substrate) is modified to operate at $2.4 \mathrm{GHz}$ with an FR4 substrate. An operating frequency of $2.4 \mathrm{GHz}$ is selected for wireless computer and ISM equipment communications. The substrates are changed to 59mil FR4 to coincide with available materials. The antenna substrate is suspended 45 mils above the ground plane due to the adhesive at the ground plane edges (see Figure 5-1). Table 5-1 defines microstrip properties for the three frequency and substrate combinations.

\begin{tabular}{|l|c|c|c|}
\hline & Nominal [1] & FR4 & Suspended FR4 \\
\hline Operating Frequency & $2.3 \mathrm{GHz}$ & $2.4 \mathrm{GHz}$ & $2.4 \mathrm{GHz}$ \\
\hline Dielectric Constant & 2.2 & 4.4 & 4.4 (FR4 only) \\
\hline Effective Dielectric Constant & 1.891 & 3.381 & 1.882 \\
\hline Loss Tangent & 0.0009 & 0.02 & 0.02 (FR4 only) \\
\hline Wavelength in Dielectric & $3,731.2 \mathrm{mils}$ & $2,677.7 \mathrm{mils}$ & $3,584.2 \mathrm{mils}$ \\
\hline Substrate Height & $63.0 \mathrm{mils}$ & $59.0 \mathrm{mils}$ & $59 \mathrm{mils}$ (+45mil air gap) \\
\hline $50 \Omega$ Line Width & $194.0 \mathrm{mils}$ & $112.7 \mathrm{mils}$ & $385.8 \mathrm{mils}$ \\
\hline
\end{tabular}

Table 5-1: Microstrip parameter comparison

The antenna is composed of a double sided 59mil FR4 board attached to a single sided 59mil FR4 board. The boards are adhered with 3M VHB (very high bond) 4950 acrylic tape as suggested in [2]. The tape is available in 45 mil thick, 750mil wide strips 
with a dielectric constant of 2.0 [10]. The strips are cut to 375 mil widths to conserve materials and adhered to the ground plane edges as shown in Figure 5-1.

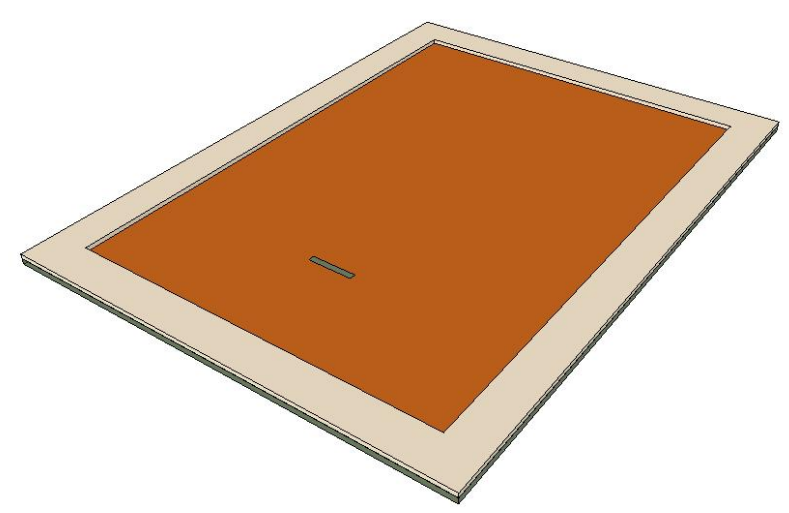

Figure 5-1: Double sided FR4 board with ground slot and adhesive (drawn to scale)

The HFSS substrate models are set to 59mil FR4 with a dielectric constant of 4.4. The substrate material, height, and dielectric constant are not adjusted because they correspond to the available PCB. A 45mil thick air layer between the antenna substrate and ground slot exists due to the adhesive at the ground plane edges (included in HFSS design).

The feed width is set to $112.7 \mathrm{mils}$ for a feed line impedance of $50 \Omega$. The feed line width is held constant because of the $50 \Omega$ characteristic impedance specification and feed line width adjustments do not affect antenna performance significantly (see Figures A-17 through A-21). The nominal feed length and termination length are initially scaled by 0.7177, ratio of FR4 and RT Duroid dielectric wavelength (see Table 5-1, $\left.\lambda_{\mathrm{FR}} / \lambda_{\text {Duroid }}=2677.7 \mathrm{mils} / 3731.2 \mathrm{mils}\right)$. The nominal slot dimensions and patch dimensions are initially scaled by 0.9606 , ratio of suspended FR4 and RT Duroid dielectric wavelength (see Table 5-1, $\lambda_{\text {Sus_FR } 4} / \lambda_{\text {Duroid }}=3,584.2 \mathrm{mils} / 3731.2 \mathrm{mils}$ ). 
The last constant parameter is the ground plane size. The single and double sided boards available at Cal Poly are 9" by 12". Ground plane sizes of 6" by 9", 4" by 9", and 4.5 " by $6 "$ are considered. Input matching and polarization ratio for all ground plane sizes are similar, but the 4.5 " by $6 "$ ground plane design yields the largest total broadside gain. The substrates and ground plane are set to 4.5" and 6" in HFSS. The scalings mentioned above results in an operating frequency of $2.445 \mathrm{GHz}$ (target operating frequency was $2.4 \mathrm{GHz}$ ) with a 4.5 " by $6 "$ ground plane.

Patch, feed, and slot dimensions are adjusted to tune the operating frequency. It is found that $\mathrm{VSWR}_{\mathrm{in}}$ is minimized and gain is maximized when only the patch and slot dimensions are used to tune the operating frequency. The operating frequency is adjusted by inversely scaling patch and slot dimensions (i.e. multiplying slot and patch dimensions by 0.5 doubles the operating frequency). Table 5-2 shows dimensions (in mils and dielectric wavelengths) for an aperture coupled patch antenna tuned to $2.4 \mathrm{GHz}$, but not optimized for input matching or gain. This antenna is referred to as Design 1.

\begin{tabular}{|l|l|l|}
\hline Feed Length & $1,412.6 \mathrm{mils}$ & $0.528 \lambda$ \\
\hline Termination Length & $565.0 \mathrm{mils}$ & $0.211 \lambda$ \\
\hline Slot Width & $59.8 \mathrm{mils}$ & $0.022 \lambda$ \\
\hline Slot Length & $542.1 \mathrm{mils}$ & $0.202 \lambda$ \\
\hline Patch Length & $1,548.8 \mathrm{mils}$ & $0.578 \lambda$ \\
\hline Patch Width & $1,161.4 \mathrm{mils}$ & $0.434 \lambda$ \\
\hline
\end{tabular}

Table 5-2: Design 1 dimensions

Figure 5-2 shows theoretical (HFSS) co-pol and cross-pol radiation patterns for Design 1. The total broadside gain is $5.291 \mathrm{~dB}$. The co-pol to cross-pol ratio is $41.69 \mathrm{~dB}$ normal to the antenna. 


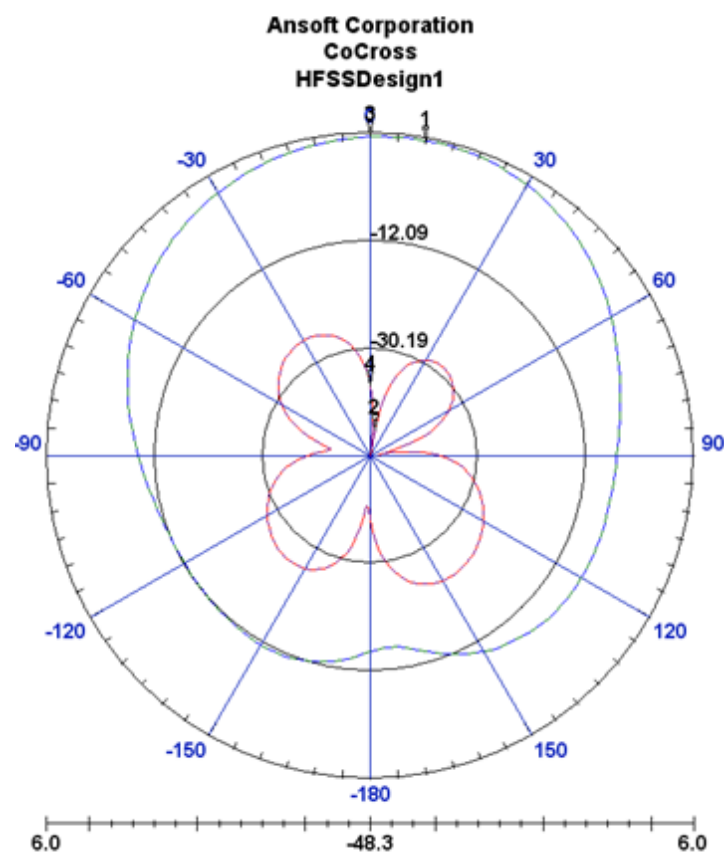

Figure 5-2: Design 1 theoretical (HFSS) radiation patterns (dB): co-pol (blue) and cross-pol (red)

Figure 5-3 shows theoretical (HFSS) $\mathrm{VSWR}_{\text {in }}$ and $\left|\mathrm{S}_{11}\right|$ for Design 1. Minimum values are $\mathrm{VSWR}_{\text {in }}$ equal to 1.340 and $\left|\mathrm{S}_{11}\right|$ equal to $-16.8 \mathrm{~dB}$ at $2.398 \mathrm{GHz}$. The $\mathrm{VSWR}_{\text {in }}$ vs. frequency plot shows that the bandwidth (VSWR in less than two) is $62 \mathrm{MHz}$ or $2.59 \%$ of the operating frequency.
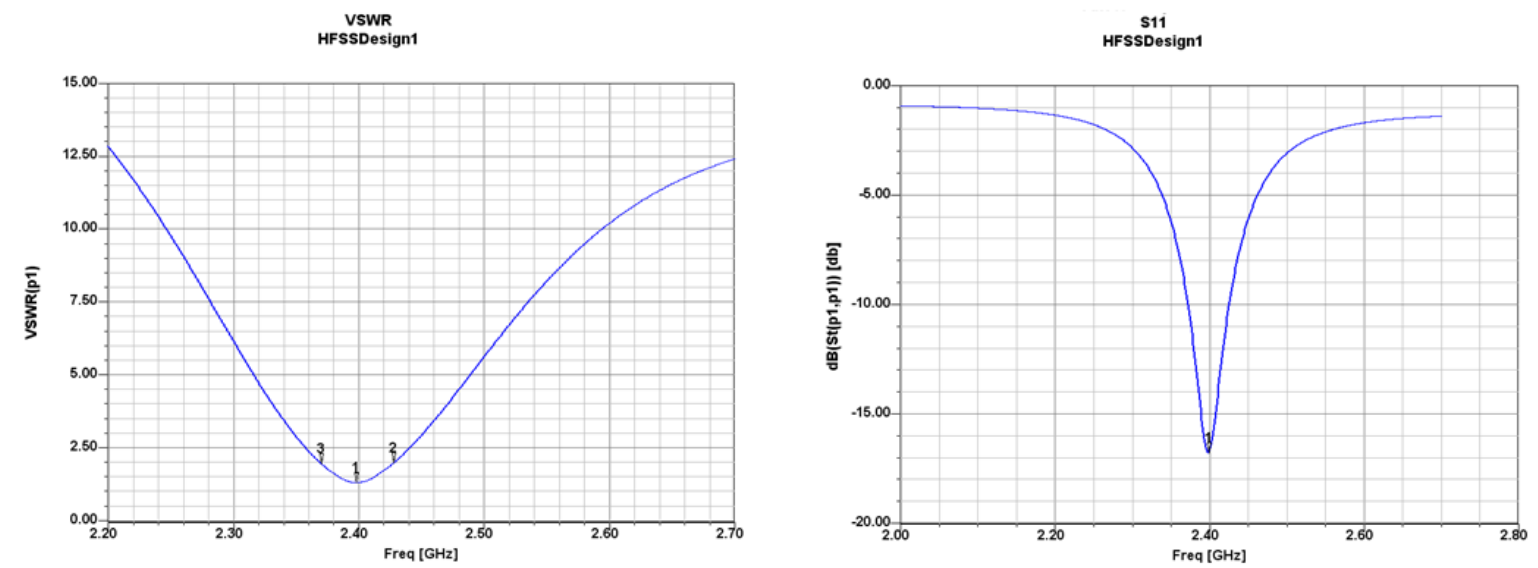

Figure 5-3: Design 1 theoretical (HFSS) VSWR $R_{\text {in }}$ and $\left|S_{11}\right|$ 
Table 5-3 shows that Design 1 has $1.71 \%$ greater percent bandwidth, 1.6dB smaller polarization ratio, and 0.514 smaller VSWR $_{\text {in }}$ compared to the nominal HFSS Duroid design. Design 1 has $0.874 \mathrm{~dB}$ smaller broadside gain than the nominal design. The loss of gain is likely due to the higher FR4 dielectric constant and loss tangent. A higher dielectric constant results in more guided waves (less radiating fringing fields) between the patch and ground plane.

\begin{tabular}{|l|l|}
\hline Operating Frequency & $2.398 \mathrm{GHz}$ \\
\hline Bandwidth & $62.0 \mathrm{MHz}$ \\
\hline Percent Bandwidth & $2.59 \%$ \\
\hline VSWR $_{\text {in }}$ at $\mathrm{f}_{\mathrm{o}}$ & 1.340 \\
\hline Input Impedance at $\mathrm{f}_{\mathrm{o}}$ & $40.1+\mathrm{j} 8.74 \Omega$ \\
\hline Broadside Pol Ratio & $41.7 \mathrm{~dB}$ \\
\hline Broadside Gain & $5.291 \mathrm{~dB}$ \\
\hline
\end{tabular}

Table 5-3: Design 1 theoretical (HFSS) performance summary

The antenna is tuned to minimize $\mathrm{VSWR}_{\text {in. }}$ The feed and termination lengths are adjusted independently in $0.03 \lambda$ steps to improve input matching. This increases the feed line current maximum to ground slot separation and therefore decreases broadside gain and coupling. It was determined that input impedance does not consistently change with feed or termination length adjustments, hence, should not be used to tune the input impedance or operating frequency. The feed and termination lengths are fixed at nominal values of $0.527 \lambda$ and $0.211 \lambda, 1,412.6 \mathrm{mils}$ and $565.0 \mathrm{mils}$.

Figure 4-7 shows that Patch Width can be used to improve input matching if input impedance has both a real component greater than $50 \Omega$ and negative reactance component or both a real component less than $50 \Omega$ and positive reactance component. Patch Width is decreased until $\mathrm{VSWR}_{\text {in }}$ is less than 1.1 and Slot Width, Slot Length, 
Patch Length, and Patch Width are decreased to retune the operating frequency to 2.4GHz. This method is not used to decrease $\mathrm{VSWR}_{\text {in }}$ below 1.1 because the polarization ratio decreases by nearly $9.09 \mathrm{~dB}$ and the gain decreases by $0.3 \mathrm{~dB}$. Table $5-4$ contains the resulting antenna dimensions, Design 2.

\begin{tabular}{|l|c|c|}
\hline & mils & $\lambda$ \\
\hline Feed Length & $1,412.6$ & 0.528 \\
\hline Termination Length & 565.0 & 0.211 \\
\hline Slot Width & 59.6 & 0.022 \\
\hline Slot Length & 539.8 & 0.206 \\
\hline Patch Length & $1,542.5$ & 0.576 \\
\hline Patch Width & 939.4 & 0.351 \\
\hline
\end{tabular}

Table 5-4: Design 2 dimensions

Figure 5-4 shows theoretical (HFSS) co-pol and cross-pol radiation patterns for Design 2. The total broadside gain is $4.970 \mathrm{~dB}$. The co-pol to cross-pol ratio is $51.63 \mathrm{~dB}$ normal to the antenna.

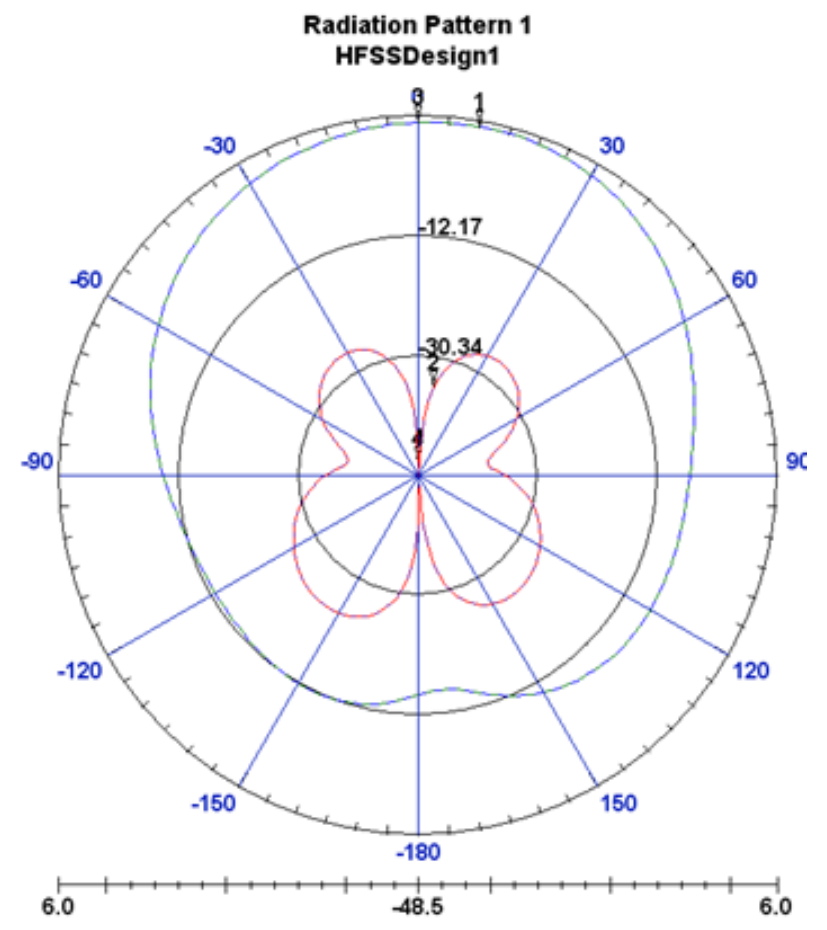


Figure 5-4: Design 2 theoretical (HFSS) radiation patterns (dB): co-pol (blue) and cross-pol (red) Figure 5-5 shows theoretical (HFSS) VSWR $\mathrm{R}_{\text {in }}$ and $\left|S_{11}\right|$ for Design 2. The minimum values are $\operatorname{VSWR}_{\text {in }}$ equal to 1.069 and $\left|\mathrm{S}_{11}\right|$ equal to $-29.6 \mathrm{~dB}$ at $2.398 \mathrm{GHz}$. The VSWR $_{\text {in }}$ vs. frequency plot indicates a bandwidth of $67 \mathrm{MHz}$ or $2.79 \%$ of the operating frequency.
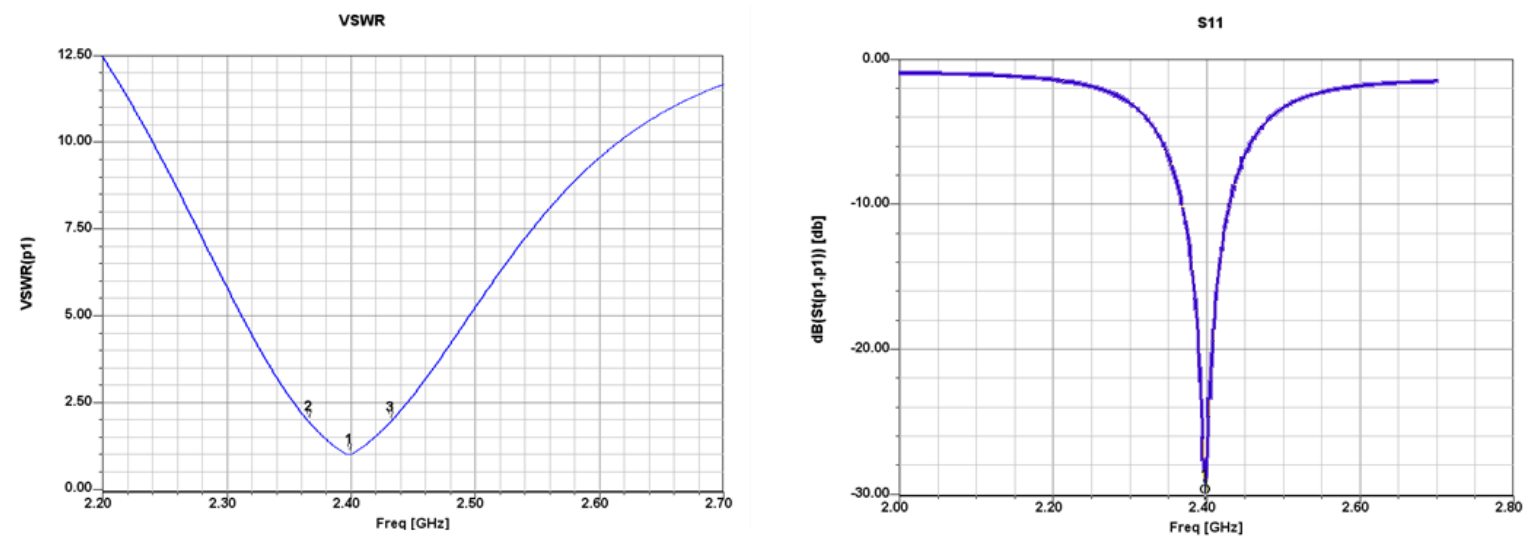

Figure 5-5: Design 2 theoretical (HFSS) VSWR in $_{\text {and }}\left|\mathbf{S}_{11}\right|$

Table 5-5 shows that Design 2 has $0.20 \%$ greater percent bandwidth, $8.34 \mathrm{~dB}$ greater polarization ratio, 0.271 lower $_{\mathrm{VSWR}_{\text {in }}}$, and $1.195 \mathrm{~dB}$ less gain relative to Design 1. Thus, decreasing Patch Width to improve input matching improves the polarization ratio and decreases gain.

\begin{tabular}{|l|l|}
\hline Operating Frequency & $2.398 \mathrm{GHz}$ \\
\hline Bandwidth & $67 \mathrm{MHz}$ \\
\hline Percent Bandwidth & $2.79 \%$ \\
\hline VSWR $_{\text {in }}$ at $\mathrm{f}_{\mathrm{o}}$ & 1.069 \\
\hline Input Impedance at $\mathrm{f}_{\mathrm{o}}$ & $48.4+\mathrm{j} 2.87 \Omega$ \\
\hline Broadside Pol Ratio & $51.63 \mathrm{~dB}$ \\
\hline Broadside Gain & $4.970 \mathrm{~dB}$ \\
\hline
\end{tabular}

Table 5-5: Design 2 theoretical (HFSS) performance summary 
Since Patch Width scaling in Design 2 improves input matching, but decreases gain, the antenna is reset to Design 1 dimensions and another input impedance tuning technique is attempted. Patch Width and Slot Length are scaled while maintaining an aspect ratio of 2.021 to 1 (Patch Width to Slot Length). Adjusting Slot Length and Patch Width together results in greater gain, but does not allow VSWR values below 1.180. Design 3 has the same Patch Length and Slot Width dimensions as Design 1. Patch Width and Slot Length are set to dimensions that yield minimum $\mathrm{VSWR}_{\text {in }}$ for all tested combinations. Table 5-6 contains Design 3 dimensions.

\begin{tabular}{|l|l|l|}
\hline Feed Length & $1,412.6 \mathrm{mils}$ & $0.528 \lambda$ \\
\hline Termination Length & $565.0 \mathrm{mils}$ & $0.211 \lambda$ \\
\hline Slot Width & $59.8 \mathrm{mils}$ & $0.022 \lambda$ \\
\hline Slot Length & $555.1 \mathrm{mils}$ & $0.207 \lambda$ \\
\hline Patch Length & $1,548.8 \mathrm{mils}$ & $0.578 \lambda$ \\
\hline Patch Width & $1,122.0 \mathrm{mils}$ & $0.419 \lambda$ \\
\hline
\end{tabular}

Table 5-6: Design 3 dimensions

Figure 5-6 displays the theoretical (HFSS) co-pol and cross-pol radiation patterns for Design 3. The total broadside gain is $5.247 \mathrm{~dB}$. The polarization ratio is $42.95 \mathrm{~dB}$ normal to the antenna. 


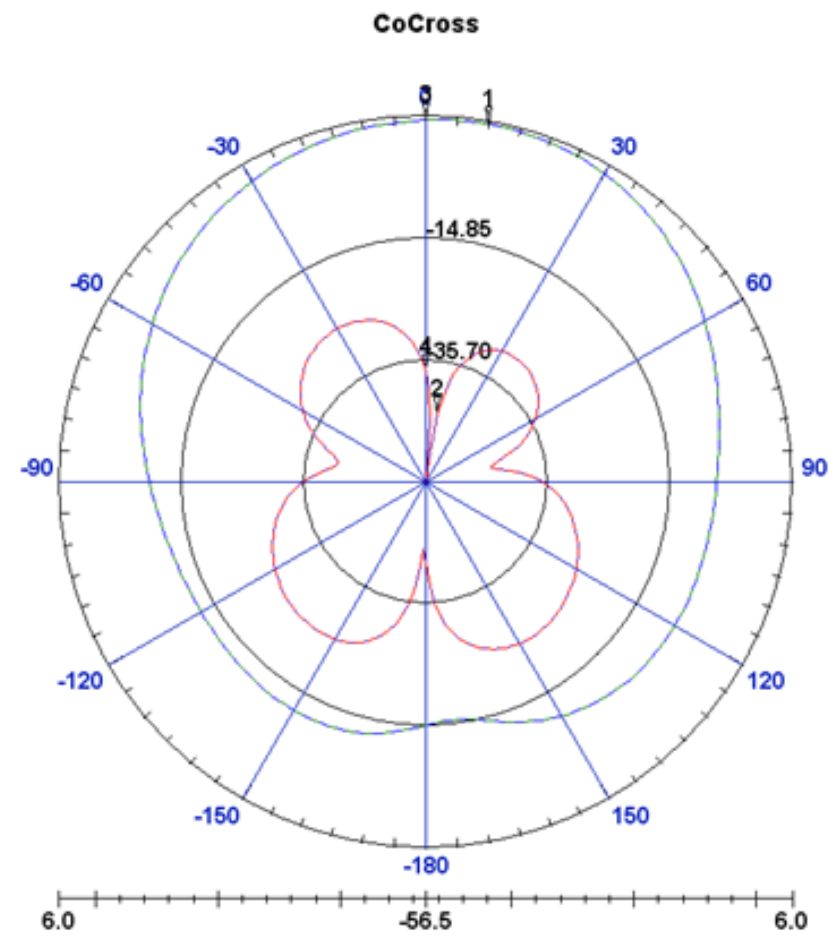

Figure 5-6: Design 3 theoretical (HFSS) radiation patterns: co-pol (blue) and cross-pol (red)

Figure 5-7 shows theoretical (HFSS) $\mathrm{VSWR}_{\text {in }}$ and $\left|\mathrm{S}_{11}\right|$ for Design 3. Minimum values are $\mathrm{VSWR}_{\text {in }}$ and $\left|\mathrm{S}_{11}\right|$ equal to 1.181 and $-21.6 \mathrm{~dB}$ at $2.396 \mathrm{GHz}$. The $\mathrm{VSWR}_{\text {in }} \mathrm{vs}$. frequency plot indicates a bandwidth of $65 \mathrm{MHz}, 2.71 \%$ of the operating frequency.
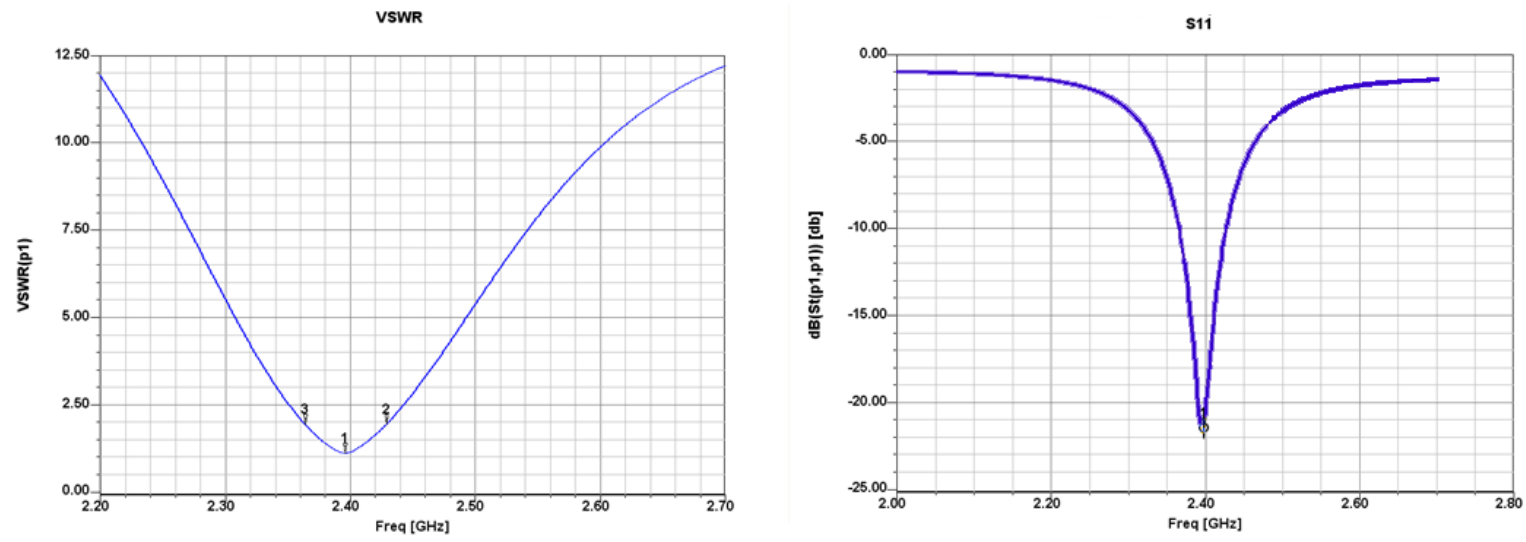

Figure 5-7: Design 3 theoretical (HFSS) VSWR in $_{\text {and }}\left|S_{11}\right|$ 
Table 5-7 contains the Design 3 performance summary. The impedance tuning that includes scaling Slot Length and Patch Width by the same factor results in $0.08 \%$ less percent bandwidth, a VSWR decrease of 0.112 , a polarization ratio increase of $9.87 \mathrm{~dB}$, and a gain increase of $0.269 \mathrm{~dB}$ compared to Design 2. This shows that input matching should be tuned by scaling Patch Width and Slot Length by the same factor.

\begin{tabular}{|l|l|}
\hline Operating Frequency & $2.396 \mathrm{GHz}$ \\
\hline Bandwidth & $65 \mathrm{MHz}$ \\
\hline Percent Bandwidth & $2.71 \%$ \\
\hline VSWR $_{\text {in }}$ at $\mathrm{f}_{\mathrm{o}}$ & 1.181 \\
\hline Input Impedance at $\mathrm{f}_{\mathrm{o}}$ & $45.1+\mathrm{j} 6.16 \Omega$ \\
\hline Broadside Pol Ratio & $50.08 \mathrm{~dB}$ \\
\hline Broadside Gain & $5.427 \mathrm{~dB}$ \\
\hline
\end{tabular}

Table 5-7: Design 3 theoretical (HFSS) performance summary

The dimensions are again set to the Design 1 values. The impedance tuning process that yields Design 3 decreases the resonance frequency to $2.396 \mathrm{GHz}$; hence, Patch Length, Slot Length, Patch Width, and Slot Width are decreased until the resonant frequency is greater than $2.4 \mathrm{GHz}$. The tuning process of adjusting Slot Length and Patch Width to tune the input impedance is performed again. Patch Width and Slot Length are scaled down until the input impedance no longer improves. The resulting dimensions are referred to as Design 4 and are displayed in Table 5-8.

\begin{tabular}{|l|l|l|}
\hline Feed Length & $1,412.6 \mathrm{mils}$ & $0.528 \lambda$ \\
\hline Termination Length & $565.0 \mathrm{mils}$ & $0.211 \lambda$ \\
\hline Slot Width & $59.6 \mathrm{mils}$ & $0.022 \lambda$ \\
\hline Slot Length & $552.8 \mathrm{mils}$ & $0.206 \lambda$ \\
\hline Patch Length & $1,542.5 \mathrm{mils}$ & $0.576 \lambda$ \\
\hline Patch Width & $1,023.6 \mathrm{mils}$ & $0.382 \lambda$ \\
\hline
\end{tabular}

Table 5-8: Design 4 dimensions 
Figure 5-8 displays the theoretical (HFSS) co-pol and cross-pol radiation patterns for Design 4. The total broadside gain is $5.061 \mathrm{~dB}$. The polarization ratio is $48.52 \mathrm{~dB}$ normal to the antenna.

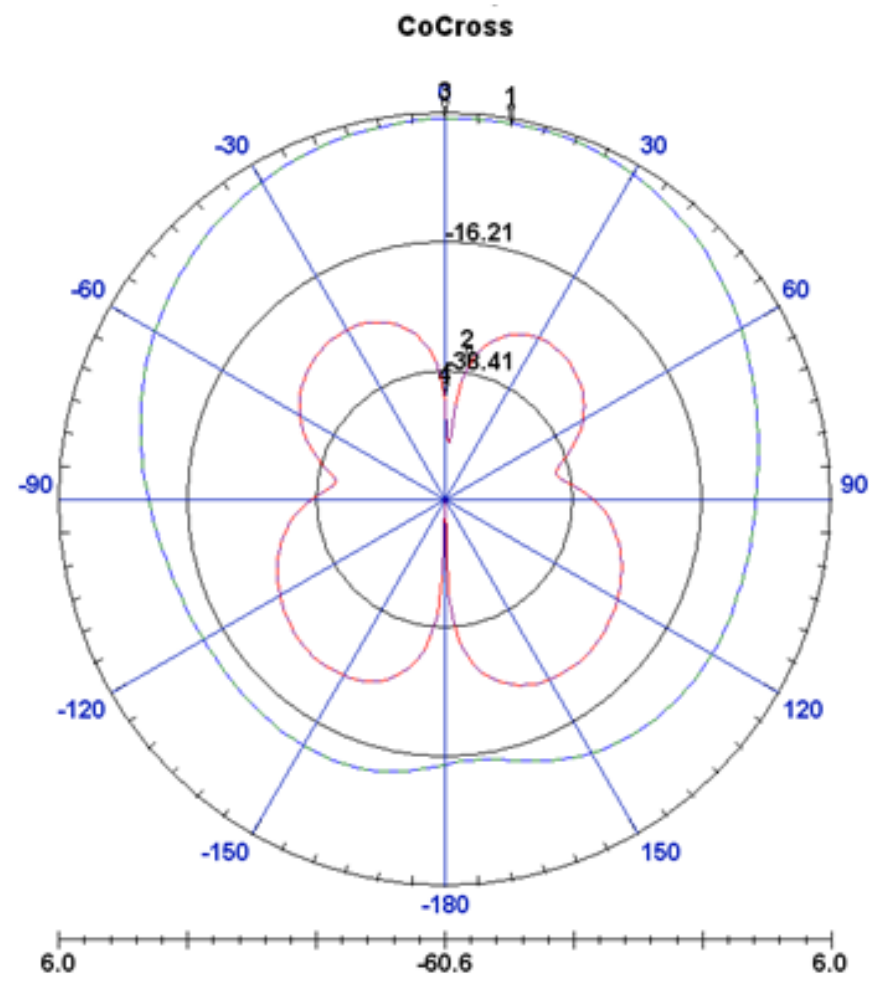

Figure 5-8: Design 4 theoretical (HFSS) radiation patterns: co-pol (blue) and cross-pol (red)

Figure 5-9 shows theoretical (HFSS) $V_{S W R}$ and $S_{11}$ for Design 4. Minimum values are $\mathrm{VSWR}_{\text {in }}$ and $\left|\mathrm{S}_{11}\right|$ equal to 1.045 and $-33.2 \mathrm{~dB}$ at $2.403 \mathrm{GHz}$. The $\mathrm{VSWR}_{\text {in }} \mathrm{Vs}$. frequency plot shows a bandwidth of $67 \mathrm{MHz}, 2.79 \%$ of the operating frequency. 

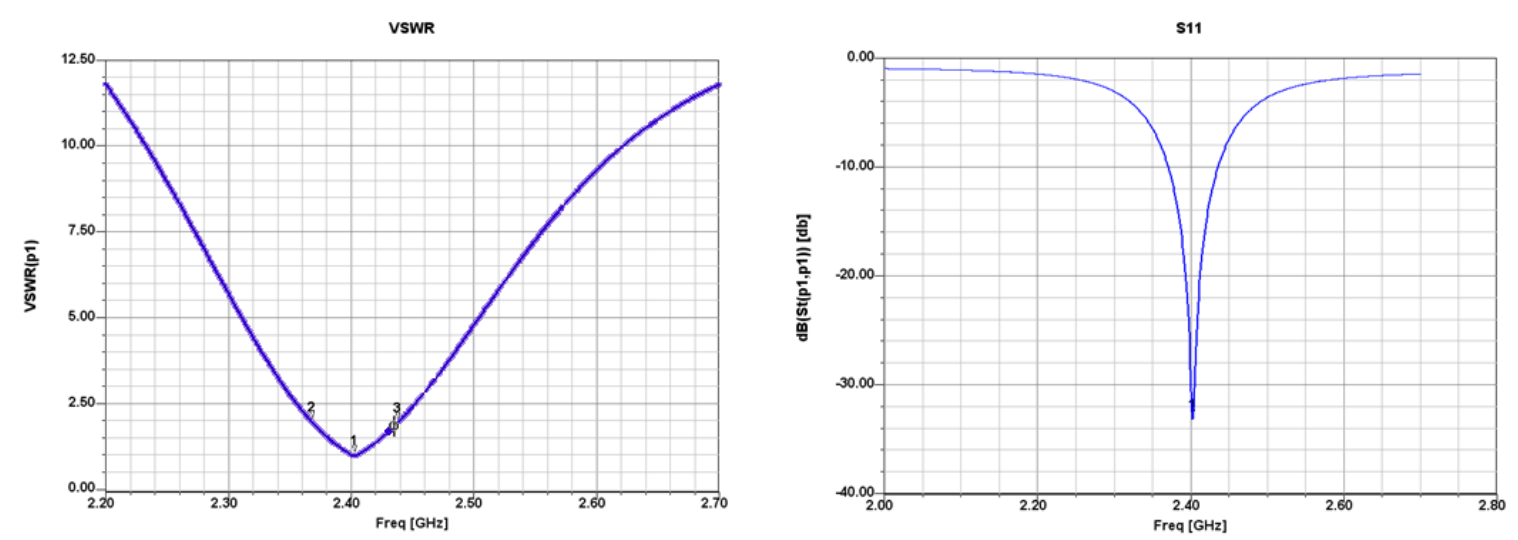

Figure 5-9: Design 4 VSWR $_{\text {in }}$ and $\left|S_{11}\right|$

Table 5-9 shows that Design 4 results in $0.08 \%$ greater percent bandwidth, a VSWR decrease of 0.136 , a polarization ratio decrease of $7.61 \mathrm{~dB}$, and a gain decrease of 0.179dB compared to Design 3. This shows that small adjustments in Slot Length and Patch Width may significantly change the polarization ratio and gain.

\begin{tabular}{|l|l|}
\hline Operating Frequency & $2.403 \mathrm{GHz}$ \\
\hline Bandwidth & $67 \mathrm{MHz}$ \\
\hline Percent Bandwidth & $2.79 \%$ \\
\hline VSWR $_{\text {in }}$ at $\mathrm{f}_{\mathrm{o}}$ & 1.045 \\
\hline Input Impedance at $\mathrm{f}_{\mathrm{o}}$ & $48.8+\mathrm{j} 1.79 \Omega$ \\
\hline Broadside Pol Ratio & $42.47 \mathrm{~dB}$ \\
\hline Broadside Gain & $5.248 \mathrm{~dB}$ \\
\hline
\end{tabular}

Table 5-9: Design 4 theoretical (HFSS) performance summary

A $915 \mathrm{MHz}$ aperture coupled patch antenna is designed in HFSS. The ground plane size is increased to $9 "$ by 12 " because of the increased patch size. The substrates and adhesive layers are the same as those for the $2.4 \mathrm{GHz}$ design. Patch Length, Patch Width, Slot Width, and Slot Length are scaled until the operating frequency is $915 \mathrm{MHz}$. The tuning procedures used to create Designs 1 through 4 and additional feed width variations are used to tune the $915 \mathrm{MHz}$ antenna, but the largest gain realized is $1.583 \mathrm{~dB}$. 
The gain for the $915 \mathrm{MHz}$ aperture coupled antenna is relatively small because the substrate is $0.015 \lambda((45 \mathrm{mils}+59 \mathrm{mils}) / 7059 \mathrm{mils})$ thick and has a dielectric constant of 4.4. Antennas radiate well with electrically thick substrates and relatively low dielectric constants [2]. This design has an electrically thin substrate, high dielectric constant, and high loss tangent compared to the nominal design. The $915 \mathrm{MHz}$ antenna is not constructed due to unacceptable gain results.

Three Gerber files for each of the four designs are created in ADS2006's Layout tool: ground plane slot to be milled on the double sided FR4 board, feed line to be milled on the other side of the double sided FR4 board, and the patch to be milled on the single sided FR4 board. The two boards are attached with 3M adhesive.

Antenna designs 1 through 4 are milled, assembled, and tested. The operating frequency, input VSWR, and E-plane (xz in Figure 2-5) and H-plane (yz in Figure 2-5) co-pol and cross-pol radiation patterns are measured in the Cal Poly anechoic chamber.

\section{Fabrication}

LPKF software translates the Gerber files into board milling instructions. The ground plane slot is milled on double sided FR4 board. Figure 5-10 shows board outlines (4" by 6") and ground plane slots for Designs 1 and 2. Two holes are milled at the board outline corners and used to align the feed line cutout dimensions on the board's reverse side. Figure 5-11 shows a $50 \Omega$ SMA connector soldered onto the feedline of the doublesided FR4 board. 


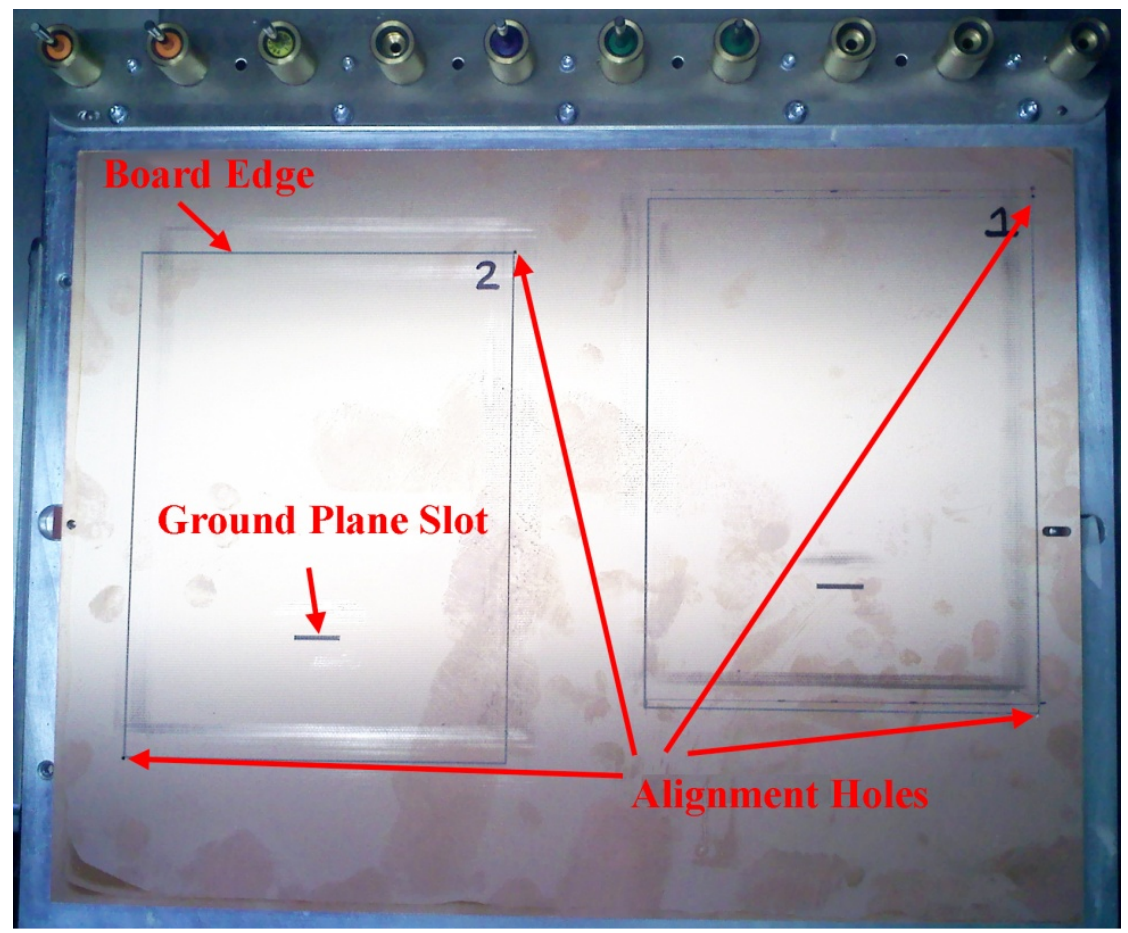

Figure 5-10: LPKF Milling Machine: Design 1 and 2 Ground Planes
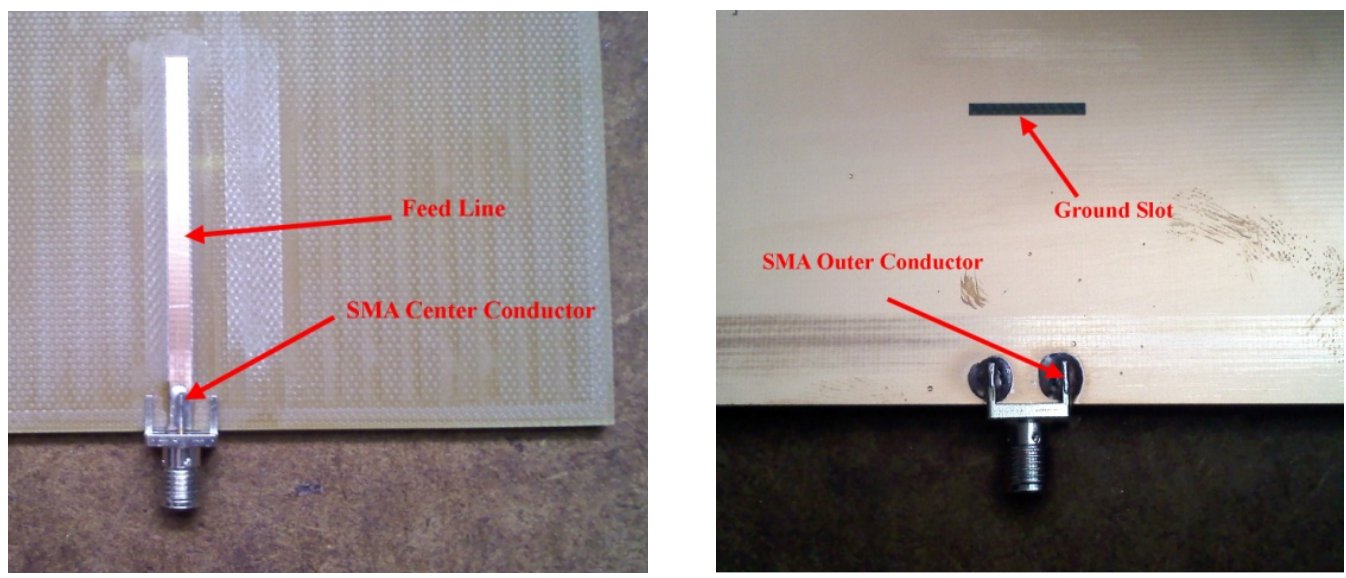

Figure 5-11: SMA Connector Soldered on Double Sided FR4 Board

The patches are milled on single-sided FR4 board located 45mils above the ground plane due to adhesive tape at the board edges. Figure 5-12 shows that the SMA ground plane prongs are 73 mils thick requiring two milled tabs (118 by 276 mils) in the patch substrate as shown in Figure 5-13 [11]. 


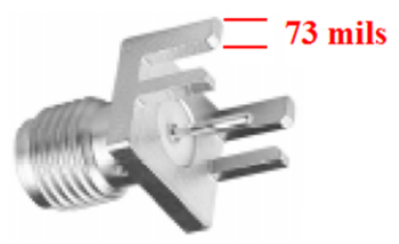

Figure 5-12: SMA Connector Ground Plane Prong Dimensions [11]

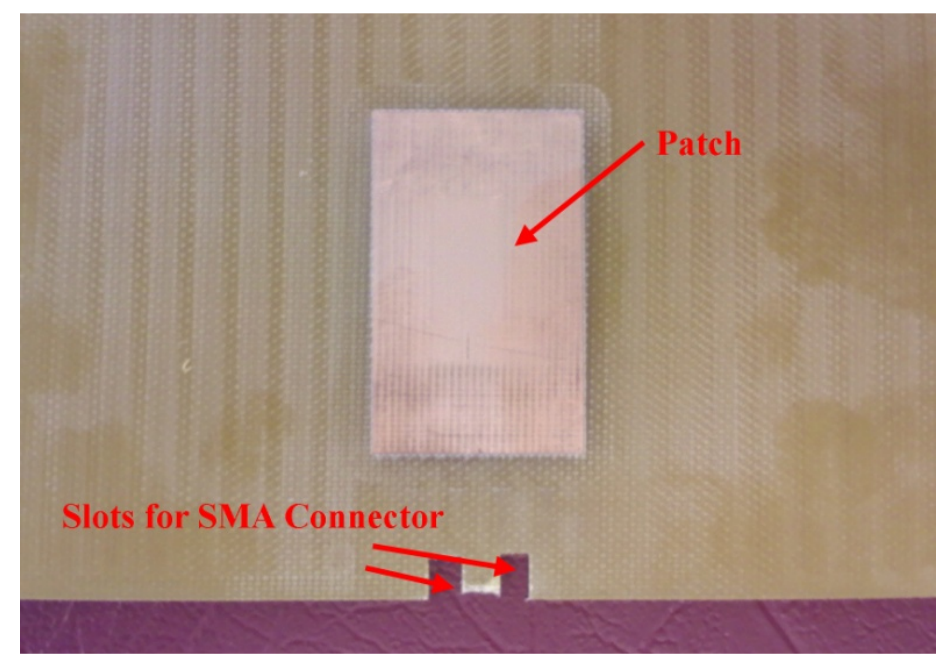

Figure 5-13: Patch and SMA Tab Cutouts

Figure 5-14 shows 3M VHB double sided adhesive (375mil width, 45mil height) on the outer edges of the ground plane [10]. 


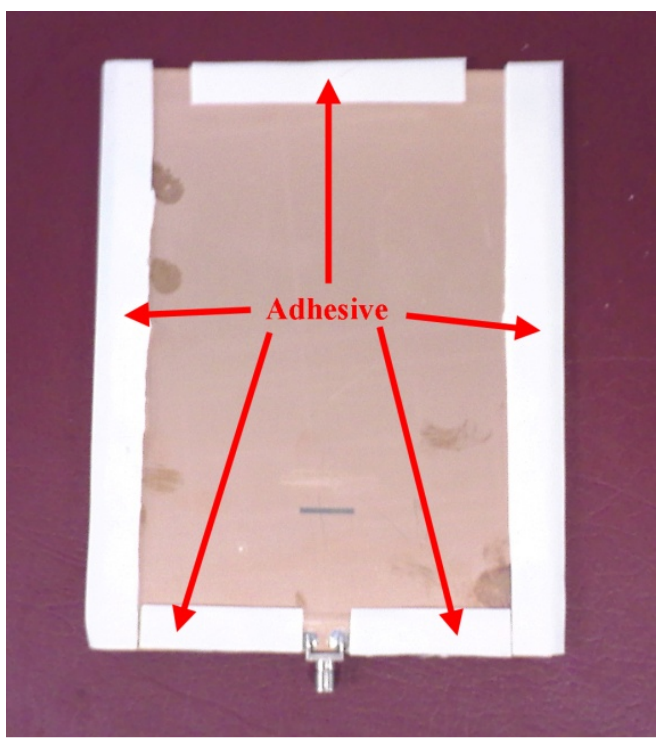

Figure 5-14: Adhesive on Ground Plane

The patch board corners are aligned with the doubled-sided ground plane corners and feed board. The boards are pressed together and remain stationary for 72 hours as suggested in [10]. Figure 5-15 shows the final structures.

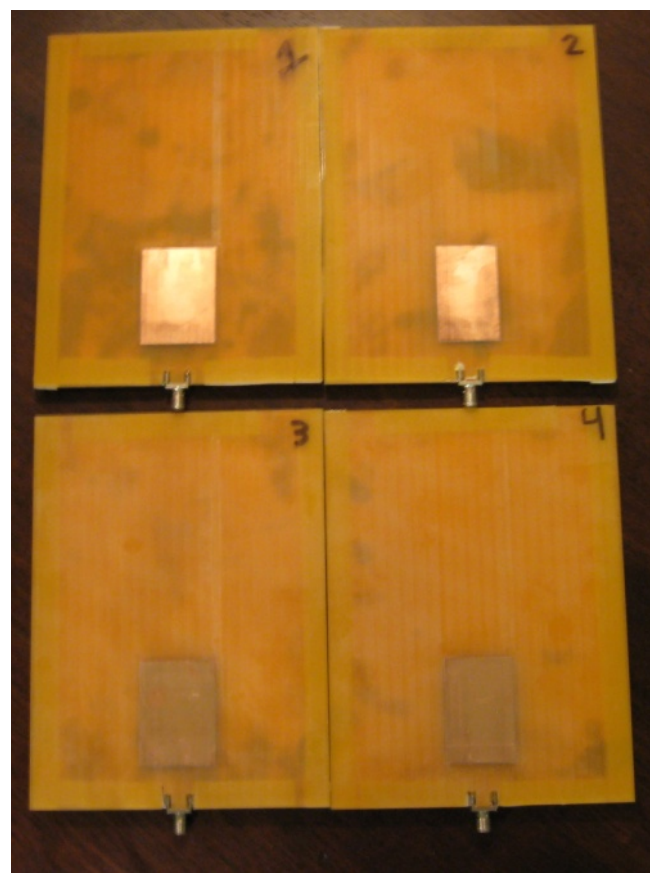

Figure 5-15: Final Antenna Structures 


\section{Characterization}

The antennas are characterized in an anechoic chamber. The antenna operating frequency is determined using an HP8720C vector network analyzer. Figures 5-16 through 5-19 contain $\left|S_{11}\right|$ and VSWR vs. frequency for Designs 1 through 4. Table 5-10 contains the antenna operating frequency determined by minimum VSWR, minimum VSWR, and bandwidth for Designs 1 through 4.

\begin{tabular}{|l|c|c|c|c|}
\hline & Design 1 & Design 2 & Design 3 & Design 4 \\
\hline Minimum VSWR & 1.080 & 1.137 & 1.137 & 1.274 \\
\hline Operating Frequency & $2.442 \mathrm{GHz}$ & $2.460 \mathrm{GHz}$ & $2.423 \mathrm{GHz}$ & $2.420 \mathrm{GHz}$ \\
\hline Bandwidth & $0.059 \mathrm{GHz}$ & $0.063 \mathrm{GHz}$ & $0.063 \mathrm{GHz}$ & $0.061 \mathrm{GHz}$ \\
\hline Percent Bandwidth & $2.42 \%$ & $2.56 \%$ & $2.60 \%$ & $2.52 \%$ \\
\hline
\end{tabular}

Table 5-10: Designs 1 - 4 experimental VSWRin, $\mathrm{f}_{0}$, and bandwidth
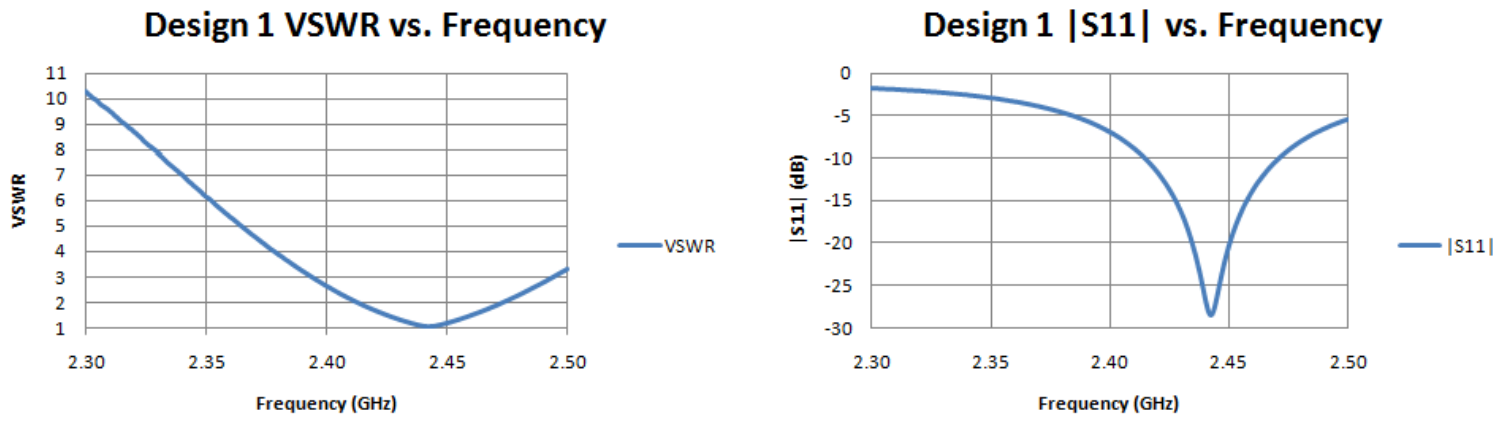

Figure 5-16: Design 1 input matching

Design 2 VSWR vs. Frequency

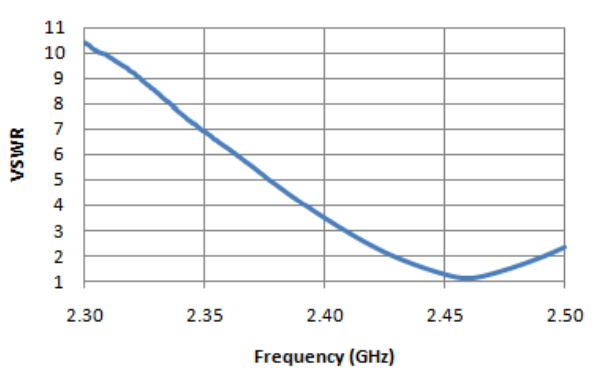

Design 2 |S11| vs. Frequency

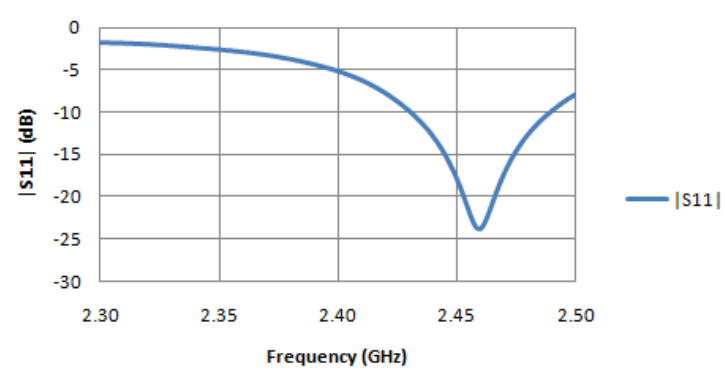

Figure 5-17: Design 2 input matching 
Design 3 VSWR vs. Frequency

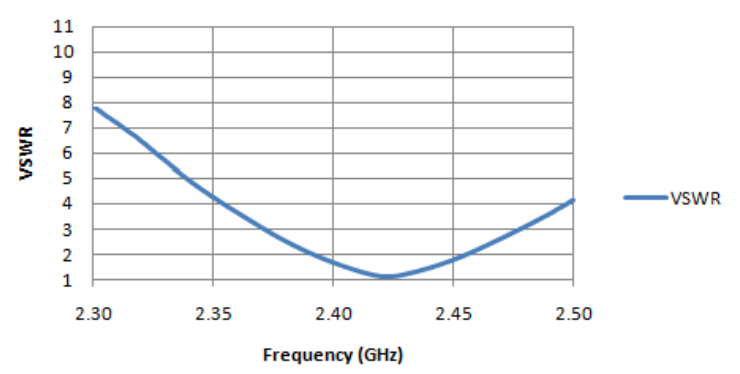

Design $3|\mathrm{~S} 11|$ vs. Frequency

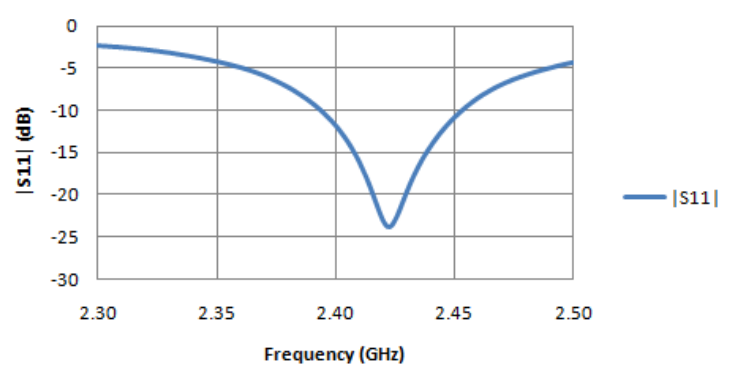

Figure 5-18: Design 3 input matching

Design 4 VSWR vs. Frequency

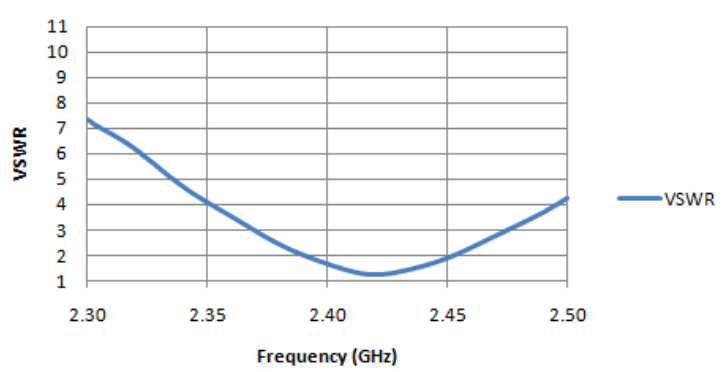

Design 4 |S11| vs. Frequency

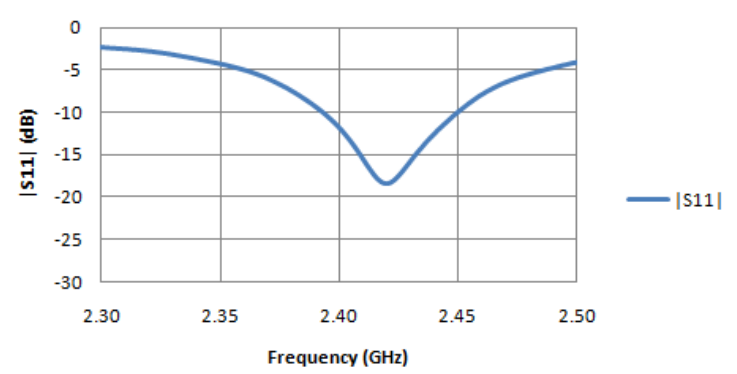

Figure 5-19: Design 4 input matching

Antenna gain is calculated using the Friis transmission formula in equation (5.1).

Figure 5-20 defines $G_{r}$ and $G_{t}$ as the receive and transmit antenna gains $(d B), P_{r}$ and $P_{t}$ as the receive and transmit power $(\mathrm{dBm}), \mathrm{L}_{\mathrm{c} 1}$ and $\mathrm{L}_{\mathrm{c} 2}$ as cable losses $(\mathrm{dB}), \mathrm{R}$ as the distance between the antenna phase centers $(\mathrm{m})$, and $\lambda$ as the free space wavelength $(\mathrm{m})$. $\mathrm{P}_{\mathrm{r}}-\mathrm{P}_{\mathrm{t}}-\mathrm{L}_{\mathrm{c} 1}-\mathrm{L}_{\mathrm{c} 2}$ equals the vector network analyzer $\left|\mathrm{S}_{21}\right|$ measurement.

$$
G_{r}=G_{t}+P_{r}-\left[P_{t}-\left(L_{c 1}+L_{c 2}\right)\right]+20 \log _{10}\left(\frac{4 \pi R}{\lambda}\right)
$$




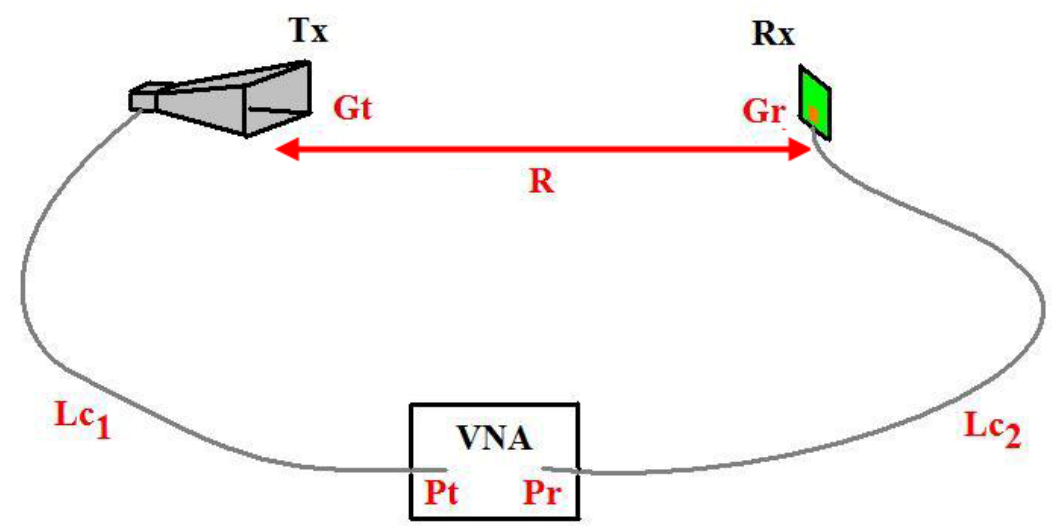

Figure 5-20: Friis transmission formula variables

Cable losses are measured over the range $2.40 \mathrm{GHz}$ to $2.46 \mathrm{GHz}$ (operating range for Designs 1 through 4) using network analyzer $\left|S_{21}\right|$ measurements. Figure 5-21 shows combined cable losses $\left(\mathrm{L}_{\mathrm{c} 1}+\mathrm{L}_{\mathrm{c} 2}\right)$ vs. frequency.

\section{Combined Cable Loss vs. Frequency}

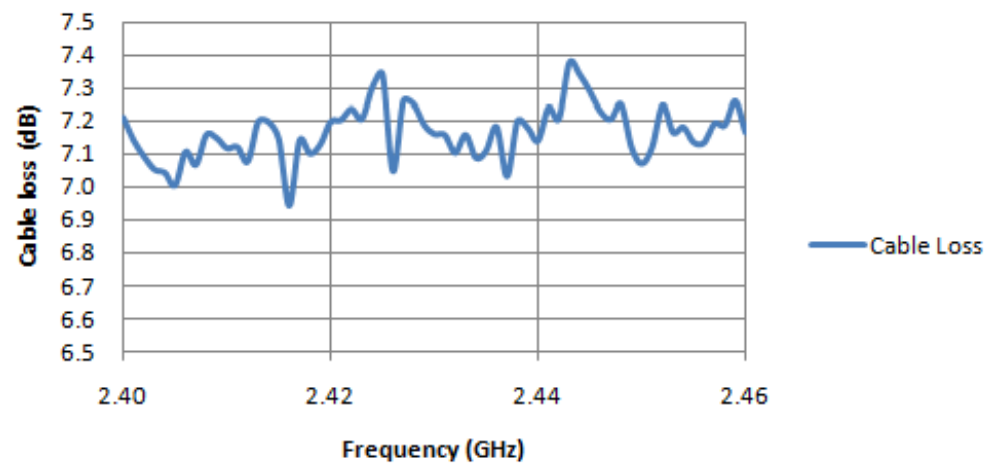

Figure 5-21: Cable Loss vs. Frequency

Gain is calculated for the standard gain horn (1.6 to $2.7 \mathrm{GHz})$ used as the transmit antenna. Because $G_{t}$ and $G_{r}$ are identical for the two horns, the Friis transmission formula reduces to equation (5.2). $\mathrm{R}$ is the distance between the standard gain horn phase centers. The $\mathrm{E}$ and $\mathrm{H}$-plane phase center locations are determined through the quadratic phase 
distribution constants $S_{\mathrm{e}}$ and $S_{\mathrm{h}}$ calculated using [8]. $S_{\mathrm{e}}$ and $S_{\mathrm{h}}$ are related to the slant radii $R_{e}$ and $R_{h}$ (see Figure 5-22) through equations (5.3) and (5.4) below where $\lambda$ is the free space wavelength. $\mathrm{R}_{\mathrm{e}}$ is calculated in equation (5.5) using horn geometry and similar triangles. Figure 5-23 shows that equation (5.5) also calculates $R_{h}$ : replace $R_{e}, a, h$, and $H$ with $\mathrm{R}_{\mathrm{h}}, \mathrm{b}$, w, and $\mathrm{W}$. The standard gain horn (part number SAS-581) has dimensions $\mathrm{H}=0.2128 \mathrm{~m}, \mathrm{~h}=0.0587 \mathrm{~m}, \mathrm{a}=0.5144 \mathrm{~m}, \mathrm{~W}=0.2953 \mathrm{~m}, \mathrm{w}=0.1127 \mathrm{~m}$, and $\mathrm{b}=0.5207 \mathrm{~m}$ resulting in $R_{e}=0.7103 m$ and $R_{h}=0.8421 \mathrm{~m}$.

$$
\begin{gathered}
G_{r}=\frac{P_{r}-\left[P_{t}-\left(L_{c 1}+L_{c 2}\right)\right]+20 \log _{10}\left(\frac{4 \pi R}{\lambda}\right)}{2}(\mathrm{~dB}) \\
S_{e}=\frac{H^{2}}{8 \lambda R_{e}} \\
S_{h}=\frac{W^{2}}{8 \lambda R_{h}} \\
\frac{R_{e}-a}{\frac{h}{2}}=\frac{R_{e}}{\frac{H}{2}} \stackrel{\text { yields }}{\longrightarrow} R_{e}=\frac{a}{1-\frac{h}{H}}
\end{gathered}
$$


h

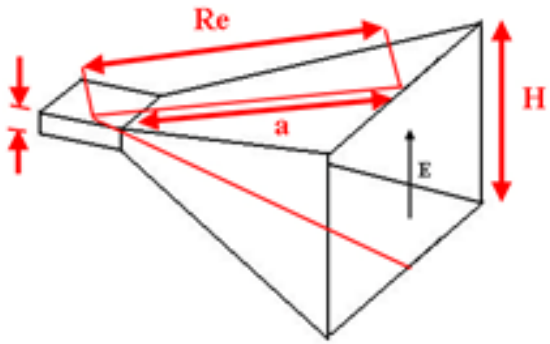

A

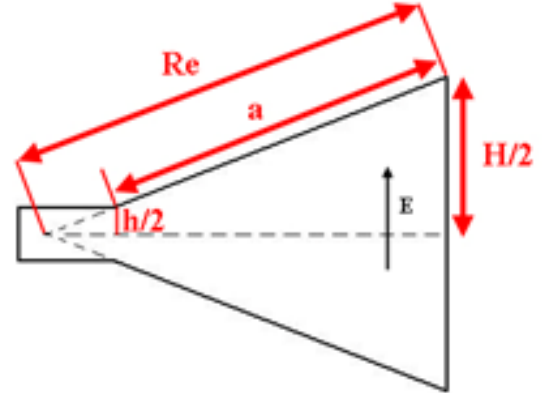

B

Figure 5-22: Gain horn E-plane geometry

A) Full view B) E-plane cross section

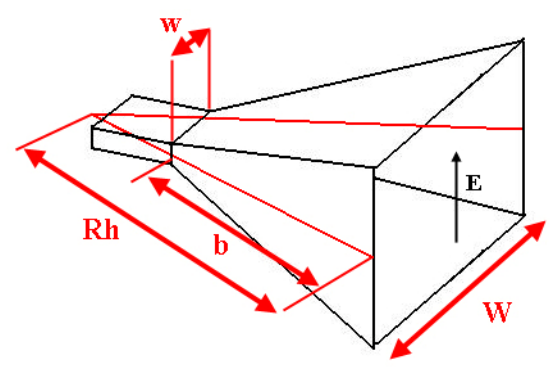

Figure 5-23: Gain horn H-plane geometry

$\mathrm{S}_{\mathrm{e}}$ and $\mathrm{S}_{\mathrm{h}}$ are calculated for frequencies between 2.40 and $2.46 \mathrm{GHz}$ (operating frequency range). $\mathrm{L}_{\mathrm{pe}}$ and $\mathrm{L}_{\mathrm{ph}}$ are distances from the aperture plane to the $\mathrm{E}$ and $\mathrm{H}$-plane phase centers (see Figure 5-24). $\mathrm{L}_{\mathrm{pe}}$ and $\mathrm{L}_{\mathrm{ph}}$ values are listed in Table 7-3 in [8].
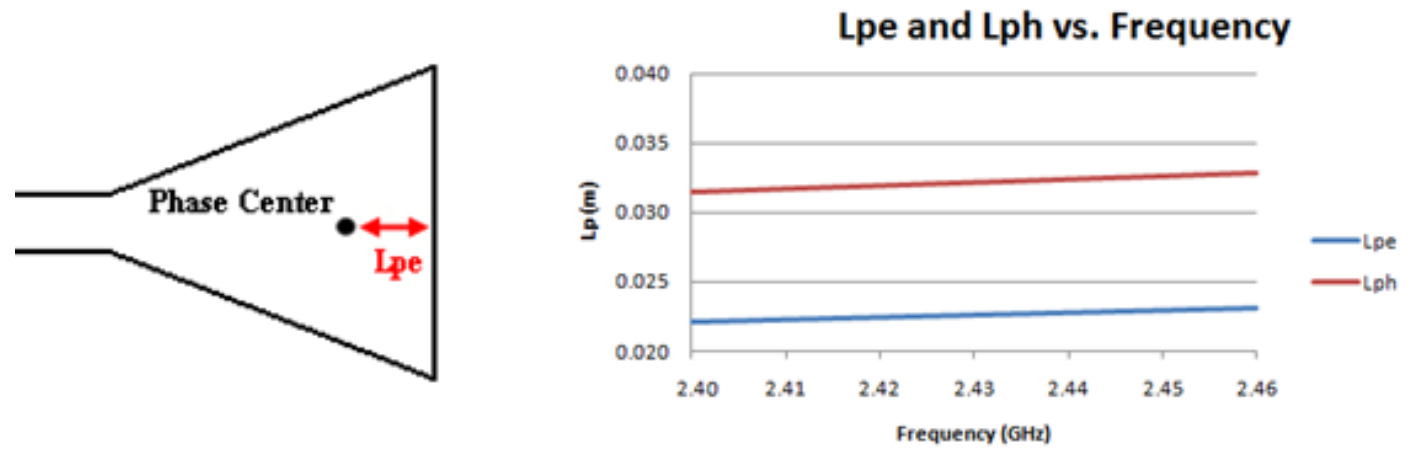

Figure 5-24: $\mathrm{L}_{\mathrm{pe}}$ vs. frequency 
The distance between the E-plane and H-plane phase centers at each frequency is $\mathrm{R}_{\mathrm{ap}}+2 \mathrm{~L}_{\mathrm{pe}}(\lambda)$ and $\mathrm{R}_{\mathrm{ap}}+2 \mathrm{~L}_{\mathrm{ph}}(\lambda)$, where $\mathrm{R}_{\mathrm{ap}}$ is the distance between the horn aperture planes. Figure 5-25 shows horn gain vs. frequency calculated with equation (5.6), where $\mathrm{R}_{\mathrm{ap}}$ is measured to be $3.407 \mathrm{~m}$. Figure 5-26 shows that the expected gain from [12] is approximately $15.5 \mathrm{~dB}$ at $2.4 \mathrm{GHz}$ (circled in red).

$$
G_{r}=\frac{\left|S_{21}\right|+L_{c 1}+L_{c 2}+20 \log _{10}\left(\frac{4 \pi\left(R_{a p}+2 L_{p e}\right)}{\lambda}\right)}{2}
$$

\section{Standard Horn Gain vs. Frequency}

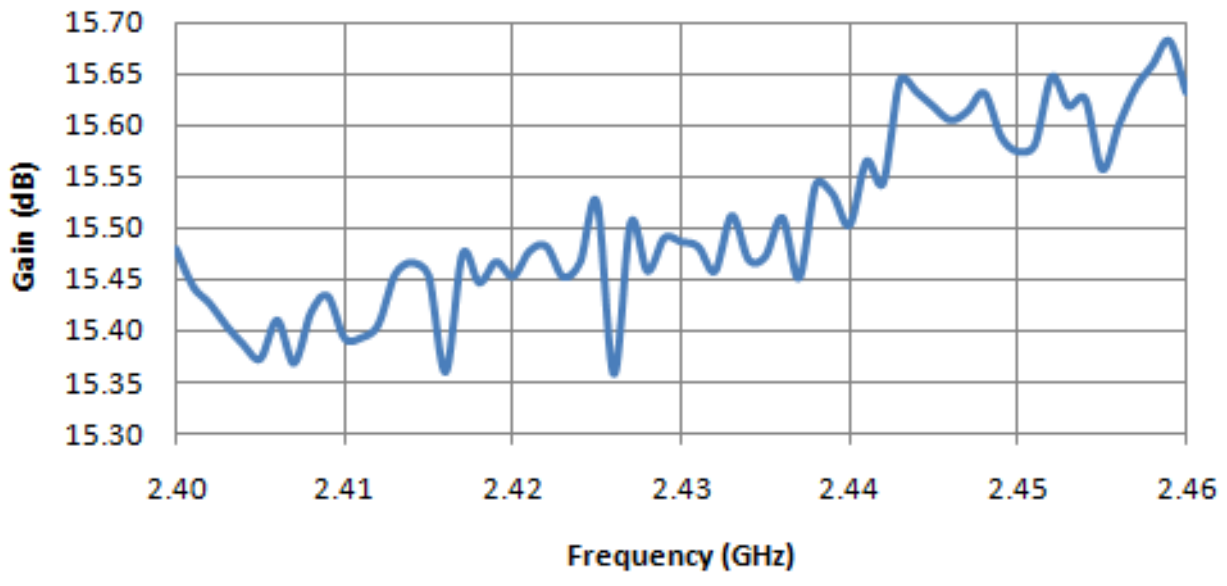

Figure 5-25: Standard gain horn gain vs. frequency 


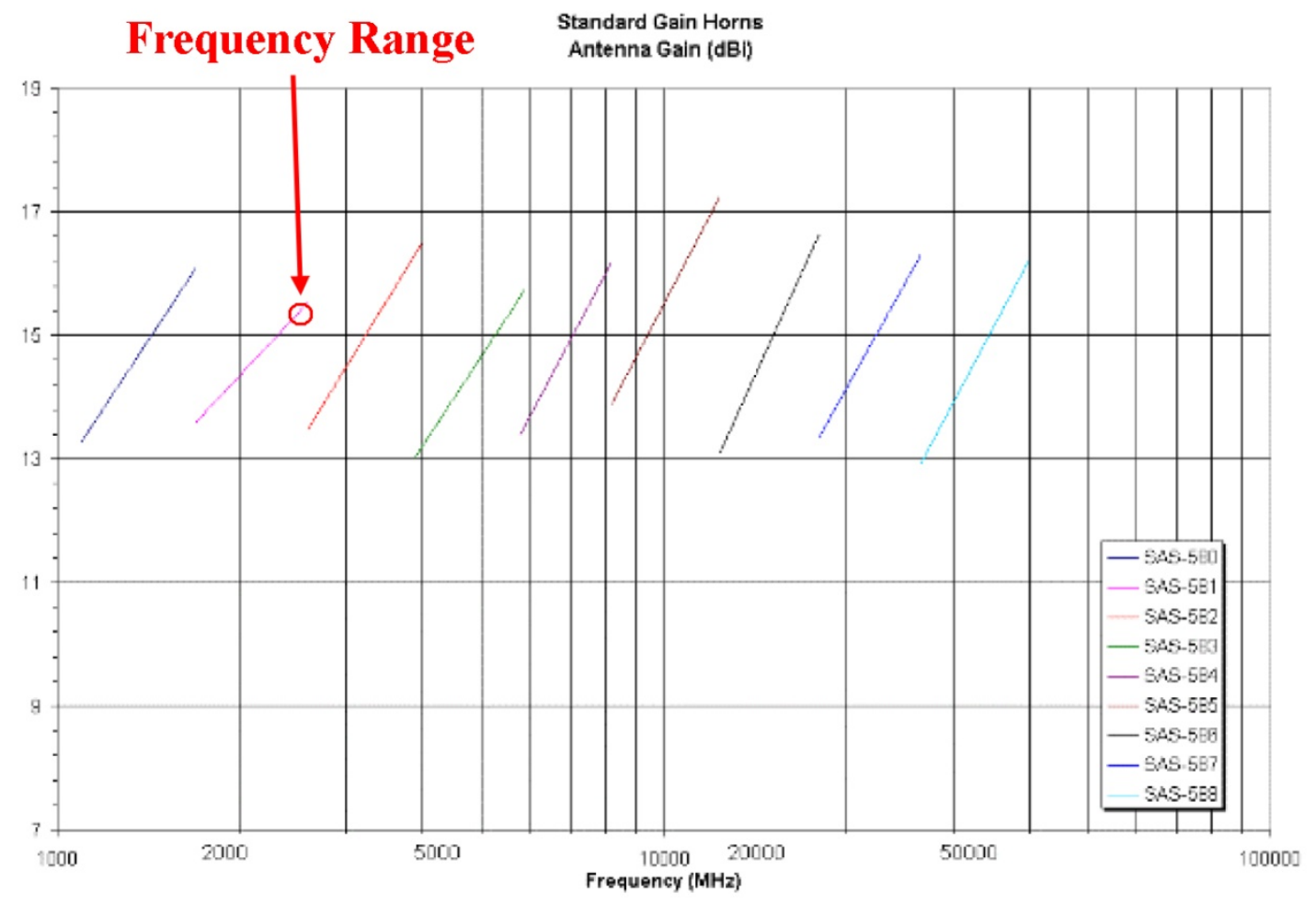

Figure 5-26: Standard gain horn gain vs. frequency [12] $(1.7$ - 2.6GHz horn data circled in red)

Figure 5-27 shows the antenna configuration for an H-plane co-pol scan. R in equation (5.7) is $\mathrm{R}_{\text {meas }}$ (measured distance between AUT and transmit gain horn aperture plane $)+\mathrm{L}_{\mathrm{ph}}(\mathrm{H}$-plane phase center distance) due to scan rotation in the standard horn $\mathrm{H}$-plane. The gain horn is rotated $90^{\circ}(\mathrm{E}$ and $\mathrm{H}$ aperture directions are interchanged in Figure 5-27) for the H-plane cross-pol scan. $R$ is $R_{\text {meas }}+L_{p e}$ (E-plane phase center distance) in this case due to scan rotation in the standard gain horn E-plane. 

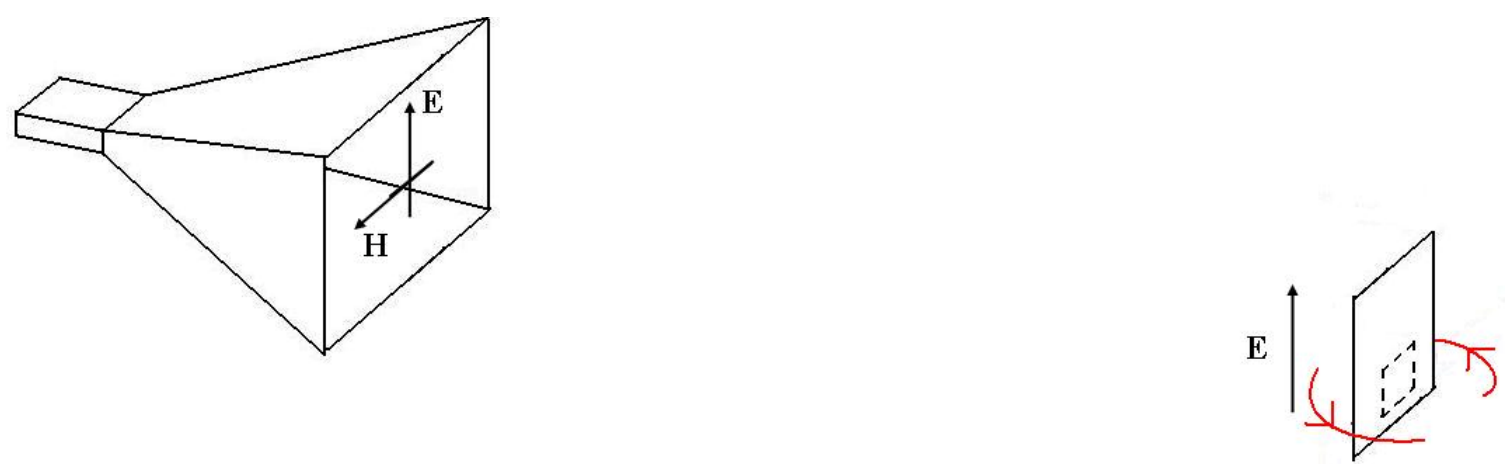

Figure 5-27: H-plane co-pol radiation pattern scan

Figure 5-28 shows the antenna configuration for an E-plane cross-pol scan. $\mathrm{R}$ in equation (5.7) is $\mathrm{R}_{\text {meas }}$ (measured distance between AUT and transmit gain horn aperture plane $)+\mathrm{L}_{\mathrm{ph}}$ (H-plane phase center distance) due to scan rotation in the standard gain horn H-plane. The gain horn is rotated $90^{\circ}$ (E and $\mathrm{H}$ aperture directions are interchanged in Figure 5-28) for the E-plane co-pol scan. $R$ is $R_{\text {meas }}+L_{p e}$ (E-plane phase center distance) in this case due to scan rotation in the standard gain horn E-plane.
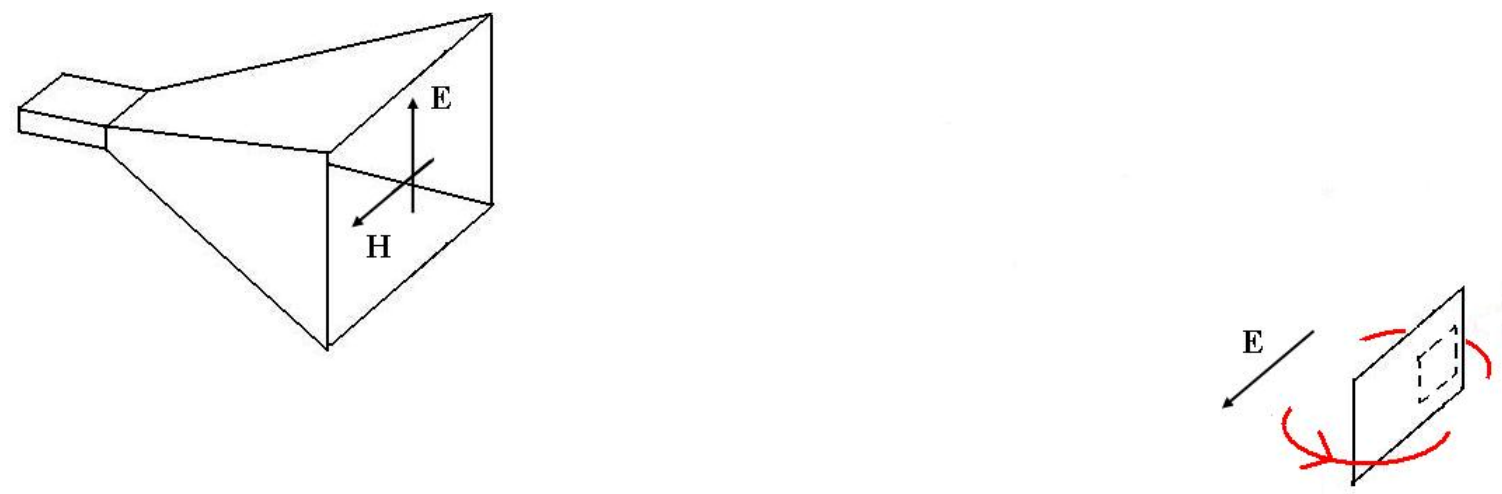

Figure 5-28: E-plane cross-pol radiation pattern scan

Eight pattern scans are measured for each aperture coupled antenna: E and H-plane co-pol and cross-pol patterns at the theoretical and experimental operating frequencies. Patch antenna gain is calculated using equation (5.7). The distance between 
the antennas is $\mathrm{R}_{\text {meas }}+\left(\mathrm{L}_{\mathrm{pe}}\right.$ or $\left.\mathrm{L}_{\mathrm{ph}}\right)$ depending on scan plane and horn configuration. $\mathrm{G}_{\mathrm{t}}$ is the standard horn gain in $\mathrm{dB}$ and $\left|\mathrm{S}_{21}\right|$ is $\left(\mathrm{P}_{\mathrm{r}}-\mathrm{P}_{\mathrm{t}}-\mathrm{L}_{\mathrm{c} 1}-\mathrm{L}_{\mathrm{c} 2}\right.$ in $\left.\mathrm{dB}\right)$ measured by the vector network analyzer. $\mathrm{R}_{\text {meas }}$ is determined to be $4.128 \mathrm{~m}$.

$$
G_{r}=G_{t}+\left|S_{21}\right|+L_{c 1}+L_{c 2}+20 \log _{10}\left(\frac{4 \pi\left(R_{\text {meas }}+\left(L_{p e} \text { or } L_{p h}\right)\right)}{\lambda}\right)
$$

Figure 5-29 displays the eight pattern scans for Design 1, while Table 5-11 shows a comparison between the experimental antenna performance and theoretical predictions.

Design 1 E-plane Co (black), Cross (blue)

(Gain(dB) vs. Theta, 2.400GHz)

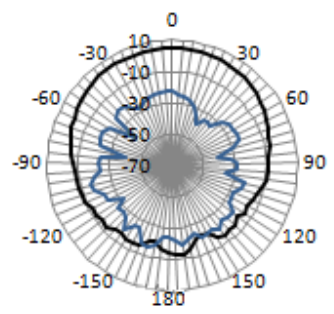

Design 1 H-plane Co (black), Cross (blue)

(Gain(dB) vs. Theta, 2.400GHz)

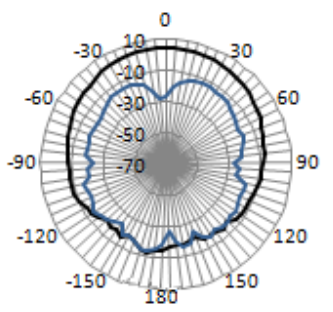

Design 1 E-plane Co (black), Cross (blue)

(Gain(dB) vs. Theta, $2.442 \mathrm{GHz}$ )

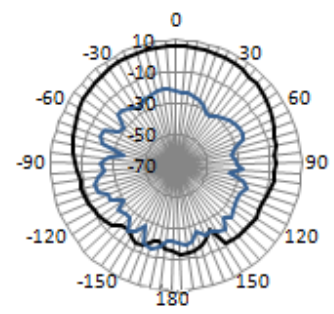

Design 1 H-plane Co (black), Cross (blue) (Gain(dB) vs. Theta, 2.442GHz)

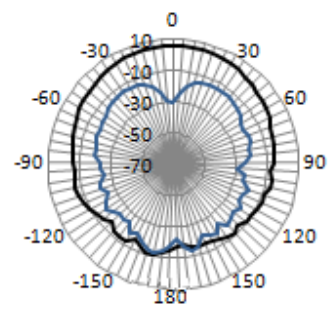

Figure 5-29: Design 1 radiation patterns 


\begin{tabular}{|l|c|c|c|}
\hline & Theoretical (HFSS) & Experimental & Error \\
\hline Operating Frequency $(\mathrm{GHz})$ & 2.398 & 2.442 & $1.83 \%$ \\
\hline Percent Bandwidth $(\%)$ & 2.59 & 2.42 & $-0.17 \Delta \%$ \\
\hline VSWR at $\mathrm{f}_{\mathrm{o}}$ & 1.340 & 1.080 & $-0.260 \Delta \mathrm{VSWR}$ \\
\hline Broadside Pol Ratio at $\mathrm{f}_{\mathrm{o}}$ & $41.7 \mathrm{~dB}$ & $28.0 \mathrm{~dB}$ & $-13.7 \mathrm{~dB}$ \\
\hline Broadside Gain at $\mathrm{f}_{\mathrm{o}}$ & $5.291 \mathrm{~dB}$ & $6.009 \mathrm{~dB}$ & $0.718 \mathrm{~dB}$ \\
\hline
\end{tabular}

Table 5-11: Design 1 theoretical and experimental performance

Figure 5-30 displays the eight pattern scans for Design 2, while Table 5-12 shows a comparison between the experimental antenna performance and theoretical predictions.

Design 2 E-plane Co (black), Cross (blue) (Gain(dB) vs. Theta, $2.400 \mathrm{GHz}$ )

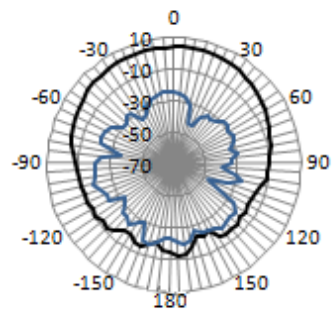

\section{Design 2 H-plane Co (black), Cross (blue)} (Gain(dB) vs. Theta, 2.400GHz)

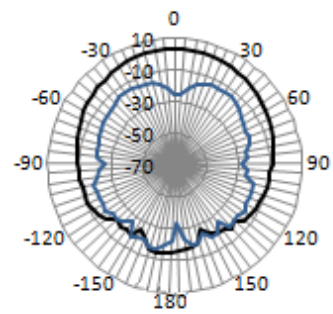

Design 2 E-plane Co (black), Cross (blue) (Gain(dB) vs. Theta, 2.460GHz)

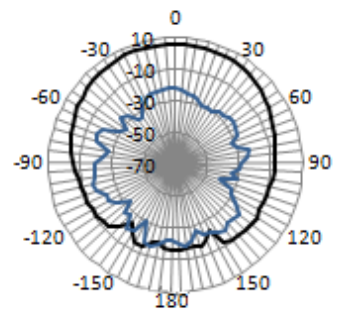

Design 2 H-plane Co (black), Cross (blue) (Gain(dB) vs. Theta, 2.460GHz)

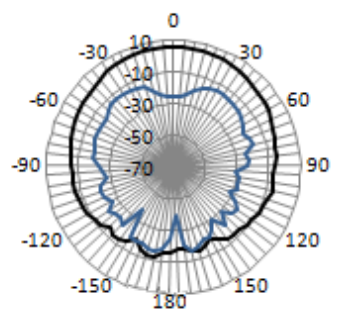

Figure 5-30: Design 2 radiation patterns 


\begin{tabular}{|l|c|c|c|}
\hline & Theoretical (HFSS) & Experimental & Error \\
\hline Operating Frequency $(\mathrm{GHz})$ & 2.398 & 2.460 & $2.59 \%$ \\
\hline Percent Bandwidth $(\%)$ & 2.79 & 2.56 & $-0.23 \Delta \%$ \\
\hline VSWR at $\mathrm{f}_{\mathrm{o}}$ & 1.069 & 1.137 & $0.068 \Delta \mathrm{VSWR}$ \\
\hline Broadside Pol Ratio at $\mathrm{f}_{\mathrm{o}}$ & $51.6 \mathrm{~dB}$ & $27.8 \mathrm{~dB}$ & $-23.8 \mathrm{~dB}$ \\
\hline Broadside Gain at $\mathrm{f}_{\mathrm{o}}$ & $4.970 \mathrm{~dB}$ & $5.836 \mathrm{~dB}$ & $0.866 \mathrm{~dB}$ \\
\hline
\end{tabular}

Table 5-12: Design 2 theoretical and experimental performance

Figure 5-31 displays the eight pattern scans for Design 3, while Table 5-13 shows a comparison between the experimental antenna performance and theoretical predictions.

Design 3 E-plane Co (black), Cross (blue) (Gain(dB) vs. Theta, 2.400GHz)

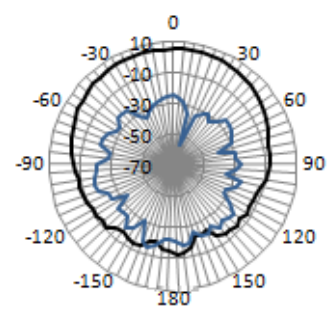

Design 3 H-plane Co (black), Cross (blue) (Gain(dB) vs. Theta, 2.400GHz)

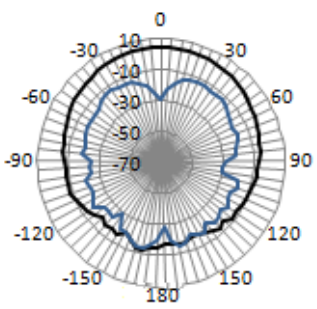

Design 3 E-plane Co (black), Cross (blue) (Gain(dB) vs. Theta, $2.423 \mathrm{GHz}$ )

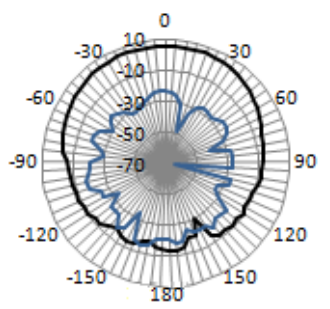

Design 3 H-plane Co (black), Cross (blue) (Gain(dB) vs. Theta, 2.423GHz)

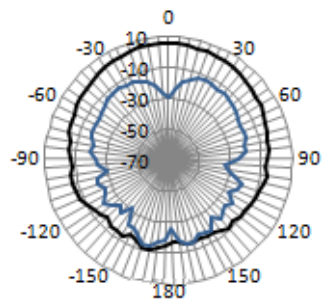

Figure 5-31: Design 3 radiation patterns 


\begin{tabular}{|l|c|c|c|}
\hline & Theoretical (HFSS) & Experimental & Error \\
\hline Operating Frequency $(\mathrm{GHz})$ & 2.396 & 2.423 & $1.13 \%$ \\
\hline Percent Bandwidth $(\%)$ & 2.71 & 2.60 & $-0.11 \Delta \%$ \\
\hline VSWR at $\mathrm{f}_{\mathrm{o}}$ & 1.181 & 1.137 & $-0.044 \Delta \mathrm{VSWR}$ \\
\hline Broadside Pol Ratio at $\mathrm{f}_{\mathrm{o}}$ & $50.1 \mathrm{~dB}$ & $28.9 \mathrm{~dB}$ & $-21.2 \mathrm{~dB}$ \\
\hline Broadside Gain at $\mathrm{f}_{\mathrm{o}}$ & $5.427 \mathrm{~dB}$ & $5.585 \mathrm{~dB}$ & $0.158 \mathrm{~dB}$ \\
\hline
\end{tabular}

Table 5-13: Design 3 theoretical and experimental performance

Figure 5-32 displays the eight pattern scans for Design 4, while Table 5-14 shows a comparison between the experimental antenna performance and theoretical predictions.

Design 4 E-plane Co (black), Cross (blue) (Gain(dB) vs. Theta, $2.400 \mathrm{GHz}$ )

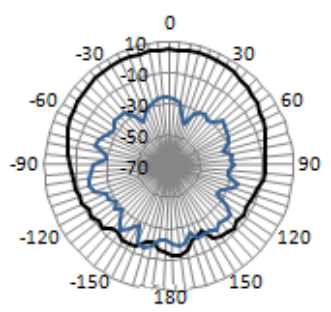

Design 4 H-plane Co (black), Cross (blue) (Gain(dB) vs. Theta, 2.400GHz)

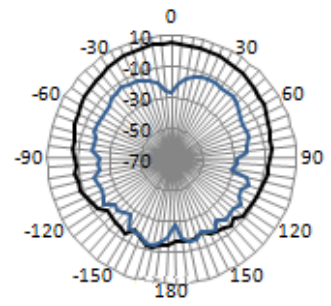

Design 4 E-plane Co (black), Cross (blue) (Gain(dB) vs. Theta, 2.420GHz)

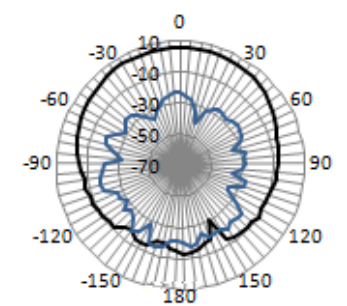

Design 4 H-plane Co (black), Cross (blue) (Gain(dB) vs. Theta, $2.420 \mathrm{GHz}$ )

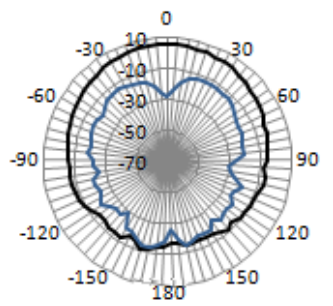

Figure 5-32: Design 4 radiation patterns 


\begin{tabular}{|l|c|c|c|}
\hline & Theoretical (HFSS) & Experimental & Error \\
\hline Operating Frequency $(\mathrm{GHz})$ & 2.403 & 2.420 & $0.71 \%$ \\
\hline Percent Bandwidth $(\%)$ & 2.79 & 2.52 & $-0.27 \Delta \%$ \\
\hline VSWR at $\mathrm{f}_{\mathrm{o}}$ & 1.045 & 1.274 & $0.229 \Delta$ VSWR \\
\hline Broadside Pol Ratio at $\mathrm{f}_{\mathrm{o}}$ & $42.5 \mathrm{~dB}$ & $28.9 \mathrm{~dB}$ & $-13.6 \mathrm{~dB}$ \\
\hline Broadside Gain at $\mathrm{f}_{\mathrm{o}}$ & $5.428 \mathrm{~dB}$ & $5.647 \mathrm{~dB}$ & $0.219 \mathrm{~dB}$ \\
\hline
\end{tabular}

Table 5-14: Design 4 theoretical and experimental performance

The antennas have polarization ratios that are at least $13.6 \mathrm{~dB}$ less than theoretical. Figures 4-13, 4-14, and 4-16 show that this could be due to fabrication or material errors resulting in larger than anticipated antenna substrate or adhesive tape height, larger or smaller than expected Slot Width size, or a Slot Length Offset.

All four antennas have Slot Length Offsets due to fabrication errors in aligning the milling holes on the double sided board. Designs 1 through 4 Slot Length Offsets are measured to be $13 \mathrm{mils}$, 23mils, $17 \mathrm{mils}$, and 14 mils, respectively.

\section{Design Procedure Summary}

Four antennas have been designed and tuned using the dimensional analysis results. All four antennas exhibit greater than $2.42 \%$ percent bandwidths, less than 1.274 $\mathrm{VSWR}_{\mathrm{in}}$, minimum $27.8 \mathrm{~dB}$ broadside polarization ratio, minimum $5.585 \mathrm{~dB}$ broadside gain, and are within $2.59 \%$ of the desired operating frequency. This shows that the new design procedure can be used to design and tune aperture coupled microstrip antennas. This new design procedure is summarized below.

- Select a low loss, electrically thin feed substrate with relatively high dielectric constant to maximize guided waves between the feed line and ground plane [2]. 
- Select a low loss, electrically thick antenna substrate with relatively low dielectric constant to maximize radiated waves at the patch edges [2].

- Set the feed line length to $0.739 \lambda$ (wavelength in feed dielectric) from feed point to open termination (see Figure 4-8). Select the feed line width for a $50 \Omega$ characteristic impedance. The ground slot and patch center are located above a point on the feed line $0.211 \lambda$ (wavelength in feed dielectric) from the open termination (see Figure 2-3).

- Set the ground plane slot length and width to $0.1477 \lambda$ and $0.0164 \lambda$ (wavelength in antenna dielectric, see Figures 2-6 and 4-1).

- Set the patch length and width to $0.4220 \lambda$ and $0.3165 \lambda$ (wavelength in antenna dielectric, see Figures 4-4) .

- Although operating frequency is dependent on patch length (see Figure 4-5), scale the slot width and length, and patch width and length by the same factor to tune the operating frequency.

- Scale slot length and patch width while maintaining an aspect ratio of 2.021 to 1 (patch width to slot length) to tune the input impedance (see Figure 4-2 and 4-7). 


\section{Future Project Recommendations}

The following list contains possible future student projects that would extend the research and testing performed in this thesis.

- Design and build aperture coupled patch antennas operating at various frequencies with different substrate materials to verify the suggested design procedure.

- Use electromagnetic theory and other analytical methods to explain results observed in the parametric study.

- Develop a computer program or series of graphs to show electric field propagation and development in the aperture coupled patch antenna.

- Develop equations to calculate N, L, and C in the equivalent circuit model.

- Perform a thorough study that compares the performance of similar microstrip fed, probe fed, and aperture coupled patch antennas. 


\section{References}

1. Ansoft High Frequency Structure Simulator v10 User's Guide. Pittsburgh, PA: Ansoft Corp., 2005. Computer Software.

2. Kuchar, Alexander. "Aperture-Coupled Microstrip Patch Antenna Array." Thesis. Technische Universität Wien, 1996.

3. Sullivan, Peter L. "Analysis of an Aperture Coupled Microstrip Antenna." Thesis. University of Massachusetts, 1985. Print.

4. Haddad, Pamela and D. M. Pozar. "Analysis of and Aperture Couple Microstrip Patch Antenna with a Thick Ground Plane.” AP-S Digest 2 (1984): 932-35.

5. Sullivan, P. L. and D. H. Schaubert. "Analysis of an aperture coupled microstrip antenna." IEEE Transaction on Antennas and Propagation AP-34 (1986): 977-84.

6. Rahim, Low, et al. "Aperture Coupled Microstrip Antenna with Different Feed Sizes and Aperture Positions." Proc. of RF and Microwave Conference, 2006. 31-35.

7. Pozar, David. "A Review of Aperture Coupled Microstrip Antennas: History, Operation, Development, and Applications." University of Massachusetts at Amherst, May 1996.

8. Milligan, Thomas. Modern Antenna Design. New York: McGraw-Hill, 1985. Print.

9. Gonzalez, Guillermo. Microwave Transistor Amplifiers Analysis and Design 2nd Edition. Upper Saddle River, New Jersey: Prentice-Hall, 1996. Print.

10. 3M VHB Tapes Technical Data. St. Paul, MN: 3M, 2009.

11. Johnson Components SMA - 50 Ohm Connectors. Waseca, MN: Johnson Components.

12. A.H. Systems Standard Gain Horn Antenna Series. Chatsworth, California: A.H. Systems, 2007.

13. Croq, F., and D. M. Pozar. "Millimeter wave design of wide-band aperture coupled stacked microstrip antennas." IEEE Trans. Antennas and Propagation 39.12 (1991): 1770-1776. 


\section{Appendix A: Complete Parametric Study}

The aperture coupled patch antenna microstrip feed line, substrates, ground plane slot, and patch dimensions are varied in HFSS to determine effects on antenna performance. The operating frequency, VSWR, percent bandwidth, polarization ratio, and broadside gain are observed for each configuration. The operating frequency is the location of minimum $\operatorname{VSWR}_{\text {in }}$ over the test bandwidth. The percent bandwidth is the ratio of frequency range over which $\mathrm{VSWR}_{\text {in }}$ is less than 2 to the operating frequency. The polarization ratio is the co-pol $\left(\theta\right.$ polarized radiation at $\left.\theta=0^{\circ}, \varphi=0^{\circ}\right)$ to cross-pol $(\theta$ polarized radiation at $\theta=0^{\circ}, \varphi=90^{\circ}$ ) ratio in the far field. The total broadside gain from all polarizations is determined at the antenna operating frequency.

The nominal antenna design from [1] is used as a baseline for comparison. For each adjustment, only one variable is varied while all other dimensions remain at nominal values. Dimensions in wavelengths are determined with ADS2009 Linecalc at 2.3GHz in $\underline{\text { RT Duroid }\left(\varepsilon_{\mathrm{r}}=2.2, \text { loss tangent }=0.0009,50 \Omega \text { microstrip line }\right)}$.

\section{Feed Line}

The aperture coupled patch antenna microstrip feed is varied in HFSS. The antenna model is shown below in Figure A-1. The feed strip is the bottom most layer (thin, long rectangle in Figure A-1). It is excited at the end labeled "FEED POINT," includes an open termination at the end labeled "OPEN TERMINATION," and is electrically isolated from all other conductive layers.

There are four feed variables: the distance from the feed point to a fixed position under the ground plane slot (feed length), the distance from the open termination to a 
fixed position under the ground plane slot (termination length), feed width offset, and width.

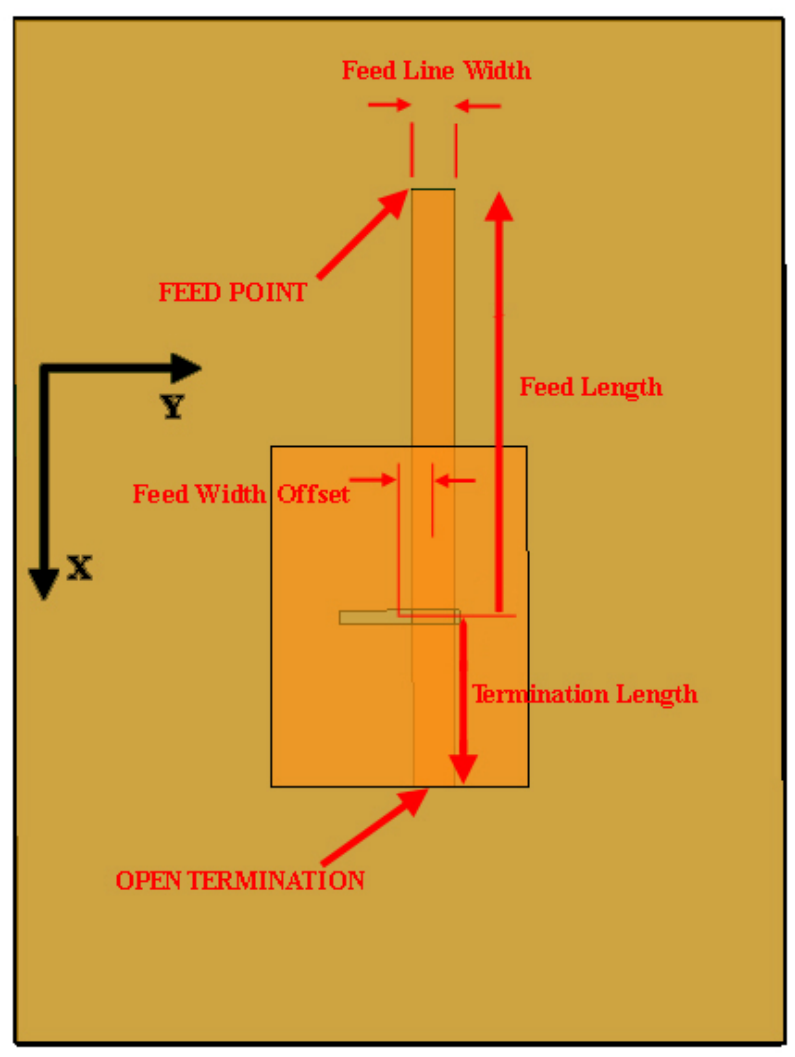

Figure A-1: Feed line variables

Feed length is nominally $0.527 \lambda$ varied with the feed point ranging from directly under the ground slot $(0 \lambda)$ to the nominal board edge $(0.728 \lambda)$. Figure A-2 shows antenna operating frequencies between $2.27 \mathrm{GHz}$ and $2.29 \mathrm{GHz}$ for all but two feed lengths, less than $0.5 \lambda$ and when the feed point is below the ground slot. 


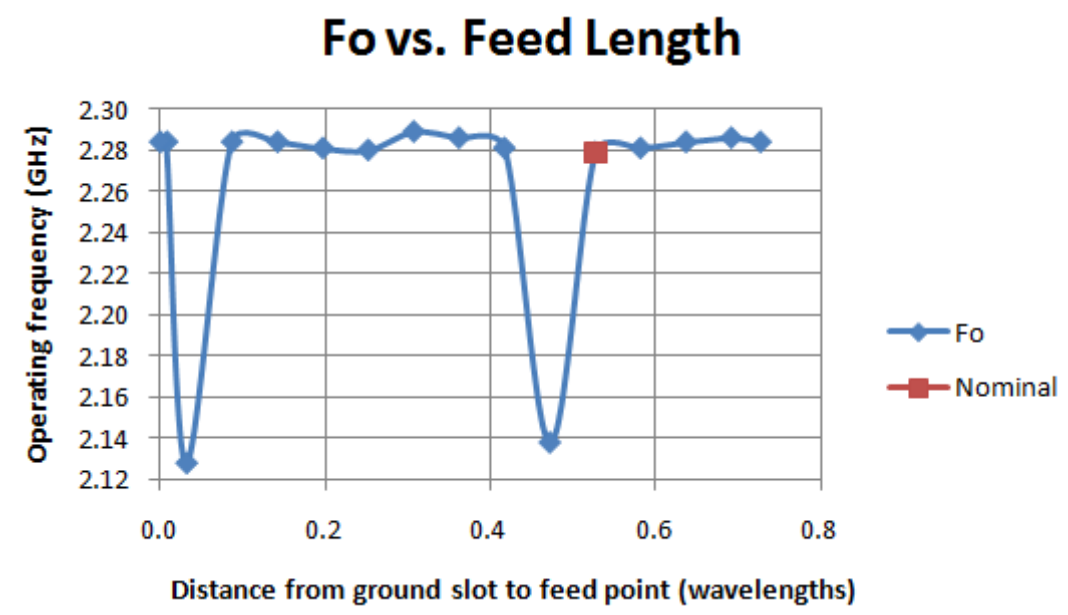

Figure A-2: Operating frequency vs. feed length

Figure A-3 indicates that feed length may be varied from $0.30 \lambda$ to $0.55 \lambda$ without adversely affecting $\operatorname{VSWR}_{\text {in }}$ (ideal $\operatorname{VSWR}_{\text {in }}$ value is 1 ). Feed length equal to $0.42 \lambda$ produces the smallest $\operatorname{VSWR}_{\text {in }}(1.701)$.

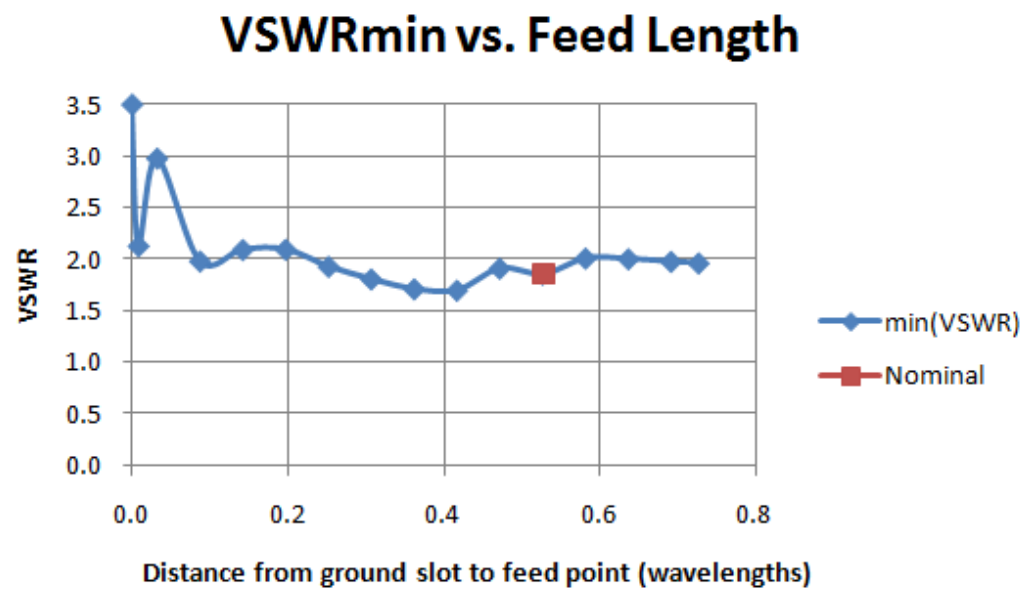

Figure A-3: VSWRin vs. feed length

Figure A-4 shows percent bandwidth for various feed lengths. Zero percent bandwidth indicates that $\mathrm{VWSR}_{\text {in }}$ is greater than 2 for all frequencies. The percent bandwidth is less than $1.09 \%$ for all tested feed lengths. The largest percent bandwidths occur for feed lengths between $0.30 \lambda$ and $0.42 \lambda$. 


\section{Percent Bandwidth vs. Feed Length}

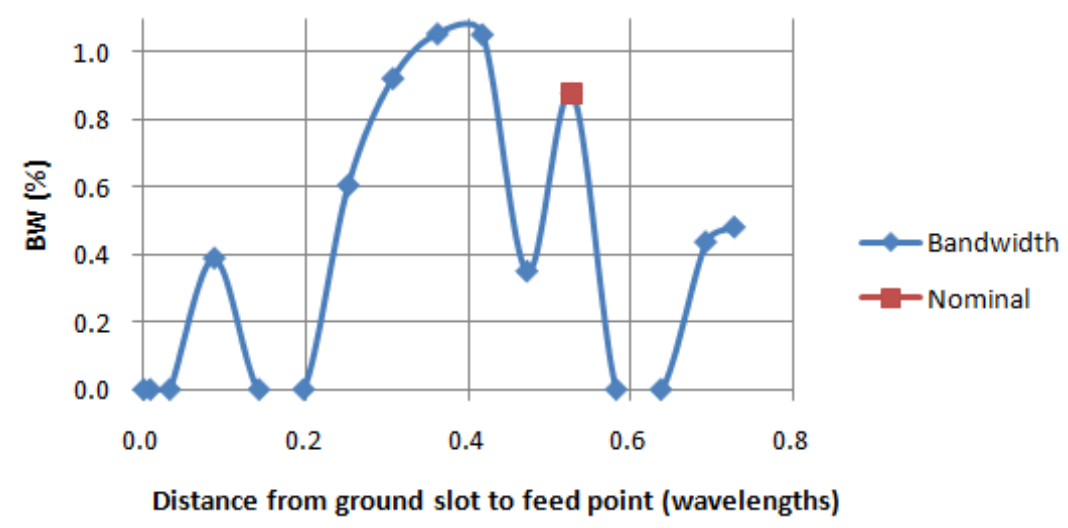

Figure A-4: Percent bandwidth vs. feed length

Figure A-5 shows polarization ratio as a function of feed length. Polarization ratio decreases if the feed length is varied by $\pm 0.15 \lambda$ or less. Figures A- 3 and A- 4 indicate that feed lengths resulting in polarization ratios greater than nominal yield percent bandwidths less than $0.44 \%$. This indicates that feed length cannot be adjusted to improve percent bandwidth and polarization ratio.

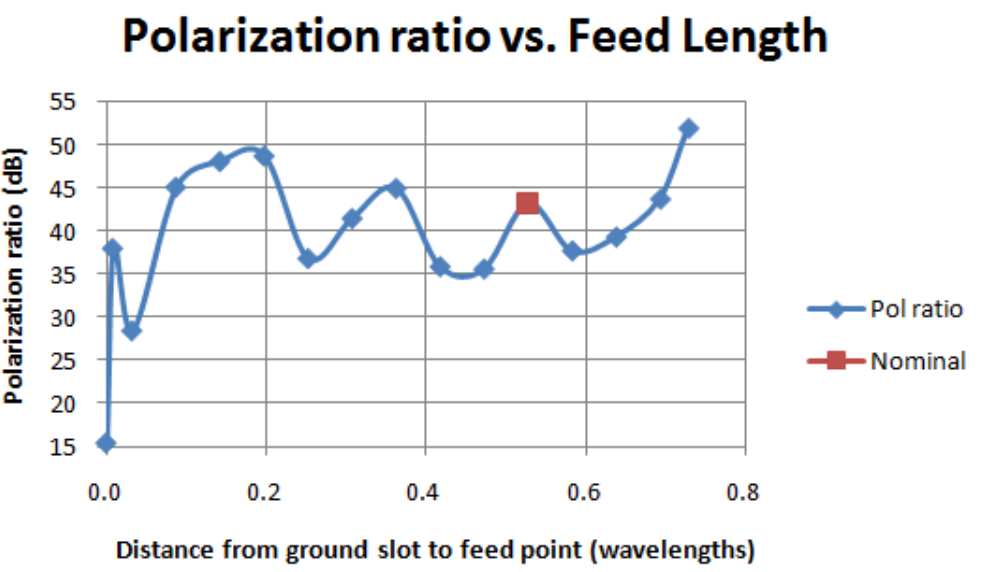

Figure A-5: Polarization ratio vs. feed length 
Figure A-6 shows feed length vs. total broadside gain. Gain is within $\pm 0.20 \mathrm{~dB}$ of nominal for feed lengths between $0.10 \lambda$ and $0.70 \lambda$.

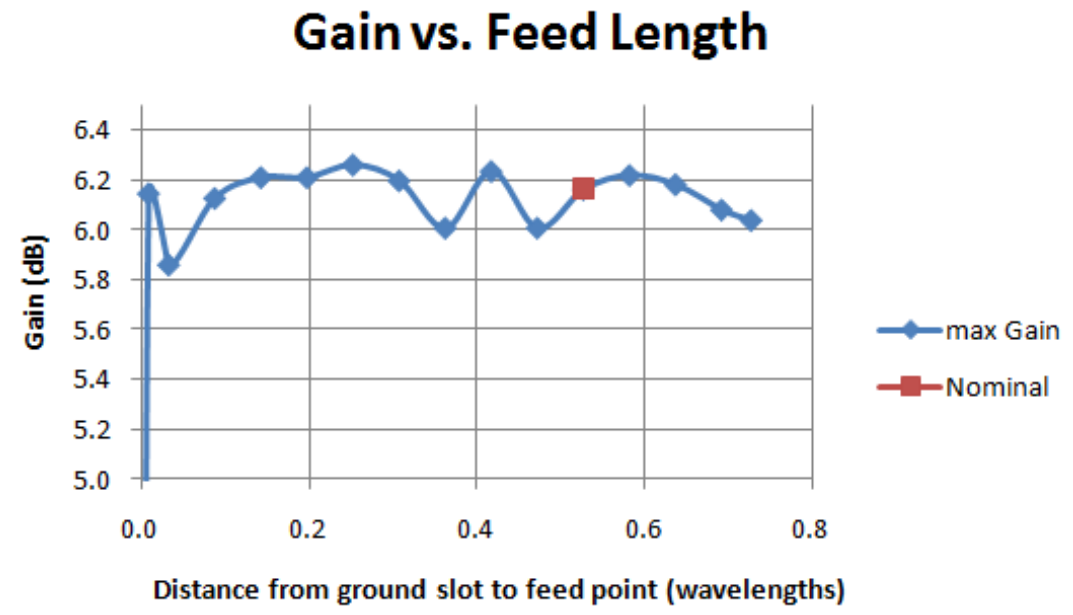

Figure A-6: Gain vs. feed length

Termination length is varied from $0.00 \lambda$ (open termination directly below ground slot) to $0.52 \lambda$ (open termination at end of board) in increments of $0.05 \lambda$. Figure A-7 indicates that the operating frequency varies by less than $0.7 \%$ of nominal for termination lengths within a factor of 2 of nominal.

Fo vs. Termination Length

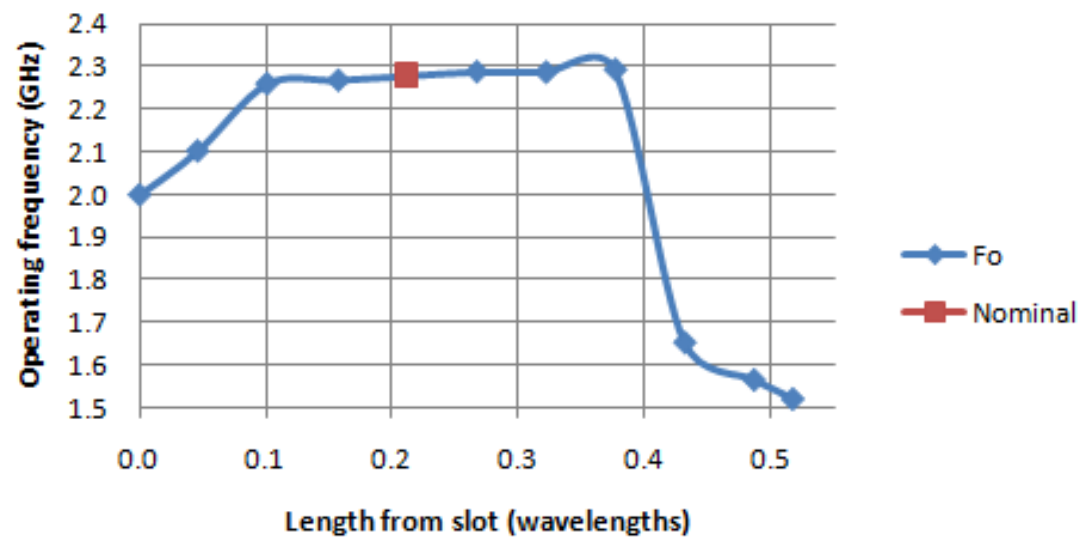

Figure A-7: Operating frequency vs. termination length 
Figure A-8 shows termination lengths between $0.1 \lambda$ and $0.4 \lambda$ yield minimum VWSR $_{\text {in }}$ values less than or equal to nominal (1.858). This is the same termination length range that produces operating frequencies within $1 \%$ of nominal. A termination length of $0.101 \lambda$ produces the smallest tested $\operatorname{VSWR}_{\text {in }}(1.03)$.

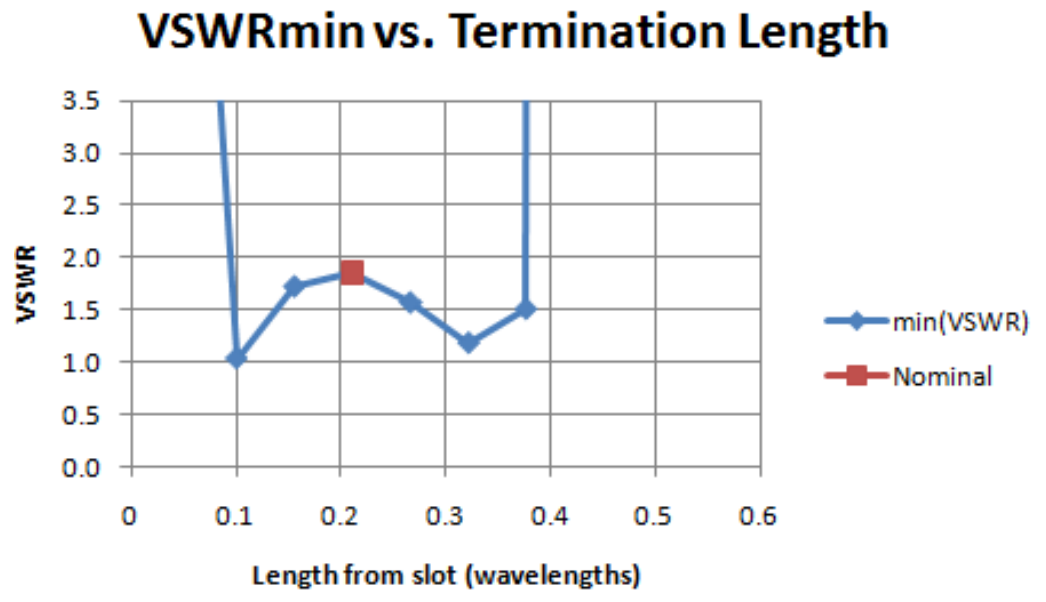

Figure A-8: VSWRin vs. feed length

Figure A-9 shows that percent bandwidth is greater than $0.8 \%$ for termination lengths between $0.1 \lambda$ and $0.4 \lambda$.

\section{Percent Bandwidth vs. Termination Length}

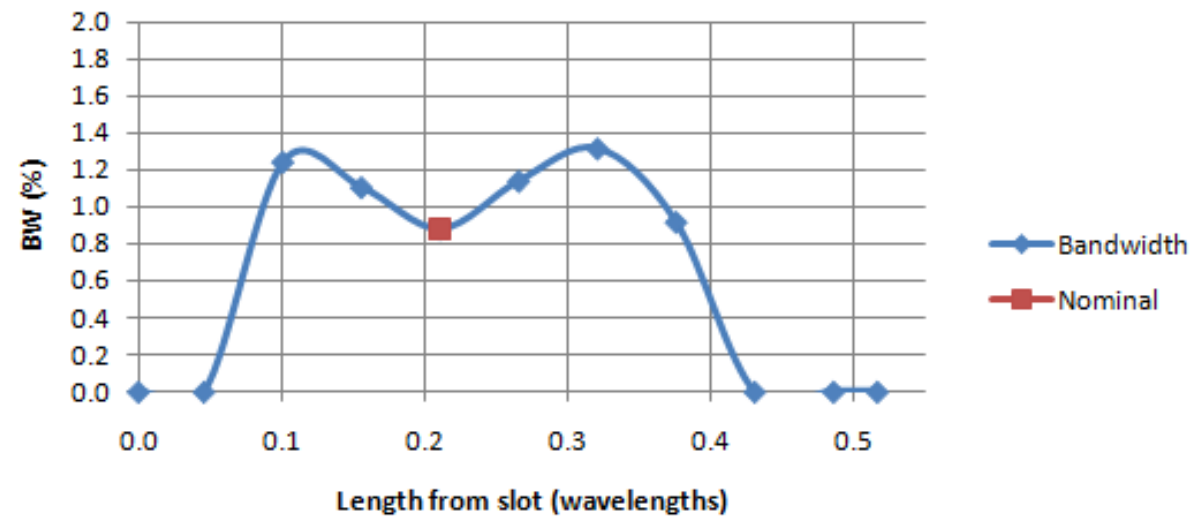

Figure A-9: Percent bandwidth vs. termination length 
Figure A-10 shows that polarization ratio is greater than $40 \mathrm{~dB}$ for termination lengths between $0.1 \lambda$ and $0.4 \lambda$. This is the same termination length range that yields the optimum $\mathrm{f}_{\mathrm{o}}$, smallest VSWR $\mathrm{V}_{\text {in }}$ values, and widest bandwidths.

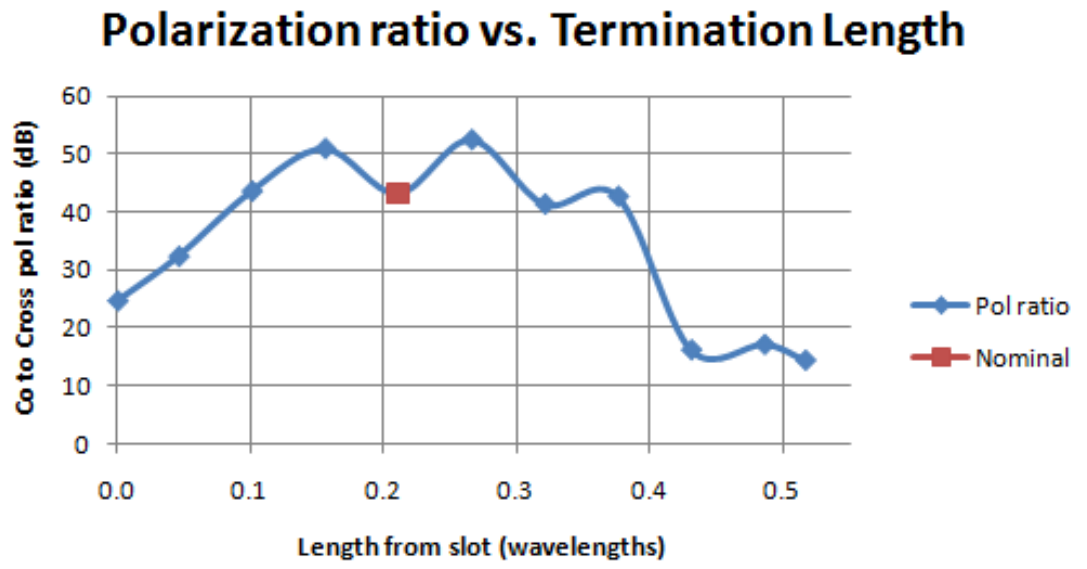

Figure A-10: Polarization ratio vs. termination length

Figure A-11 shows that total broadside gain is greater than $6 \mathrm{~dB}$ with termination lengths between $0.2 \lambda$ and $0.4 \lambda$. The termination length may be increased to twice its nominal length and maintain a minimum $6 \mathrm{~dB}$ gain.

\section{Gain vs. Termination Length}

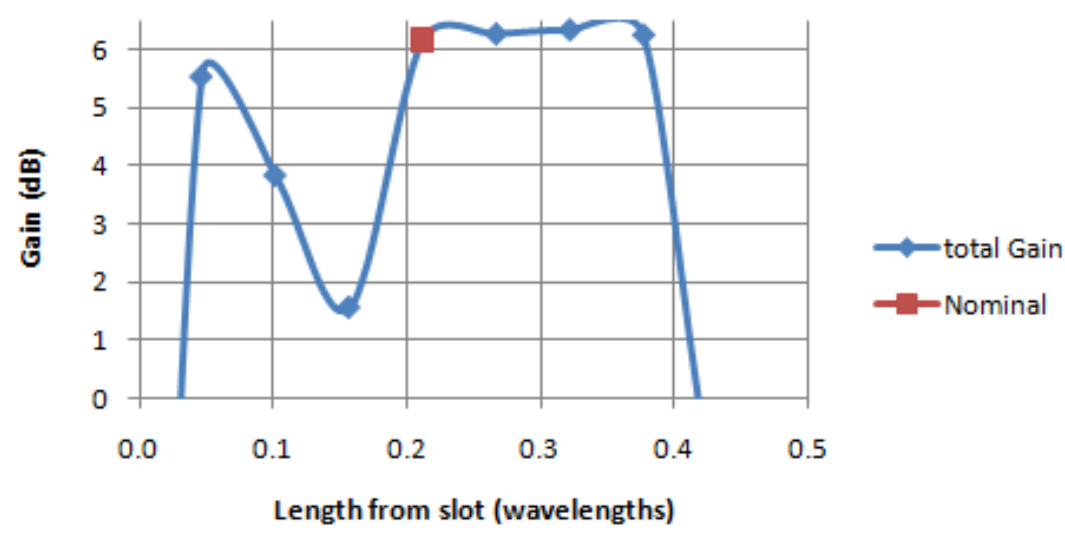

Figure A-11: Gain vs. termination length 
Feed width offset is varied from $0.000 \lambda$ (nominal) to $0.084 \lambda$ (the feed strip is no longer under the ground plane slot). Figure A-12 indicates that adjusting feed width offset will change operating frequency by less than $10 \%$ of nominal.

\section{Fo vs. Feed Width Offset}

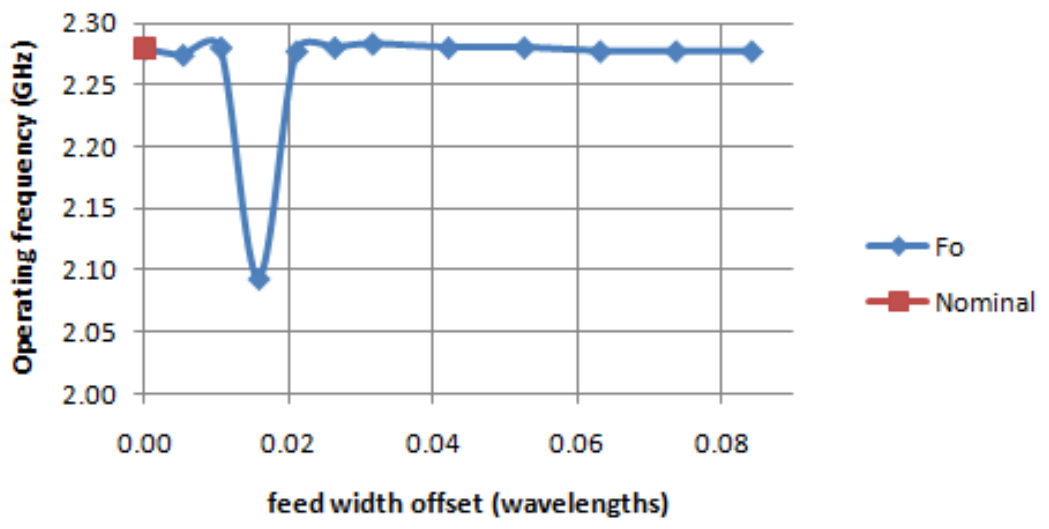

Figure A-12: Operating frequency vs. feed width offset

Figure A-13 shows that for feed width offset values less than $0.063 \lambda$, but not equal to $0.016 \lambda, \mathrm{VSWR}_{\text {in }}$ is less than 2 . The antenna is most closely matched $\left(\mathrm{VSWR}_{\text {in }}=1.043\right)$ when the feed width offset is $0.042 \lambda$. However, this offset causes broadside gain to decrease by approximately $3 \mathrm{~dB}$ (Figure A-16).

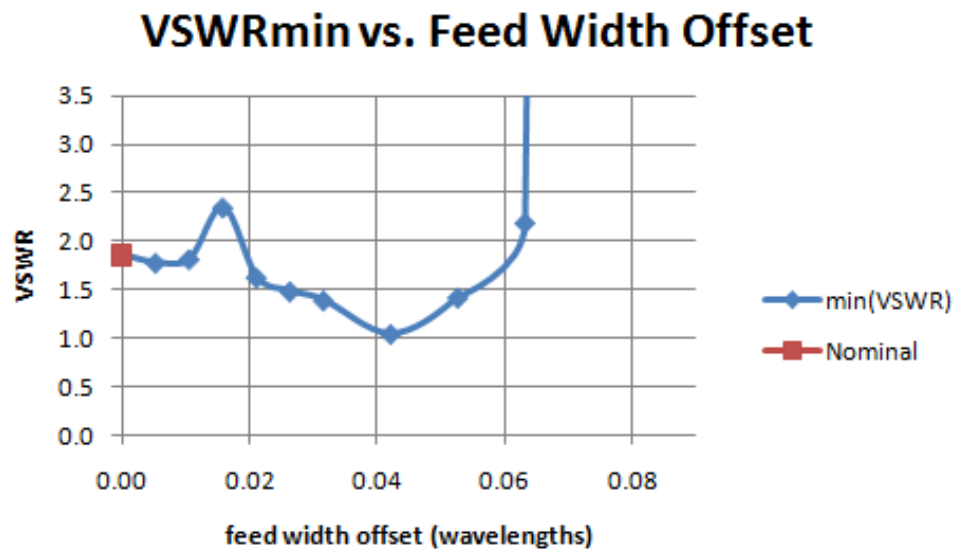

Figure A-13: VSWRin vs. feed width offset 
Figure A-14 shows that feed width offsets between $0.021 \lambda$ and $0.042 \lambda$ yield the largest percent bandwidths. However, broadside gain is less than $4 \mathrm{~dB}$ in this range (see Figure A-16).

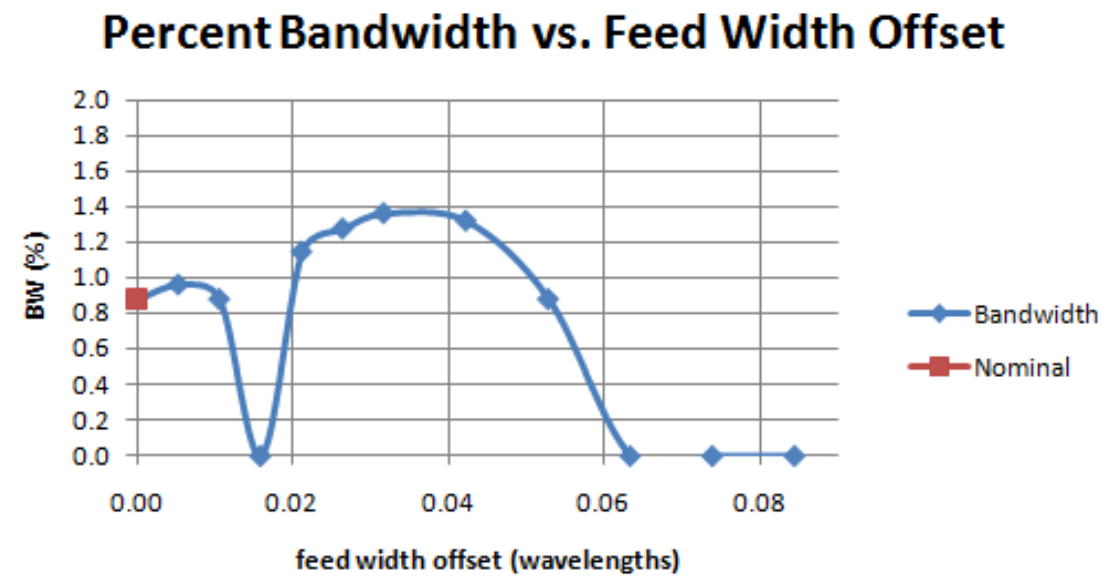

Figure A-14: Bandwidth vs. feed width offset

Figure A-15 shows that polarization ratio is greater than $40 \mathrm{~dB}$ when feed width offset is less than $0.050 \lambda$, but not equal to $0.016 \lambda$.

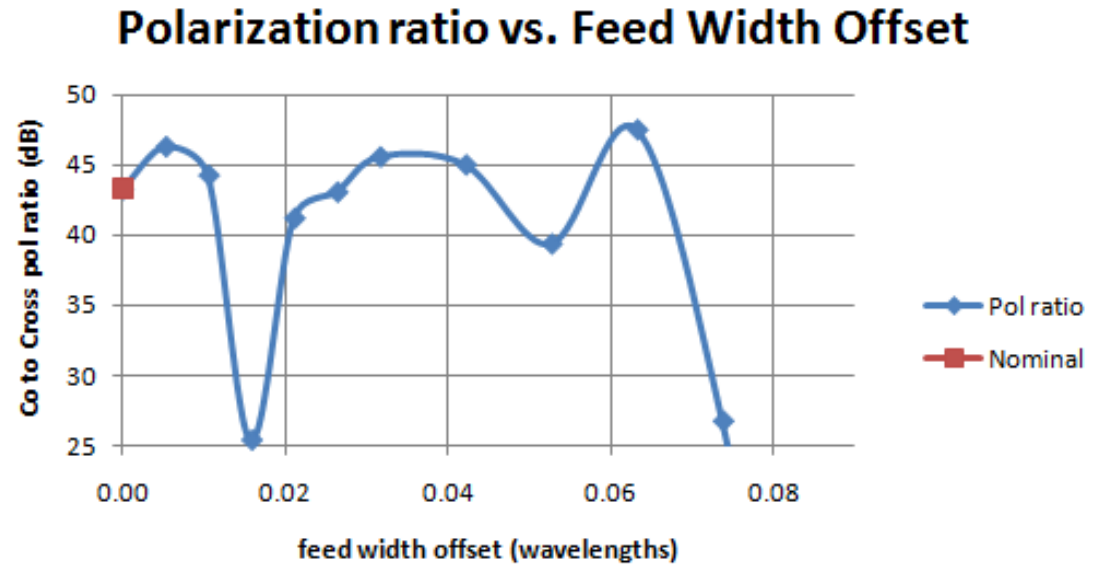

Figure A-15: Polarization ratio vs. feed width offset

Figure A-16 shows that broadside gain decreases by at least $4 \mathrm{~dB}$ for feed width offsets less than $0.01 \lambda$. 


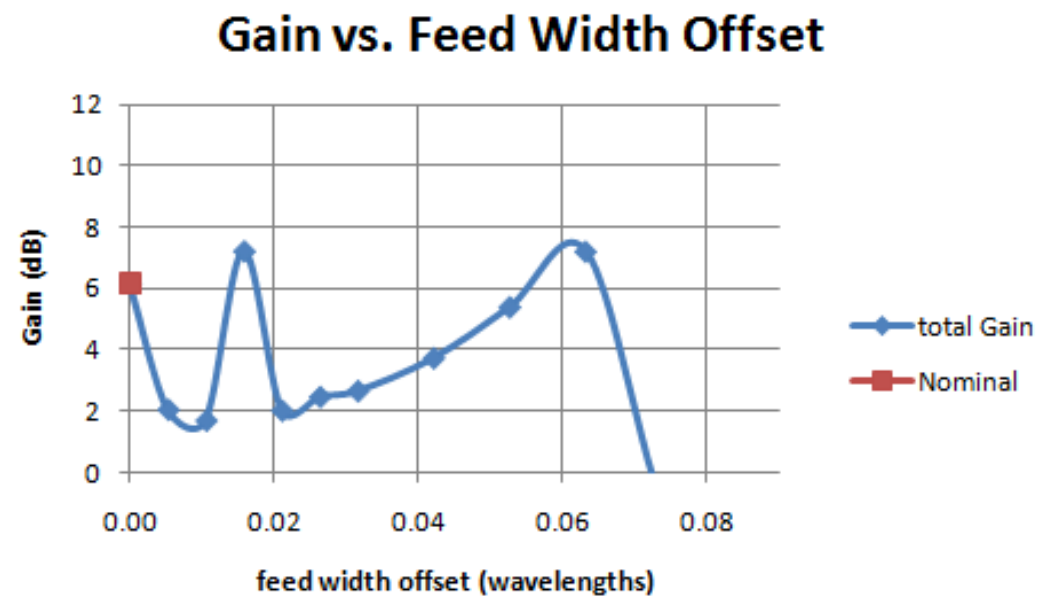

Figure A-16: Gain vs. feed width offset

Feed line width is nominally 194.9 mils for a $49.8 \Omega$ line. The feed strip is modeled in ADS2006A as a 194.9mil wide microstrip line on a 63mil height substrate with a 2.2 dielectric constant and ground plane. The feed line width is varied by \pm 100 mils of nominal in increments of 20 mils $(\approx 0.05 \mathrm{~cm}$ or $0.005 \lambda)$.

Figure A-17 indicates that the line width changes the operating frequency by less than $\pm 1.0 \%$.

Fo vs. Feed Line Width

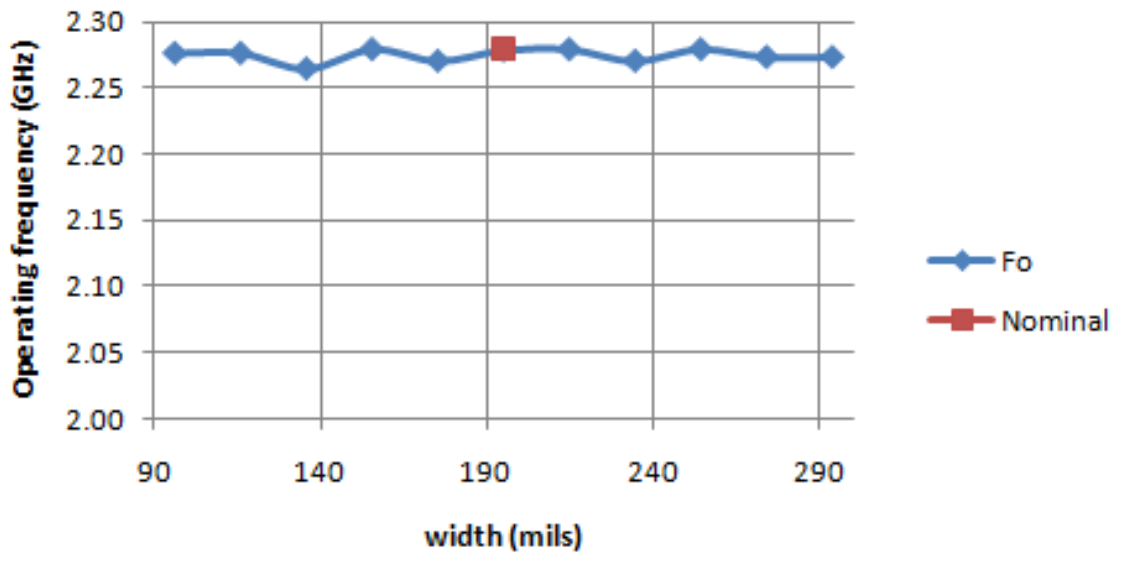

Figure A-17: Operating frequency vs. line width 
Figure A-18 indicates that varying line width by \pm 100 mils will not increase $\mathrm{VSWR}_{\text {in }}$ by more than $2 \%$ and may even improve input matching.

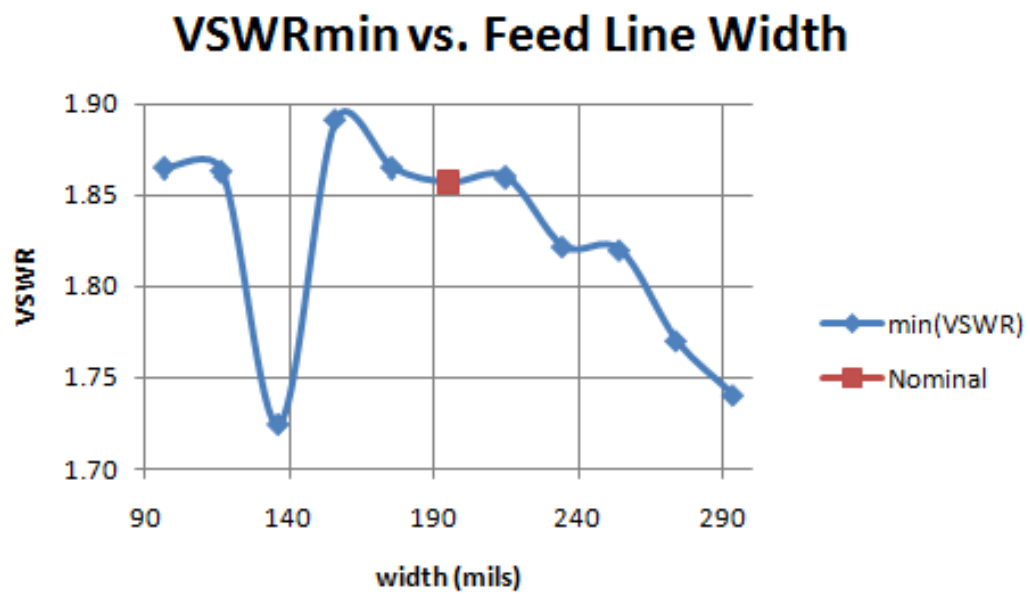

Figure A-18: VSWRin vs. line width

Figure A-19 shows that percent bandwidth changes by less than $0.2 \%$ for all tested line widths.

\section{Percent Bandwidth vs. Feed Line Width}

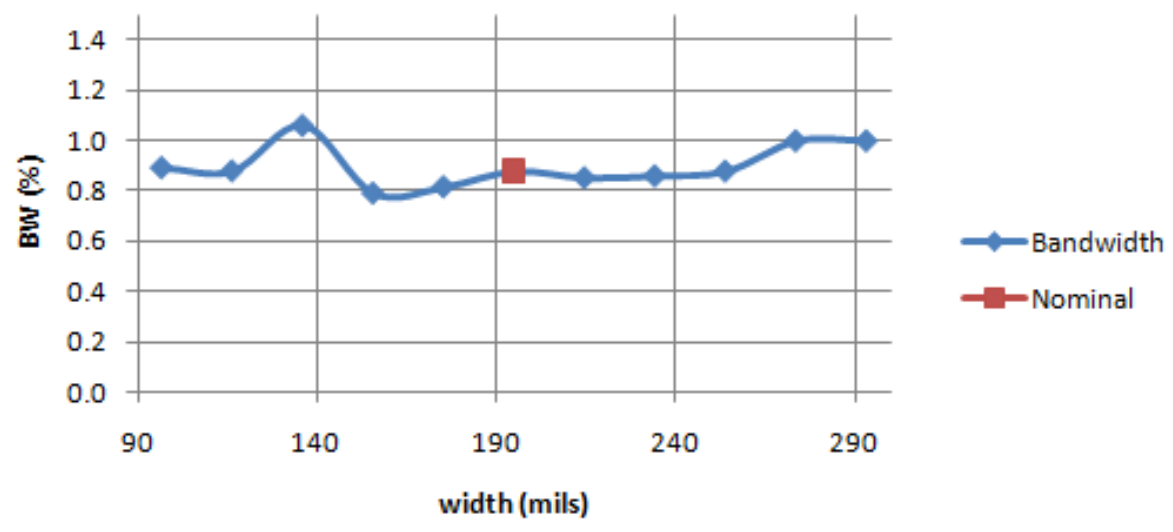

Figure A-19: Bandwidth vs. line width 
Figure A-20 shows that polarization ratio is between $43 \mathrm{~dB}$ and $50 \mathrm{~dB}$ for all line widths between 160 and 290mils.

\section{Polarization ratio vs. Feed Line Width}

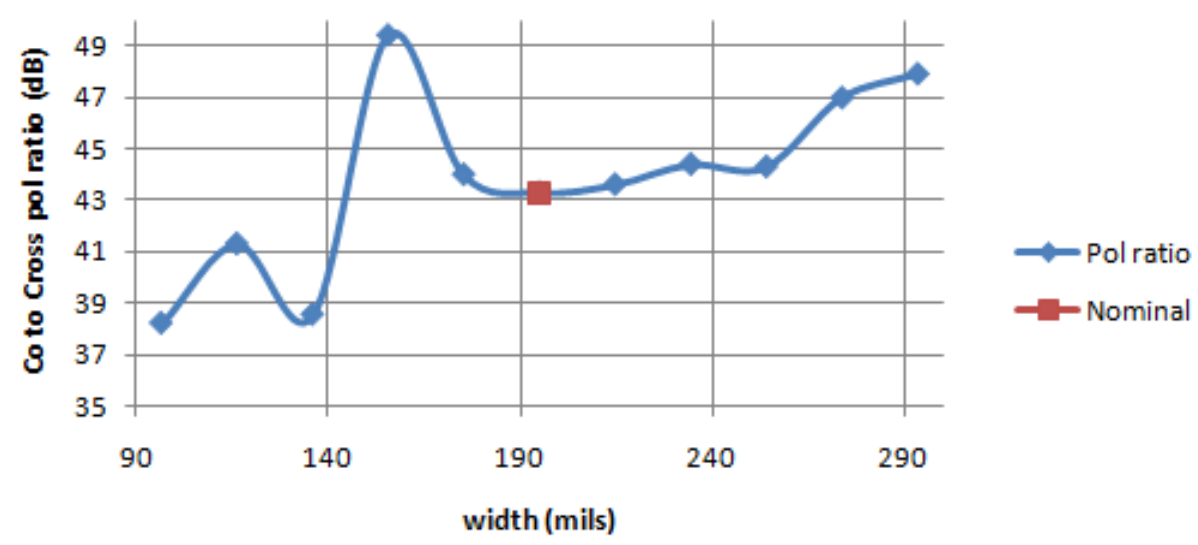

Figure A-20: Polarization ratio vs. line width

Figure A-21 indicates that changing line width from its nominal value decreases broadside gain by at least $4 \mathrm{~dB}$. This indicates that the feed line width should not be used to tune the antenna.

\section{Gain vs. Feed Line Width}

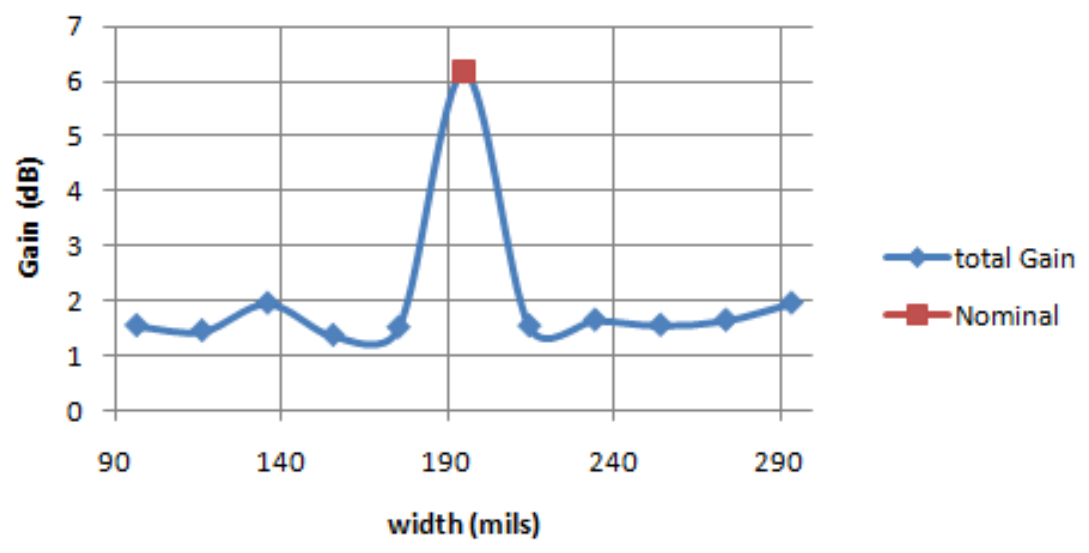

Figure A-21: Gain vs. line width 


\section{Substrates}

Substrate heights and material are varied in HFSS. Figure A-22 shows an antenna side view. The layers from bottom to top are feed line, feed substrate, ground plane, antenna substrate, and patch. The terms "feed substrate" and "antenna substrate" are adopted from [7]. The nominal substrates are 63mil height RT Duroid 5880 [1].

The substrates are varied in four test sets: feed substrate height from $0.010 \lambda$ to $0.024 \lambda$, antenna substrate height from $0.010 \lambda$ to $0.024 \lambda$ ( 37.3 to $90 \mathrm{mils}$ ), both substrates simultaneously over the same range. and the substrate material (from RT Duroid to FR4).

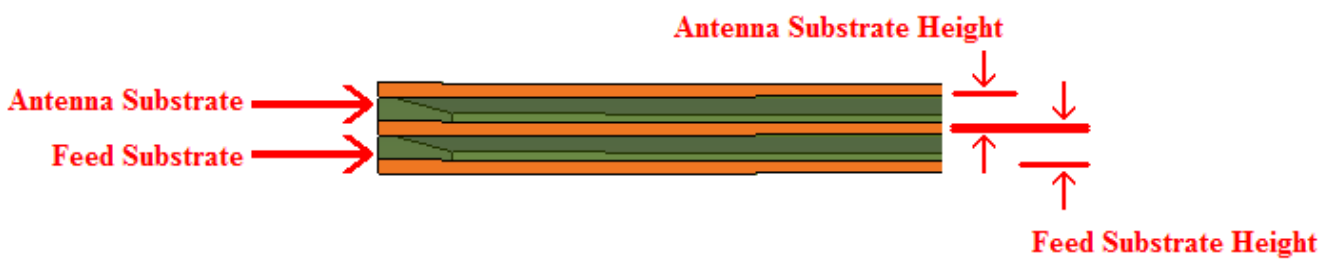

Figure A-22: Aperture coupled antenna substrates

Nominal feed substrate height is 63mil, equivalent to $0.017 \lambda$ (wavelength in microstrip line found using ADS2006A's Linecalc at 2.3GHz). Figure A-23 indicates that substrate height variations within $\pm 0.007 \lambda$ of nominal changes the operating frequency by less than $0.48 \%$. 


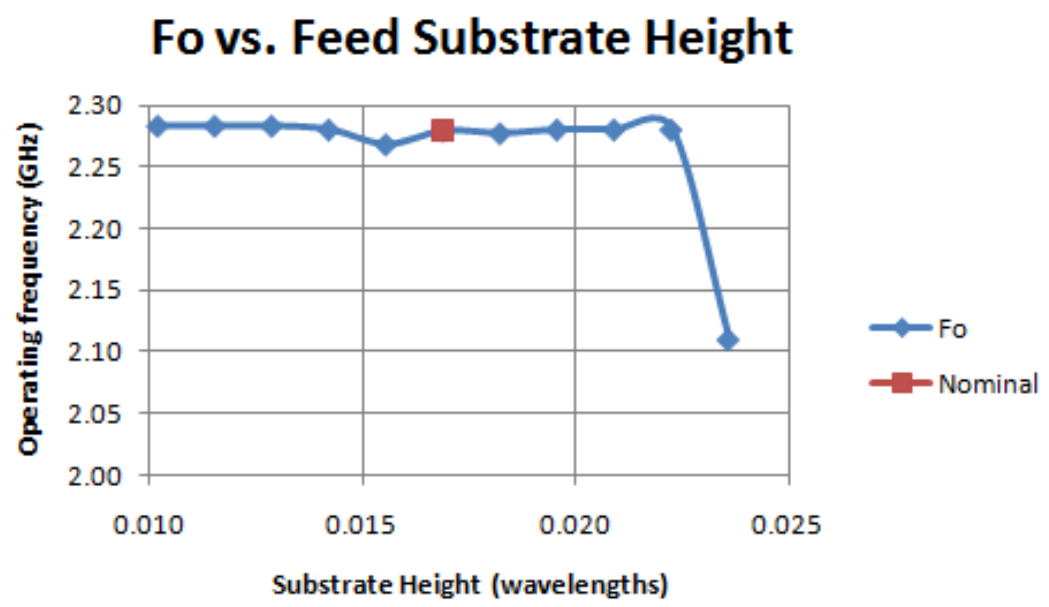

Figure A-23: Operating frequency vs. feed substrate height

Figure A-24 shows that for feed substrate heights between $0.010 \lambda$ to $0.024 \lambda$, $\mathrm{VSWR}_{\text {in }}$ decreases by an average of -0.649 per $0.010 \lambda$ increase in feed substrate height. A feed substrate height of $0.022 \lambda$ results in minimum $\operatorname{VSWR}_{\text {in }}(1.617)$.

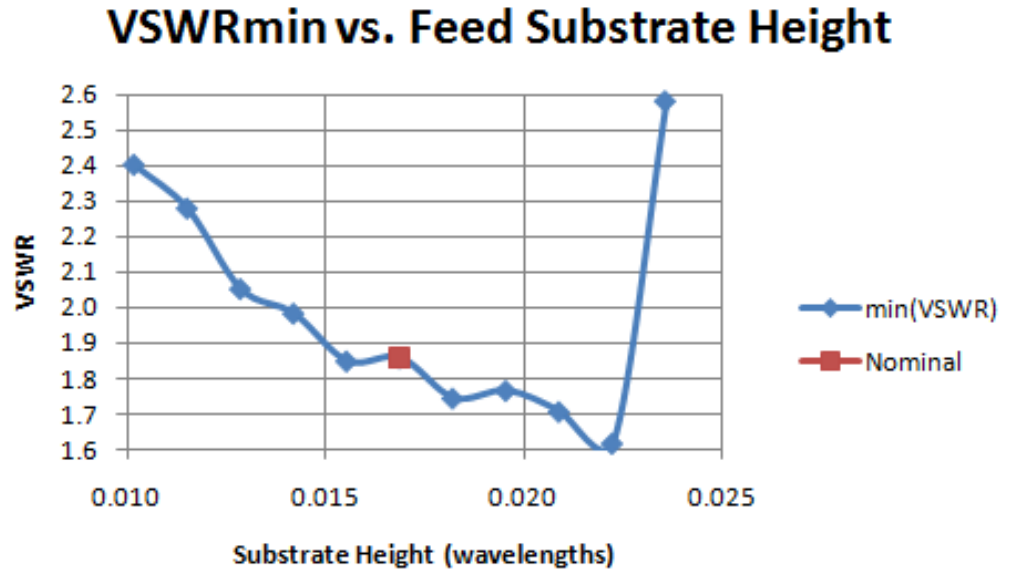

Figure A-24: VSWRin vs. feed substrate height

Figure A-25 shows that percent bandwidth is less than $1.18 \%$ for all analyzed feed substrate heights. 


\section{Percent Bandwidth vs. Feed Substrate Height}

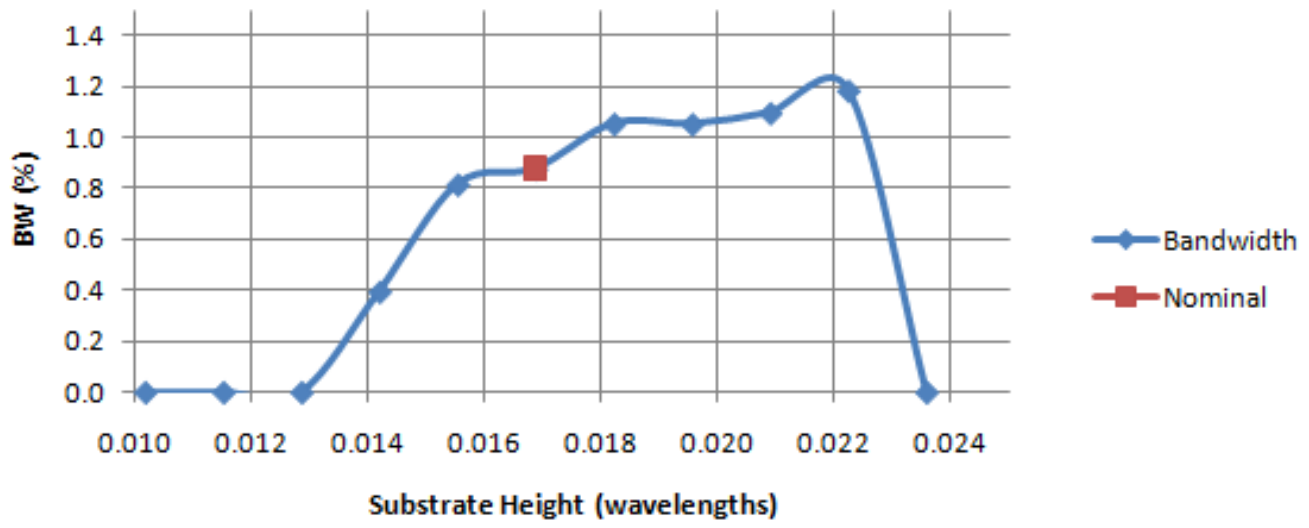

Figure A-25: Bandwidth vs. feed substrate height

Figure A-26 shows that if the feed substrate height is varied by $\pm 0.001 \lambda$ from its nominal value, the polarization ratio decreases by $3.0 \mathrm{~dB}$ or more. This indicates that manufacturing errors in feed substrate height will cause smaller than expected polarization ratios.

\section{Polarization Ratio vs. Feed Substrate Height}

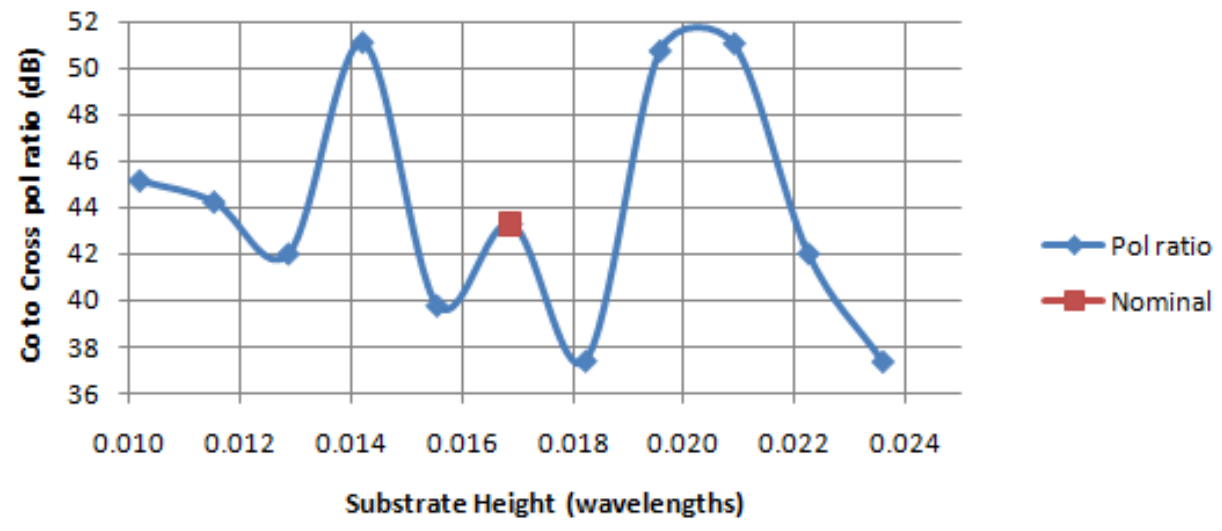

Figure A-26: Polarization ratio vs. feed substrate height

Figure A-27 shows that broadside gain is between $6.00 \mathrm{~dB}$ and $6.25 \mathrm{~dB}$ for feed substrate heights between $0.016 \lambda$ and $0.022 \lambda$. 


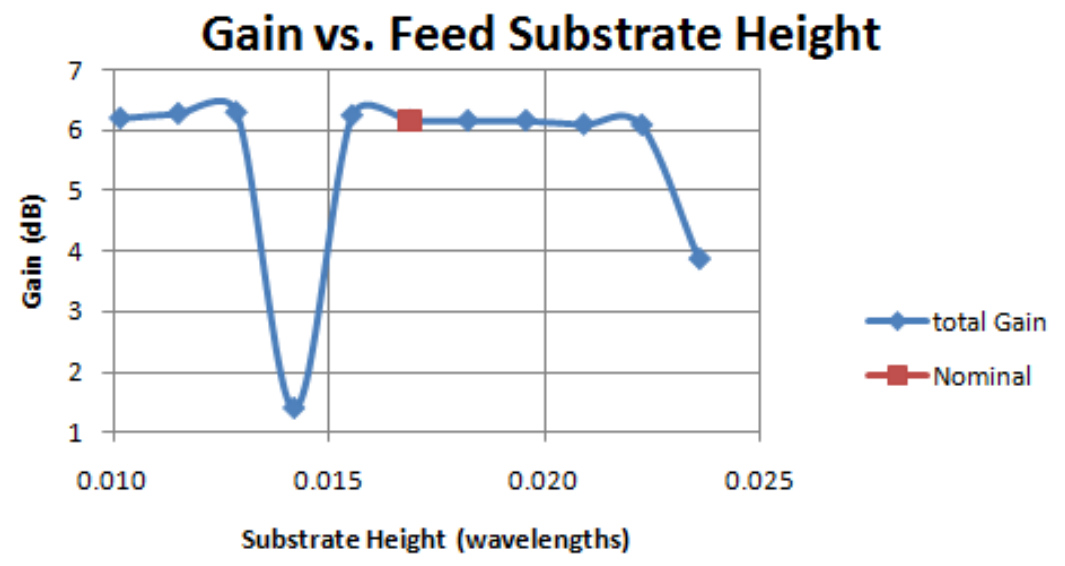

Figure A-27: Gain vs. feed substrate height

Nominal antenna substrate height is 63 mil, equivalent to $0.017 \lambda$ (wavelength in microstrip line found using ADS2006A's Linecalc at 2.3GHz). The substrate height is varied from $0.010 \lambda$ to $0.032 \lambda$ ( 37.3 to $120 \mathrm{mils}$ ).

Figure A-28 indicates that antenna substrate height may be increased up to $0.014 \lambda$ above its nominal value with $\pm 0.31 \%$ maximum operating frequency variation.

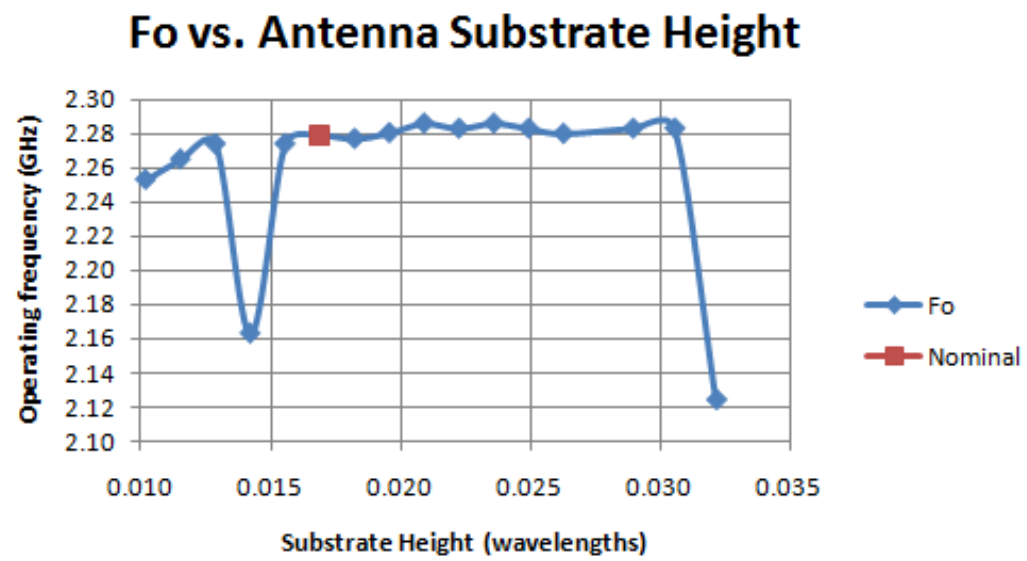

Figure A-28: Operating frequency vs. antenna substrate height 
Figure A-29 shows that increasing antenna substrate height up to $0.025 \lambda$ decreases $\operatorname{VSWR}_{\text {in }}$. Antenna substrate height of $0.025 \lambda$ results in the smallest $\mathrm{VSWR}_{\mathrm{in}}$ (1.048).

\section{VSWRmin vs. Antenna Substrate Height}

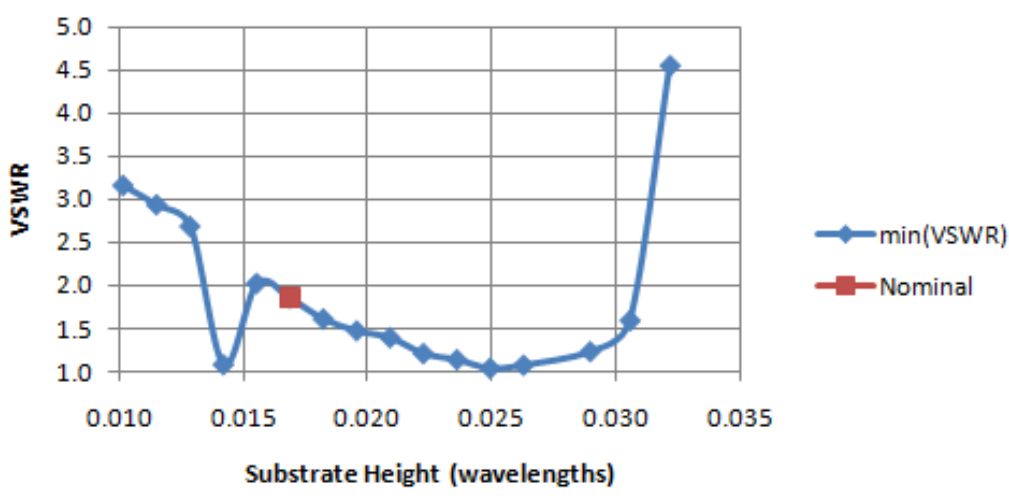

Figure A-29: VSWRin vs. antenna substrate height

Figure A-30 shows that increasing antenna substrate height up to $0.014 \lambda$ above its nominal value increases percent bandwidth to $2.01 \%$. This occurs because increasing antenna substrate thickness decreases the quality factor, which increases bandwidth [13].

\section{Percent Bandwidth vs. Antenna Substrate Height}

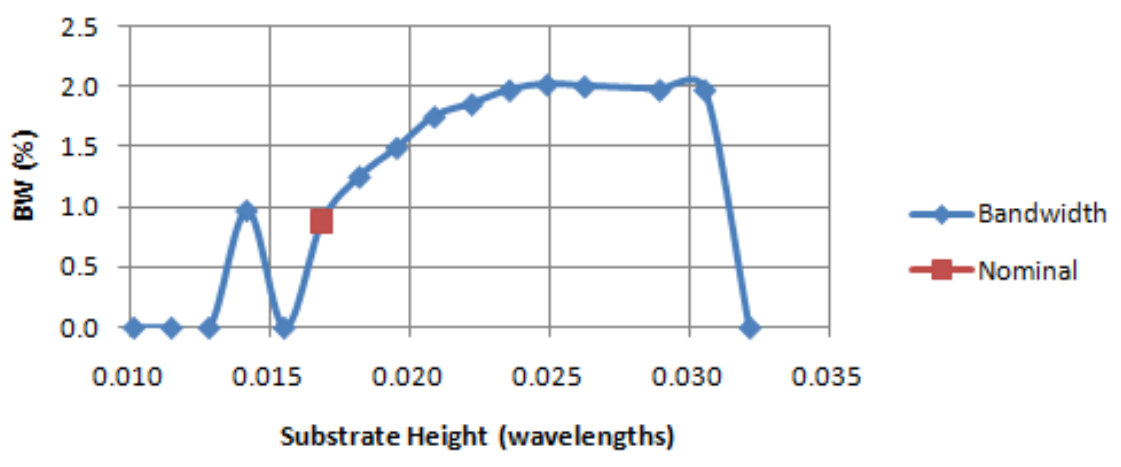

Figure A-30: Bandwidth vs. antenna substrate height 
Figure A-31 shows that errors in the nominal antenna substrate height may cause less than expected polarization ratios.

\section{Polarization Ratio vs. Antenna Substrate Height}

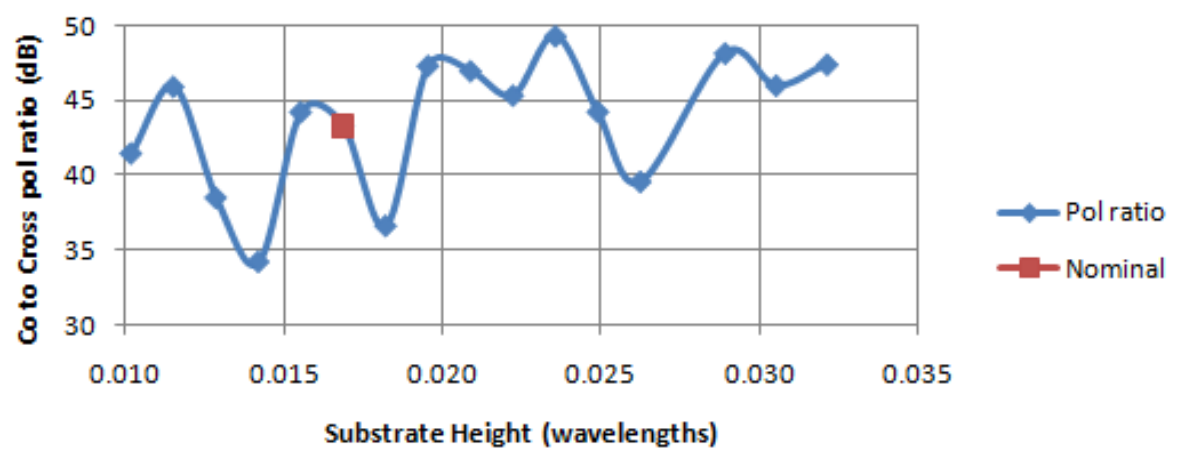

Figure A-31: Polarization ratio vs. antenna substrate height

Figure A-32 shows that broadside gain is between $6.16 \mathrm{~dB}$ and $6.32 \mathrm{~dB}$ for antenna substrate heights between $0.016 \lambda$ and $0.031 \lambda$.

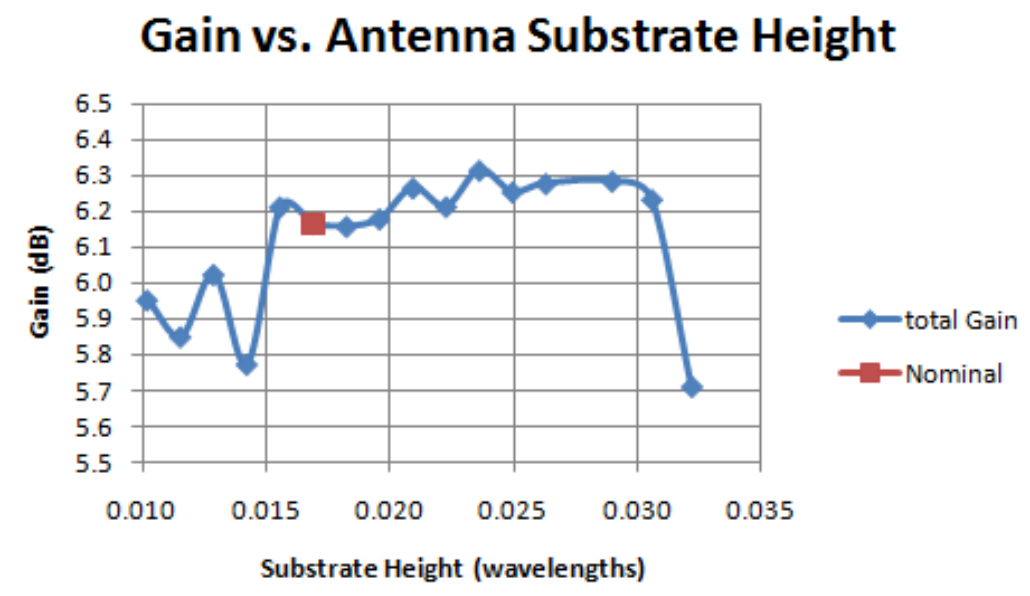

Figure A-32: Gain vs. antenna substrate height

Figure A-33 shows input reactance at the operating frequency vs. feed substrate height. Equivalent radiation capacitance decreases as substrate height increases ffrom 
equations (3.4) and (3.6) \}. This results in a less capacitive input impedance. Figure A-33 and [13] confirm that increasing antenna substrate height increases input reactance.

\section{$\operatorname{Im}\{$ Zin $\}$ vs. Antenna Substrate Height}

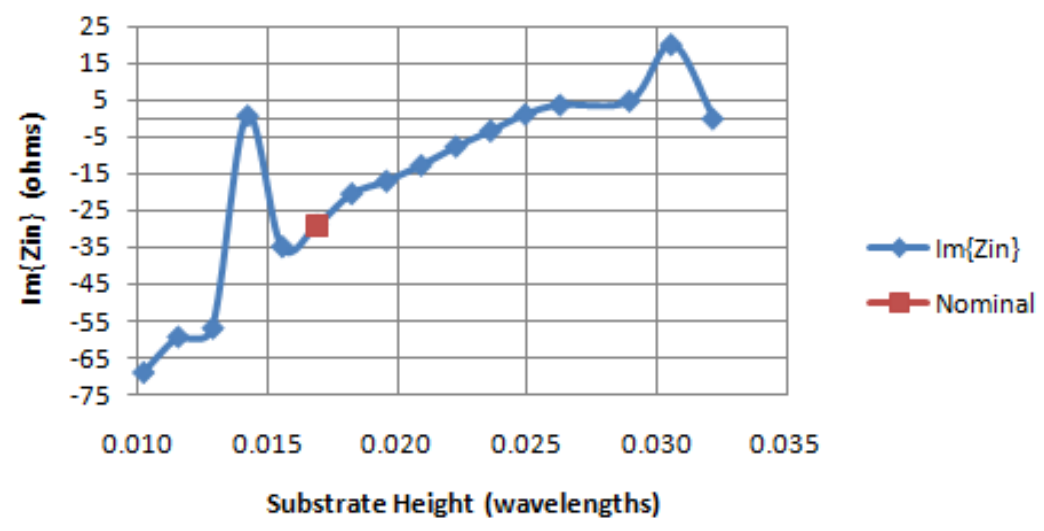

Figure A-33: $\operatorname{Im}\left\{Z_{\text {in }}\right\}$ vs. antenna substrate height

\section{Ground Plane Slot}

The ground plane slot dimensions and location are varied in HFSS. Figure A-34 shows an expanded view of the ground plane in orange and ground plane slot in yellow. Slot Width Offset and Slot Length Offset are the distances from the center of the slot to a point directly below the center of the radiating patch (z-axis). Slot Width Offset and Slot Length Offset are nominally 0 . The nominal slot dimensions are $0.148 \lambda$ by $0.016 \lambda$ (Slot Length by Slot Width) equivalent to 551.2mils by 61.0mils (wavelength in dielectric found with ADS2006A linecalc at $2.3 \mathrm{GHz}$ for $50 \Omega$ line). 


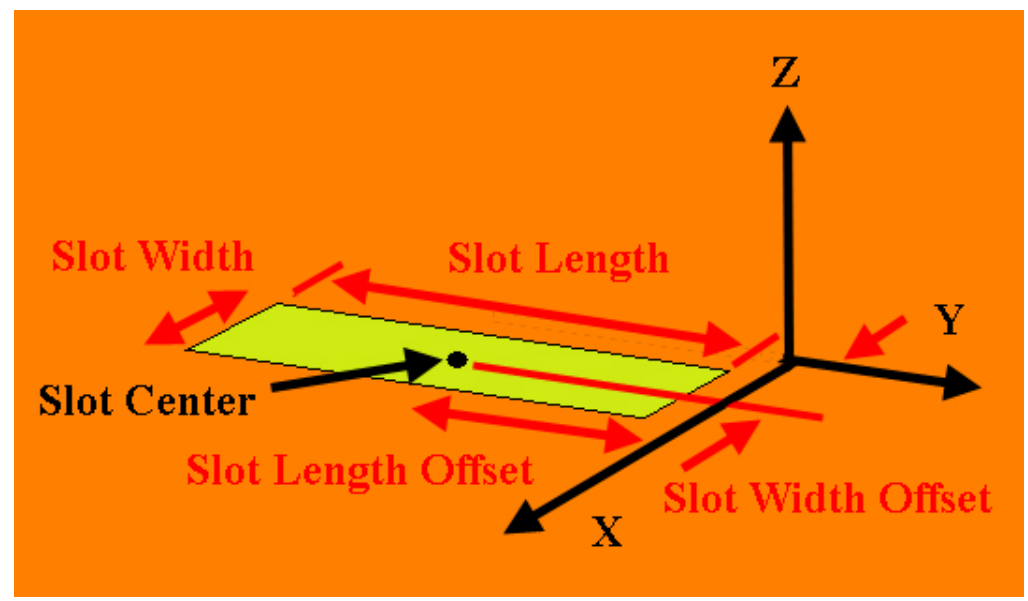

Figure A-34: Slot Dimensions and Variables

The ground slot is varied in five ways: Slot Length only, Slot Width only, Slot Length and Slot Width by the same factor, Slot Width Offset only, and Slot Length Offset only.

Slot Length is nominally 551.2mils and is varied between 61.0 and $787.4 \mathrm{mils}$. Figure A-35 shows that the operating frequency is between $2.328 \mathrm{GHz}$ and $2.104 \mathrm{GHz}$ for Slot Lengths between 315.0 and 787.4 mils. The abscissa axis is in mils instead of wavelengths due to the wide operating frequency range. Decreasing Slot Length to 196.9 mils or less results in operating frequencies greater than $6 \mathrm{GHz}$. The ground plane slot acts as an aperture which excites the patch. The increased frequency is likely due to the smaller aperture supporting a higher order mode. 


\section{Fo vs. Slot Length}

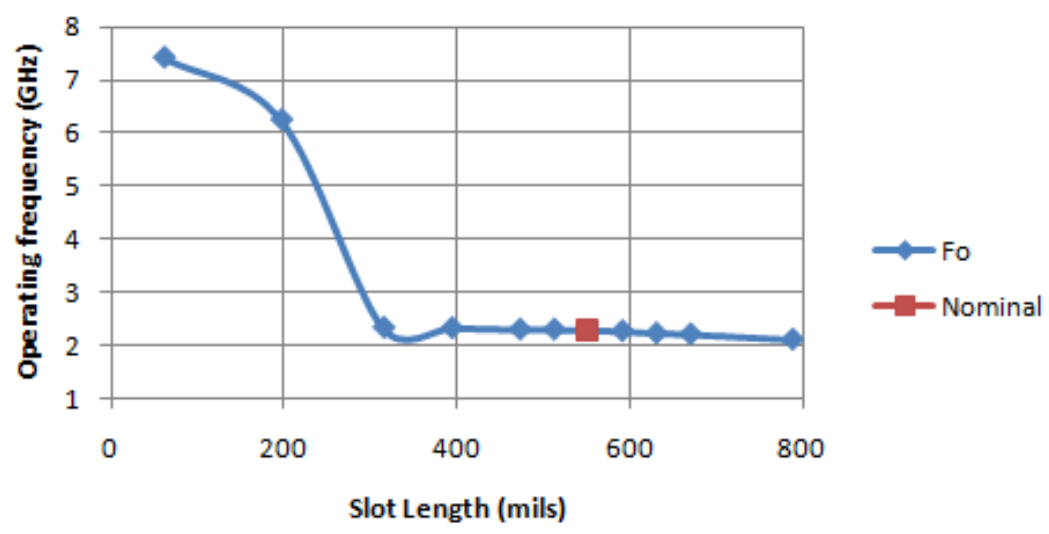

Figure A-35: Operating frequency vs. Slot Length

Figure A-36 indicates that increasing Slot Length increases input resistance and decreases input reactance.
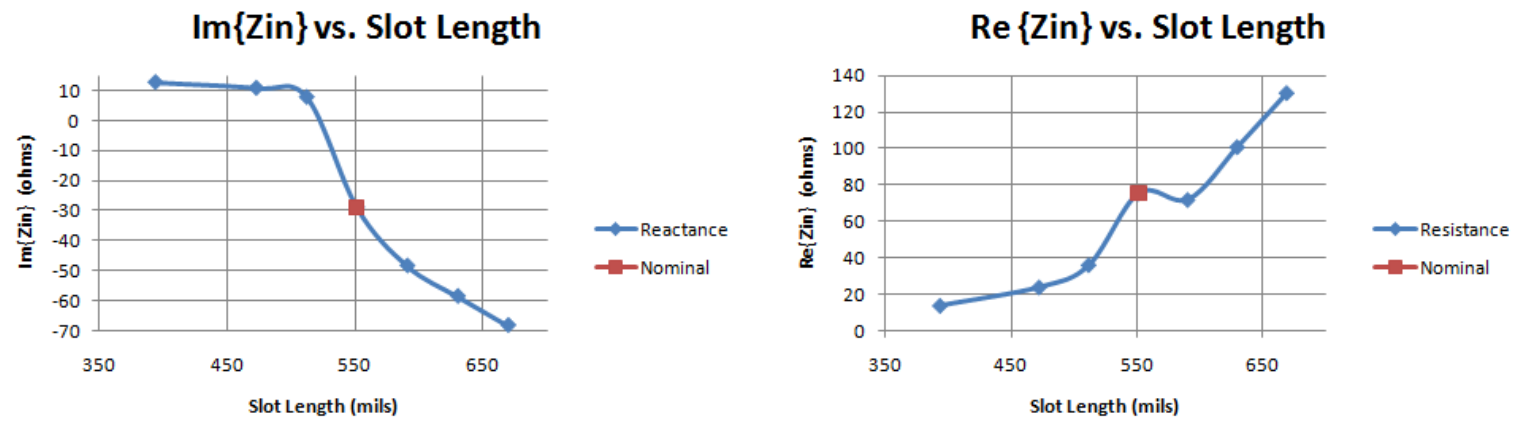

Figure A-36: Impedance vs. Slot Length

Figure A-37 shows that decreasing Slot Length by 40mils yields a less than nominal VSWR in. This result agrees with Figure A-36: decreasing Slot Length to approximately 25 mils below nominal (551.2mils) results in $Z_{\text {in }}$ equal to $50+\mathrm{j} 0 \Omega$. 


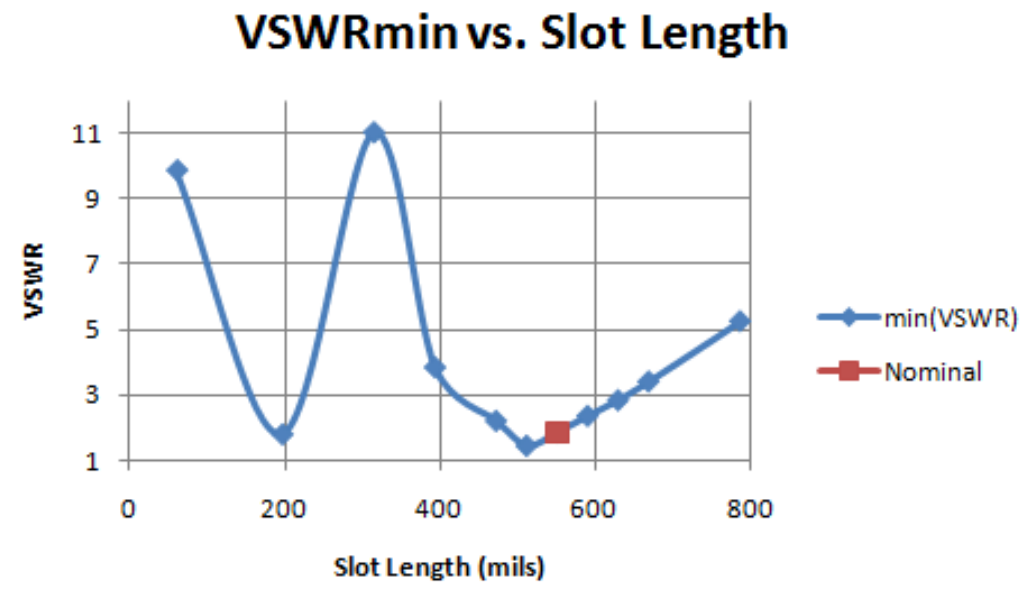

Figure A-37: VSWRin vs. Slot Length

Figure A-38 shows that decreasing nominal Slot Length by 40mils increases percent bandwidth to $1.4 \%$. The bandwidth increase is due to the improved input matching (see Figures A-34 and A-35) yielding a wider frequency range over which $\operatorname{VSWR}_{\text {in }}$ is less than 2.

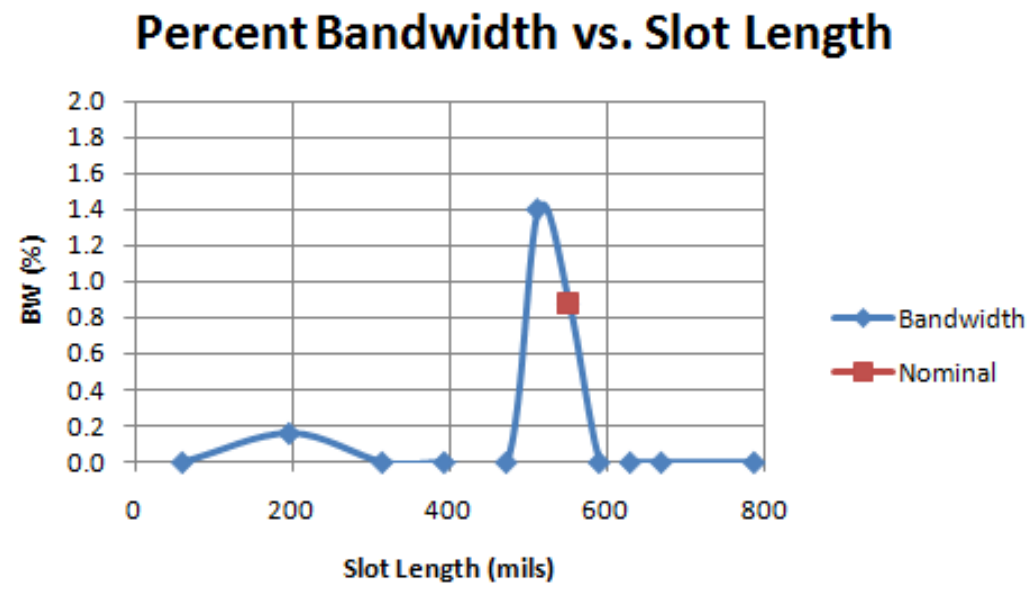

Figure A-38: Percent bandwidth vs. Slot Length

Figures A-39 and A-40 show that Slot Length values resulting in polarization ratios greater than $35 \mathrm{~dB}$ have gain fluctuations less than $\pm 0.600 \mathrm{~dB}$. Over this range of 
Slot Length values, the cross-pol gain fluctuates as much as $\pm 6.000 \mathrm{~dB}$ and the co-pol gain (which is nearly equal to total gain) changes by less than $0.374 \mathrm{~dB}$. It is known that increasing Slot Length increases feed line and patch coupling [7]. However, cross-pol coupling is affected approximately $\pm 5.0 \mathrm{~dB}$ more than co-pol coupling. Due to increased cross-pol gain (see Figure A-41), decreasing Slot Length to less than half its nominal value results in polarization ratios less than $15 \mathrm{~dB}$.

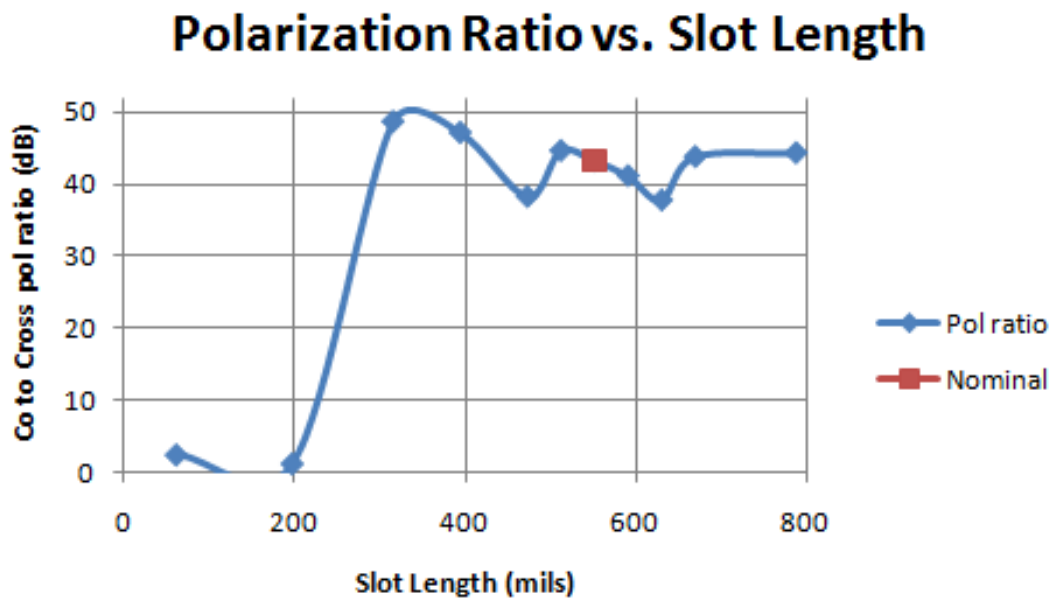

Figure A-39: Polarization ratio vs. Slot Length

Figure A-40 show that total broadside gains greater than $7.0 \mathrm{~dB}$ are caused by cross-pol broadside gains of $3.0 \mathrm{~dB}$ or more (see Figure A-41, nominal cross-pol gain is $-37.28 \mathrm{~dB}$ ). Total gain differs by less than $\pm 0.6 \mathrm{~dB}$ for Slot Length values between 315.0 and 787.4mils. 
Gain vs. Slot Length

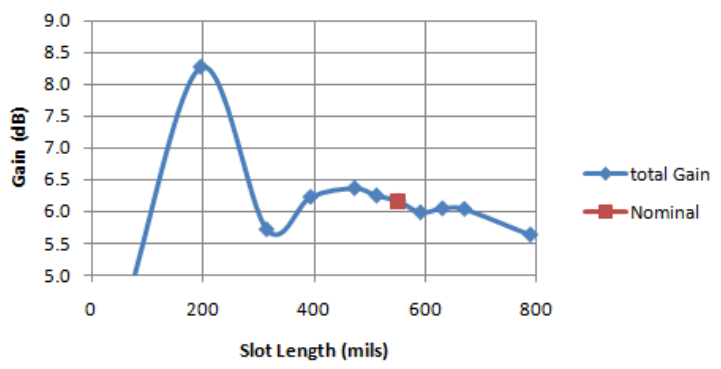

Co-pol Gain vs. Slot Length

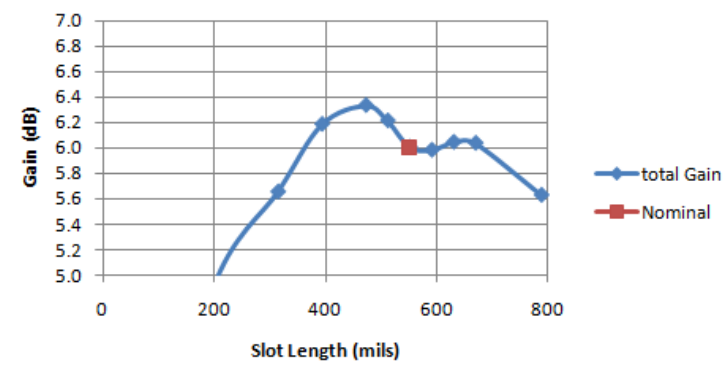

Figure A-40: Total and Co-pol gain vs. Slot Length

\section{Cross-pol Gain vs. Slot Length}

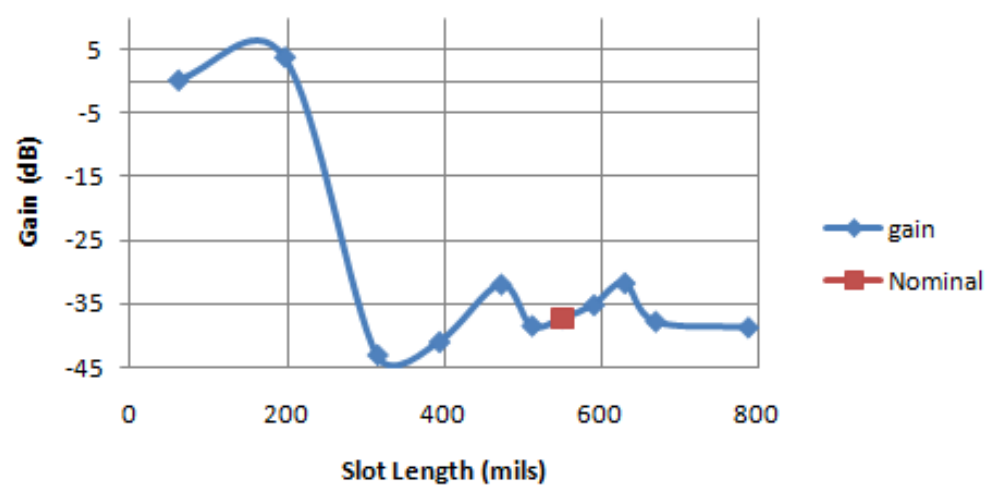

Figure A-41: Cross-pol gain vs. Slot Length

Slot Width is nominally 61.0mils and is varied between 11.8 and 196.9 mils. Figure A-42 shows that Slot Width values between 11.8 and 160.0mils result in operating frequencies between $2.10 \mathrm{GHz}$ and $2.32 \mathrm{GHz}$. Increasing Slot Width excites a higher order mode. 
Fo vs. Slot Width

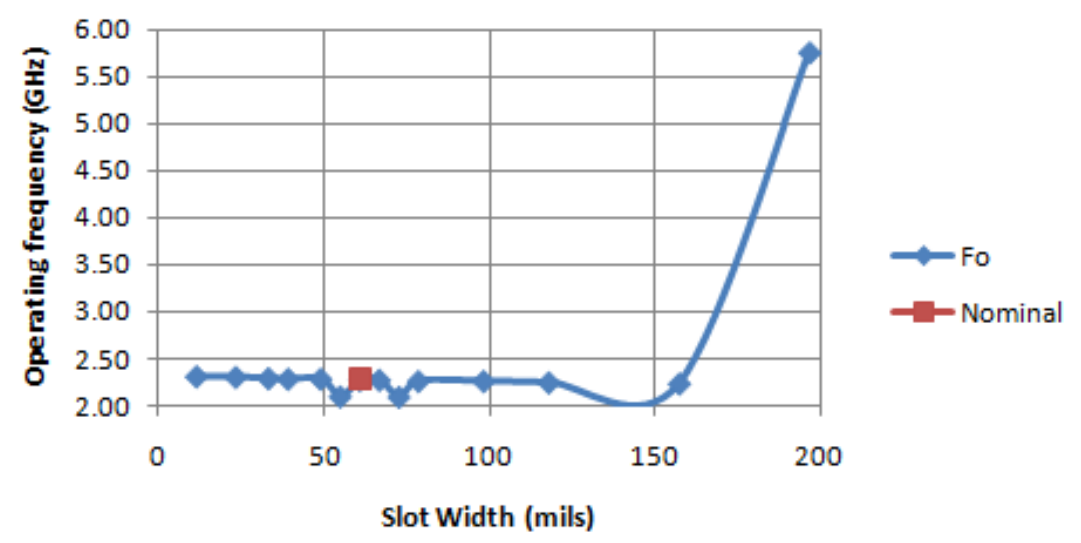

Figure A-42: Operating frequency vs. Slot Width

Figure A-43 shows minimum VSWR $_{\text {in }}$ vs. Slot Width. $Z_{\text {in }}$ is nominally $75.5-\mathrm{j} 29.0 \Omega$ at the operating frequency. Slot Width values between 11.8 and $49.2 \mathrm{mils}$ result in reactances less than $-\mathrm{j} 29.0 \Omega$ at the operating frequency (except for Slot Width equal to $78.7 \mathrm{mils}$ ) and, therefore, larger $\mathrm{VSWR}_{\text {in }}$ values. This indicates that impedance tuning may require slot dimension adjustments.

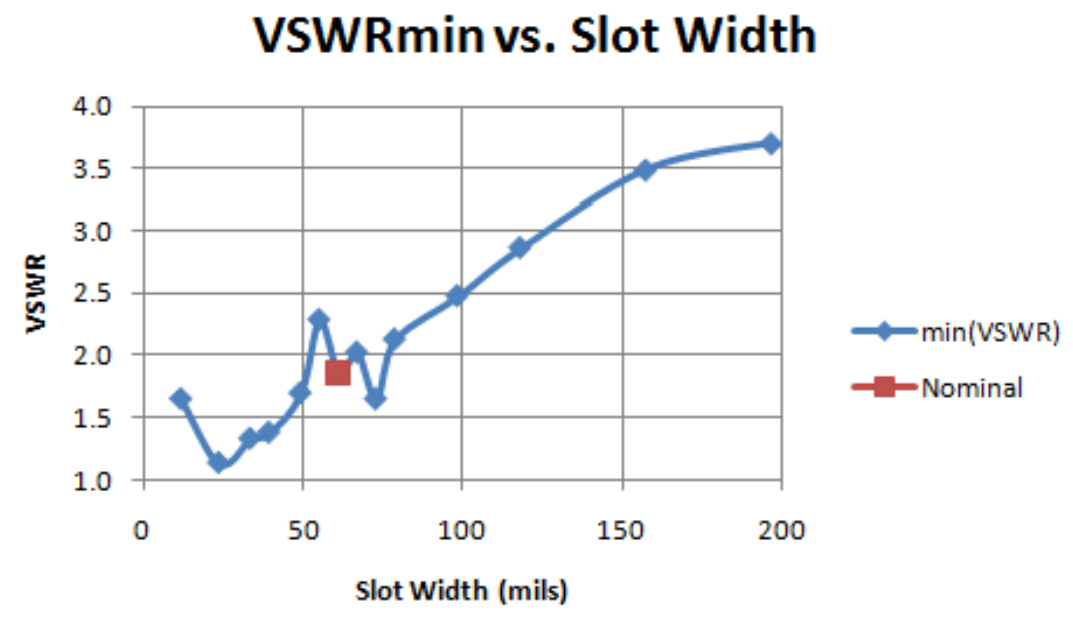

Figure A-43: VSWRin vs. Slot Width 
Figure A-44 that Slot Widths between 23.6 and 49.2mils result in percent bandwidths greater than $1.0 \%$. Figures A-43 and A-44 indicate that Slot Width fabrication errors of \pm 6.0 mils can cause $\mathrm{VSWR}_{\text {in }}$ to be greater than 2 over all frequencies.

\section{Percent Bandwidth vs. Slot Width}

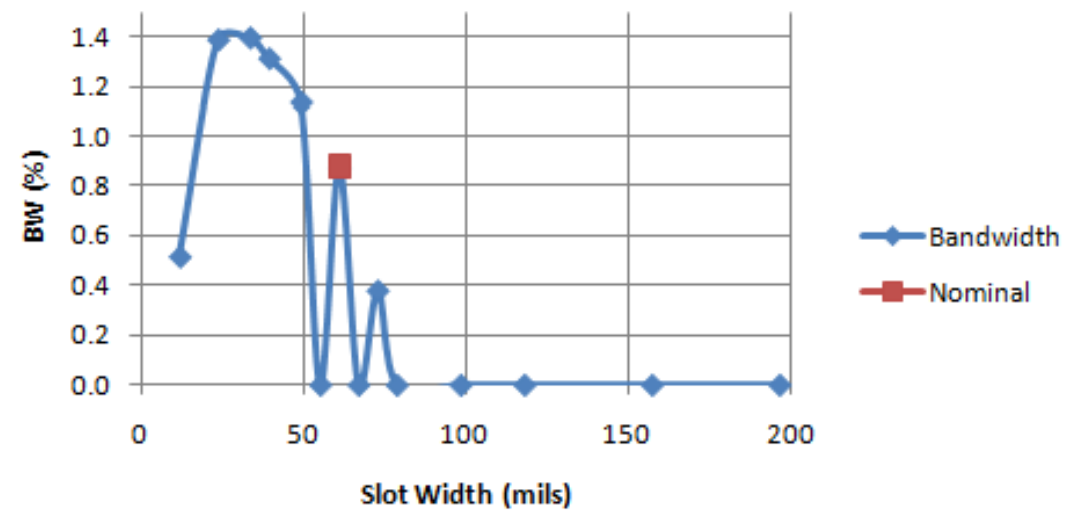

Figure A-44: Percent bandwidth vs. Slot Width

Figure A-45 shows that polarization ratio varies between $31.68 \mathrm{~dB}$ and $58.92 \mathrm{~dB}$ for Slot Widths between 11.8 and 157.5 mils. Figure A-46 shows that Slot Width values in this range yield total broadside gains between $5.76 \mathrm{~dB}$ and $6.34 \mathrm{~dB}$. Due to polarization ratios greater than $25.00 \mathrm{~dB}$, total gain is approximately equal to co-pol gain. This shows that varying Slot Width causes cross-pol gain variations up to $\pm 17.00 \mathrm{~dB}$. Figures A-39, A-40, A-41, A-45, and A-46 show that changing slot dimensions affects cross-pol coupling more than co-pol coupling through the ground plane slot aperture. 


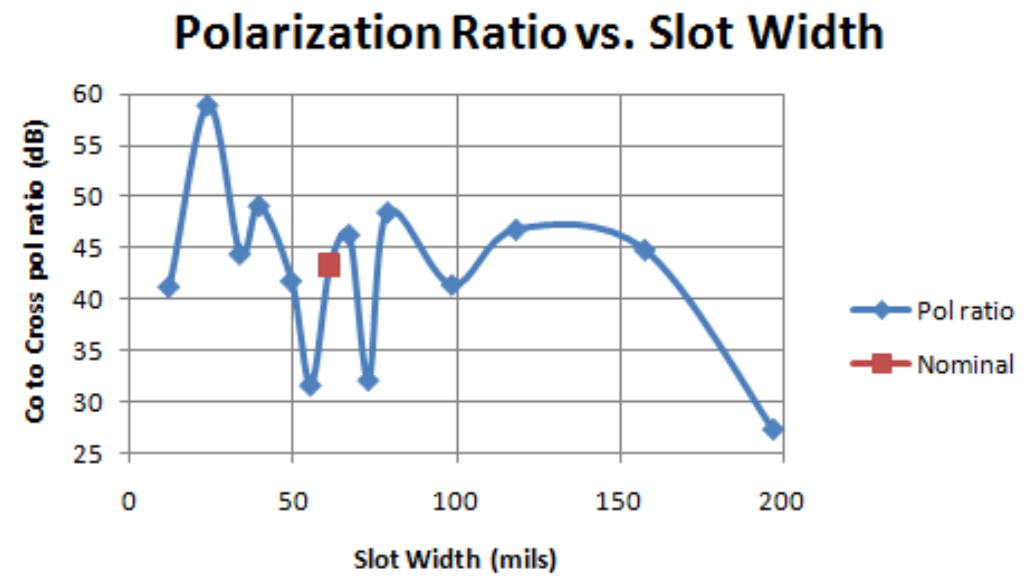

Figure A-45: Polarization ratio vs. Slot Width

Figure A-46 shows that total broadside gain is between $5.76 \mathrm{~dB}$ and $6.34 \mathrm{~dB}$ if operating frequency is less than $2.50 \mathrm{GHz}$ (see Figure A-42). Total gain increases to $8.94 \mathrm{~dB}$ when the operating frequency increases to $5.76 \mathrm{GHz}$ because the cross-pol gain increases to $-18.61 \mathrm{~dB}$ (nominal value $-37.28 \mathrm{~dB}$ ). Figure A-46 indicates that Slot Length can be varied from $0.003 \lambda$ to $0.042 \lambda$ and affect total gain by less than $\pm 0.34 \mathrm{~dB}$.
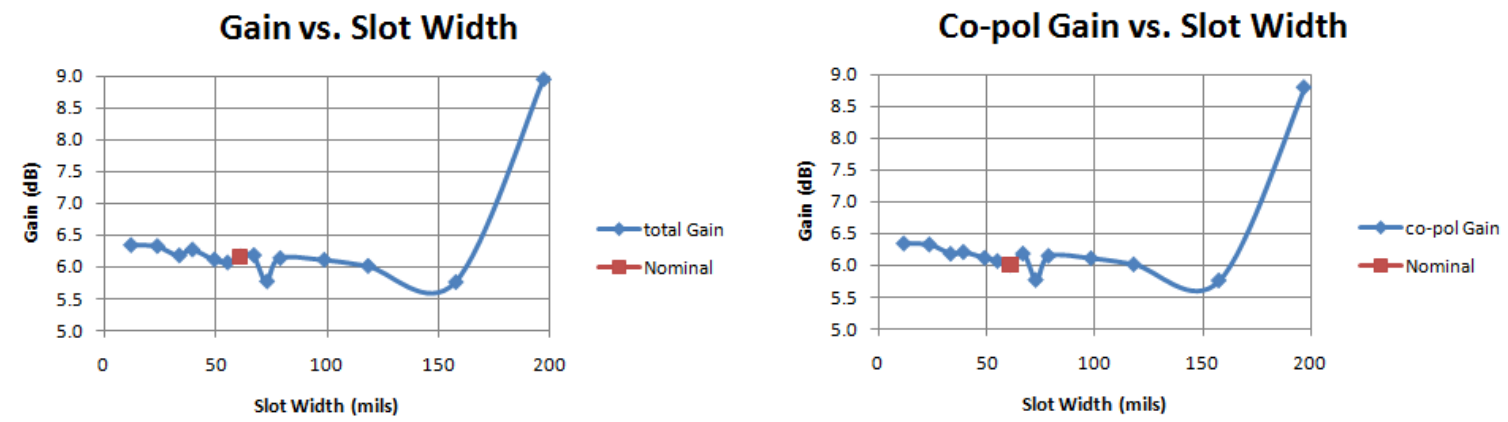

Figure A-46: Total gain and co-pol gain vs. Slot Length

Slot Width and Slot Length are simultaneously varied from $30 \%$ to $170 \%$ of their nominal values of 61.0 and 551.2mils, respectively. Figure A-47 shows that increasing slot dimensions up to $170 \%$ of their nominal sizes changes the operating frequency by 
less than $17.0 \%$ of nominal value. Scaling down the slot dimensions excites higher order modes and increases the operating frequency up to $297.0 \%$ of nominal value.

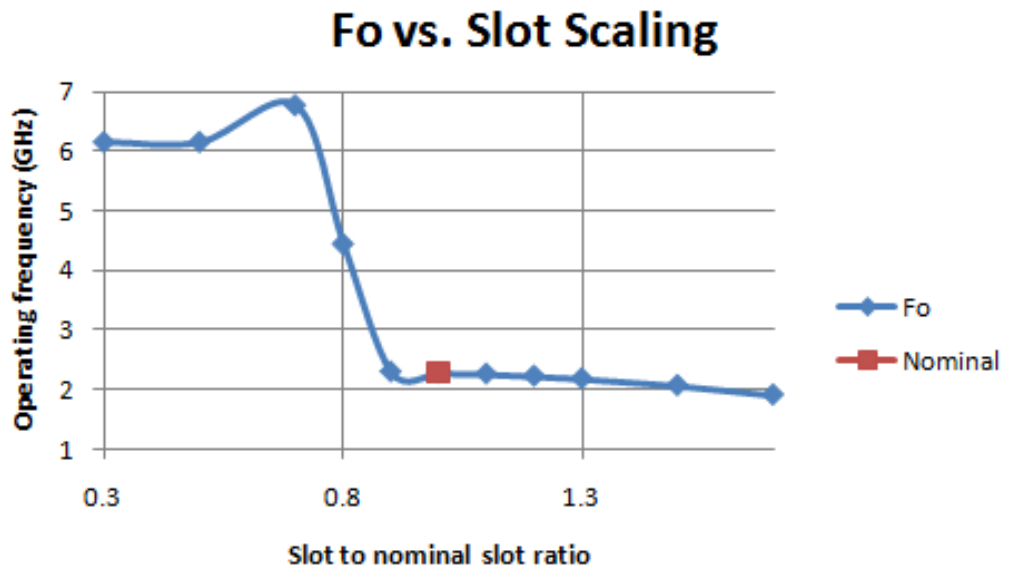

Figure A-47: Operating frequency vs. slot scaling

Figure A-48 indicates that scaling the slot dimensions by $\pm 10 \%$ of nominal values decreases $V_{S W R}$. The minimum $\operatorname{VSWR}_{\text {in }}(1.044)$ is obtained by scaling the slot dimensions to $70 \%$ of their nominal values; however, the operating frequency nearly triples (see Figure A-47).

VSWRmin vs. Slot Scaling

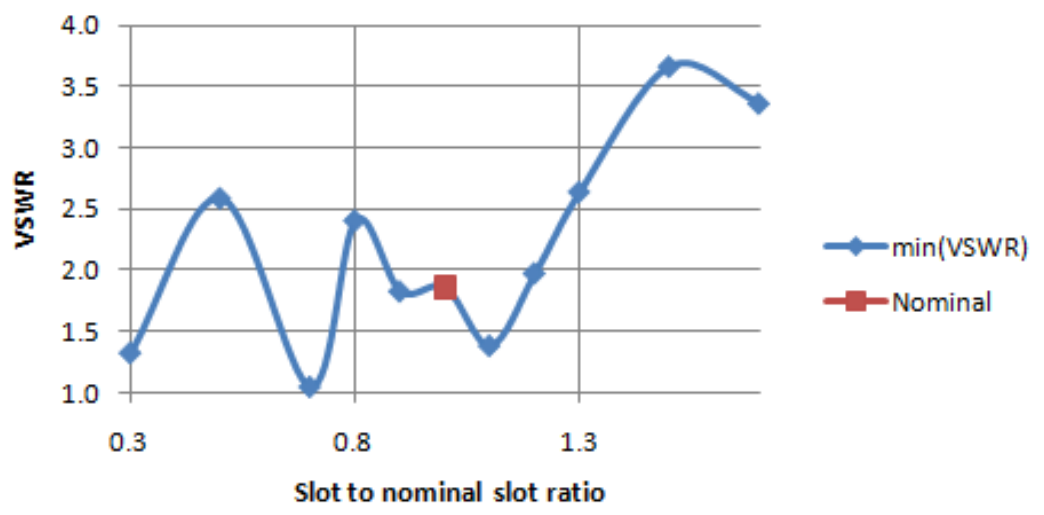

Figure A-48: VSWRin vs. slot scaling 
Figure A-49 shows that increasing nominal slot dimensions by $10 \%$ increases percent bandwidth by $14.2 \%$. Scaling slot dimensions to $70 \%$ of nominal values increases percent bandwidth to $63.9 \%$.

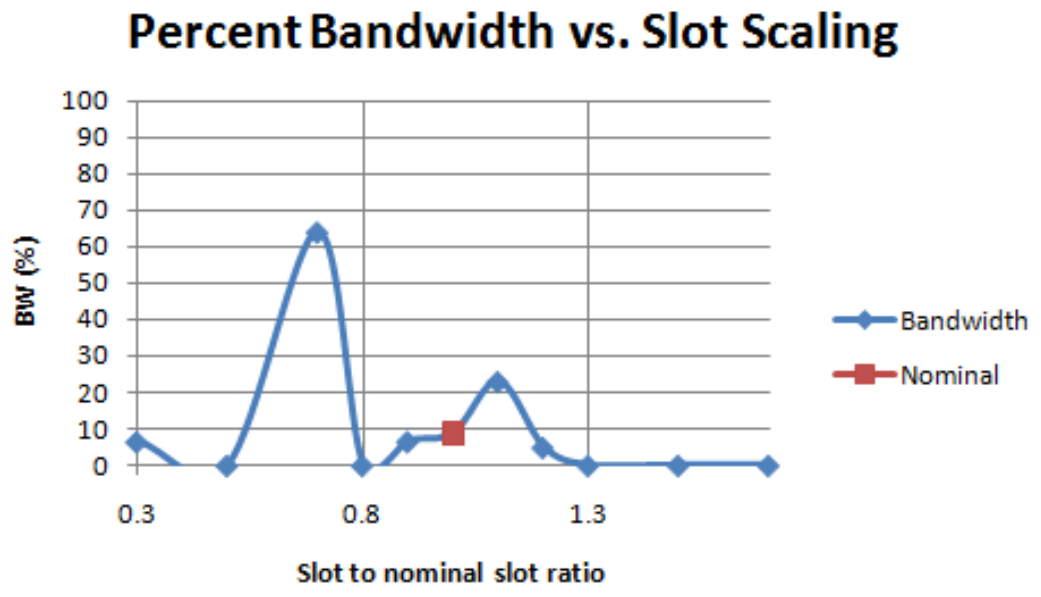

Figure A-49: Bandwidth vs. slot scaling

Figure A-50 shows that decreasing slot dimensions by $20 \%$ or more results in polarization ratios less than $14.0 \mathrm{~dB}$. Increasing slot dimensions by $10 \%$ causes a polarization ratio increase to $56.8 \mathrm{~dB}$.

Polarization Ratio vs. Slot Scaling

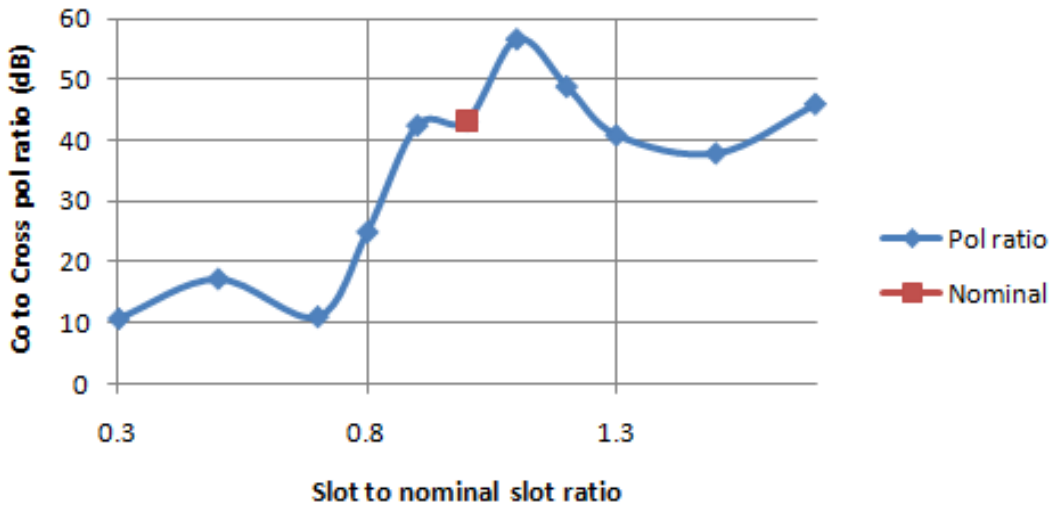

Figure A-50: Polarization ratio vs. slot scaling 
Figure A-51 shows that the three largest broadside gain values correspond to the three smallest slot sizes due to increased cross-pol gain (see Figure A-50).
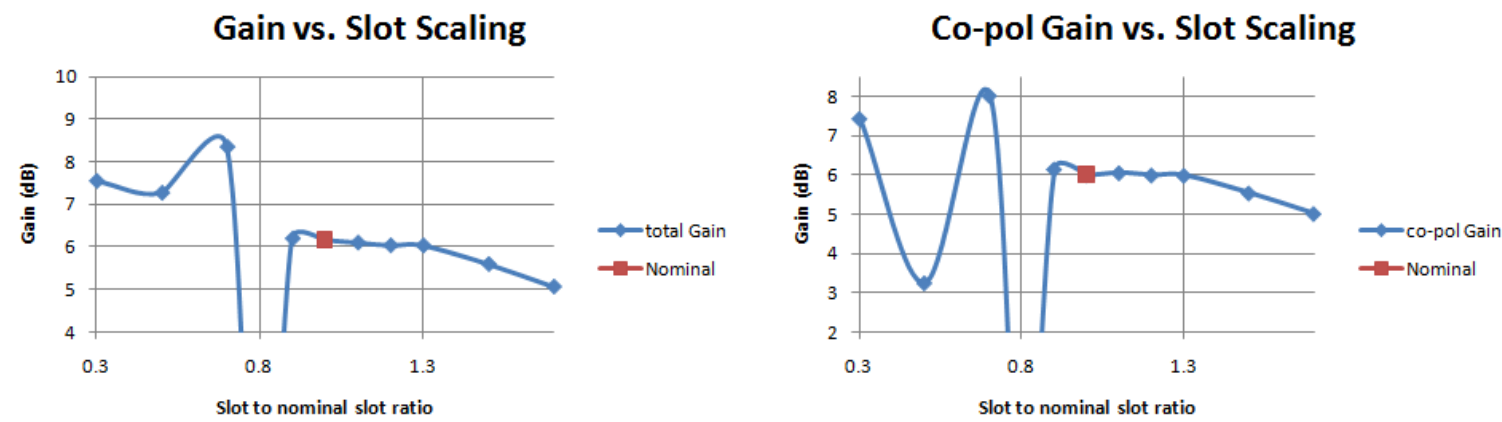

Figure A-51: Total gain and co-pol gain vs. slot scaling

Slot Length Offset is varied from $0.000 \lambda$ to $0.074 \lambda$ (wavelength in dielectric at $2.3 \mathrm{GHz}$ ) equivalent to 0.0 to $275.6 \mathrm{mils}$ (275.6mils is half the nominal Slot Length). Slot Length Offset is varied in one direction (i.e. 0 to $0.074 \lambda$, not $\pm 0.074 \lambda$ ) because the antenna is symmetric about the $\mathrm{x}$-axis. Slot Length Offset is nominally 0.

Figure A-52 shows that the operating frequency changes less than $\pm 7.68 \%$ of nominal $\mathrm{f}_{\mathrm{o}}$ for all Slot Length Offsets.

\section{Fo vs. Slot Length Offset}

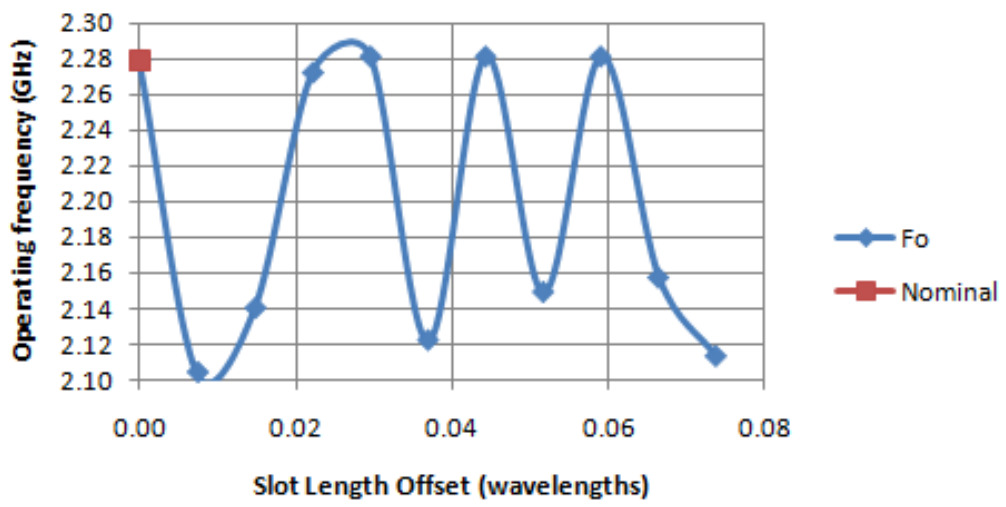

Figure A-52: Operating frequency vs. Slot Length Offset 
Figure A-53 indicates that $\mathrm{VSWR}_{\text {in }}$ variation is inversely proportional to operating frequency. All Slot Length Offsets exhibiting decreased operating frequency

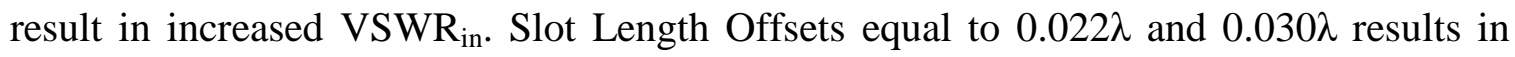
$\mathrm{VSWR}_{\text {in }}$ equal to 1.335 and 1.413.

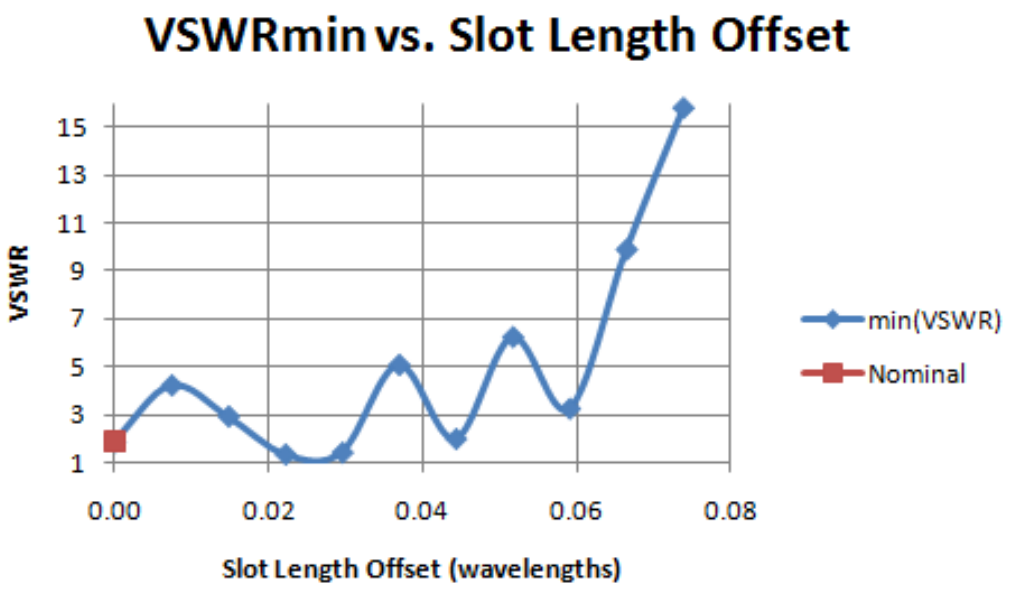

Figure A-53: VSWRin vs. Slot Length Offset

Figure A-54 shows that Slot Length Offset equal to $0.022 \lambda$ and $0.030 \lambda$ results in percent bandwidths greater than $1.4 \%$.

\section{Percent Bandwidth vs. Slot Length Offset}

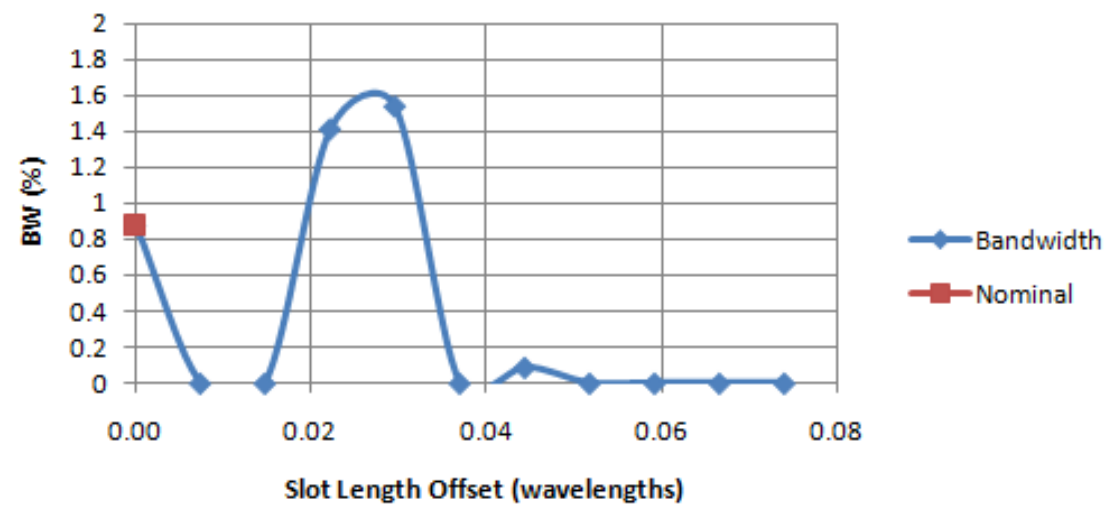

Figure A-54: Bandwidth vs. Slot Length Offset 
Figure A-55 shows that polarization ratio decreases by $10.89 \mathrm{~dB}$ for Slot Length Offset equal to $0.007 \lambda$ (27.6mils). This indicates that fabrication errors causing an off-center ground plane slot over the feed line and under the patch decrease polarization ratio. However, increasing Slot Length Offset to $0.015 \lambda$ increases polarization ratio to 50.22dB. Figure A-53 shows that $\mathrm{VSWR}_{\text {in }}$ is 2.922 for a Slot Length Offset equal to $0.015 \lambda$.

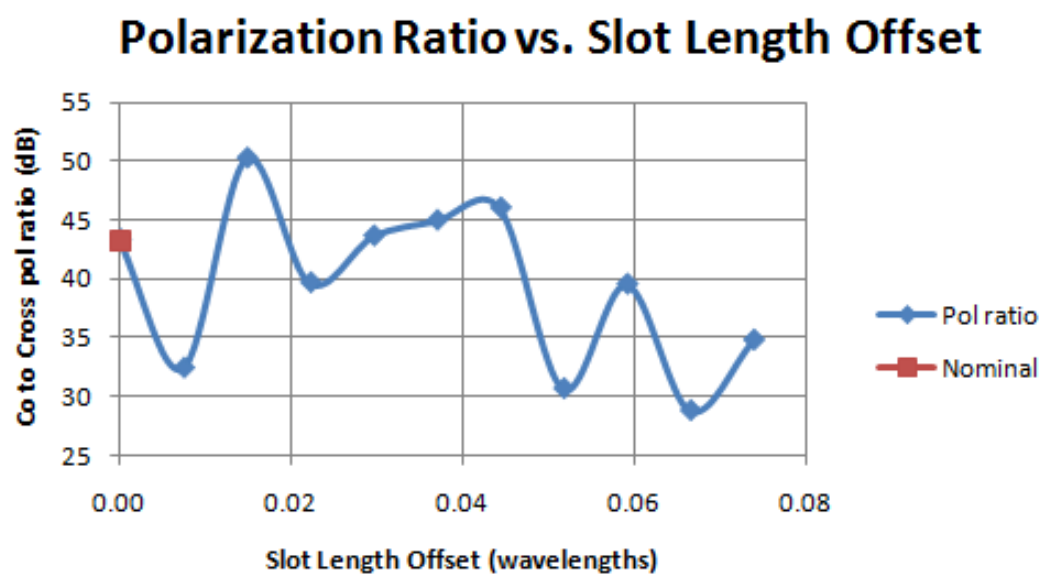

Figure A-55: Polarization ratio vs. Slot Length Offset

Figures A-52 and A-56 demonstrate that varying Slot Length Offset has similar effects on gain and operating frequency. All Slot Length Offsets resulting in operating frequencies less than $2.26 \mathrm{GHz}$ also yield gains less than $5.9 \mathrm{~dB}$. All Slot Length Offsets resulting in operating frequencies greater than $2.26 \mathrm{GHz}$ also yield gains greater than 5.9dB. Figures A-53 and A-56 indicate Slot Length Offsets that produce local gain maxima (with respect to Slot Length Offset) also produce local VSWR $\mathrm{in}_{\text {in }}$ minima. 


\section{Gain vs. Slot Length Offset}

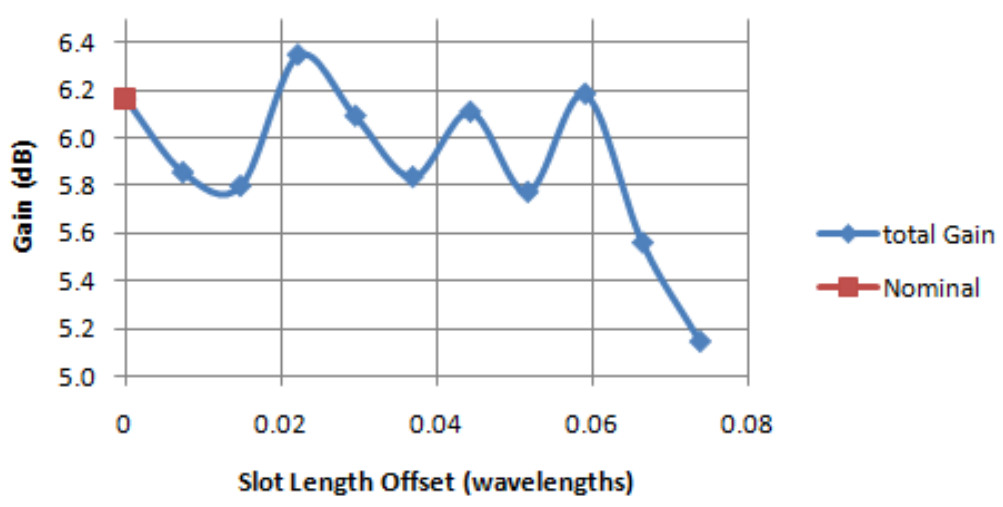

Figure A-56: Gain vs. Slot Length Offset

Slot Width Offset is nominally 0 and varied between \pm 653 .0mils. Figure A-57 shows that for ten of twelve values, the operating frequency increases as the Slot Width Offset magnitude increases. The center of the ground plane slot is nominally displaced 787.4 mils $(0.211 \lambda$ in dielectric at $2.3 \mathrm{GHz}$, see Chapter 1$)$ away from the radiating patch edges in the $\mathrm{x}$ direction. Figure A-57 shows that shifting the ground plane slot by approximately $\pm 394 \mathrm{mils}(0.1055 \lambda$ in dielectric at $2.3 \mathrm{GHz})$ in the $\mathrm{x}$ direction doubles the operating frequency. This occurs because the distance from the ground plane slot center to one radiating edge at twice the nominal frequency is the same electrical size as the patch length at the nominal frequency for Slot Width Offset equal to 0. Also, when Slot Width Offset is approximately \pm 700 mils, the operating frequency nearly doubles again for the same reason. 


\section{Fo vs. Slot Width Offset}

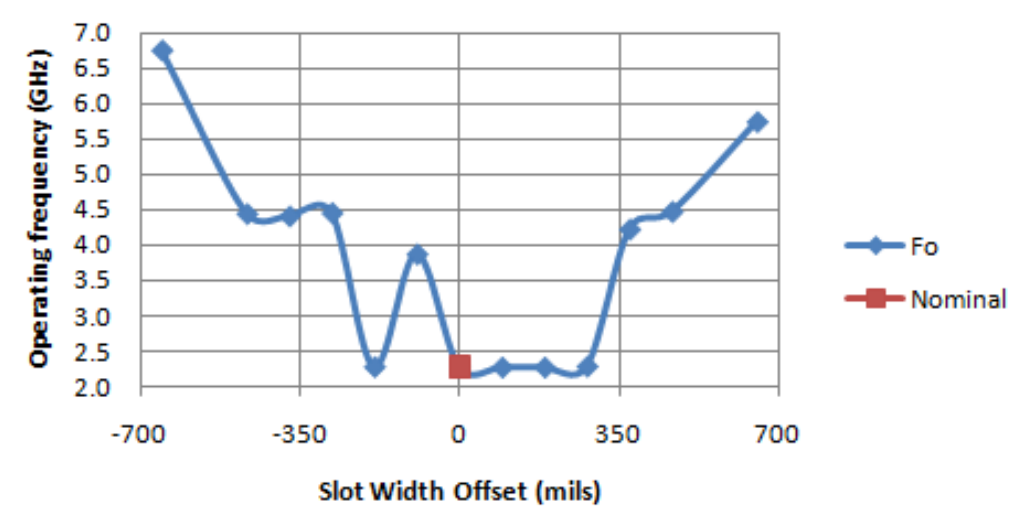

Figure A-57: Operating frequency vs. Slot Width Offset

Figure A-58 indicates that for all but two Slot Width Offset values, VSWR in is less than the nominal VSWR ${ }_{\text {in. }}$. Slot Width Offset equal to -93.3mils yields $V_{S W R}$ in equal to 4.676. This implies that moving the ground plane slot away from the open terminated end of the feed line causes a mismatch at the feed.

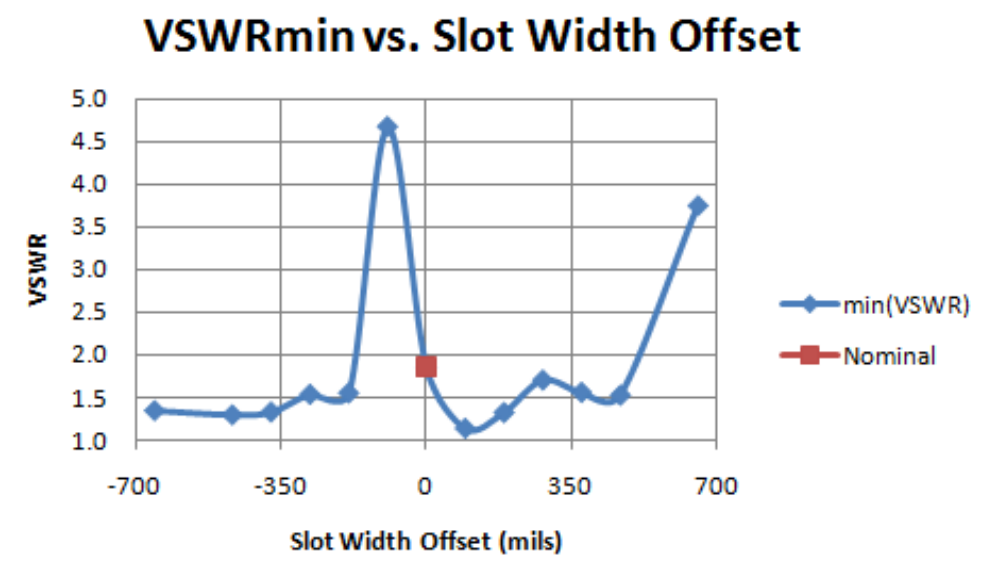

Figure A-58: VSWRin vs. Slot Width Offset

Figure A-59 shows that for ten of the twelve non-zero Slot Width Offset values, the percent bandwidth increases relative to the nominal value. 


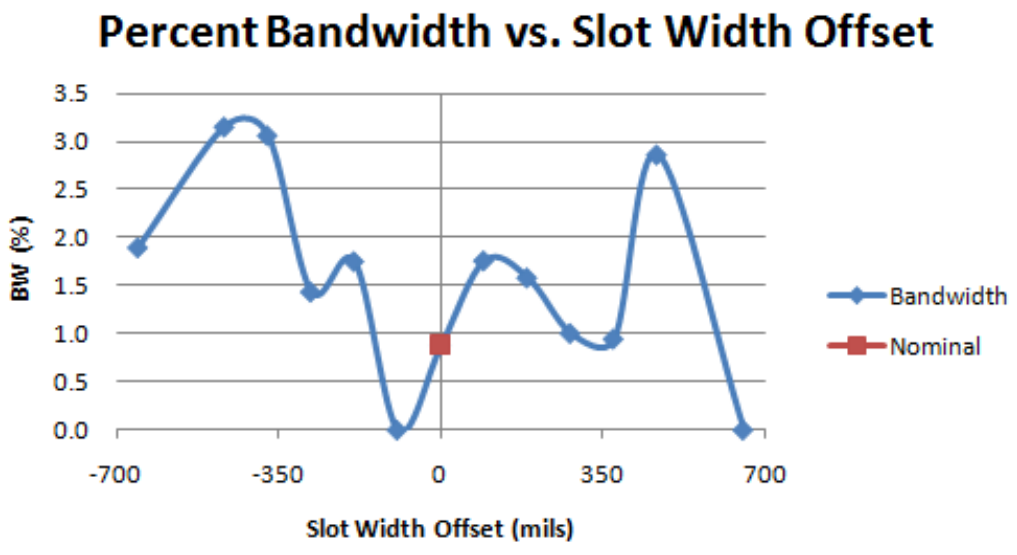

Figure A-59: Bandwidth vs. Slot Width Offset

Figure A-60 shows that ,although there are ten Slot Width Offset values that improve $\mathrm{VSWR}_{\text {in }}$ and percent bandwidth, only a 279.9mil Slot Width Offset also improves polarization ratio.

\section{Polarization Ratio vs. Slot Width Offset}

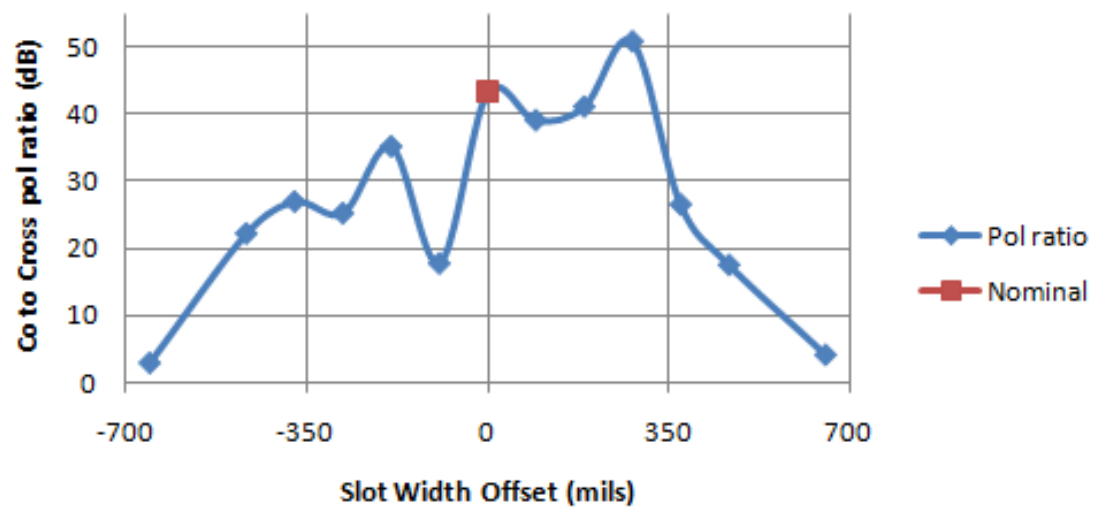

Figure A-60: Polarization ratio vs. Slot Width Offset

Figure A-61 shows that Slot Width Offsets that yield broadside gain values greater than $7.0 \mathrm{~dB}$ result in polarization ratios less than $30.0 \mathrm{~dB}$. This indicates that varying Slot Width Offset does not increase both gain and polarization ratio significantly. 

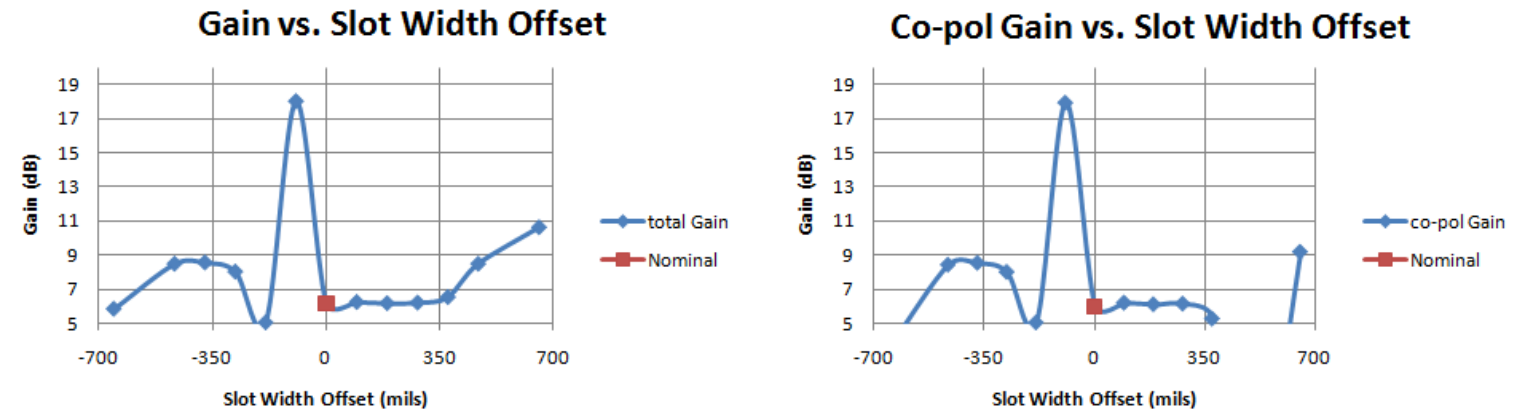

Figure A-61: Gain vs. Slot Width Offset

\section{Patch}

The patch dimensions and location are varied in HFSS. Figure A-62 shows the four patch variables: Patch Width, Patch Length, Patch Width Offset, and Patch Length Offset. The offsets are measured from the coordinate system origin (see Figure 2-5) to the patch center.

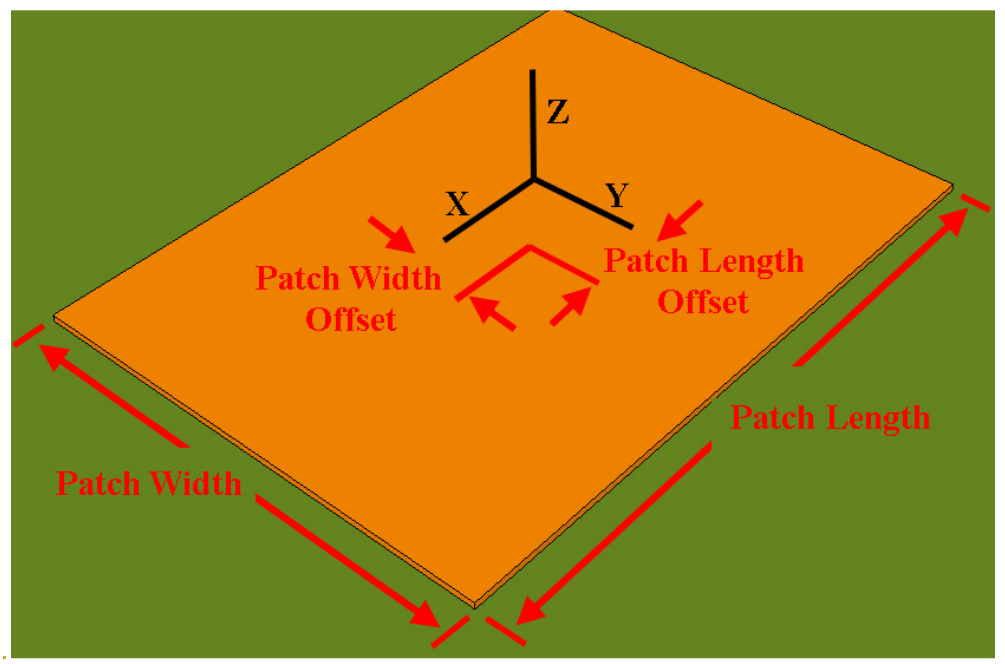

Figure A-62: Patch variables 
Patch Width is nominally $1,181.1$ mils equal to $0.317 \lambda$ (wavelength in microstrip line found using ADS2006A's Linecalc at $2.3 \mathrm{GHz}$ for $50 \Omega$ line). Figure A-63 shows that resonant frequency is independent of Patch Width.

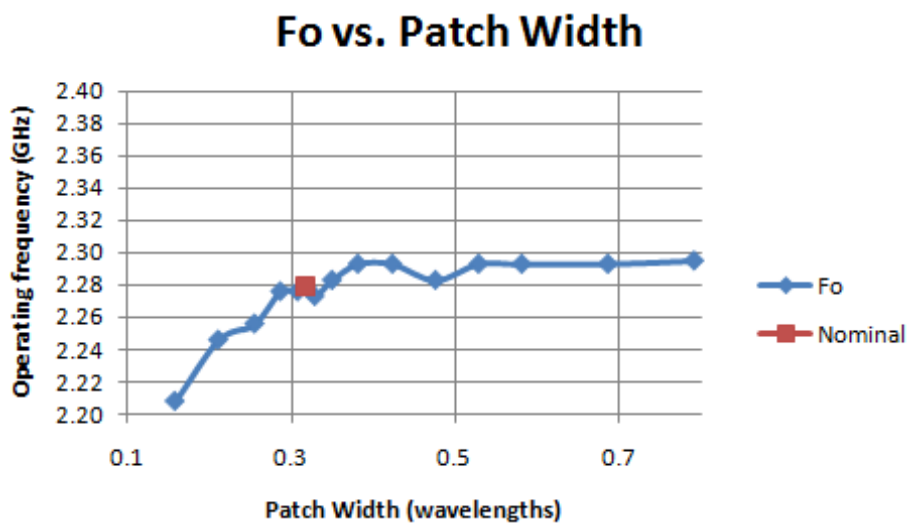

Figure A-63: Operating frequency vs. Patch Width

Figure A-64 shows the input impedance at resonance vs. Patch Width. Increasing Patch Width increases reactance and decreases resistance. The nominal antenna design has an input impedance of $75.5-\mathrm{j} 29.0 \Omega$. Patch Width equal to $0.475 \lambda$ results in an input impedance of $51.8+\mathrm{j} 0.93 \Omega$. This indicates that Patch Width can be used to improve input matching if the input impedance has both a real component greater than $50 \Omega$ and negative reactance component or both a real component less than $50 \Omega$ and positive reactance component.
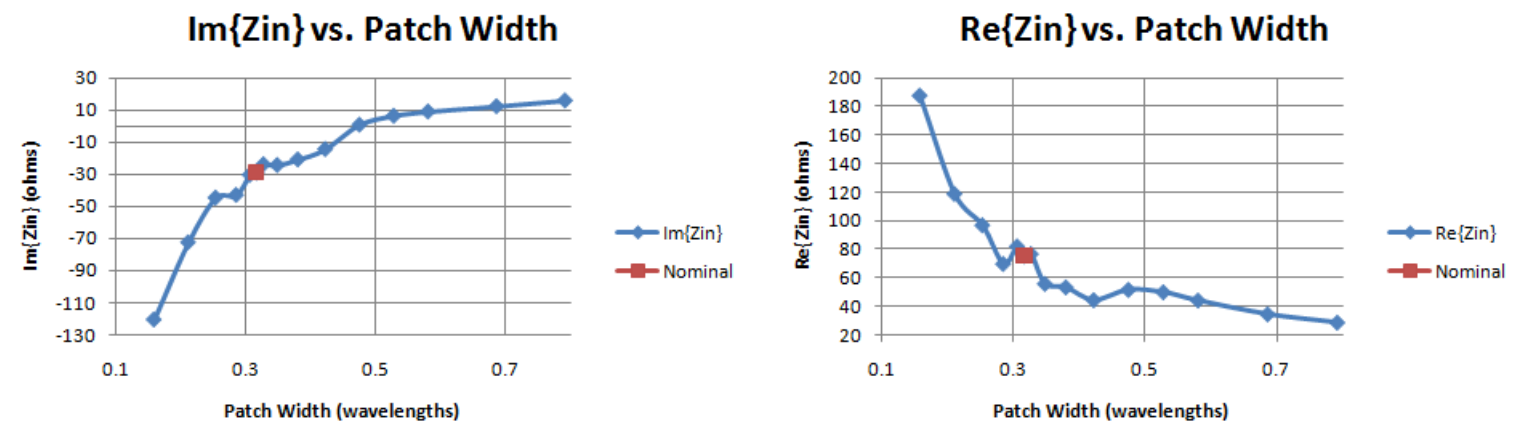

Figure A-64: Zin vs. Patch Width 
Figure A-65 shows that increasing Patch Width results in improved input impedance matching, see Figure A-64. Patch Width equal to $0.475 \lambda$ yields the smallest $\operatorname{VSWR}_{\text {in }}(1.041)$.

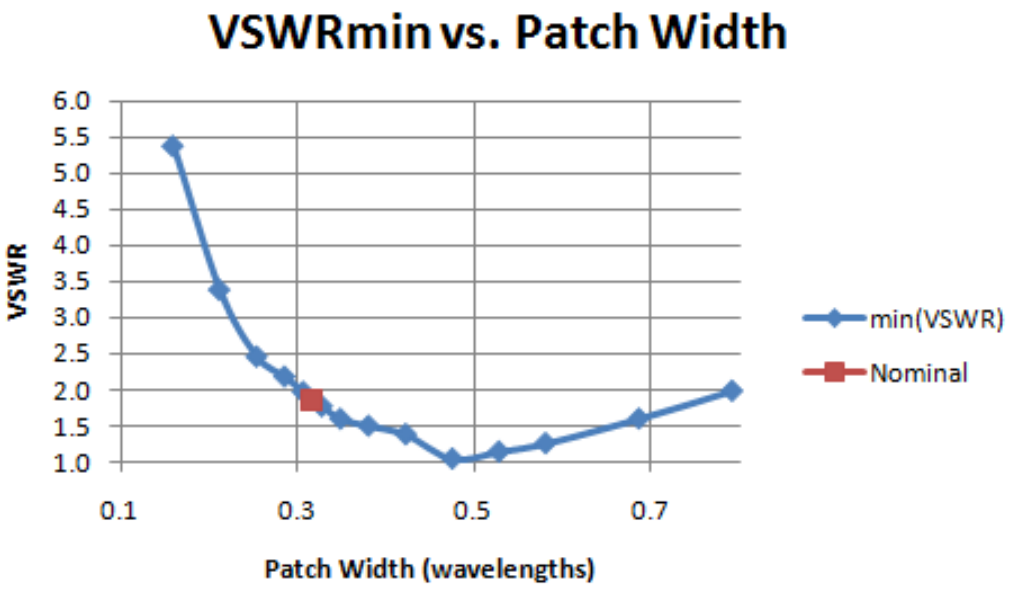

Figure A-65: VSWRin vs. Patch Width

Figure A-66 shows that Patch Width values that decrease VSWR $_{\text {in }}$ also increase percent bandwidth, due to improved input matching (see Figure A-64). This yields a wider frequency range over which $\mathrm{VSWR}_{\text {in }}$ is less than 2. Adjusting Patch Width to improve input matching will also improve bandwidth.

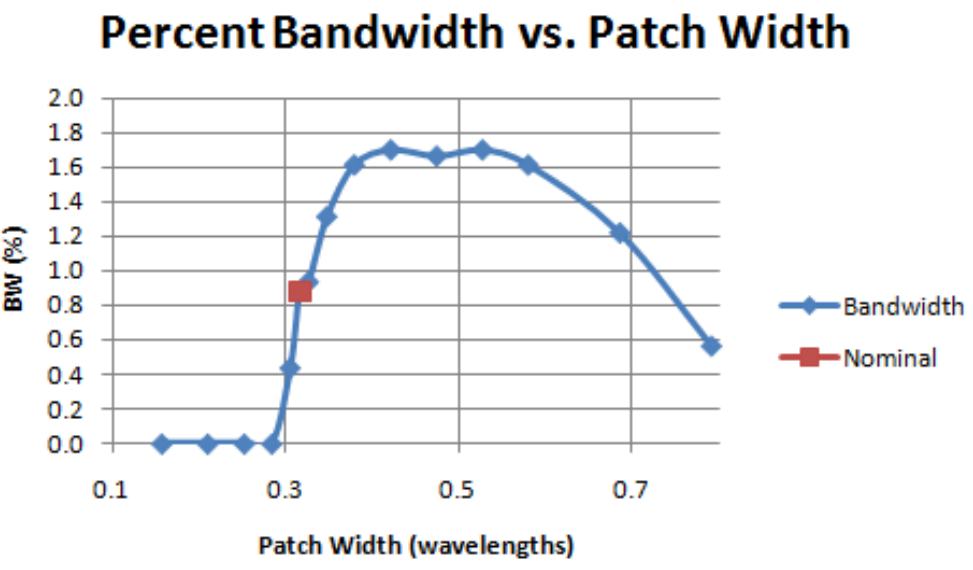

Figure A-66: Percent Bandwidth vs. Patch Width 
Figure A-67 shows that only five Patch Width values that improve bandwidth also improve polarization ratio. A Patch Width equal to $0.527 \lambda$ results in a polarization ratio $18.53 \mathrm{~dB}$ greater than nominal, the second largest bandwidth, and the second smallest VSWR $_{\text {in }}$ (see Figures A-65 and A-66).

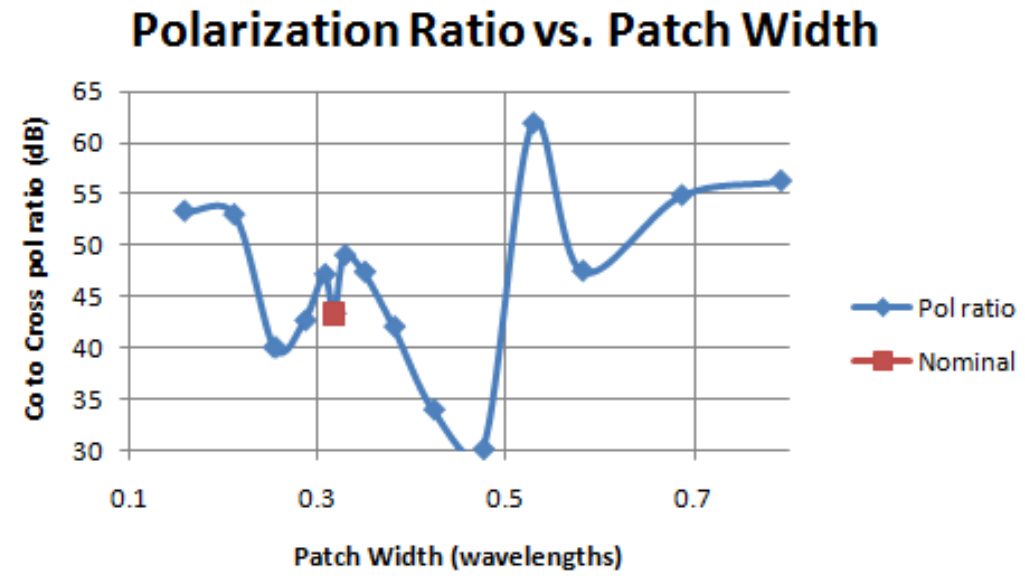

Figure A-67: Polarization ratio vs. Patch Width

Figure A-68 shows that increasing Patch Width increases gain, but may decrease polarization ratio. A Patch Width of $0.527 \lambda$ increases gain by $0.606 \mathrm{~dB}$ and results in an optimum combination of input matching, bandwidth, and polarization ratio.

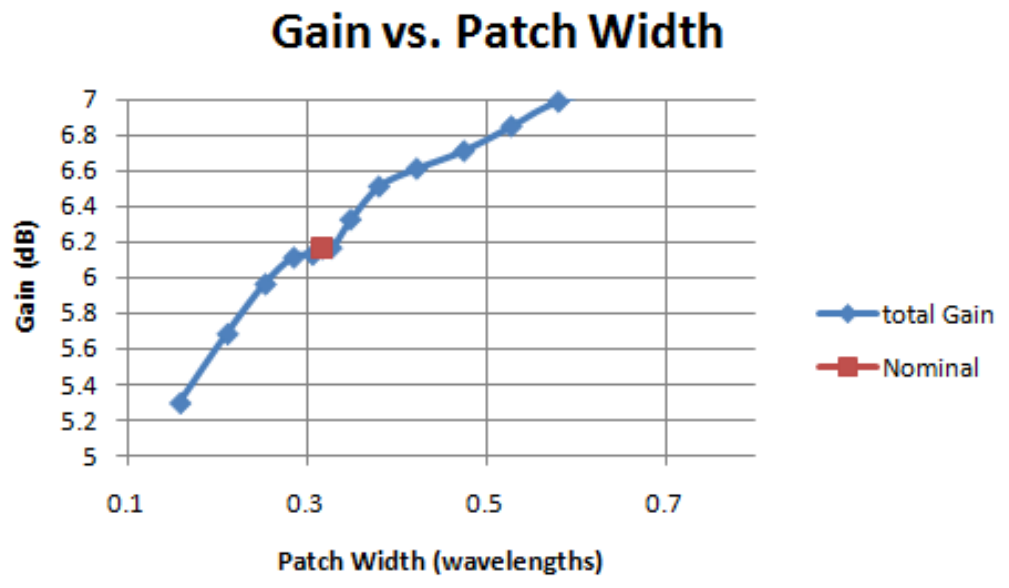

Figure A-68: Gain vs. Patch Width 
Patch Length is nominally $1,574.8$ mils equal to $0.422 \lambda$ (wavelength in microstrip line found using ADS2006A's Linecalc at 2.3GHz). Figure A-69 shows that increasing Patch Length decreases operating frequency. Resonant frequency approximates a constant slope function of Patch Length between 780 and 2,500mils. The average slope in this range is $-1.295 \mathrm{kHz} / \mathrm{inch}$. Adjusting Patch Length tunes the operating frequency.
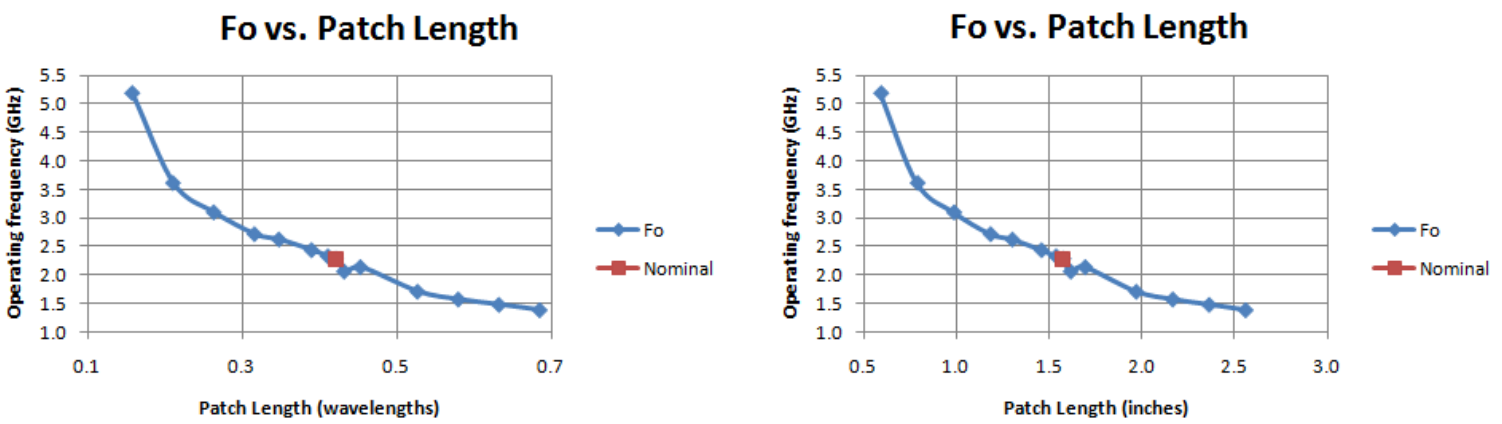

Figure A-69: Operating frequency vs. Patch Length

Figure A-70 shows that only 4 of 13 Patch Length adjustments result in VSWR in less than nominal. This indicates that varying Patch Length to obtain the desired operating frequency may cause a mismatch at the input. However, the input impedance can be adjusted by varying Slot Length and/or Patch Width.

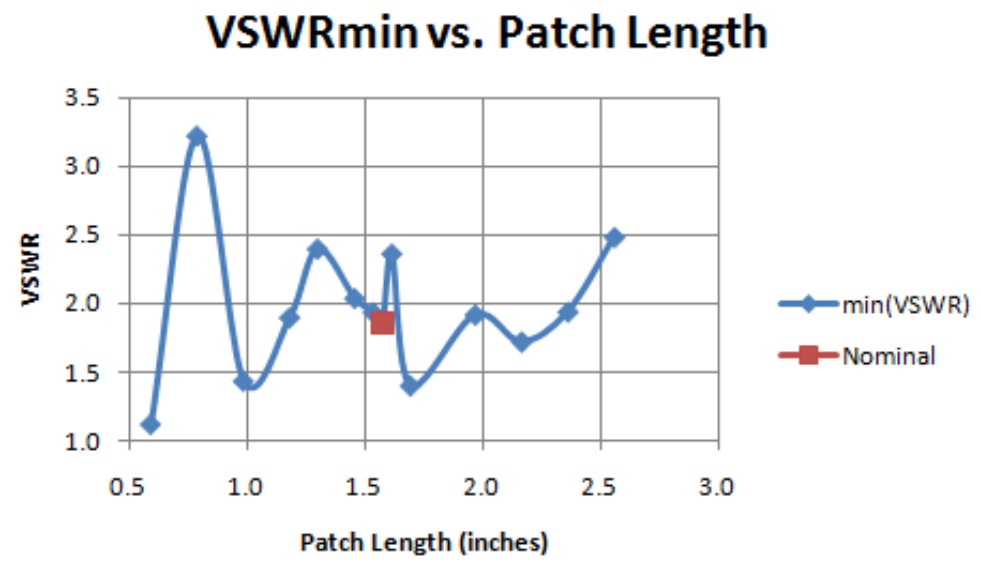

Figure A-70: VSWRin vs. Patch Length 
Figure A-71 shows an approximately inverse response of Figure A-70 because bandwidth is defined in terms of VSWR $\mathrm{Vin}_{\text {. }}$. All Patch Length values that decrease VSWR $\mathrm{in}_{\text {in }}$ also increase percent bandwidth.

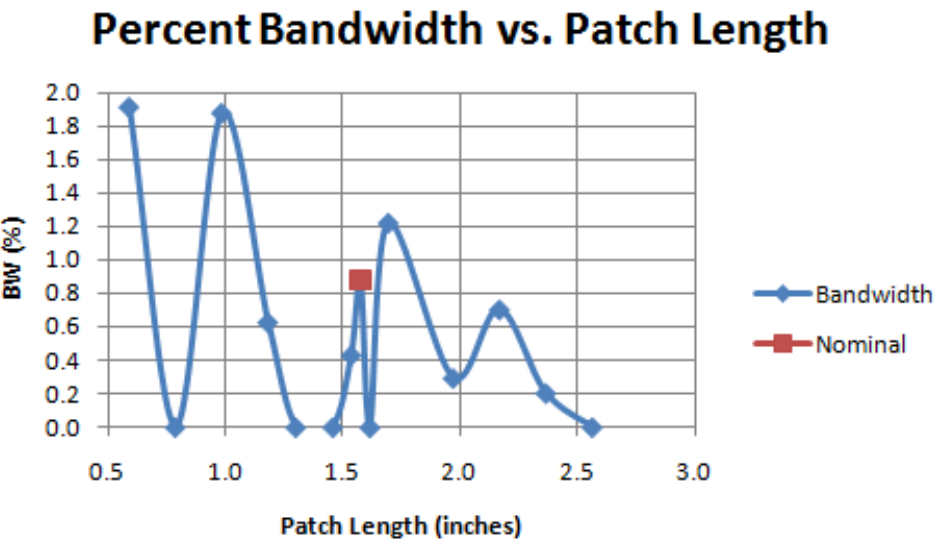

Figure A-71: Percent Bandwidth vs. Patch Length

Figure A-72 shows that only one Patch Length value yields a polarization ratio at least $1.0 \mathrm{~dB}$ greater than nominal. Adjusting Patch Length to tune the operating frequency will likely decrease the polarization ratio.

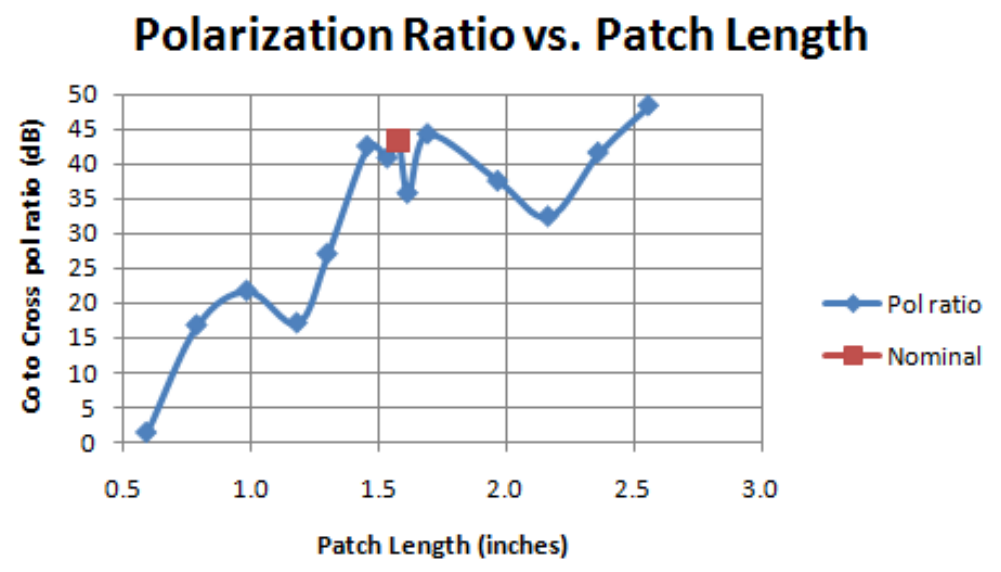

Figure A-72: Polarization ratio vs. Patch Length 
For most adjustments, increasing Patch Length decreases gain due to the decrease in resonant frequency (See Figure A-69). As the resonant frequency decreases, the upper substrate becomes electrically thin (antenna substrate height is 59 mils), which produces less radiation from fringing fields. Guided waves between the patch and ground plane dominate over radiating fields in electrically thin substrates [2].

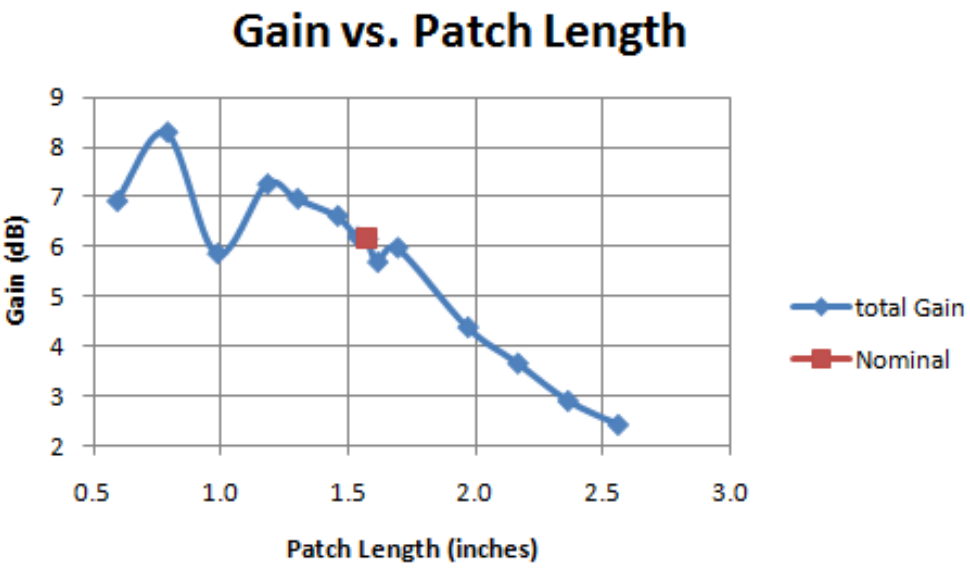

Figure A-73: Gain vs. Patch Length

Patch Width Offset varies between 0 (nominal) and $0.158 \lambda$ (half of nominal Patch Width). Figure A-74 shows that adjusting Patch Width Offset changes the resonant frequency by less than $\pm 7.3 \%$.

\section{Fo vs. Patch Width Offset}

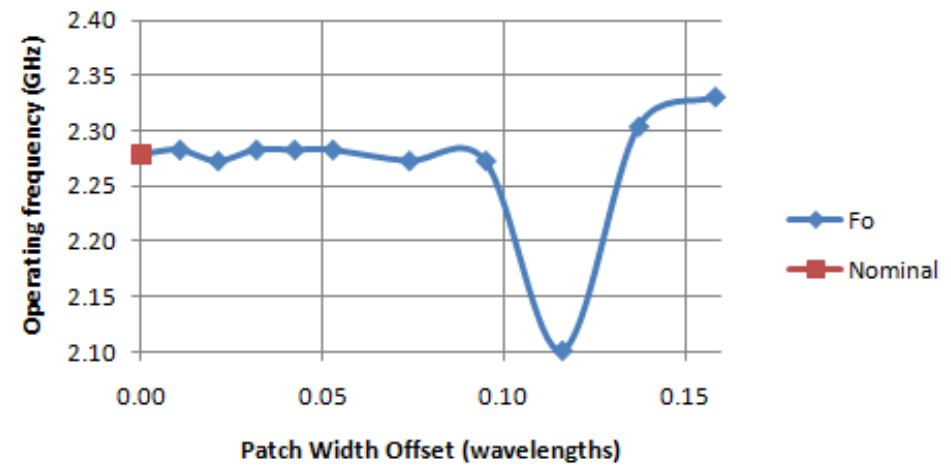

Figure A-74: Operating frequency vs. Patch Width Offset 
Figure A-75 shows that Patch Width Offset values less than $0.085 \lambda$ or greater than $0.130 \lambda$ results in $\mathrm{VSWR}_{\text {in }}$ less than 2.

VSWRmin vs. Patch Width Offset

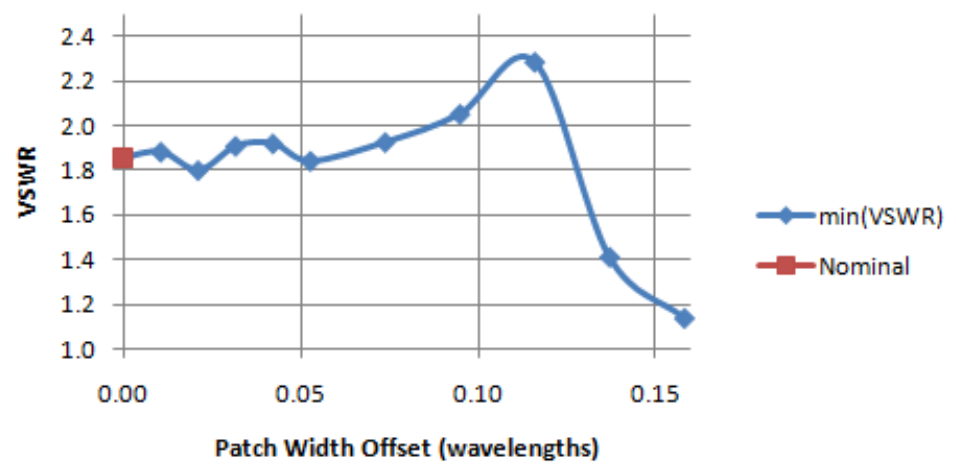

Figure A-75: VSWRin vs. Patch Width Offset

Figure A-76 is approximately an inverse response of Figure A-75 because bandwidth is defined in terms of VSWR $\mathrm{V}_{\text {in }}$.

\section{Percent Bandwidth vs. Patch Width Offset}

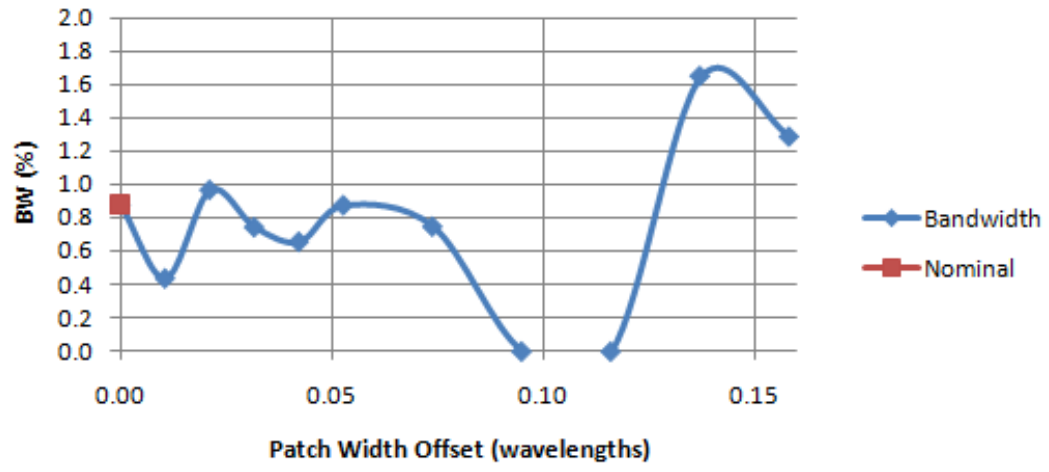

Figure A-76: Percent Bandwidth vs. Patch Width Offset

Figure A-77 indicates that fabrication errors resulting in Patch Width Offset less than $0.010 \lambda$ (equivalent to $37.3 \mathrm{mils}$ ) will increase polarization ratio. Figure A-78 
indicates that small fabrication errors in this range will not significantly affect broadside gain.

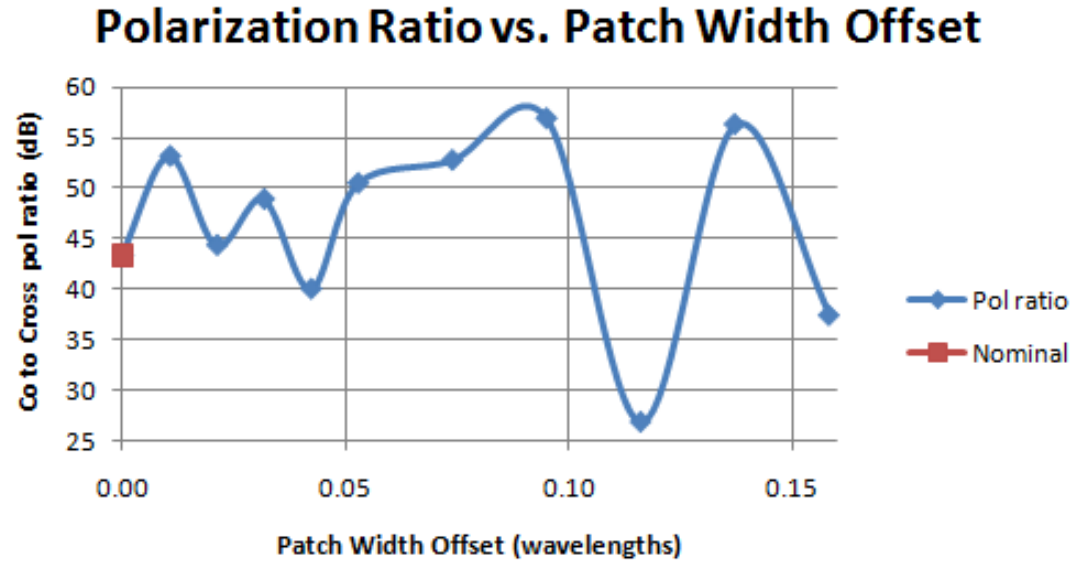

Figure A-77: Polarization ratio vs. Patch Width Offset

Figure A-78 shows that broadside gain is within $\pm 0.547 \mathrm{~dB}$ of nominal for all Patch Width Offsets.

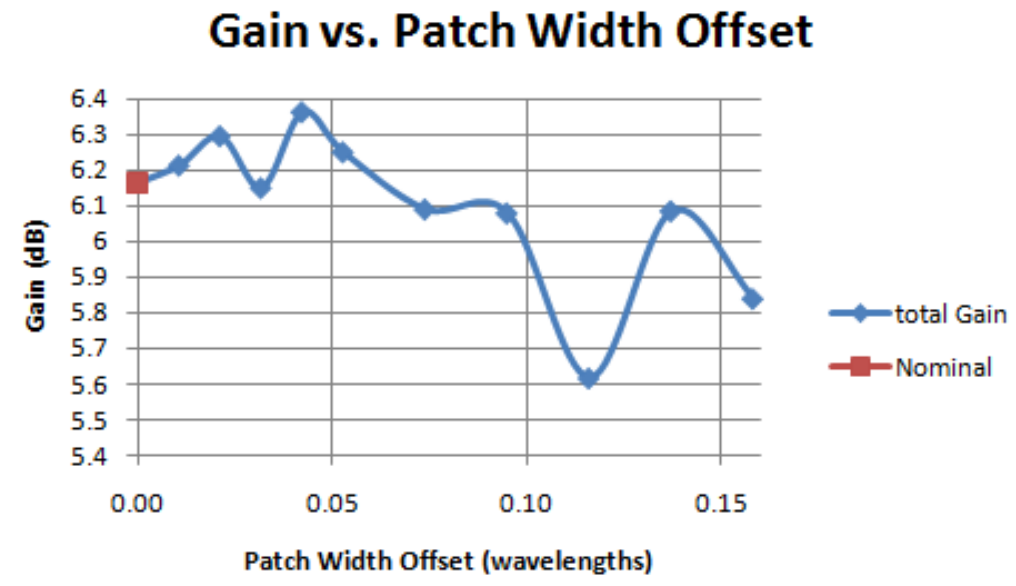

Figure A-78: Gain vs. Patch Width Offset

Patch Length Offset is varied between 0 (nominal) and 590.6mils. Figure A-79 shows that changing Patch Length Offset by more than \pm 390.0 mils excites higher order modes. Nominally, the patch extends 787.4 mils $(0.211 \lambda$ at $2.3 \mathrm{GHz})$ away from the 
ground slot in the $\pm x$-directions (see Figures 2-5 and 3-1). A higher order mode is excited for a Patch Length Offset values of approximately 450.0mils (or -450.0mils) because the patch extends $0.211 \lambda$ away from the ground slot in positive $\mathrm{x}$-direction (or negative $\mathrm{x}$-direction) at approximately double the nominal frequency. The operating frequency is determined by the smallest VSWR $_{\text {in }}$. The operating frequency peak at Patch Length Offset equal to -118.1 mils is due to $\mathrm{VSWR}_{\text {in }}$ greater than 2.8 at all frequencies (see Figure A-80).

Fo vs. Patch Length Offset

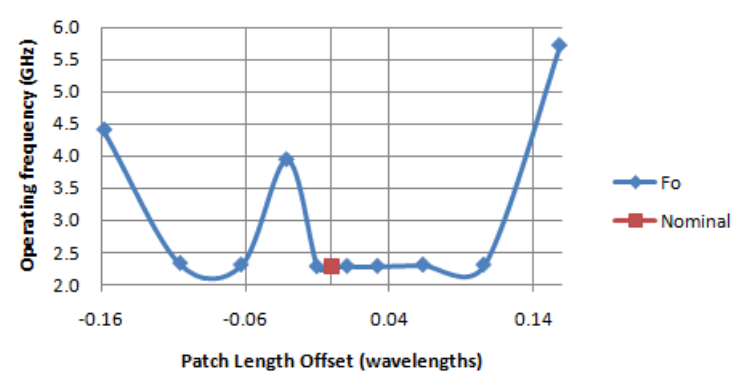

Fo vs. Patch Length Offset

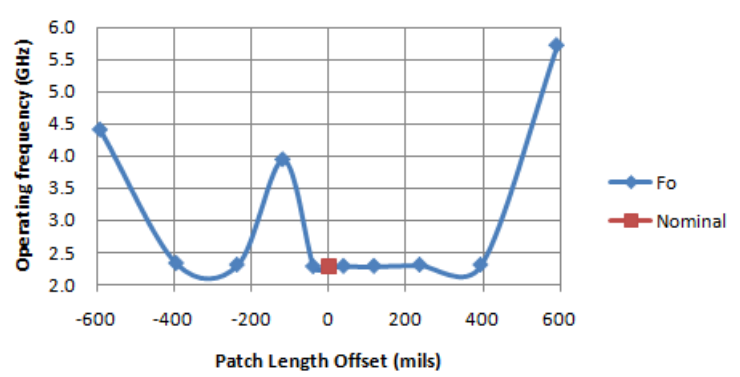

Figure A-79: Operating frequency vs. Patch Length Offset

Figures A-80 shows that a positive Patch Length Offset decreases $\mathrm{VSWR}_{\text {in. }}$ The frequency peak in Figure A-79 corresponds with the VSWR peak in Figure A-80 indicating that VSWR $\mathrm{in}_{\text {in }}$ is greater than 2.8 over all frequencies for a Patch Length Offset value of -118.1mils. 


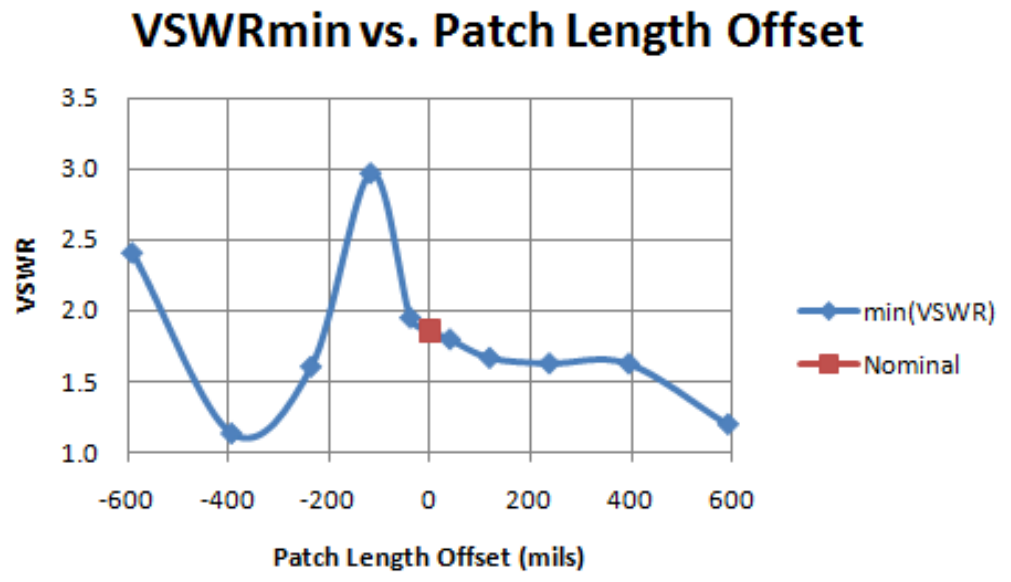

Figure A-80: VSWRin vs. Patch Length Offset

Figure A-81 is approximately an inverse image of Figure A-80 because bandwidth is defined in terms of $\mathrm{VSWR}_{\mathrm{in}}$.

\section{Percent Bandwidth vs. Patch Length Offset}

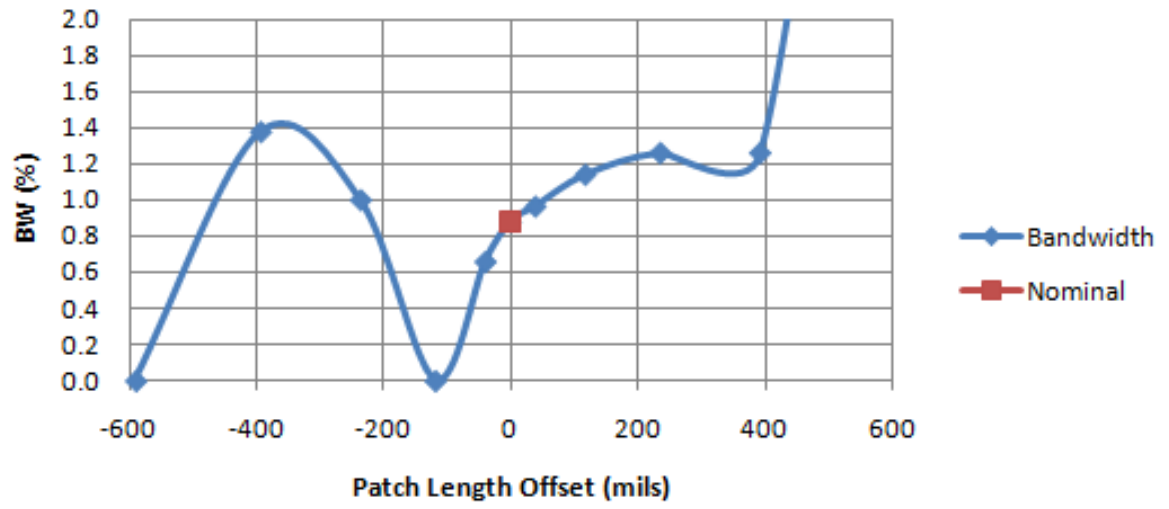

Figure A-81: Percent Bandwidth vs. Patch Length Offset

Figure A-82 shows that polarization ratio is maximum for a Patch Length Offset value of 39.4mils. This offset also improves input matching. 


\section{Polarization Ratio vs. Patch Length Offset}

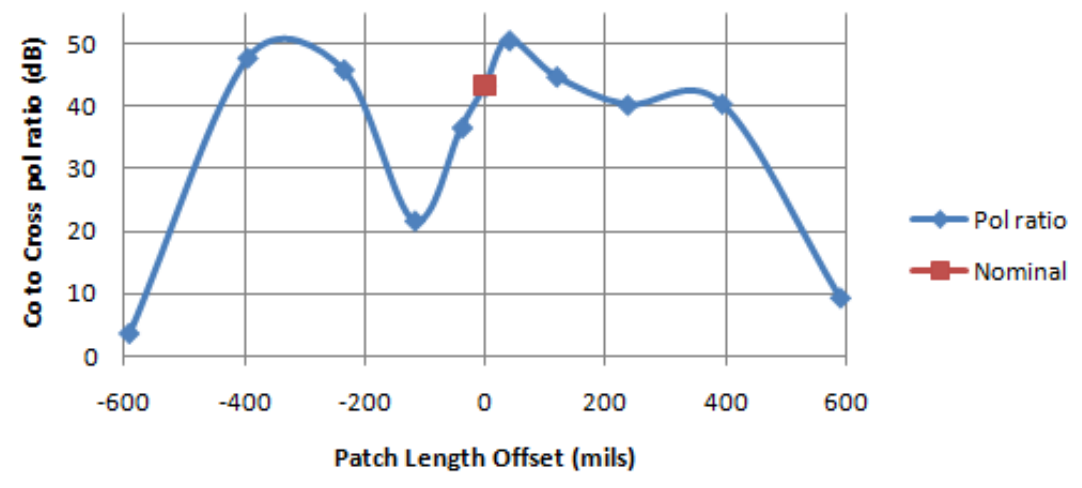

Figure A-82: Polarization ratio vs. Patch Length Offset

Figure A-83 shows that a Patch Length Offset value of -118.1 mils decreases gain by $4.452 \mathrm{~dB}$ due to a $\mathrm{VSWR}_{\text {in }}$ value less than 2.8 (see Figure A-80). All other Patch Length Offsets between \pm 400 .0mils vary gain by less than $\pm 0.160 \mathrm{~dB}$.

\section{Gain vs. Patch Length Offset}

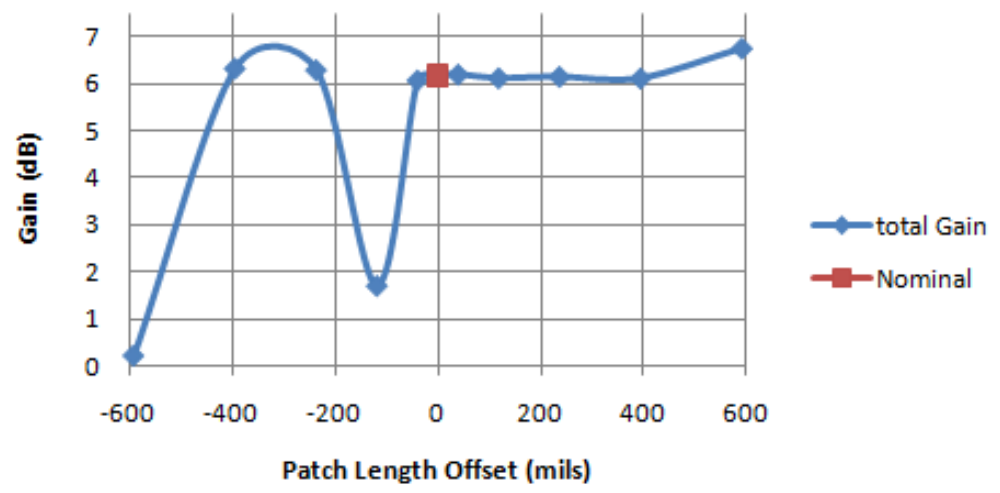

Figure A-83: Gain vs. Patch Length Offset 


\section{Appendix B: Matlab Code}

The following Matlab code plots operating frequency vs. patch length curve found in Figure 4-6.

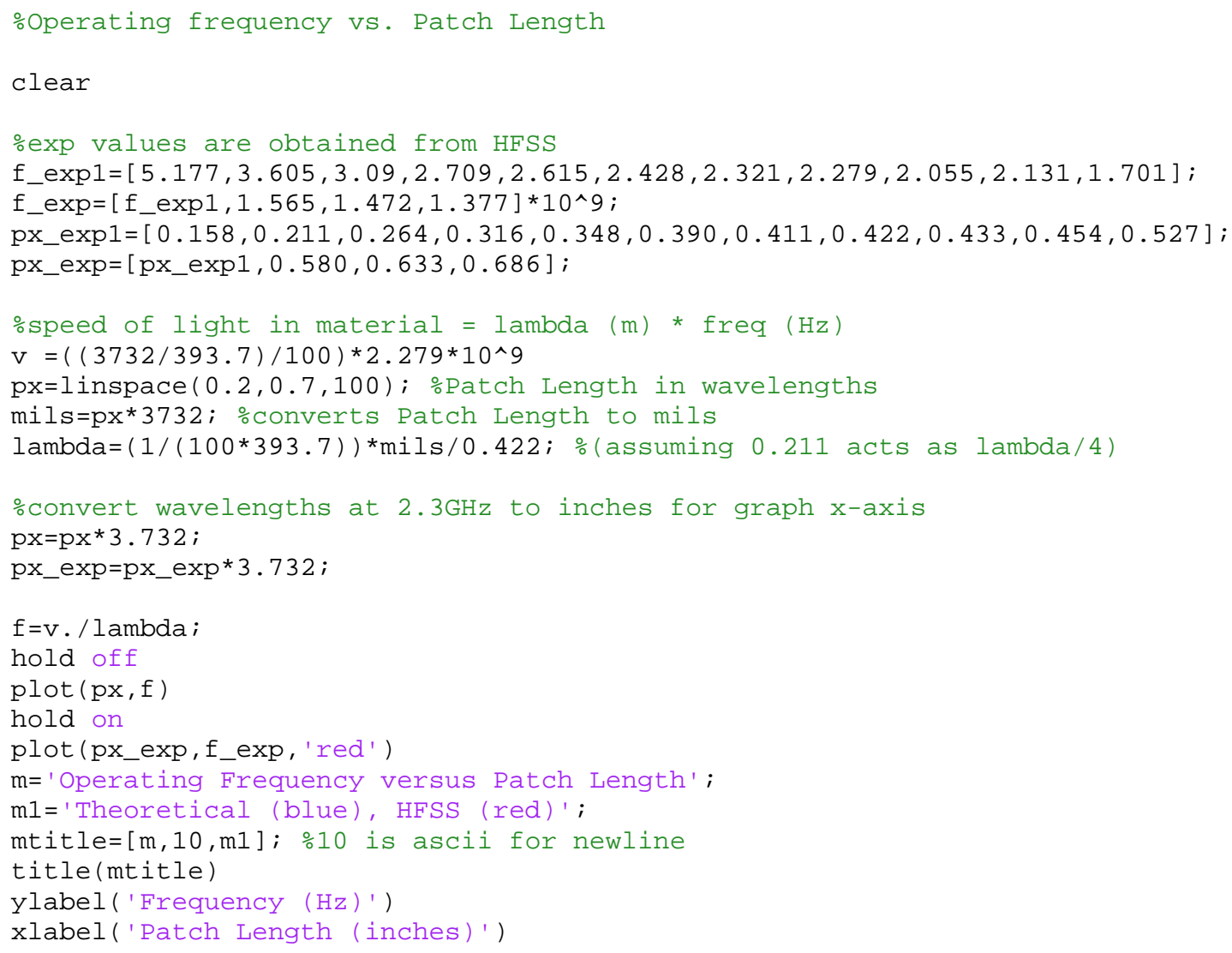

